\title{
RERTR-12 Post-irradiation Examination Summary Report
}

Francine Rice, Walter Williams, Adam Robinson, Jason Harp, Mitch Meyer, Barry Rabin

Barney Hadden, Technical Editor

February 2015

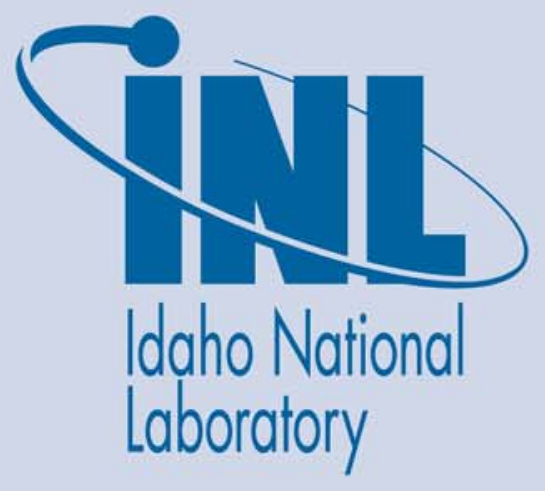

The INL is a U.S. Department of Energy National Laboratory operated by Battelle Energy Alliance 


\section{DISCLAIMER}

This information was prepared as an account of work sponsored by an agency of the U.S. Government. Neither the U.S. Government nor any agency thereof, nor any of their employees, makes any warranty, expressed or implied, or assumes any legal liability or responsibility for the accuracy, completeness, or usefulness, of any information, apparatus, product, or process disclosed, or represents that its use would not infringe privately owned rights. References herein to any specific commercial product, process, or service by trade name, trade mark, manufacturer, or otherwise, does not necessarily constitute or imply its endorsement, recommendation, or favoring by the U.S. Government or any agency thereof. The views and opinions of authors expressed herein do not necessarily state or reflect those of the U.S. Government or any agency thereof. 
INL/EXT-14-33066

Revision 1

\section{RERTR-12 \\ Post-irradiation Examination Summary Report}

Francine Rice, Walter Williams, Adam Robinson, Jason Harp, Mitch Meyer, Barry Rabin

Barney Hadden, Technical Editor

February 2015

Idaho National Laboratory Idaho Falls, Idaho 83415

http://www.inl.gov

Prepared for the

U.S. Department of Energy

Office of NA

Under DOE Idaho Operations Office

Contract DE-AC07-05ID14517 



\title{
RERTR-12 \\ Post-irradiation Examination Summary Report
}

\author{
INL/EXT-14-33066 \\ Revision 1
}

February 2015

Approved by:

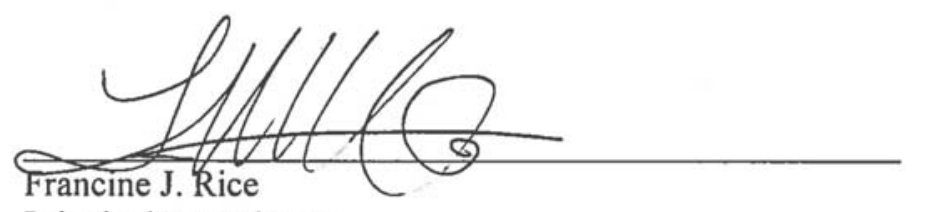

Principal Investigator
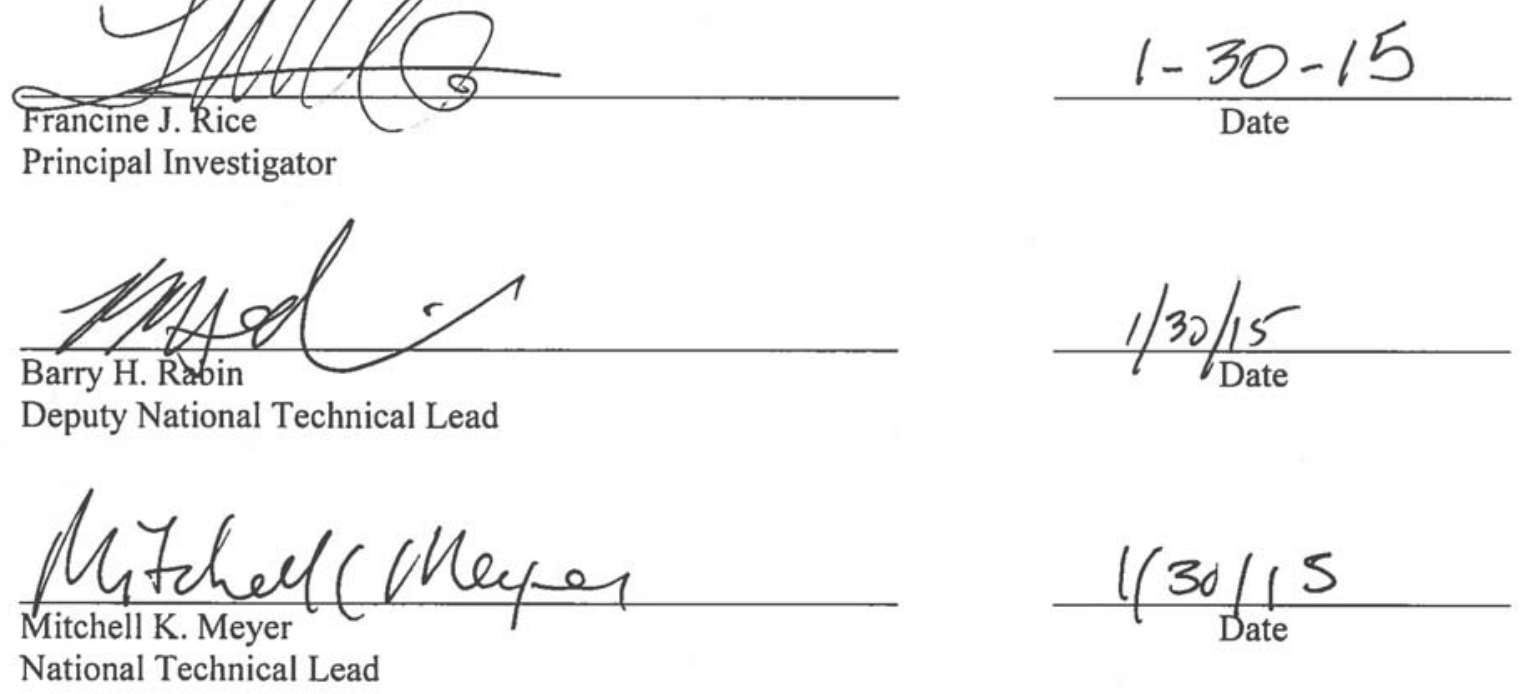

Kenneth E. Rosenberg
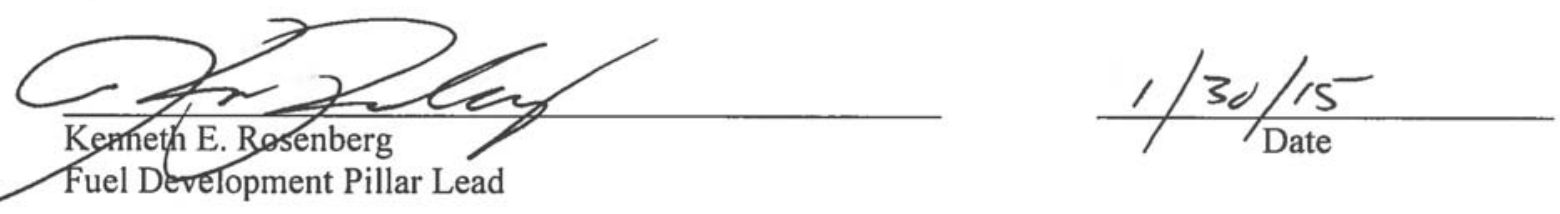



\begin{abstract}
The following report contains the results and conclusions from post-irradiation examinations performed on RERTR-12 Insertion 2 experimental fuel plates. These examinations include eddy-current testing to measure oxide growth; neutron radiography for evaluating the condition of the fuel prior to sectioning and determination of fuel relocation and geometry changes; gamma scanning to provide relative measurements for burnup and indication of fuel- and fission-product relocation; profilometry to measure dimensional changes of the fuel plate; analytical chemistry to benchmark the physics burnup calculations; metallography to examine the microstructural changes in the fuel, interlayer and cladding; and microhardness testing to determine the material-property changes of the fuel and cladding. These characterization activities were conducted specifically to demonstrate that:
\end{abstract}

- The mechanical integrity of fuel meat, cladding, and interlayers, including the diffusion barrier, is maintained

- Fuel geometry is stable and predictable

- Changes in channel gap do not compromise the ability to cool the fuel

- Swelling is stable and predictable. 


\section{ACKNOWLEDGMENTS}

The authors wish to acknowledge the invaluable contributions of researchers Jan-Fong Jue, Dennis Keiser, Jeff Giglio, Jeff Berg, and Hot Fuel Examination Facility process engineers Paul Lind and Katelyn Wachs. 


\section{CONTENTS}

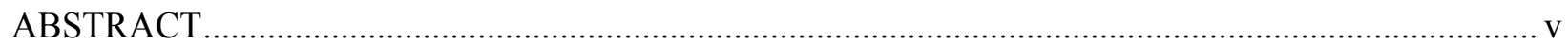

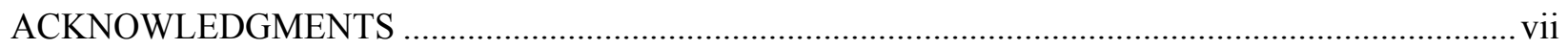

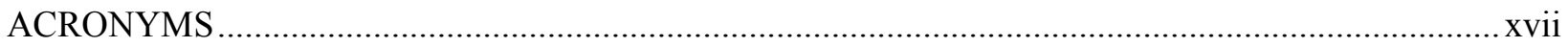

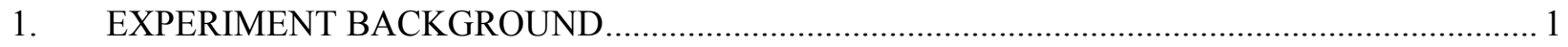

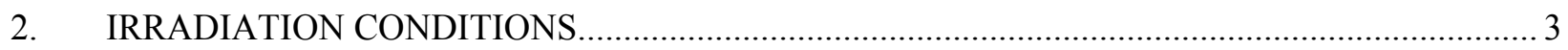

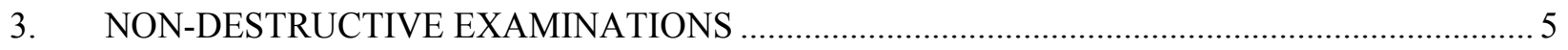

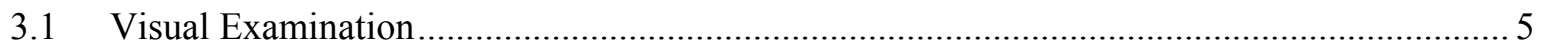

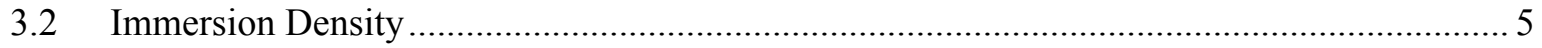

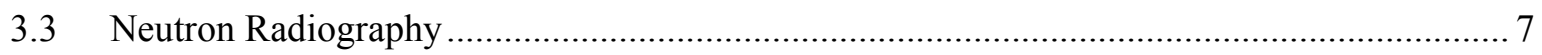

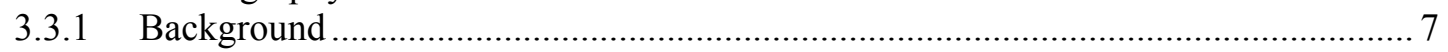

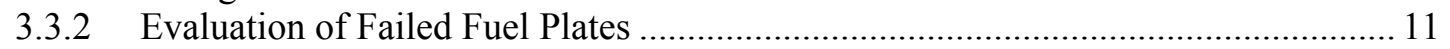

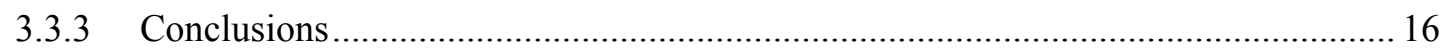

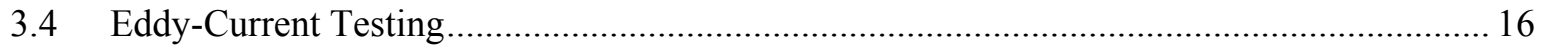

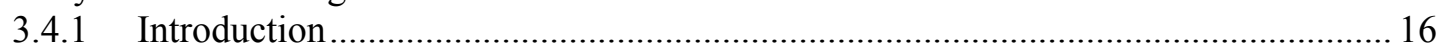

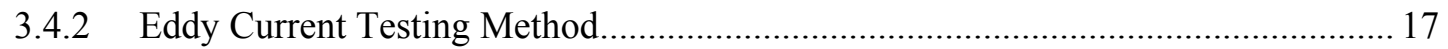

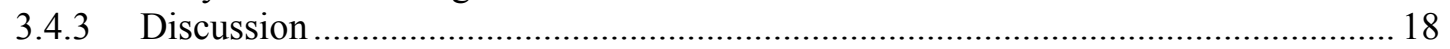

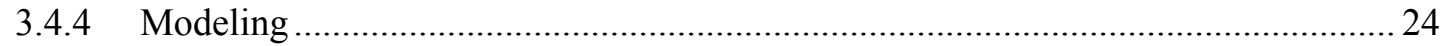

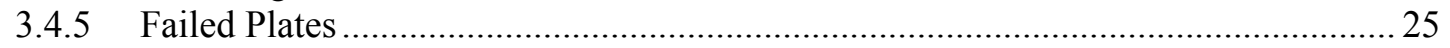

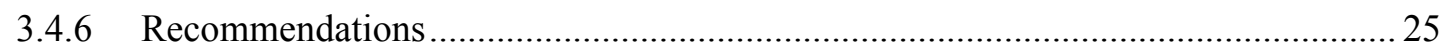

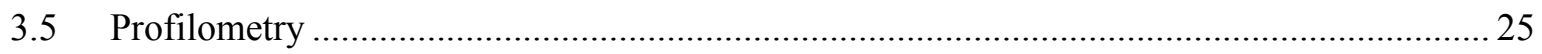

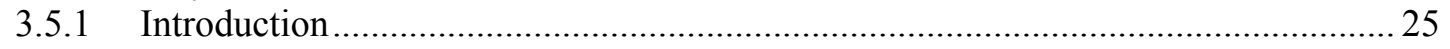

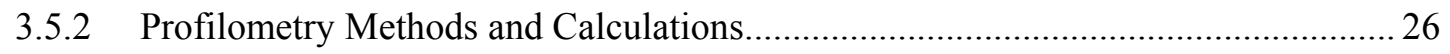

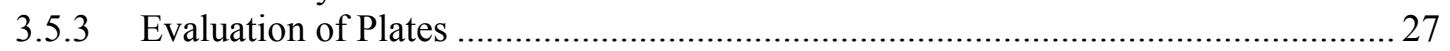

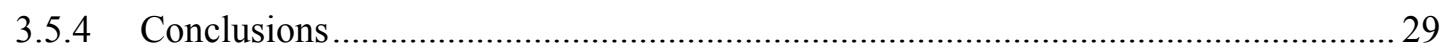

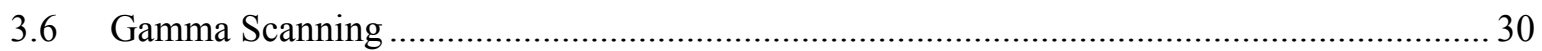

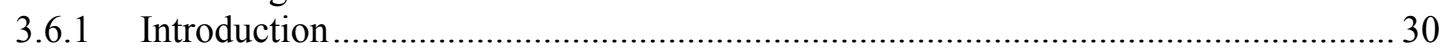

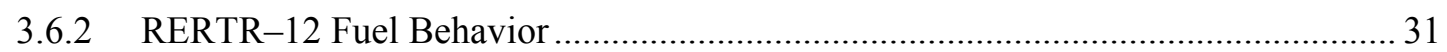

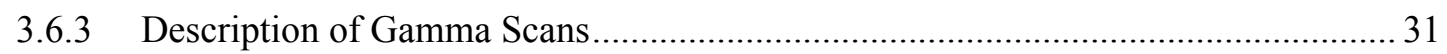

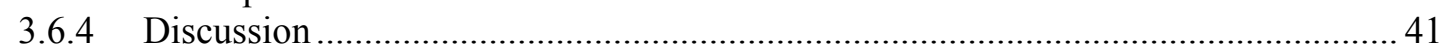

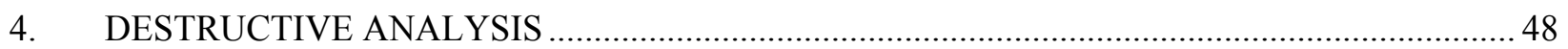

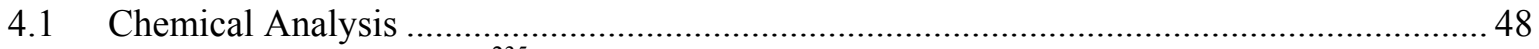

4.1.1 Measurement of ${ }^{235} \mathrm{U}$ Depletion in Six RERTR-12 Mini-plates.................................. 48

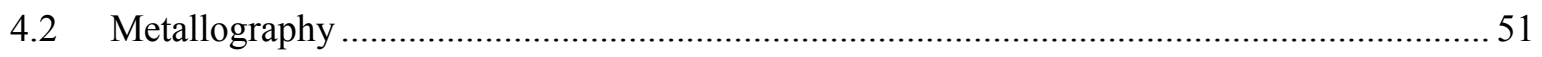

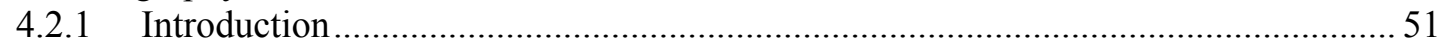

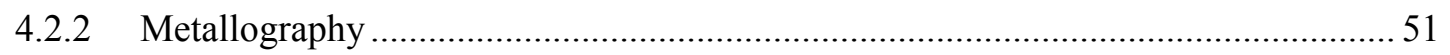

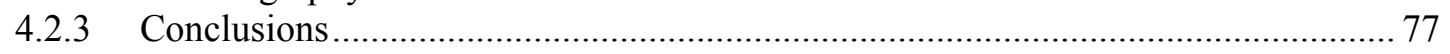

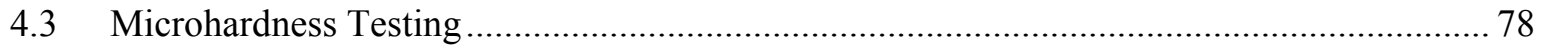

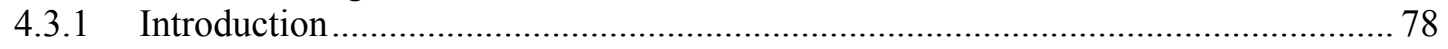

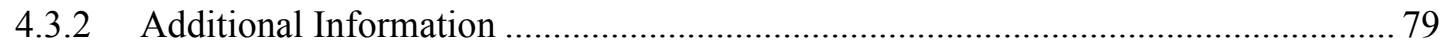

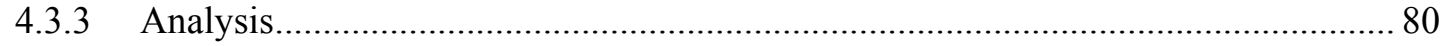




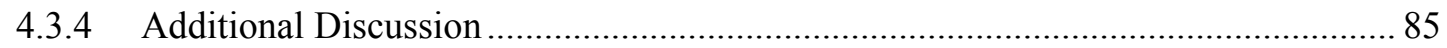

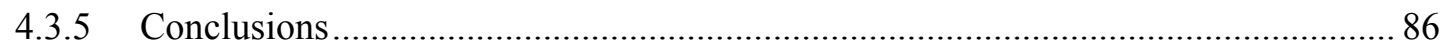

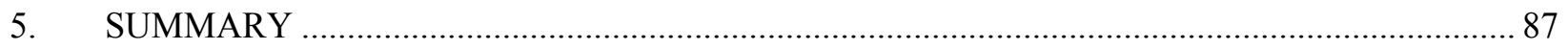

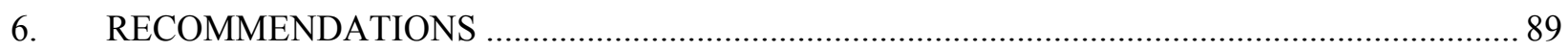

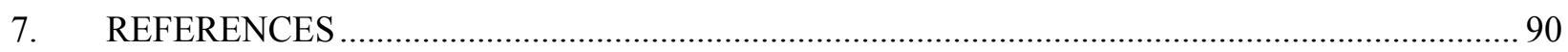

\section{FIGURES}

Figure 1. Orientation of RERTR-12 capsule and image of the layout of the capsule. 2

Figure 2. Photographs of plates that exhibited high swelling behavior. (a) L1P7A0 exhibited higher-than-projected volume increase, but did not exhibit blistering or pillowing, (b) L1P754 exhibited blistering/pillowing behavior (c) the blister/pillow on L1P759 was larger with increased fission density (d) further increasing pillow volume with increased fission density for plate L1P785.

Figure 3. Immersion-density test results plotting fuel swelling versus average fission density in irradiated plates.. 7

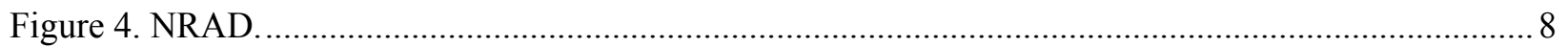

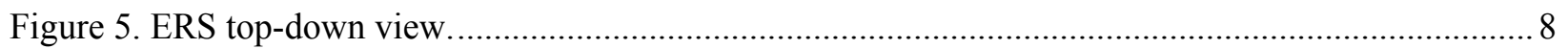

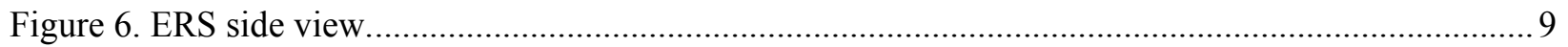

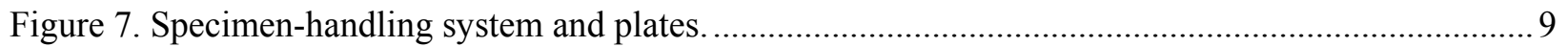

Figure 8. L1P7A0 radiograph (top) and color map (bottom). Longitudinal and transverse lines indicate locations from which pixel intensity plots in Figure 9 were taken.

Figure 9. Relative pixel intensity in transverse (left) and longitudinal (right) directions of L1P7A0. See Figure 8 for locations of section lines.

Figure 10. Resolvable cracks in fuel using a configuration perpendicular to plate face.

Figure 11. Non-resolvable crack in fuel using a configuration perpendicular to plate face.

Figure 12. L1P754 radiograph (top) and color map (bottom).

Figure 13. L1P759 radiograph (top) and color map (bottom).

Figure 14. Relative pixel intensity for a longitudinal section (upper left, see Figure 13 for section line), transverse section across the center defect (upper right, see Figure 13 for section line), and across the pillow in the lower section of the plate (bottom)......

Figure 15. L1P785 radiograph (top) and color map (bottom).

Figure 16. Relative pixel intensity in a transverse section across the pillow near the bottom (left) end of the fuel plate (upper left), transverse across the center section (upper right, see Figure 15 for section line), and in the longitudinal direction (bottom, see Figure 15 for section line)

Figure 17. Oxide measurement locations for $\mathrm{X} 1$ and $\mathrm{X} 2$ plates.

Figure 18. Oxide measurement locations for X3, Y1, Y2, Y3, and Z plates. ....

Figure 19. Plate surface oxide-thickness values as a function of average surface heat flux. 
Figure 20. Metallographic image of L1P5C2 showing oxide growth on the plate surface with thickness measurements.

Figure 21. Metallographic image of L1P5C2 showing oxide growth and thickness measurements. .........21

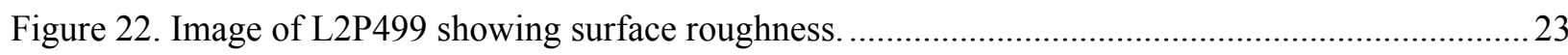

Figure 23. Standard deviation of measurements as a function of oxide thickness...................................2 24

Figure 24. Predicted oxide-thickness maximums versus observed oxide-thickness maximums...............25

Figure 25. Profilometry-based swelling fraction vs average plate fission density for Insertion 2 and failed plates.

Figure 26. Profilometry-based swelling fraction \% vs average plate fission density for Insertion 2 only. 29

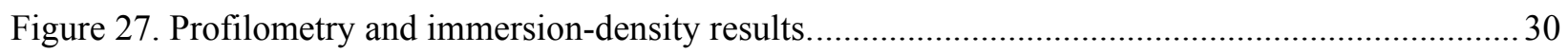

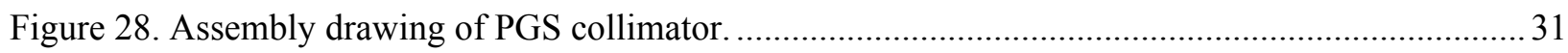

Figure 29. Approximate areas scanned by PGS for RERTR-12 plates at different orientations................ 32

Figure 30. Typical RERTR-12 PGS Spectrum with key peaks labeled by their radionuclide. Plate

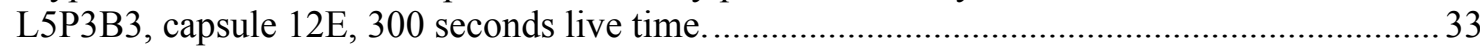

Figure 31. Vertical scan of plates from RERTR-12 Capsule A. .......................................................... 35

Figure 32. Vertical scan of plates from RERTR-12 Capsule B. ......................................................... 35

Figure 33. Vertical scan of plates from RERTR-12 Capsule C. .......................................................... 36

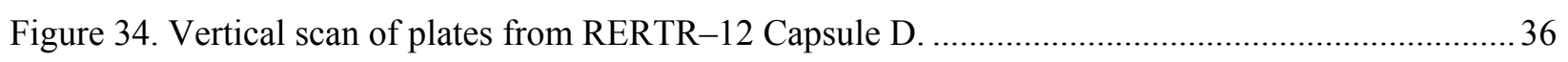

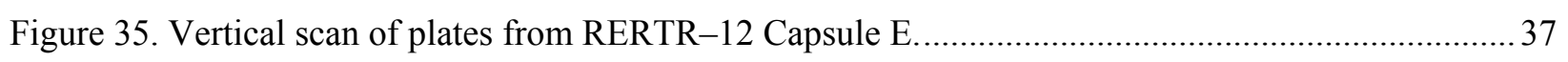

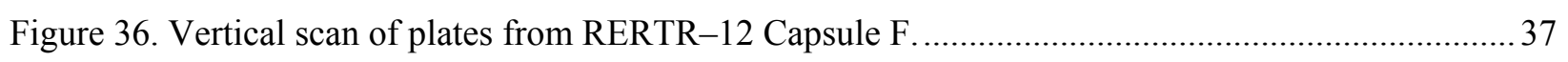

Figure 37. Vertical scan of plates from RERTR-12 Capsule G. ............................................................. 38

Figure 38. Transverse scan of plates from RERTR-12 Capsule A......................................................... 38

Figure 39. Transverse scan of plates from RERTR-12 Capsule B....................................................... 39

Figure 40. Transverse scan of plates from RERTR-12 Capsule C and Capsule D. ................................. 39

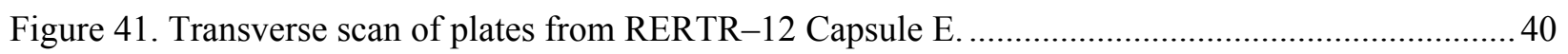

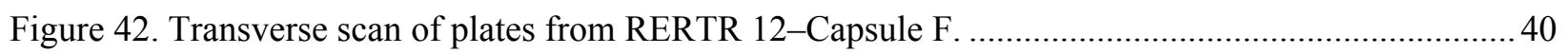

Figure 43. Transverse scan of plates from RERTR-12 Capsule G........................................................ 41

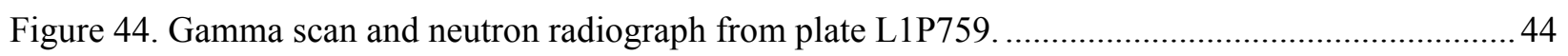

Figure 45. Gamma scan and neutron radiograph from plate L1P785 .................................................. 45

Figure 46. Gamma scan and neutron radiograph from plate L1P754 .................................................. 45

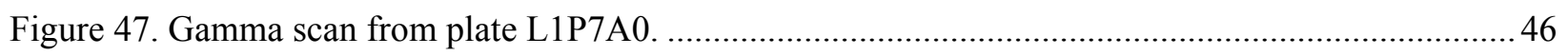

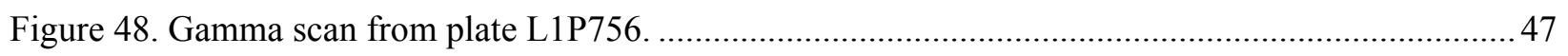

Figure 49. Example of sample location for verification of ${ }^{235} \mathrm{U}$ depletion in RERTR-12 plates. ............. 48

Figure 50. Location of samples for verification of ${ }^{235} \mathrm{U}$ depletion along the width of RERTR-12 mini-plate L1P773. .50 
Figure 51. SEM image of the cladding-to-cladding bond line and surrounding area in unirradiated fuel plate L1P756.

Figure 52. Optical image of the cladding-to-cladding bond line and surrounding area in irradiated fuel plate L1P759.

Figure 53. SEM micrograph of unirradiated archive plate L2P497 of the same feedstock material (alloy 344) that comprises L2P499 which was irradiated. It contains carbide/oxide inclusions that are characteristic of this feedstock with carbon content of $>500 \mathrm{ppm}$. It can be seen that the asymmetric grains up to 100 micrometers in length are present in the microstructure.

Figure 54. Optical micrograph of fuel plate L2P499 (Mount: 42V) after irradiation to a fission density of $2.5 \times 10^{21} \mathrm{f} / \mathrm{cm}^{3}$. The remaining grains are approximately half of the starting grain size for this material. Fission-gas bubbles decorate the grain boundaries.

Figure 55. Shown in the two micrographs, (a) and (b) of L2P499/42V (etched). Average fission density: $2.48 \times 10^{21} \mathrm{f} / \mathrm{cm}^{3}$. Y-12 source material with the characteristic carbide/oxide inclusions. The micrographs illustrate the efficacy of a nitric solution to further resolve grain structure. In image (a), the fission-gas bubbles at the grain boundaries appear to indicate the initial growth of the boundaries between grains as a result of fission-gas-induced recrystallization. .55

Figure 56. L1P462, mount of the middle cross-section. Average fission density: $3.34 \times 10^{21} \mathrm{f} / \mathrm{cm}^{3}$. The fraction recrystallized for the given fission density is similar to L1P020 shown in Figure 59.

Figure 57. SEM micrograph of unirradiated plate L1P775, which is the same alloy material (alloy 328) and the starting microstructure as the irradiated plate L1P776 shown in Figure 58.

Figure 58. L1P776, mount of the mid-plane section. Fission density: $3.9 \times 10^{21} \mathrm{f} / \mathrm{cm}^{3}$. The fraction recrystallized is obviously increasing and fission-gas bubbles are more apparent.

Figure 59. RERTR-8 Plate L1P020, mount 39W. Average fission density: $6.0 \times 10^{21} \mathrm{f} / \mathrm{cm}^{3}$. Remaining grain structure can still be resolved optically.

Figure 60. L1P784, mount 44V. Average fission density: $6.3 \times 10^{21} \mathrm{f} / \mathrm{cm}^{3}$. Optically resolvable grains have been almost completely transformed. Fission-gas bubbles are coarsening, and incipient interconnection of bubbles is evident.

Figure 61. L1P7A0, mount 28W. Average fission density: $7.7 \times 10^{21} \mathrm{f} / \mathrm{cm}^{3}$. Optically resolvable grains have been consumed by recrystallization. Fission-gas bubbles are coarsening, and interconnection of bubbles is evident.

Figure 62. SEM micrograph of plate L1P757, which is the same alloy material (alloy 331) and the starting microstructure for the irradiated plate L1P759, shown in Figure 63.

Figure 63. Plate L1P759, mount 26W. Average fission density: $8.7 \times 10^{21} \mathrm{f} / \mathrm{cm}^{3}$. This plate blistered in-reactor. Interconnection of bubbles is evident in this micrograph of the middle of the fuel meat.

Figure 64. Plate L1P759, mount 25W. Average fission density: $8.7 \times 10^{21} \mathrm{f} / \mathrm{cm}^{3}$. The micrograph shows the $\mathrm{U}-\mathrm{Mo} / \mathrm{Zr}$ interaction zone. This bubble interconnection (perhaps exaggerated by specimen preparation pullout from polishing) effect is far more pronounced in the Mo-depleted region just into the fuel from the $\mathrm{Zr}$ interlayer. 
Figure 65. Estimated grain volume fraction recrystallized as a function of fission density. These data were generated using point counting (this method is explained in Section 4.2.2.5) and are considered preliminary pending studies of specimens following etching treatments (recommended to better resolve grains) and a larger sampling of microstructural data.

Figure 66. An SEM image of the cladding/zirconium/U-10Mo interfaces. A well-defined interaction layer can be observed at the cladding-to-zirconium interface.

Figure 67. An optical image of plate L1P759, mount: $26 \mathrm{~W}$ at $500 \times$ magnification. Average fission density: $8.7 \times 10^{21} \mathrm{f} / \mathrm{cm}^{3}$. The indicated diffusion layer is typical of the post-irradiation condition. ${ }^{3}$.....

Figure 68. Preliminary trend approximation based of interaction layer growth as a function of fission density for plates shown in Figure 73-Figure 77.

Figure 69. A schematic of the microstructure of a HIPed fuel plate co-rolled at $650^{\circ} \mathrm{C}$ and HIPed at $560^{\circ} \mathrm{C}$ with $70^{\circ} \mathrm{C} /$ hour cooling rate.

Figure 70. A low-magnification SEM micrograph showing the typical interaction layer between $\mathrm{U}-\mathrm{Mo}$ and $\mathrm{Zr}$.

Figure 71. SEM image of met mount JJ1032 (the archived sister for the irradiated plate L1P776) shown in Figure 72, showing a large area without a visible interaction layer on U$\mathrm{Mo} / \mathrm{Zr}$ interface. A gap between $\mathrm{Zr}$ and U-Mo, about 20-30 $\mu \mathrm{m}$ long, was observed. 65

Figure 72. Plate L1P776. Average fission density $3.9 \times 10^{21} \mathrm{f} / \mathrm{cm}^{3}$. APD: $25049 \mathrm{~W} / \mathrm{cm}^{3}$..... 65

Figure 73. Plate L1P462. Average fission density: $3.3 \times 10^{21} \mathrm{f} / \mathrm{cm}^{3}$. APD: $11037 \mathrm{~W} / \mathrm{cm}^{3} \ldots \ldots \ldots \ldots \ldots \ldots \ldots . . . . . . . . . .66$

Figure 74. Plate L1P758. Average fission density: $5.0 \times 10^{21} \mathrm{f} / \mathrm{cm}^{3}$. APD: $17251 \mathrm{~W} / \mathrm{cm}^{3} \ldots \ldots \ldots \ldots \ldots \ldots \ldots . . . . . . . . .66$

Figure 75. Plate L1P784. Average fission density: $6.3 \times 10^{21} \mathrm{f} / \mathrm{cm}^{3}$. APD: $21383 \mathrm{~W} / \mathrm{cm}^{3} \ldots \ldots \ldots \ldots \ldots \ldots \ldots . . \ldots 7$

Figure 76. Plate L1P754. Average fission density: $8.1 \times 10^{21} \mathrm{f} / \mathrm{cm}^{3}$. APD: $25372 \mathrm{~W} / \mathrm{cm}^{3} \ldots \ldots \ldots \ldots \ldots \ldots \ldots . . . \ldots 7$

Figure 77. Plate L1P759. Average fission density: $8.7 \times 10^{21} \mathrm{f} / \mathrm{cm}^{3}$. APD: $26745 \mathrm{~W} / \mathrm{cm}^{3} \ldots \ldots \ldots \ldots \ldots \ldots \ldots . . . \ldots 8$

Figure 78. Optical image of plate L1P482. Average fission density: $3.0 \times 10^{21} \mathrm{f} / \mathrm{cm}^{3}$. Average power density (APD): $5386 \mathrm{~W} / \mathrm{cm}^{3}$. (a) and (b) are not etched and etched, respectively.

Figure 79. Cross-section montages of plates L1P754 (a) with a longitudinal segment, L1P759

(b) and L1P7A0 (c) with transverse segments. .70

Figure 80. Micrograph (a) of plate L1P759 Ave FD: $8.7 \times 10^{21} \mathrm{f} / \mathrm{cm}^{3}$ showing brittle cracks with no rounding of corners. Micrograph (b) of a $\mathrm{UO}_{2}$ pellet-type fuel illustrating 'healing' of cracks from Hoffmann. ${ }^{7}$

Figure 81. 500× micrographs of cross-sections from RERTR-12 plates L1P784(a), L1P754(b), and L1P759(c), with average fission densities of $6.3 \times 10^{21}, 8.1 \times 10^{21}$ and $8.7 \times 10^{21}$ $\mathrm{f} / \mathrm{cm}^{3}$, respectively, showing the typical bubble morphology at the zirconium U-10Mo fuel interface.

Figure 82. Micrographs of cross-sections (left to right) from plates L1P04A (RERTR-9A with 4043 Al interlayer), (a) L1P020 (RERTR-8), (b) and L1P05A (RERTR-9B with 4043$\mathrm{Al}$ interlayer), (c) plates with average fission densities of $5.3 \times 10^{21}, 6.0 \times 10^{21}$, and 6.2 $\times 10^{21} \mathrm{f} / \mathrm{cm}^{3}$ respectively. Fuel is the dark region; cladding is lighter, and fission-gas bubbles are black. 
Figure 83. Examples of fuel separation with (a) and without (b) zirconium interlayer for plates L1P754 (RERTR-12, average fission density: $8.1 \times 10^{21} \mathrm{f} / \mathrm{cm}^{3}$ ) and L1P020 (RERTR8 , average fission density: $6.0 \times 10^{21} \mathrm{f} / \mathrm{cm}^{3}$ ), respectively. L1P754 was observed to be pillowed after irradiation and L1P020 separated during specimen preparation.

Figure 84. SEM image of a fresh fuel specimen showing features typical of the clad/U-Mo interaction layer. .75

Figure 85. Plate L5P3B1, mount 51V. Average fission density: $2.49 \mathrm{E}+21 \mathrm{f} / \mathrm{cm}^{3}$. Low-fission-density micrograph of cladding/U-Mo interaction layer (thick fuel meat plate).

Figure 86. L1P759, mount 26W. Average fission density: $8.31 \mathrm{E}+21 \mathrm{f} / \mathrm{cm}^{3}$. High-fission-density micrograph of cladding/U-Mo interaction layer. 75

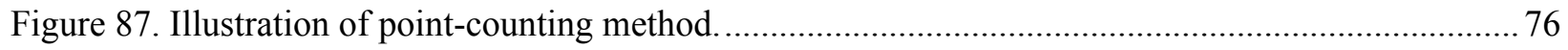

Figure 88. Data for estimated porosity increase in the Mo-depleted region........................................... 77

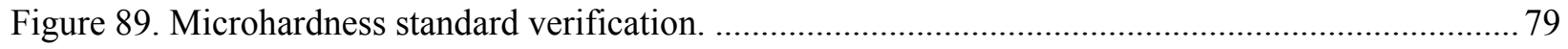

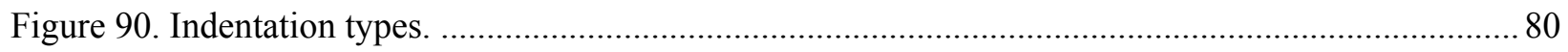

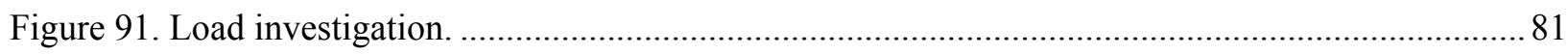

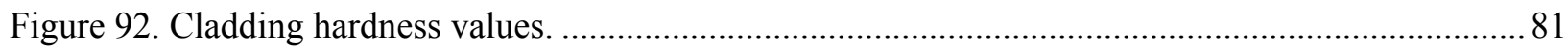

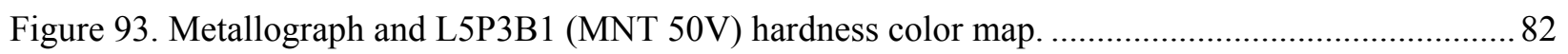

Figure 94. Metallograph and L5P3C2 (MNT 52V), 170 micron grid................................................... 82

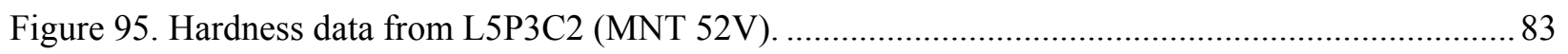

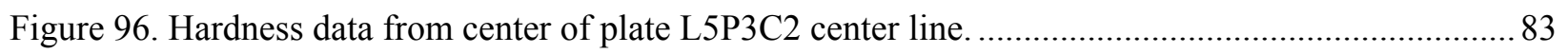

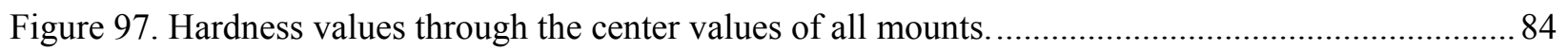

Figure 98. Hardness vs burnup by sample mount number (see Table 18) .............................................. 85

Figure 99. Indent on L2P499 (MNT 42V) micrograph (left) and microhardness tester (right)................. 85

Figure 100. Indents from plate L5P3C2 (MNT 52V, left ) and L1P020 (MNT 39W, right).................... 86

\section{TABLES}

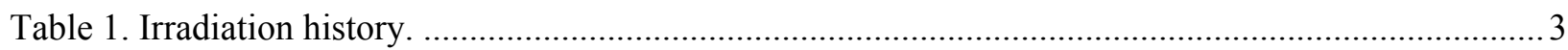

Table 2. Beginning-of-life irradiation conditions (average) ${ }^{\mathrm{a}}$.................................................................. 3

Table 3. End-of-cycle (EOC) 146A irradiation conditions (average) ....................................................... 4

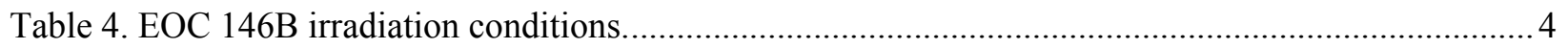

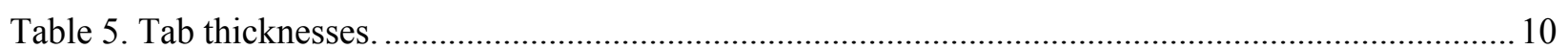

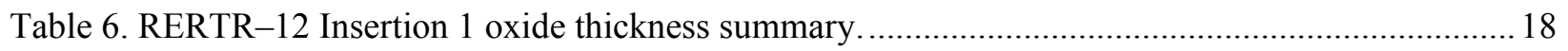

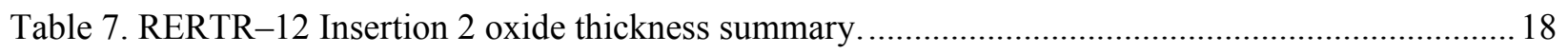

Table 8. Summary of oxide thickness measured using metallographic cross-sections.............................22

Table 9. Comparison between measured oxide and predicted oxide using the modified Griess

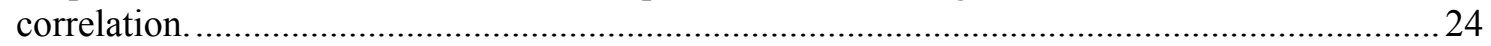

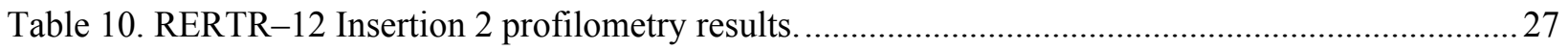


Table 11. Scanning parameters for the different plate sets.

Table 12. ${ }^{235} \mathrm{U}$ depletion in samples from RERTR-12 mini-plates established using three different fission products and ${ }^{235} \mathrm{U} /{ }^{238} \mathrm{U}$ ratio.

Table 13. ${ }^{235} \mathrm{U}$ depletion in ten samples from RERTR-12 mini-plate LP1773 established using three different fission products and ${ }^{235} \mathrm{U} /{ }^{238} \mathrm{U}$ ratio. 50

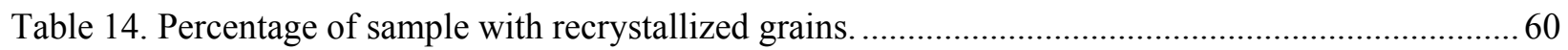

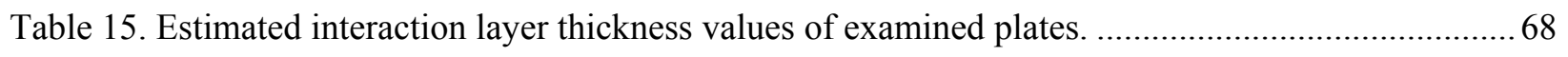

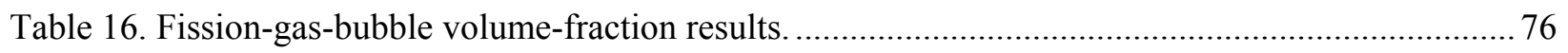

Table 17. Data for estimated areal fraction porosity increase in the Mo-depleted region. ......................... 77

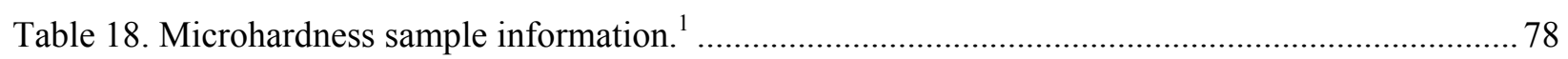




\section{ACRONYMS}

AFIP

ATR

BOL

DOE

EFPD

GTRI

HEU

HFEF

HIP

INL

LEU

NNSA

NRC

PIE

PLATE

RERTR

SEM
ATR Full-size-plate In center flux trap Position

Advanced Test Reactor

beginning of life

United States Department of Energy

effective full-power days

Global Threat Reduction Initiative

highly enriched uranium

Hot Fuel Examination Facility

hot isostatic pressing

Idaho National Laboratory

low-enriched uranium

National Nuclear Security Administration

U.S. Nuclear Regulatory Commission

post-irradiation examination

plate lifetime accurate thermal evaluation (fuel performance code)

Reduced Enrichment Research and Test Reactor

scanning electron micrography 
xviii 


\section{RERTR-12 \\ Post-irradiation Examination Summary Report}

\section{EXPERIMENT BACKGROUND}

The Reduced Enrichment for Research and Test Reactors (RERTR)-12 experiment was designed to test monolithic uranium-molybdenum fuel plates with a zirconium diffusion barrier at a range of operating conditions to investigate the effects of fission density and fission rate on fuel behavior. The RERTR-12 experiment consisted of six capsules, each with eight fuel plates, fabricated using co-rolling and hot isostatic pressing (HIP). The fuel foils consisted of U-10Mo with various ${ }^{235} \mathrm{U}$ enrichments in order to achieve desired surface heat flux, fission rates, and fission densities.

Data collected in this experiment can be used to demonstrate that fuel performance requirements are met. Experimental results will be used to assure that fuel plates maintain mechanical integrity, are geometrically stable in reactor, and display stable and predictable irradiation behavior. Specifically, data collected demonstrate the following for the reference $\mathrm{U}-\mathrm{Mo} / \mathrm{Zr}$ fuel design, using fuel plates fabricated by the co-rolling/HIP processes, having three fuel-to-cladding thickness ratios:

- The mechanical integrity of fuel meat, cladding, and interlayers, including the diffusion barrier, is maintained

- Fuel geometry is stable and predictable

- Changes in channel gap do not compromise the ability to cool the fuel

- Swelling is stable and predictable.

Post-irradiation characterization was performed using quality requirements as implemented by written procedures and approved test plans, according to the program's quality assurance plan. Data obtained from these characterization activities are considered scoping data and are not currently intended for fuel qualification.

The capsules were oriented in the reactor in such a way that the first plate in the capsule is oriented facing the core center, with plates two, three and four behind each previous plate. This resulted in a plateto-plate fission-density and fission-rate gradient, decreasing from plate one to four and from five to eight in all of the capsules. This capsule and plate orientation can be seen in Figure 1. Irradiation of the X1 and X2 capsules was completed first (referred to as RERTR-12 Insertion 1), and the capsules were shipped to the Hot Fuels Examination Facility (HFEF) at the Idaho National Laboratory (INL) for examination. 

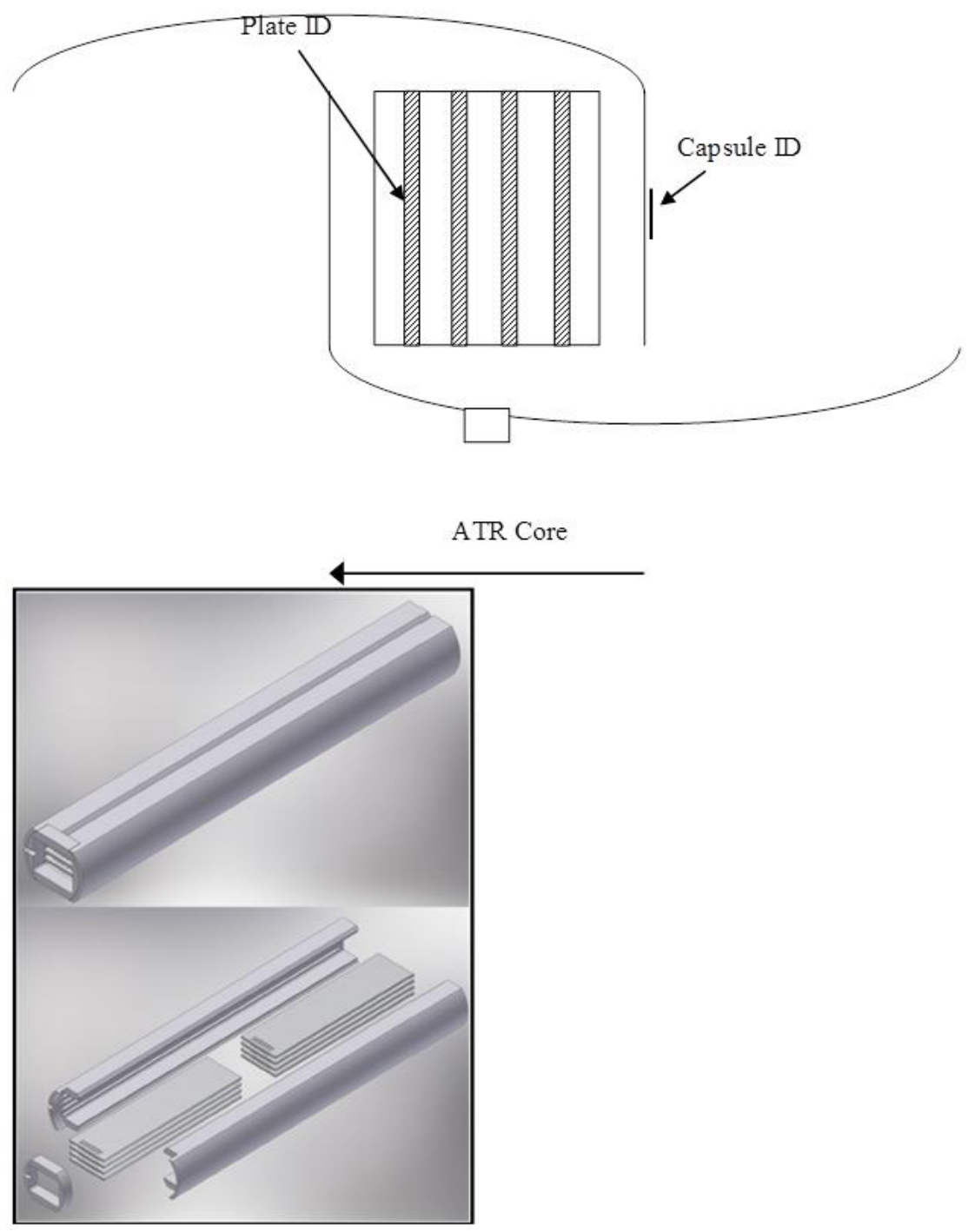

Figure 1. Orientation of RERTR-12 capsule and image of the layout of the capsule. 


\section{IRRADIATION CONDITIONS}

The RERTR-12 test assembly containing the X1 and X2 capsules was irradiated during cycle 146A and 146B as outlined in Table 1. Detailed information on fission power and burnup, calculated using MCNP and ORIGEN, is located in Table 2 through Table $4 .^{1}$

Table 1. Irradiation history.

\begin{tabular}{|c|c|c|c|c|c|c|c|}
\hline $\begin{array}{c}\text { ATR } \\
\text { CYCLE }\end{array}$ & $\begin{array}{c}\text { RERTR-12 } \\
\text { Capsules } \\
\text { Irradiated }\end{array}$ & Dates Irradiated & $\begin{array}{c}\text { Cycle } \\
\text { EFPDs }\end{array}$ & $\begin{array}{c}\text { Mid-Cycle } \\
\text { Scram Decay } \\
\text { Days }\end{array}$ & $\begin{array}{c}\text { South Lobe } \\
\text { Source } \\
\text { Post-Cycle } \\
\text { Decay Days }\end{array}$ & $\begin{array}{c}\text { Total } \\
\text { Power } \\
\text { (MW) }\end{array}$ & $\begin{array}{c}\text { Pore } \\
\text { Power } \\
\text { (MW) }\end{array}$ \\
\hline 146A & $\mathrm{X} 3, \mathrm{X} 1, \mathrm{X} 2$ & $\begin{array}{c}02 / 08 / 2010- \\
04 / 03 / 2010\end{array}$ & 50.5 & 4 & 18 & 25.4 & 112.1 \\
\hline 146B & $\mathrm{Z}, \mathrm{X} 3, \mathrm{X} 2$ & $\begin{array}{c}04 / 21 / 2010- \\
05 / 30 / 2010\end{array}$ & 39.2 & 0 & 20 & 25.0 & 116.0 \\
\hline
\end{tabular}

Table 2. Beginning-of-life irradiation conditions (average). ${ }^{\mathrm{a}}$

\begin{tabular}{|c|c|c|c|c|}
\hline \multicolumn{2}{|c|}{ Configuration } & Plate & $\begin{array}{c}\text { Fission Power Density } \\
\left(\mathrm{W} / \mathrm{cm}^{3}\right)\end{array}$ & $\begin{array}{c}\text { Surface Heat Flux } \\
\left(\mathrm{W} / \mathrm{cm}^{2}\right)\end{array}$ \\
\hline $\mathrm{C}-1$ & \multirow{8}{*}{$\frac{5}{x}$} & L1P772 & 40385.69 & 512.90 \\
\hline $\mathrm{C}-2$ & & L1P773 & 27534.58 & 349.69 \\
\hline $\mathrm{C}-3$ & & L1P591 & 18675.73 & 237.18 \\
\hline $\mathrm{C}-4$ & & L1P460 & 15977.82 & 202.92 \\
\hline$C-5$ & & L1P774 & 38680.25 & 491.24 \\
\hline$C-6$ & & L1P776 & 26682.33 & 338.87 \\
\hline C-7 & & L1P592 & 18091.41 & 229.76 \\
\hline $\mathrm{C}-8$ & & L1P461 & 15345.90 & 194.89 \\
\hline D-1 & \multirow{8}{*}{$\overline{\dot{x}}$} & L1P754 & 34585.25 & 439.23 \\
\hline D-2 & & L1P755 & 23861.36 & 303.04 \\
\hline D-3 & & L1P593 & 16363.12 & 207.81 \\
\hline D-4 & & L1P462 & 13847.56 & 175.86 \\
\hline D-5 & & L1P756 & 29499.31 & 374.64 \\
\hline D-6 & & L1P758 & 19933.00 & 253.15 \\
\hline D-7 & & L1P595 & 13741.86 & 174.52 \\
\hline D-8 & & L1P463 & 11592.44 & 147.22 \\
\hline
\end{tabular}


Table 3. End-of-cycle (EOC) 146A irradiation conditions (average).

\begin{tabular}{|c|c|c|c|c|c|c|c|}
\hline \multicolumn{2}{|c|}{ Configuration } & Plate & $\begin{array}{l}\text { Fission } \\
\text { Power } \\
\text { Density } \\
\left(\mathrm{W} / \mathrm{cm}^{3}\right)\end{array}$ & $\begin{array}{c}\text { Surface } \\
\text { Heat } \\
\text { Flux } \\
\left(\mathrm{W} / \mathrm{cm}^{2}\right)\end{array}$ & $\begin{array}{c}\text { \% Depletion } \\
{ }^{235} \mathrm{U} \\
(\%)\end{array}$ & $\begin{array}{c}\text { Fission } \\
\text { Density } \\
\text { (fissions/ } \\
\mathrm{cm}^{3} \text { ) }\end{array}$ & $\begin{array}{c}\text { Fission Rate } \\
\text { Density } \\
\text { (fissions/ } \\
\mathrm{cm}^{3} / \mathrm{s} \text { ) }\end{array}$ \\
\hline C-1 & \multirow{8}{*}{$\frac{F}{x}$} & L1P772 & 34351.87 & 436.27 & $23.67 \%$ & $5.78 \mathrm{E}+21$ & $1.32 \mathrm{E}+15$ \\
\hline $\mathrm{C}-2$ & & L1P773 & 25728.43 & 326.75 & $16.97 \%$ & $4.06 \mathrm{E}+21$ & $9.31 \mathrm{E}+14$ \\
\hline $\mathrm{C}-3$ & & L1P591 & 17522.66 & 222.54 & $16.19 \%$ & $2.76 \mathrm{E}+21$ & $6.33 \mathrm{E}+14$ \\
\hline $\mathrm{C}-4$ & & L1P460 & 14567.75 & 185.01 & $17.09 \%$ & $2.35 \mathrm{E}+21$ & $5.39 \mathrm{E}+14$ \\
\hline $\mathrm{C}-5$ & & L1P774 & 33720.67 & 428.25 & $22.98 \%$ & $5.59 \mathrm{E}+21$ & $1.28 \mathrm{E}+15$ \\
\hline C-6 & & L1P776 & 25049.54 & 318.13 & $16.46 \%$ & $3.93 \mathrm{E}+21$ & $9.01 \mathrm{E}+14$ \\
\hline $\mathrm{C}-7$ & & L1P592 & 17028.84 & 216.27 & $15.78 \%$ & $2.69 \mathrm{E}+21$ & $6.17 \mathrm{E}+14$ \\
\hline $\mathrm{C}-8$ & & L1P461 & 14069.49 & 178.68 & $16.46 \%$ & $2.26 \mathrm{E}+21$ & $5.18 \mathrm{E}+14$ \\
\hline D-1 & \multirow{8}{*}{$\overline{\tilde{x}}$} & L1P754 & 30905.77 & 392.50 & $20.93 \%$ & $5.08 \mathrm{E}+21$ & $1.16 \mathrm{E}+15$ \\
\hline D-2 & & L1P755 & 22910.27 & 290.96 & $14.99 \%$ & $3.57 \mathrm{E}+21$ & $8.18 \mathrm{E}+14$ \\
\hline D-3 & & L1P593 & 15607.02 & 198.21 & $14.32 \%$ & $2.43 \mathrm{E}+21$ & $5.57 \mathrm{E}+14$ \\
\hline D-4 & & L1P462 & 12927.56 & 164.18 & $15.01 \%$ & $2.06 \mathrm{E}+21$ & $4.72 \mathrm{E}+14$ \\
\hline D-5 & & L1P756 & 27253.67 & 346.12 & $18.12 \%$ & $4.37 \mathrm{E}+21$ & $1.00 \mathrm{E}+15$ \\
\hline D-6 & & L1P758 & 19752.69 & 250.86 & $12.82 \%$ & $3.04 \mathrm{E}+21$ & $6.97 \mathrm{E}+14$ \\
\hline D-7 & & L1P595 & 13558.95 & 172.20 & $12.30 \%$ & $2.08 \mathrm{E}+21$ & $4.77 \mathrm{E}+14$ \\
\hline D-8 & & L1P463 & 11316.61 & 143.72 & $12.93 \%$ & $1.76 \mathrm{E}+21$ & $4.03 \mathrm{E}+14$ \\
\hline
\end{tabular}

Table 4. EOC 146B irradiation conditions.

\begin{tabular}{|c|c|c|c|c|c|c|c|}
\hline \multicolumn{2}{|c|}{ Configuration } & Plate & $\begin{array}{l}\text { Fission } \\
\text { Power } \\
\text { Density } \\
\left(\mathrm{W} / \mathrm{cm}^{3}\right)\end{array}$ & $\begin{array}{l}\text { Surface } \\
\text { Heat Flux } \\
\left(\mathrm{W} / \mathrm{cm}^{2}\right) \\
\end{array}$ & $\begin{array}{c}\% \text { Depletion } \\
{ }^{235} \mathrm{U} \\
(\%)\end{array}$ & $\begin{array}{l}\text { Fission } \\
\text { Density } \\
\text { (fissions/ } \\
\mathrm{cm}^{3} \text { ) }\end{array}$ & $\begin{array}{c}\text { Fission Rate } \\
\text { Density } \\
\text { (fissions/ } \\
\mathrm{cm}^{3} / \mathrm{s} \text { ) } \\
\end{array}$ \\
\hline D-1 & \multirow{8}{*}{$\stackrel{\tilde{N}}{\tilde{x}}$} & L1P754 & 25372.83 & 322.23 & $33.57 \%$ & $8.13 \mathrm{E}+21$ & $1.05 \mathrm{E}+15$ \\
\hline D-2 & & L1P755 & 19950.20 & 253.37 & $24.64 \%$ & $5.86 \mathrm{E}+21$ & $7.56 \mathrm{E}+14$ \\
\hline D-3 & & L1P593 & 13504.89 & 171.51 & $23.45 \%$ & $3.99 \mathrm{E}+21$ & $5.15 E+14$ \\
\hline D-4 & & L1P462 & 11037.25 & 140.17 & $24.40 \%$ & $3.34 \mathrm{E}+21$ & $4.31 \mathrm{E}+14$ \\
\hline D-5 & & L1P756 & 22679.32 & 288.03 & $29.29 \%$ & $7.05 \mathrm{E}+21$ & $9.10 \mathrm{E}+14$ \\
\hline D-6 & & L1P758 & 17251.74 & 219.10 & $21.11 \%$ & $5.00 \mathrm{E}+21$ & $6.45 \mathrm{E}+14$ \\
\hline D-7 & & L1P595 & 11716.82 & 148.80 & $20.12 \%$ & $3.41 \mathrm{E}+21$ & $4.40 \mathrm{E}+14$ \\
\hline D-8 & & L1P463 & 9669.87 & 122.81 & $21.00 \%$ & $2.86 \mathrm{E}+21$ & $3.69 \mathrm{E}+14$ \\
\hline
\end{tabular}




\section{NON-DESTRUCTIVE EXAMINATIONS \\ 3.1 Visual Examination}

The RERTR-12 test irradiated miniature fuel plates of a single fuel design and three foil/cladding thickness ratios over a range of fission densities, including very high fission densities that envelope full

${ }^{235} \mathrm{U}$ burnup in LEU fuel. ${ }^{2}$ Four of the 56 plates that were irradiated exhibited abnormally high swelling, and three plates exhibited pillows after irradiation, all at higher fission density, as shown in Figure 2.

\subsection{Immersion Density}

A plot of swelling behavior from all RERTR-12 mini-plates, measured by immersion density, is shown in Figure 3. Three mini-plates from RERTR-12 Insertion 2 failed, either by delamination or by exhibiting excessive swelling. One mini-plate (L1P754) from RERTR-12 Insertion 1 also failed and is included here for completeness.

Immersion-density measurements were taken on all of the RERTR-12 plates both prior to and after irradiation. Each test plate is first weighed dry, then submersed into the fluid and weighed again. The results of each measurement are recorded along with the temperature of the fluid. Using the dry weight, submerged weight, and the temperature-corrected density of the fluid, the volume and density of the sample can be calculated using Equation 1:

Volume $_{\text {Sample }}=\frac{\text { Mass }_{\text {dry }}-\text { mass }_{\text {submerged }}}{\rho_{\text {fluid }}}$

For intact plates, change in plate thickness is driven by the change in fuel-meat volume caused by fuel swelling. Several plates demonstrated bulk swelling significantly higher than projected by the currently accepted U-Mo swelling correlation. Calculated fuel-plate-swelling values (\%) from these four plates, from highest to lowest swelling, are listed below, along with the corresponding plate average fission density (fissions $/ \mathrm{cm}^{3}$ ):

- $\quad \operatorname{L} 1 \mathrm{P} 785(268 \%, 9.15 \mathrm{E}+21)$

- $\operatorname{L} 1 \mathrm{P} 759(169 \%, 8.72 \mathrm{E}+21)$

- $\quad \mathrm{L} 1 \mathrm{P} 754(119 \%, 8.13 \mathrm{E}+21)$

- $\quad$ L1P7A0 $(98 \%, 7.71 \mathrm{E}+21)$.

Pillowing of fuel plates L1P785 and L1P759 was clearly identified during visual examination. The failure of plate L1P754 was suspected during visual examination and confirmed using neutron radiography (see Section 3.3). In delaminated fuel plates, the plate-swelling values shown in Figure 3 incorporate substantial void volume in addition to fuel-meat volume and are not representative of U-Mo alloy swelling. Plate L1P7A0 did not show indications of foil cracking or relocation during visual examination or neutron radiography. Plate L1P465 $(46 \%, 3.78 \mathrm{E}+21)$ also has higher-than-anticipated swelling and was further investigated using point-by-point analysis of profilometry data (see Section 3.5). 


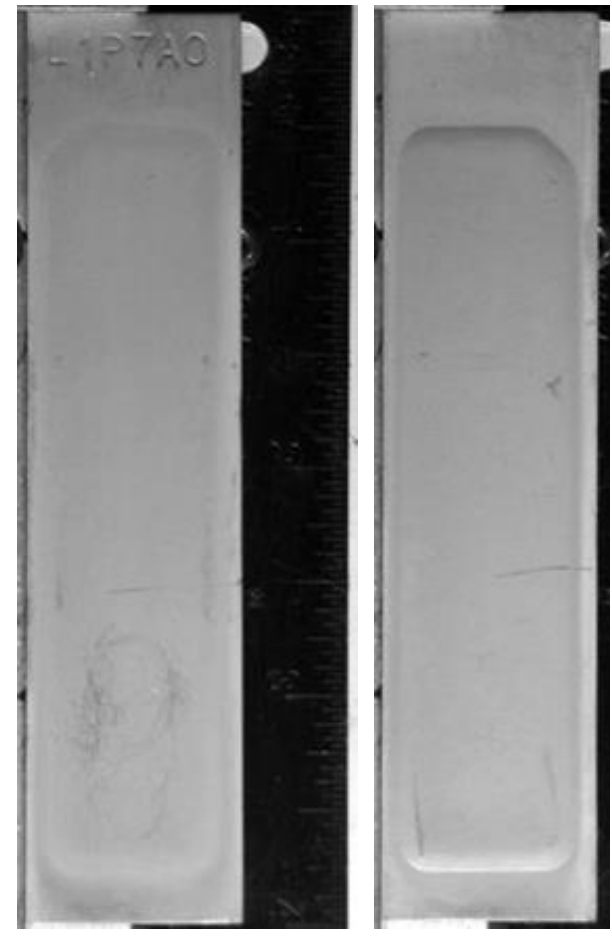

(a)

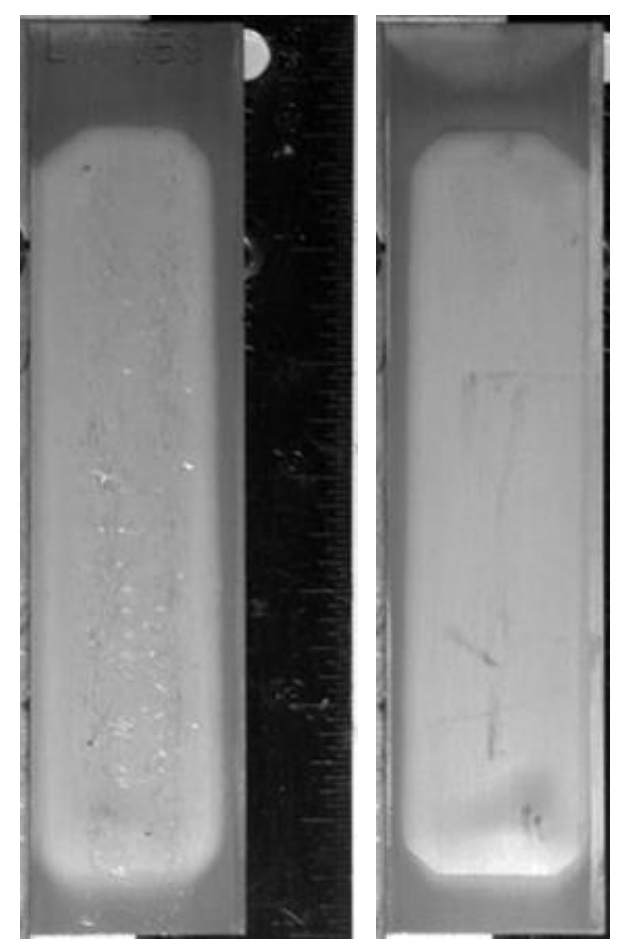

(c)

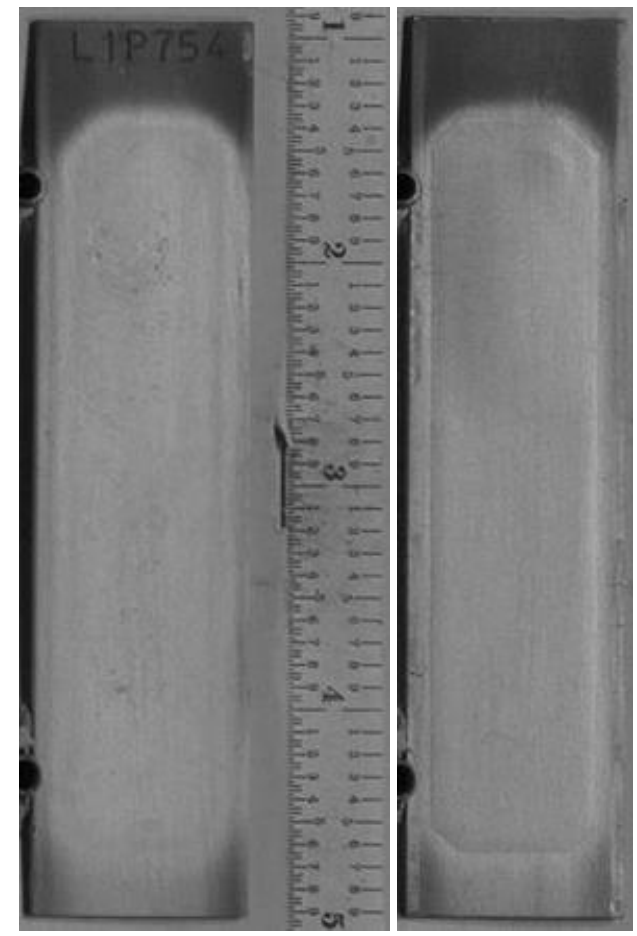

(b)
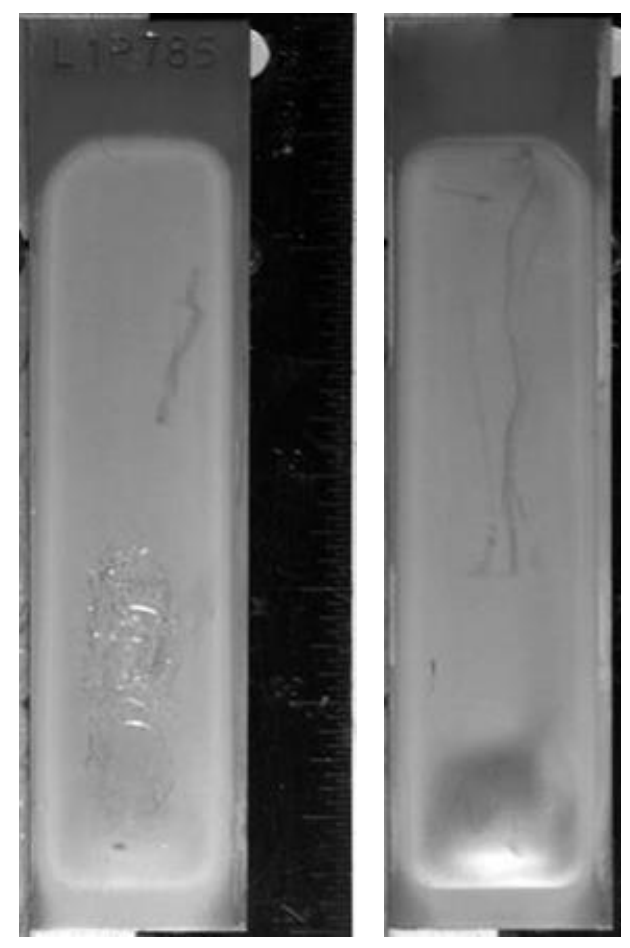

(d)

Figure 2. Photographs of plates that exhibited high swelling behavior. (a) L1P7A0 exhibited higher-than-projected volume increase, but did not exhibit blistering or pillowing, (b) L1P754 exhibited blistering/pillowing behavior (c) the blister/pillow on L1P759 was larger with increased fission density (d) further increasing pillow volume with increased fission density for plate L1P785. 


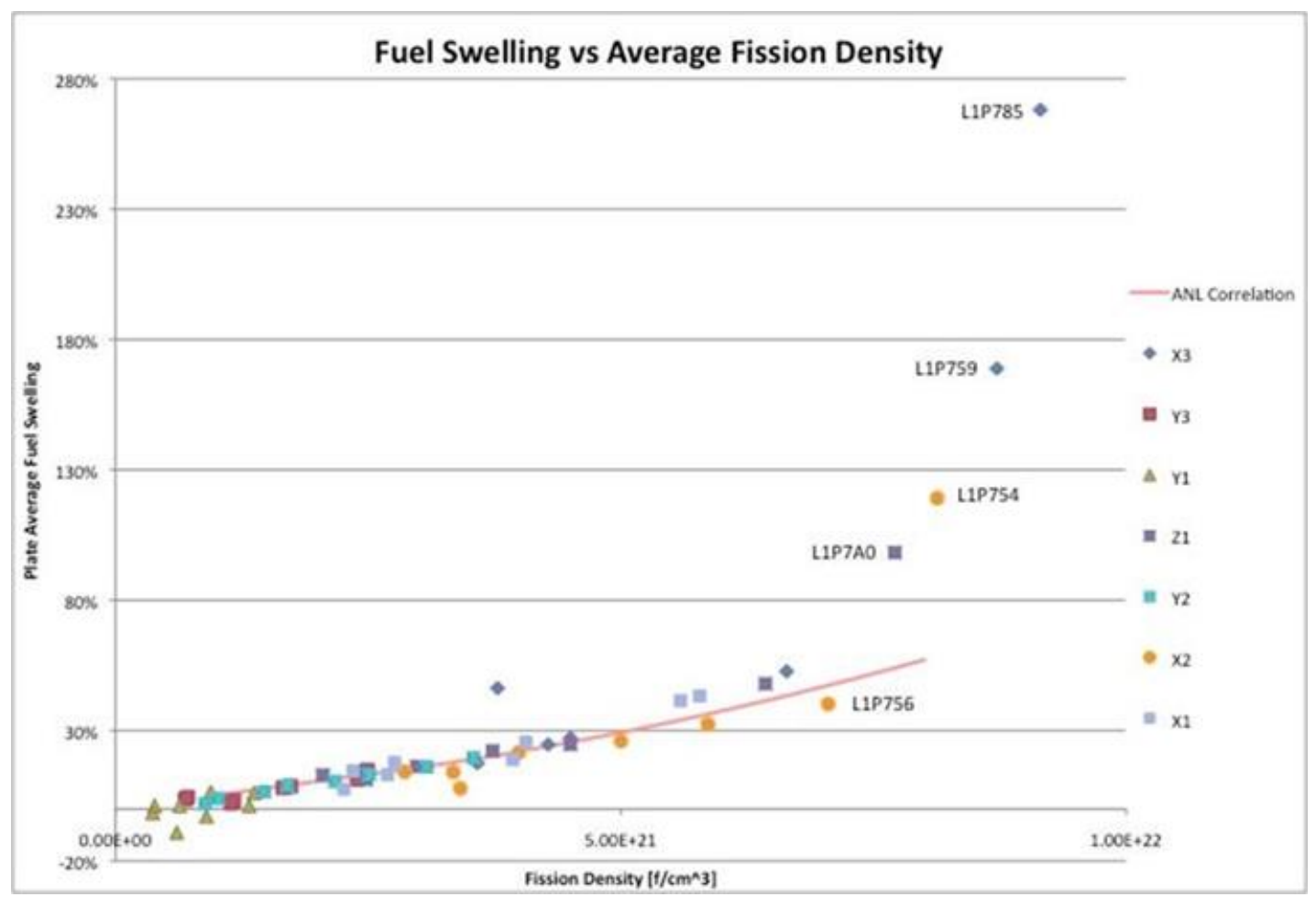

Figure 3. Immersion-density test results plotting fuel swelling versus average fission density in irradiated plates.

\subsection{Neutron Radiography}

Neutron radiography is a non-destructive characterization method that was used to evaluate the mechanical integrity and geometric stability of the fuel test plates prior to performing destructive examinations. Indications of loss of the integrity of a plate's geometric stability include cracking of the fuel foil, relocation of fuel, and large variations in fuel density throughout the plate. Radiographic images were used to guide further post-irradiation examination (PIE) and to benchmark and validate the nondestructive characterization data.

\subsubsection{Background}

The Neutron Radiography Reactor (NRAD) facility was used to perform radiographic inspection of the irradiated fuel plates. The principles of neutron radiography are similar to those of the commonly applied x-ray radiography; variations in image density result from the absorption characteristics of the material being imaged. Neutron imaging is used to identify geometric features or discontinuities in nuclear fuel, including cracks, pores and voids, and inclusions.

A Testing, Research, Isotopes, General Atomic (TRIGA) reactor, NRAD, (shown in Figure 4 ) is located below HFEF. NRAD makes use of the east radiography station (ERS) to perform NDE on radioactive samples. Schematics of the ERS are shown as Figure 5 and Figure 6. 


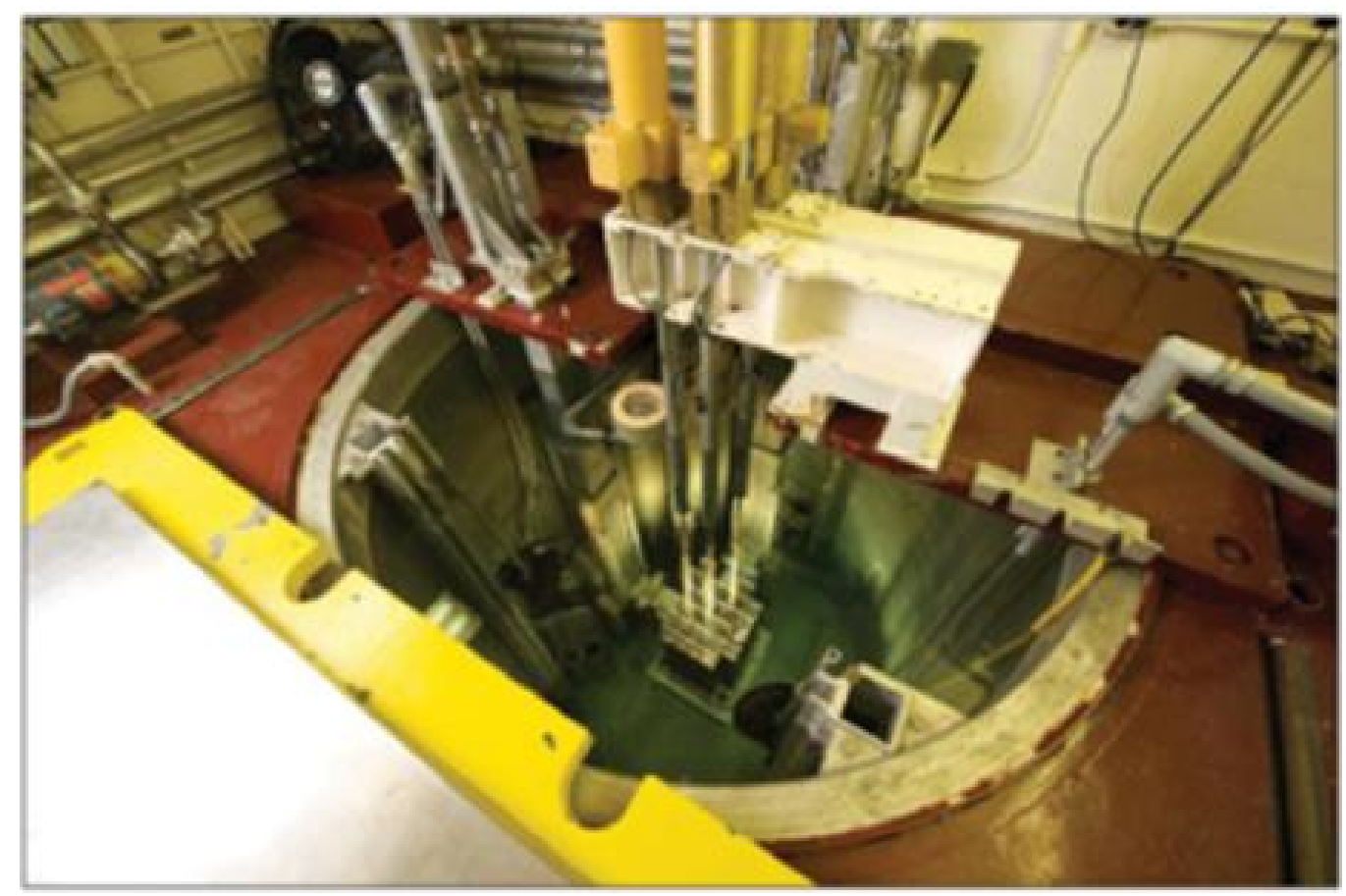

Figure 4. NRAD.

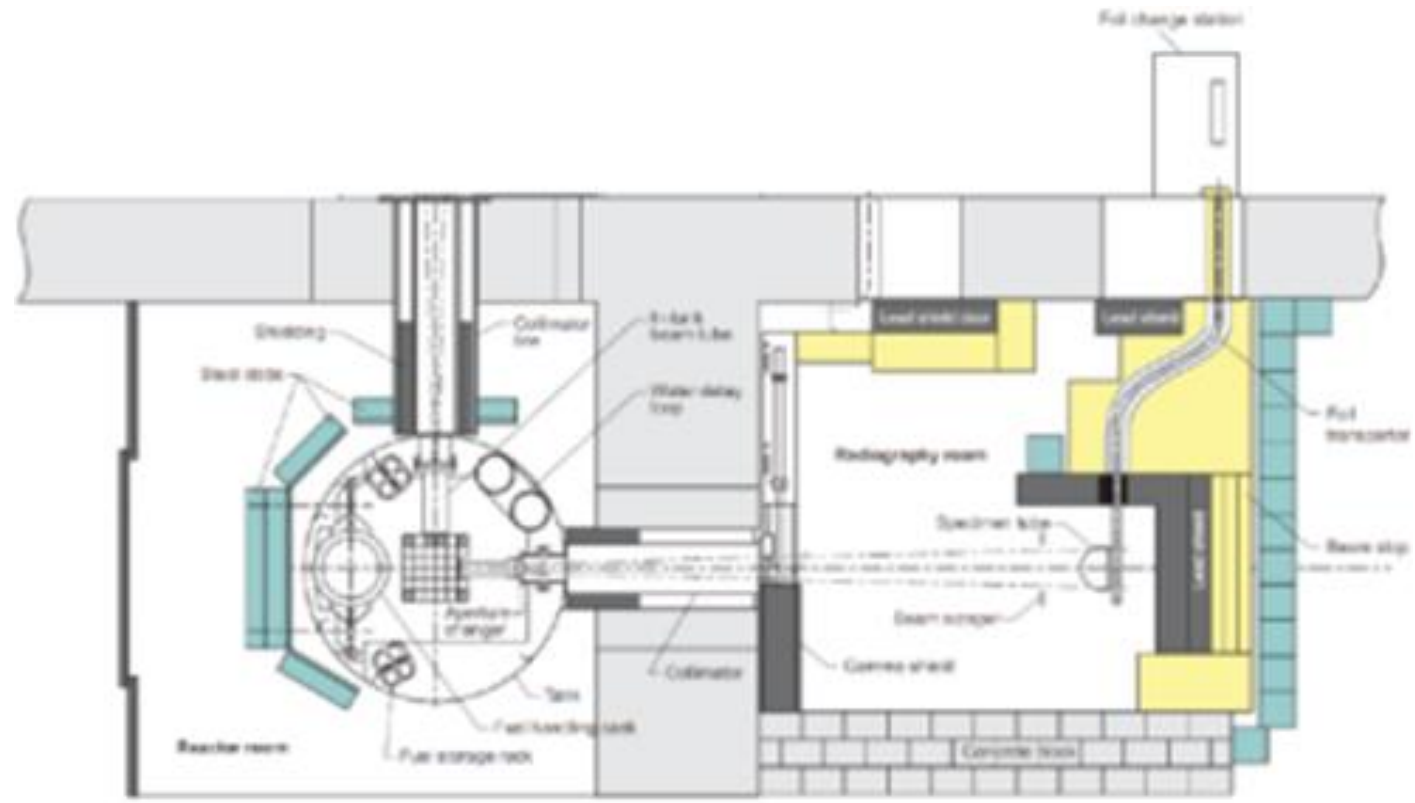

Figure 5. ERS top-down view. 


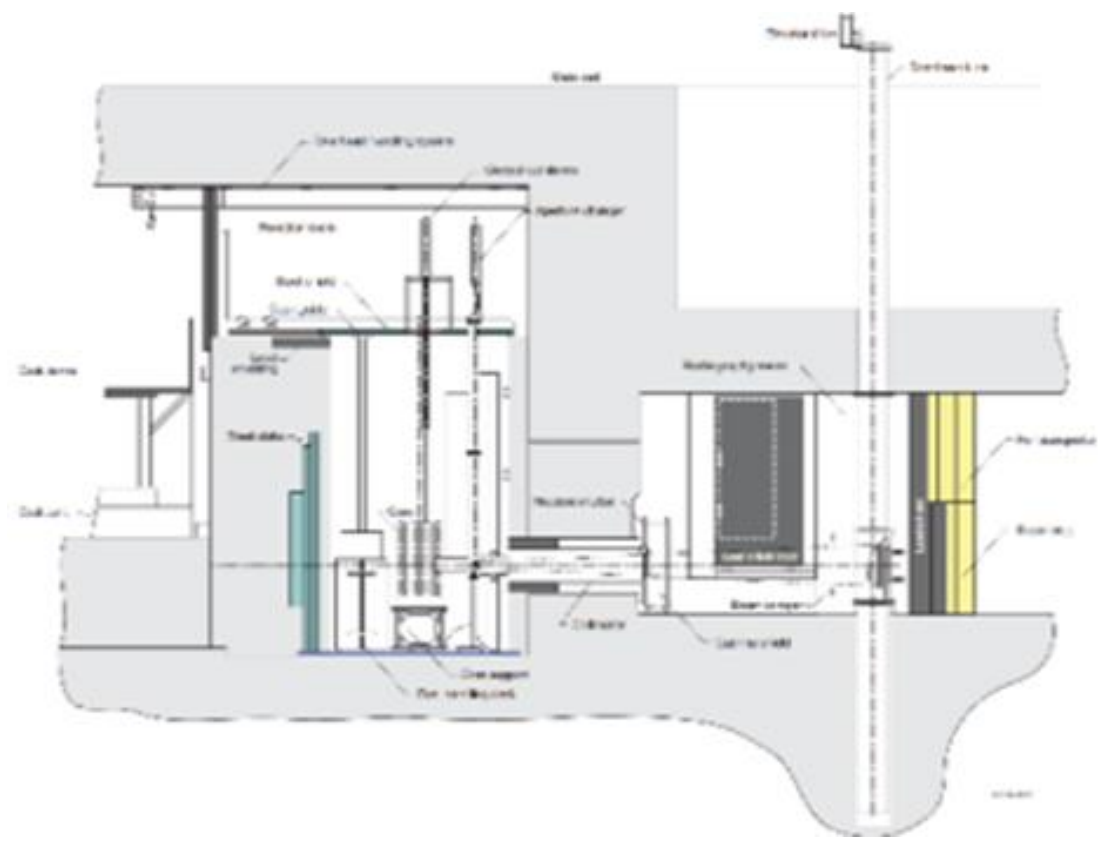

Figure 6. ERS side view.

The process of nuclear radiography at HFEF begins in the hot cell, where the sample of interest is placed in a handling fixture and lowered through an elevator system located above the ERS into the beam line. The RERTR-12 fuel plates were loaded into a sample-handling fixture of the type illustrated in Figure 7.

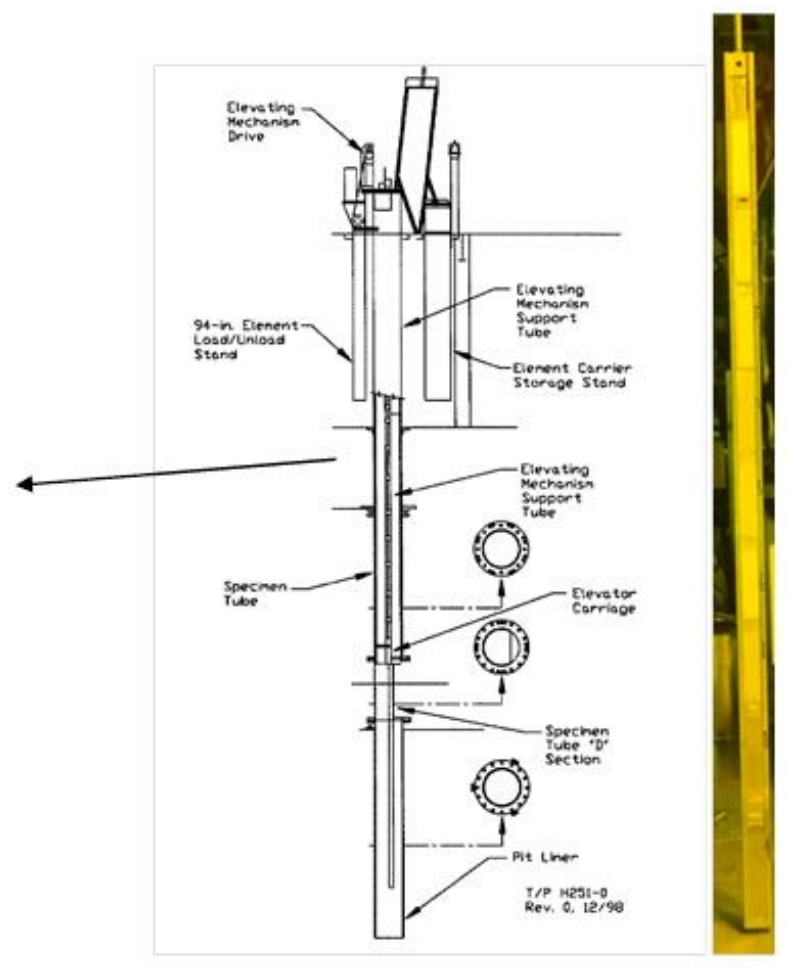

Figure 7. Specimen-handling system and plates. 
A radiograph of the resolution test piece is taken along with the radiograph of the fuel plates. This is done using ASTM image-quality indicators, a beam-purity indicator (BPI), and a sensitivity indicator (SI). The BPI is used to detect the presence of scattered neutrons that affect image contrast. Image resolution can be determined by comparing the smallest visually detected dimension to the known SI dimensions.

The vertical gamma-scan holder is loaded with the two uranium-bearing reference plates (DU-1 and HEU-1) at the bottom of the holder, with the plates of interest stacked on top of the standards. These reference plates were included as a scoping experiment to determine whether burnup or fuel relocation could be quantified. Each reference plate $(1.0$ in. $\times 5.75$ in. $\times 0.080$ in.) contains six tabs of uranium metal, with tab thicknesses ranging from 0.0056 to $0.0331 \mathrm{in}$. Tab stacks were prepared using uraniummetal foils. The plates are otherwise composed of 6061 aluminum.

Reference plate DU-1, contains depleted uranium (DU), $0.2 \%$ enriched. Reference plate HEU-1 contains highly enriched uranium (HEU), 93\% enriched. Table 5 shows the actual measured thickness of the uranium tabs.

Table 5. Tab thicknesses.

\begin{tabular}{|l|c|c|c|c|c|c|}
\hline DU-01 \\
\hline Tab number & 1 & 2 & 3 & 4 & 5 & 6 \\
\hline Thickness (in.) & 0.0056 & 0.0104 & 0.0161 & 0.0208 & 0.0264 & 0.031 \\
\hline
\end{tabular}

\begin{tabular}{|l|c|c|c|c|c|c|}
\hline HEU-01 \\
\hline Tab number & 1 & 2 & 3 & 4 & 5 & 6 \\
\hline Thickness (in.) & 0.0057 & 0.0104 & 0.016 & 0.0246 & 0.027 & 0.0331 \\
\hline
\end{tabular}

Dysprosium and indium foils - separated by a notched cadmium sheet and backed by another to provide filtering and eliminate backscatter, respectively - are then loaded into a carrier and sent into the beam line behind the sample. The foils are exposed for twenty-two minutes in the $\sim 6 \times 10^{6} \mathrm{n} / \mathrm{cm}^{-2} / \mathrm{s}^{-1}$ beam with a length-to-diameter (L/D) ratio of 125 in every RERTR-12 shot. The two foils, Dy and In, are used in conjunction to capture both thermal and epithermal neutrons in the same exposure. The epithermal shot is necessary due to the inability of thermal neutrons to penetrate through larger specimens; it allows the visualization of the entire sample and emphasizes different features.

The foils are then transferred to separate cassettes and vacuum-sealed in contact with film. The Dy foil is used with D3SC AGFA Structurix, single-coated, high-contrast, ultra-fine-grain x-ray film. The In foil is used with T-2000 Kodak Industrex, double-coated-emulsion, high-contrast, very-fine-grain x-ray film. These cassettes are then compressed in a vacuum to eliminate blurring caused by the shifting of plates, and stored in a darkroom until at least five half-lives have passed. In every RERTR-12 case, the film was exposed for a minimum of 12 hours. (Dy has a 2.3 hour half-life; In has a 54 minute half-life.) The films are then developed and scanned into a digital image using a FineScan 2750 scanner at 1200 dpi resolution.

Photographs of the identified plates, the dysprosium and indium radiographs of the plates, and the density standard test pieces, together with detailed shot logs, are electronically archived. The completed shot logs and copies of completed forms are ordered by shot number and contain the elevator position, angle, foil type, transporter position, L/D, shot time, date, film cassette used, foil pit RAM (mR/hr), and Dy and In foil, cadmium, and foil cassette used. 


\subsubsection{Evaluation of Failed Fuel Plates}

\subsubsection{Mini-plate L1P7AO}

L1P7A0 exhibited a swelling rate higher than predicted (see Figure 2) by the currently accepted UMo fuel swelling correlation and established in non-destructive PIE of other RERTR-12 plates. It exhibited nearly uniform swelling with no obvious visual signs of pillowing or indications of local pillowing as measured by profilometry. Figure 8 provides both a radiograph and color map of plate L1P7A0, and Figure 9 displays the pixel intensity in the radiographs over the surface of the plate, read across the center and from the top to the bottom of the plate. Because fuel swelling was constrained by the cladding rails, an increase in fuel-meat thickness is seen near the boundaries, caused by irradiation creep of U-Mo. This is evident in the color map (Figure 8) as well as the intensity plots (Figure 9). Based on cracking of the fuel meat observed in metallography samples and the observed decrease in fuel-meat density, it is postulated that the plate delaminated by in-plane cracking through the fuel meat. This cracking would not have been detectable using in-plane neutron radiography if the cracks were perpendicular to the neutron beam, and no fuel relocation occurred. The plate cut-away schematics shown in Figure 10 and Figure 11 provide additional clarity for the type of cracks the perpendicular-to-plate face configuration can and cannot resolve. It is recommended that radiographs in several additional orientations be performed for similar high swelling plates if observed in future PIE campaigns.
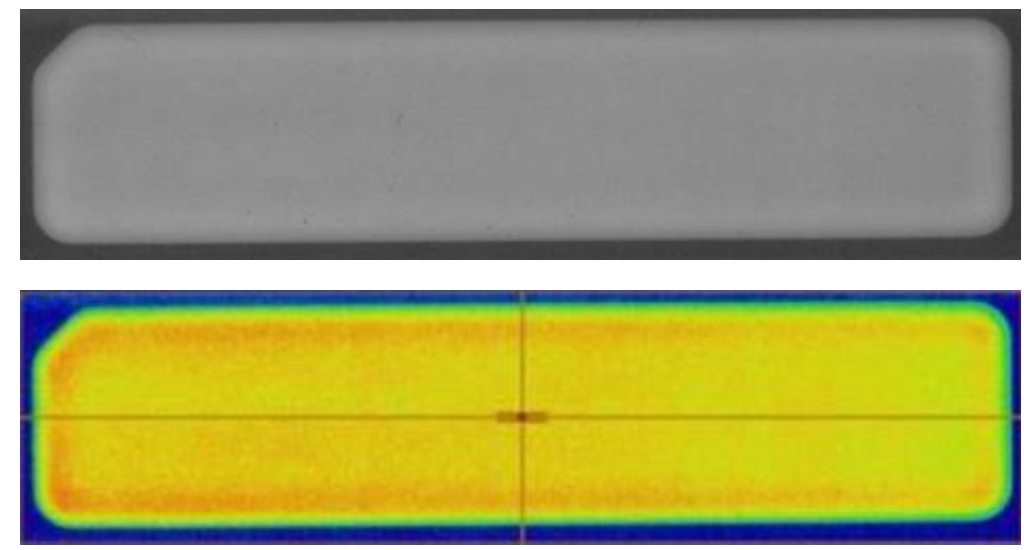

Figure 8. L1P7A0 radiograph (top) and color map (bottom). Longitudinal and transverse lines indicate locations from which pixel intensity plots in Figure 9 were taken. 

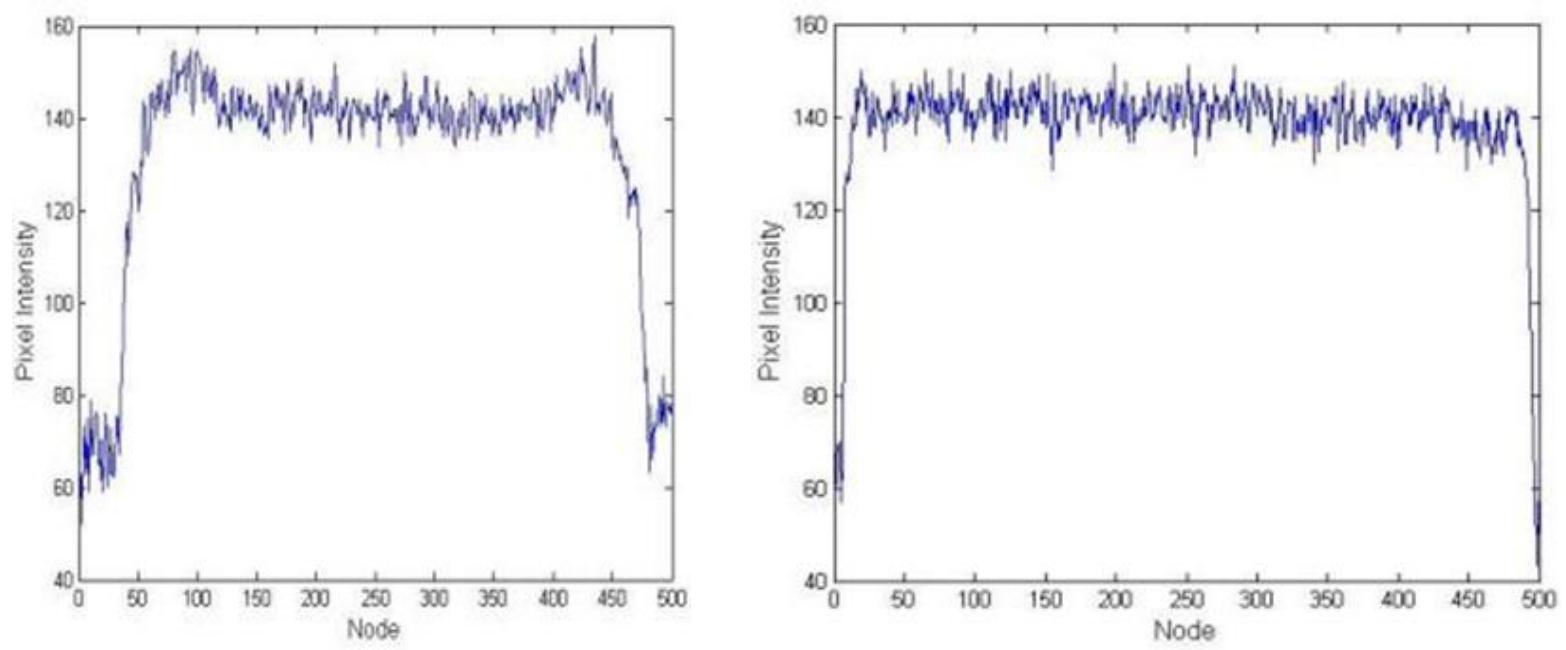

Figure 9. Relative pixel intensity in transverse (left) and longitudinal (right) directions of L1P7A0. See Figure 8 for locations of section lines.

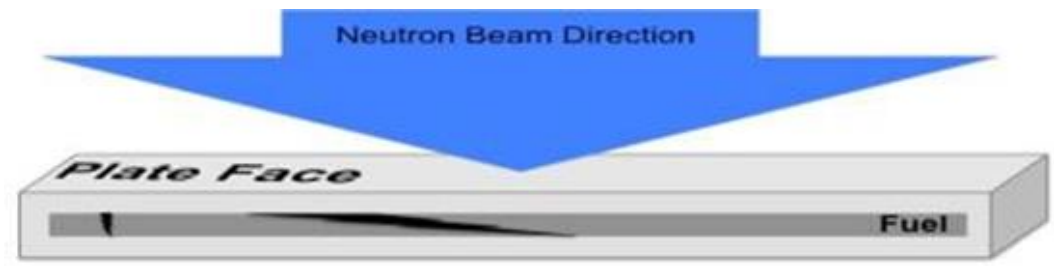

Figure 10. Resolvable cracks in fuel using a configuration perpendicular to plate face.

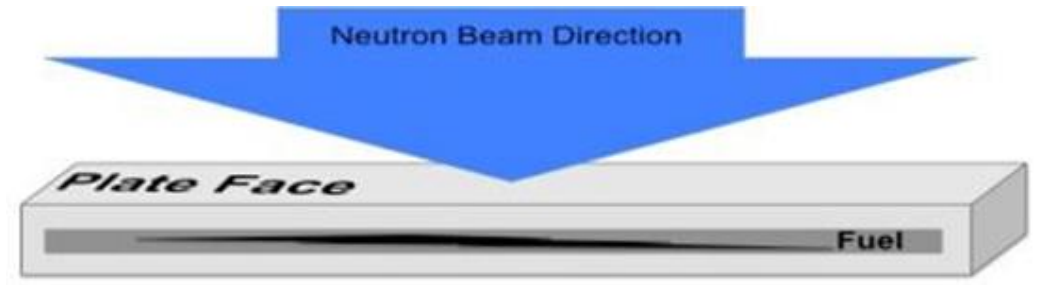

Figure 11. Non-resolvable crack in fuel using a configuration perpendicular to plate face.

\subsubsection{Mini-plate L1P754}

Plate L1P754 was shipped to HFEF for examination prior to the remainder of the plates discussed in this report. The mid plane of the plate shows swelling peaks inset from the edge of the foil caused by fuel creep and edge constraint. At an average fission density of $8 \times 10^{21}$ fissions $/ \mathrm{cm}^{3}\left(1.2 \times 10^{22}\right.$ peak fissions $/ \mathrm{cm}^{3}$ ), fission-gas bubbles are clearly visible throughout the fuel foil under metallography. Figure 12 shows the pillowed region at the top of the plate with fuel relocation clearly evident. 

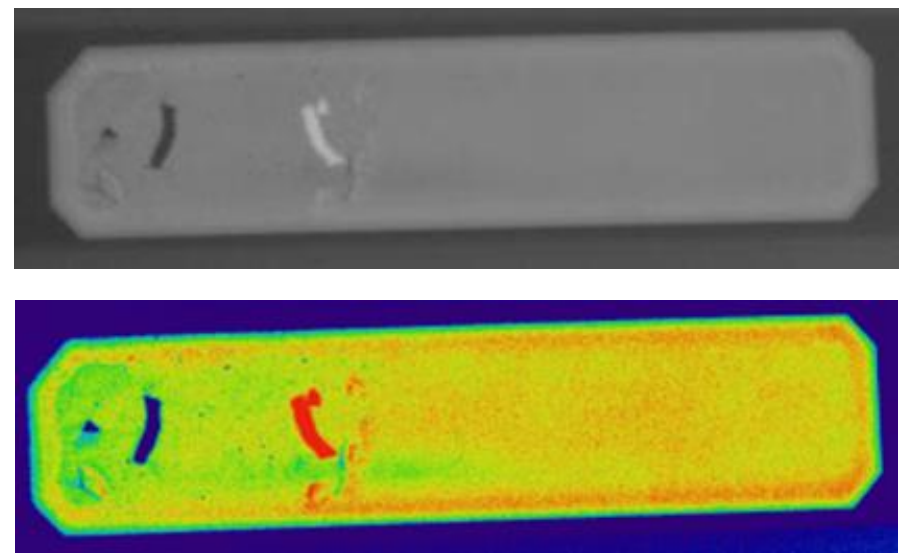

Figure 12. L1P754 radiograph (top) and color map (bottom).

\subsubsection{Mini-plate L1P759}

L1P759 failed due to in-reactor pillowing. Fuel movement to positions near the edges of the fuel foil occurred as a result of fuel creep and edge constraint (see Figure 13). Profilometry measurements indicate that the plate failed over most of the fuel zone. Fuel relocation to the pillowed lower region of the plate occurred, causing peaks in image intensity in the radiograph (see Figure 14). The shape of relocated fuel matches the shape of the missing fuel locations in the lower third of the fuel plate. In the upper half of the plate, the bright areas that indicate relocated fuel are more closely positioned next to regions of lower image density. The radiographs indicate that the relocated fuel may have a conical aspect in the through-thickness direction. The fuel also shows extensive cracking without relocation of fuel over the entire fuel zone. This can be most clearly seen as higher intensity lines through the fuel zone in the color map. The cracking patterns differ with location on the fuel plate. Near the top and bottom regions of the fuel, the cracks are more closely spaced, and the cracking pattern gives the appearance of fuel that has been fractured, which could be the result of higher stress in these regions. ${ }^{3}$ At the bottom of the fuel zone, inside the area of increased fuel thickness caused by creep, a small cluster of bright spots appears, which indicates a region of high fuel density that does not appear to be associated with either fuel creep or cracking. In the central region of the fuel, cracks run at an angle of approximately 30 degrees from the lateral (horizontal) and are inclined in the same direction. Two of the cracks appear to exhibit increased fuel density along the crack line, potentially indicating fuel beginning to overlap across the crack.

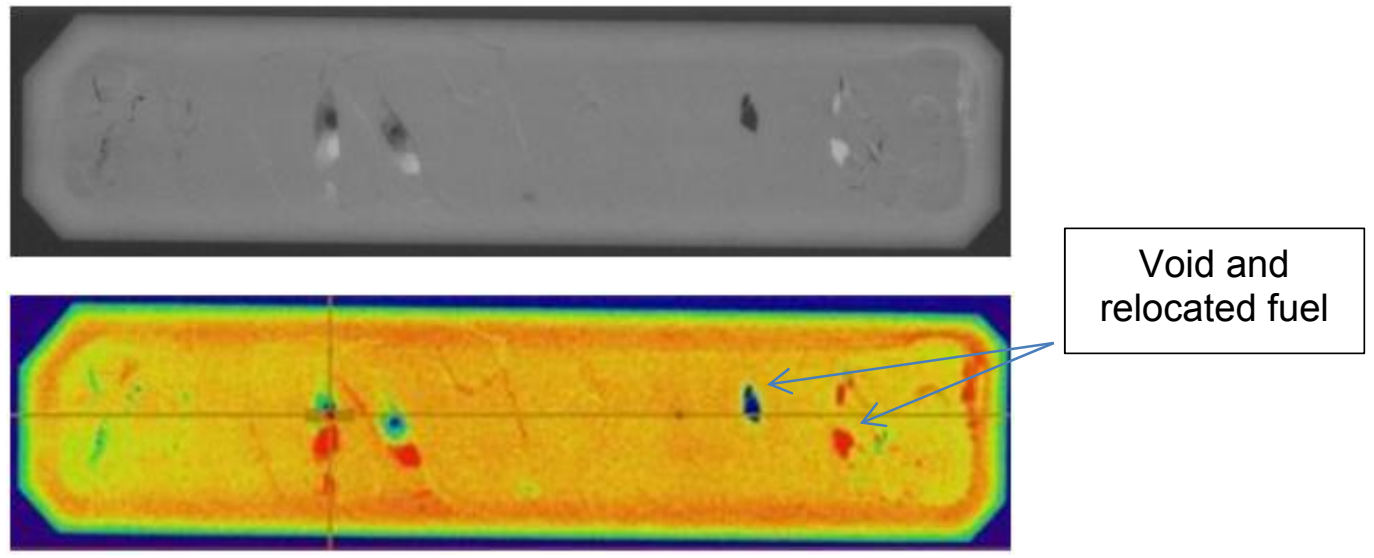

Figure 13. L1P759 radiograph (top) and color map (bottom). 

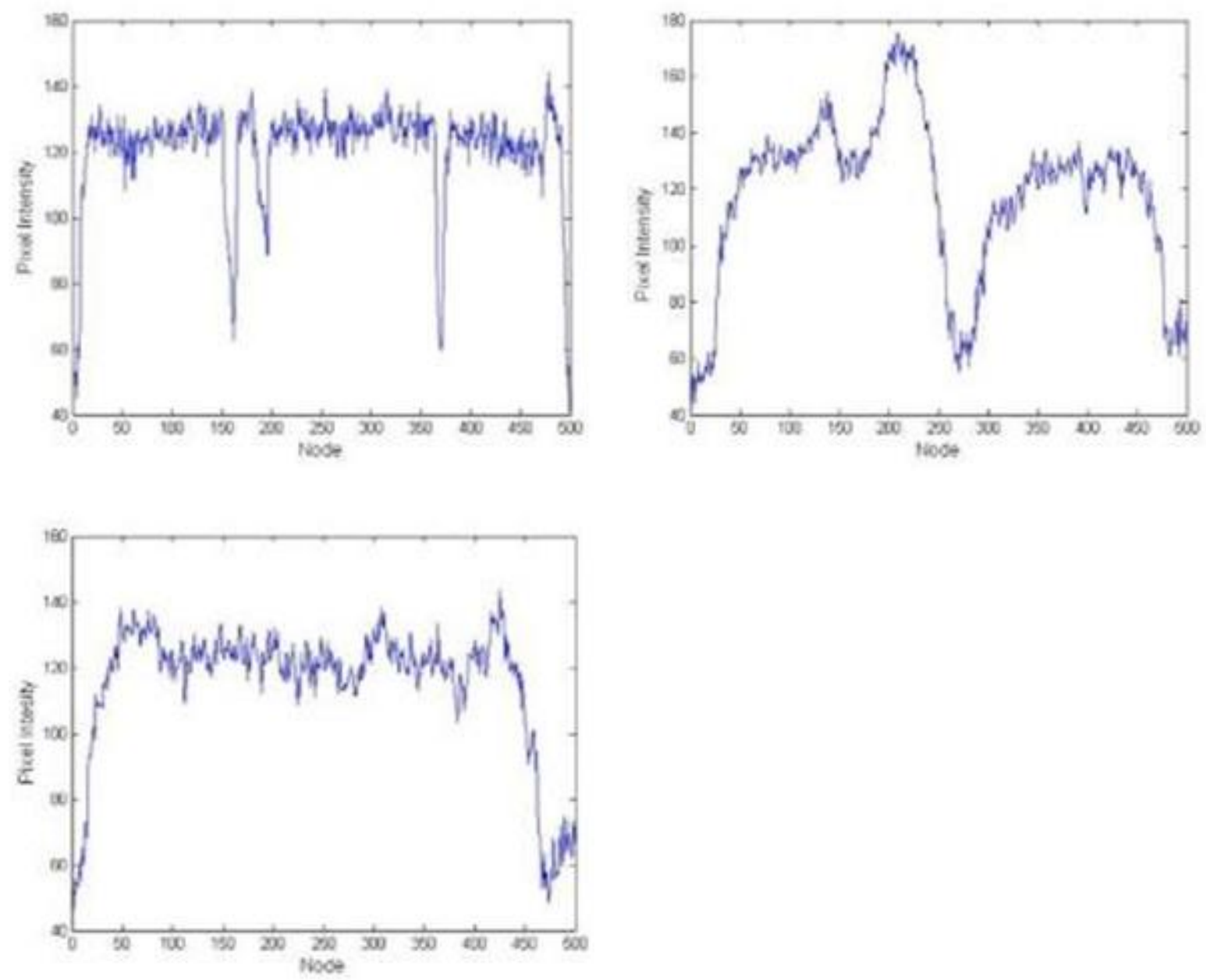

Figure 14. Relative pixel intensity for a longitudinal section (upper left, see Figure 13 for section line), transverse section across the center defect (upper right, see Figure 13 for section line), and across the pillow in the lower section of the plate (bottom).

\subsubsection{Mini-plate L1P785}

L1P785 shows a large amount of cracking in the U-Mo fuel meat without clear indications of pieces of fuel breaking out of the foil and relocating. The appearance of features that appear to be ridges, where sections of fuel have pushed against each other and have begun to overlap, are evident in the color map in Figure 15. The transverse intensity plots shown at the top of Figure 16 indicate considerable fuel relocation by creep toward the edges of the fuel plate is higher in the pillowed region of the fuel plate than at the plate center. 

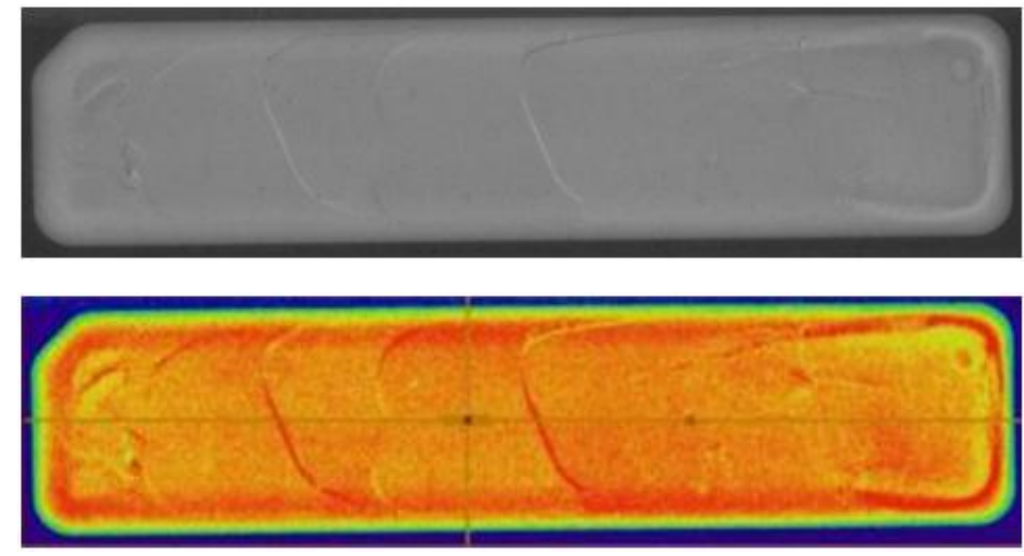

Figure 15. L1P785 radiograph (top) and color map (bottom).
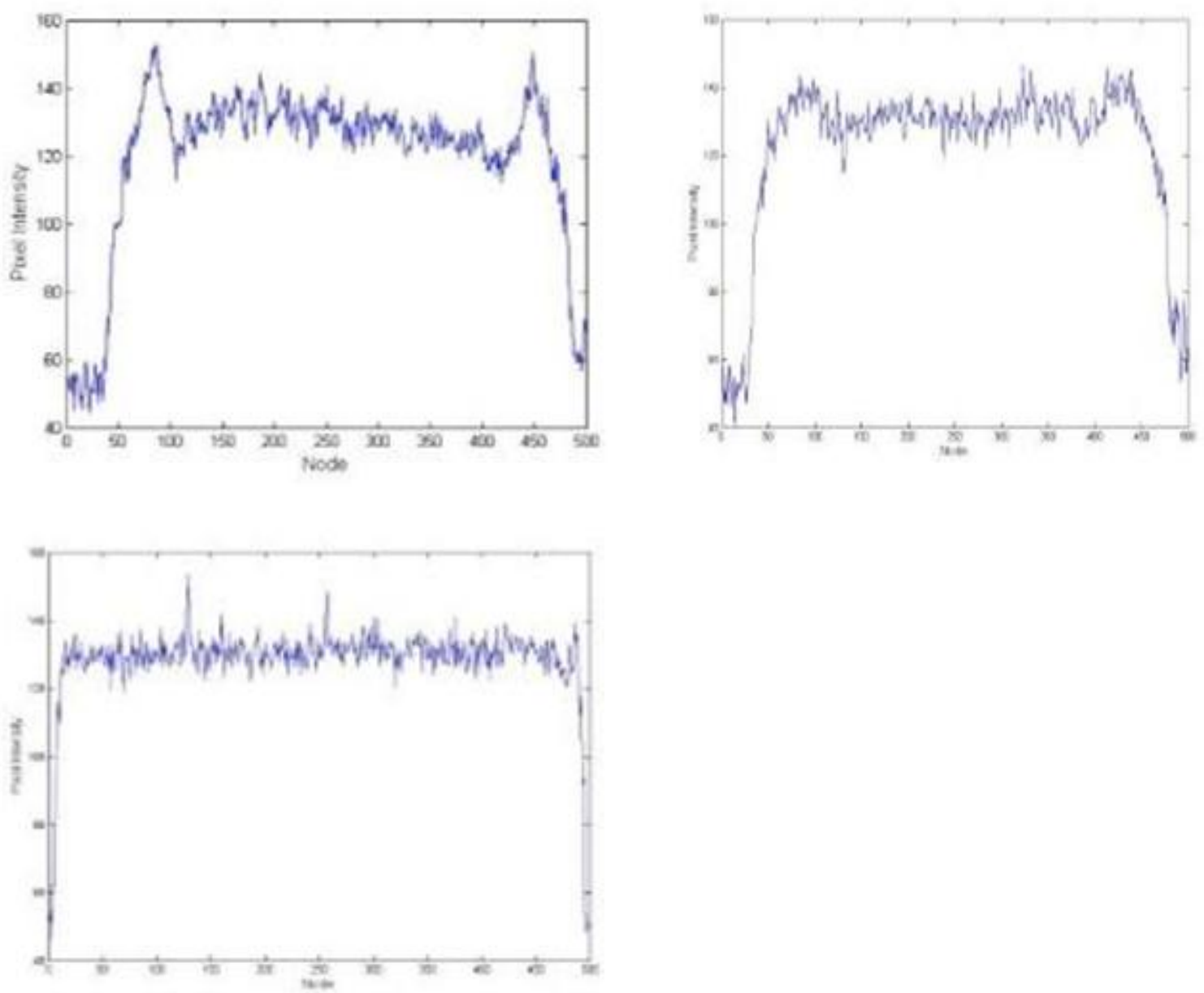

Figure 16. Relative pixel intensity in a transverse section across the pillow near the bottom (left) end of the fuel plate (upper left), transverse across the center section (upper right, see Figure 15 for section line), and in the longitudinal direction (bottom, see Figure 15 for section line). 


\subsubsection{Conclusions}

The majority of mini-plates show an increase in fuel density near the boundaries of the fuel meat. This increase in density is caused by fuel creep. During irradiation, the fuel creeps laterally, but is restrained by the cladding rail. The net result is a 'bulge' or thickening of U-Mo along the edge of the fuel meat. This thickening is observed in the intensity of the radiograph and in axial and transverse plots of image density. It is consistent with metallographic observations of the cross-sectional shape of the fuel meat.

Plate L1P7A0 exhibited higher-than-anticipated swelling, but visually appeared comparable to plates that did not fail, showing no indication of failure-related features in the radiograph. The method of radiography used, however, would not identify fuel cracking perpendicular to the neutron beam. The use of radiography at additional orientations is recommended for future analysis of fuel plates that exhibit anomalous swelling.

Fuel plates L1P785 and L1P759 both had substantial fuel-meat cracking with fuel relocation, fuelmeat separation, and fuel-plate pillowing. When a failure location is near an edge, the observed fuel relocation tends towards the edge, creating a larger creep bulge than over the rest of the plate. When the feature is observed in the center of the plate, as in L1P759, relocated fuel can move variously, including following cracks or approaching larger defects: for instance, a pillow in the fuel.

\subsection{Eddy-Current Testing}

\subsubsection{Introduction}

This section documents the results from eddy current testing to measure the oxide thickness on the surface of RERTR-12 irradiation test plates.

Industrial eddy-current techniques are used to measure the thickness of nonconductive coatings on nonferrous metal substrates. This is done using a system whereby a wire coil conducting a high-frequency alternating current is used to create an alternating magnetic field at the surface of the instrument's probe. When the probe is brought near a conductive surface, the alternating magnetic field will form eddy currents on the surface. The substrate characteristics and the distance of the probe from the substrate (the coating thickness) affect the magnitude of the eddy currents. The magnitude of the currents is measured by the probe and converted into an equivalent thickness. This thickness represents the boehmite oxide that has formed on the surface of the fuel plate during irradiation. Oxide-thickness data are used in conjunction with thermal modeling to determine fuel temperature, and important parameter in evaluating fuel performance.

Post-irradiation eddy-current testing is performed using a commercially available, hand-held eddy-current probe (ETA3.3H spring-loaded eddy probe) affixed to the Remote Fuel Metrology System (RFMS). The Remote Fuel Metrology System (RFMS) holds the fuel plates and positions the eddy-current measurement device on the plate surface. The signal from the probe is sent through a feed-through to a hand-held readout outside the hot cell, where the results are recorded.

Understanding of oxide-layer growth is also necessary for predictive modeling as part of the pre-irradiation safety analysis, which investigates the possibility of oxide spallation and plate blistering. The plate -surface temperatures are calculated using the Petukhov heat-transfer correlation, which is then used to calculate the oxide growth using an established correlation.

\subsubsection{Testing Requirements}

Eddy-current testing of all GTRI fuel plates is conducted in accordance with pre-established test plans. The system parameters, specimen information (including plate ID and orientation), results of the calibration checks, and measurement results are documented. 
All eddy-current testing is done in accordance with ASTM-E376-11 under supervision of an HFEF process engineer. ${ }^{4}$ Calibration of the system is verified and recorded prior to taking measurements on each plate. Calibration of the eddy-current system is required prior to oxide-thickness measurements on RERTR fuel plates. The calibration standards are fabricated from certified Mylar standards and certified 6061 aluminum.

Prior to the measurement of each fuel plate, a calibration check must be performed at the zero-thickness location at the center of the standards plate and using at least two certified calibration standards. The calibration check must be performed three times on each calibration standard. The average of the three measurements must be within the following tolerances:

Zero check: $\pm 2 \mu \mathrm{m}$

$22.00 \mu \mathrm{m}$ standard: $\pm 3 \mu \mathrm{m}$

$74.66 \mu \mathrm{m}$ standard: $\pm 7 \mu \mathrm{m}$

Prior to conducting measurements on each plate, any surface defects, bowing, warping, foreign material, discoloration, or other anomalies in surface condition are documented.

\subsubsection{Eddy Current Testing Method}

The eddy-current measurements taken on the RERTR-12 X1 and X2 plates consisted of three equi-spaced transverse measurements across the width of the plate at 3 axial increments, as shown in Figure 17. Eddy-current measurements taken on plates from the X3, Y1, Y2, Y3, and Z capsules were expanded to take 4 axial increments shown in Figure 18. Each test location had three measurements taken to ensure measurement reliability. Both the face and back of each fuel plate were measured.

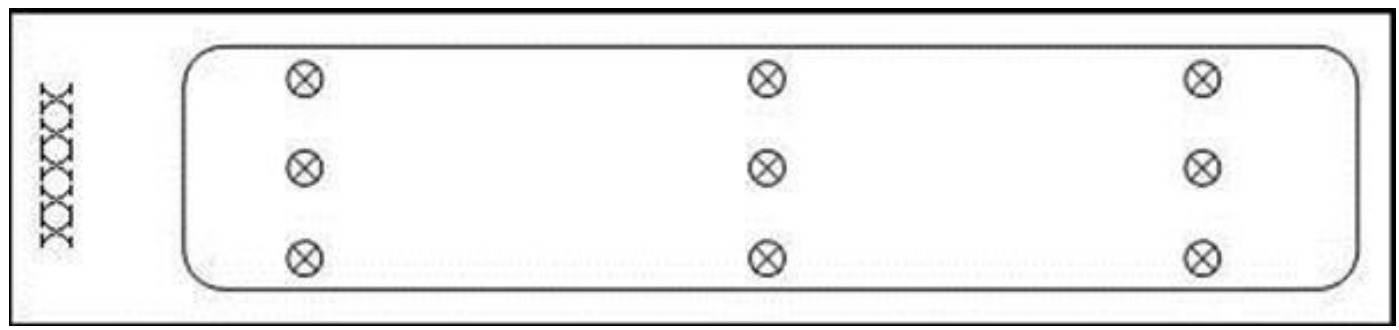

Figure 17. Oxide measurement locations for X1 and X2 plates.

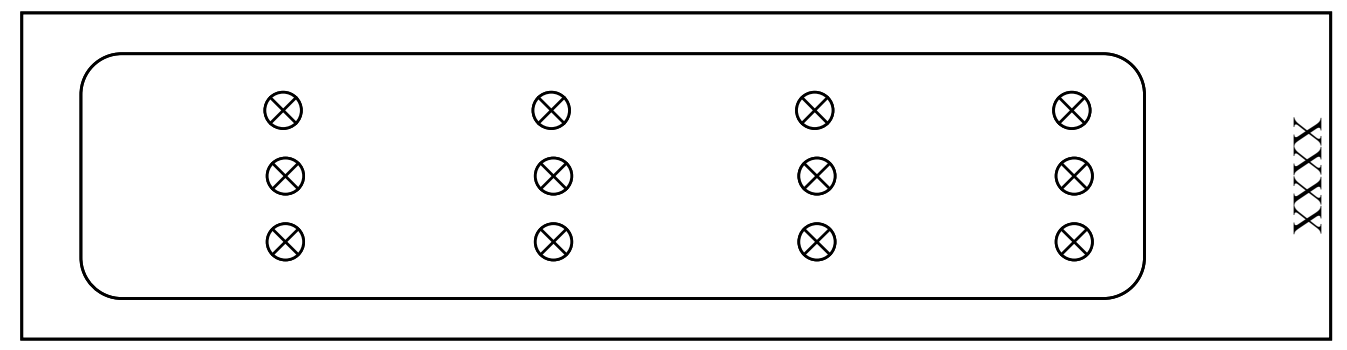

Figure 18. Oxide measurement locations for X3, Y1, Y2, Y3, and Z plates.

The accuracy of an eddy-current-testing measurement depends on the instrument, its calibration and standardization, part geometry (any curvature or bowing), magnetic permeability, surface roughness, coating thickness, coating uniformity, substrate thickness, edge effects (between 1/4 and up to 1/2 in. from edges), cleanliness, and probe pressure. These parameters are held as constant as possible during each measurement campaign and between measurement campaigns. 


\subsubsection{Discussion}

The fuel-plate oxide prefilming process implemented for the RERTR-12 test was changed from prior test campaigns. This process change resulted in thinner fuel plate oxide-thickness values, and smaller oxide-thickness-measurement scatter than in previous tests. Because of this change in the process from previous experiments, the only appropriate data set to which the RERTR-12 Insertion 2 data can be compared is the RERTR-12 Insertion 1 data. A summary of the data sets that includes the average thickness on both the front and the back of the fuel plates as well as the standard deviation between every measurement set can be seen in Table 6 and Table 7 .

Table 6. RERTR-12 Insertion 1 oxide-thickness summary.

\begin{tabular}{|c|c|c|c|c|c|c|}
\hline \multirow{3}{*}{ Capsule } & Plate ID & $\begin{array}{c}\text { Front Oxide } \\
\text { Ave }\end{array}$ & Ave StDev & $\begin{array}{c}\text { Back Oxide } \\
\text { Ave }\end{array}$ & $\begin{array}{c}\text { Plate } \\
\text { Ave StDev }\end{array}$ & Maximum \\
\hline \multirow{5}{*}{} & L1P460 & 5.8 & 0.3 & 5.70. & 5 & 10.5 \\
\cline { 2 - 7 } & L1P592 & 4.9 & 0.5 & 1.8 & 0.3 & 6.9 \\
\cline { 2 - 7 } & L1P591 & 3.2 & 0.3 & 2.9 & 0.2 & 4.8 \\
\cline { 2 - 7 } X1 & L1P461 & 5.7 & 0.8 & 5.0 & 0.4 & 8.5 \\
\cline { 2 - 7 } & L1P773 & 3.1 & 0.4 & 4.3 & 0.2 & 7.8 \\
\cline { 2 - 7 } & L1P772 & 11.0 & 0.2 & 8.3 & 0.2 & 13.2 \\
\cline { 2 - 7 } & L1P774 & 10.9 & 0.3 & 8.3 & 0.2 & 13.2 \\
\cline { 2 - 7 } & L1P776 & 3.8 & 0.2 & 4.2 & 0.3 & 6.2 \\
\hline & L1P756 & 8.3 & 0.4 & 7.1 & 0.3 & 9.7 \\
\cline { 2 - 7 } & L1P755 & 6.8 & 0.3 & 7.4 & 0.5 & 12.0 \\
\cline { 2 - 7 } & L1P593 & 4.5 & 0.4 & 4.1 & 0.6 & 7.0 \\
\cline { 2 - 7 } & L1P595 & 4.4 & 0.2 & 6.4 & 0.3 & 14.0 \\
\cline { 2 - 7 } & L1P462 & 6.4 & 0.4 & 6.1 & 0.3 & 10.0 \\
\cline { 2 - 7 } & L1P758 & 3.8 & 0.3 & 7.0 & 0.3 & 9.0 \\
\cline { 2 - 7 } & L1P463 & 8.0 & 0.4 & 7.9 & 0.4 & 10.5 \\
\cline { 2 - 7 } & L1P754 & 11.7 & 0.3 & 8.8 & 0.8 & 15.8 \\
\hline
\end{tabular}

Table 7. RERTR-12 Insertion 2 oxide-thickness summary.

\begin{tabular}{|c|c|c|c|c|c|c|}
\hline \multirow{3}{*}{ Capsule } & Plate ID & $\begin{array}{c}\text { Front Oxide } \\
\text { Ave }\end{array}$ & Ave StDev & $\begin{array}{c}\text { Back Oxide } \\
\text { Ave }\end{array}$ & Ave StDev & $\begin{array}{c}\text { Plate } \\
\text { Maximum }\end{array}$ \\
\hline \multirow{7}{*}{} & L1P759 & 7.5 & 0.5 & 6.7 & 0.2 & 7.5 \\
\cline { 2 - 7 } & L1P785 & 6.6 & 0.2 & 7.6 & 0.2 & 7.6 \\
\cline { 2 - 7 } X3 & L1P464 & 2.3 & 0.2 & 1.2 & 0.2 & 3.6 \\
\cline { 2 - 7 } & L1P465 & 3.8 & 0.2 & 3.3 & 0.2 & 7.5 \\
\cline { 2 - 7 } & L1P590 & 0.9 & 0.1 & 0.9 & 0.2 & 2.2 \\
\cline { 2 - 7 } & L1P596 & 1.3 & 0.2 & 3.2 & 0.3 & 8.4 \\
\cline { 2 - 7 } & L1P784 & 2.9 & 1.2 & 3.7 & 0.2 & 3.7 \\
\cline { 2 - 7 } & L1P786 & 1.6 & 0.2 & 1.5 & 0.2 & 7.1 \\
\hline
\end{tabular}




\begin{tabular}{|c|c|c|c|c|c|c|}
\hline Capsule & Plate ID & $\begin{array}{c}\text { Front Oxide } \\
\text { Ave }\end{array}$ & Ave StDev & $\begin{array}{c}\text { Back Oxide } \\
\text { Ave }\end{array}$ & Ave StDev & $\begin{array}{c}\text { Plate } \\
\text { Maximum }\end{array}$ \\
\hline \multirow{8}{*}{ Y1 } & L5P3F8 & 3.3 & 0.2 & 1.9 & 0.1 & 4.5 \\
\hline & L5P2C7 & 3.4 & 0.2 & 3.3 & 0.2 & 5.8 \\
\hline & L5P3F0 & 3.5 & 0.3 & 2.8 & 0.2 & 7.1 \\
\hline & L5P3G2 & 2.2 & 0.2 & 1.9 & 0.2 & 3.7 \\
\hline & L5P3G3 & 2.6 & 0.2 & 2.6 & 0.1 & 3.5 \\
\hline & L5P2A4 & 2.3 & 0.1 & 1.8 & 0.2 & 3.4 \\
\hline & L5P1B5 & 2.5 & 0.2 & 2.2 & 0.2 & 4.0 \\
\hline & L5P1B0 & 2.5 & 0.2 & 2.8 & 0.2 & 4.6 \\
\hline \multirow{8}{*}{ Y2 } & L5P1B7 & 1.8 & 0.3 & 1.0 & 0.3 & 2.9 \\
\hline & L5P1B9 & 1.2 & 0.2 & 1.0 & 0.2 & 2.8 \\
\hline & L5P2A3 & 1.0 & 0.2 & 1.2 & 0.3 & 2.5 \\
\hline & L5P2C0 & 1.0 & 0.2 & 1.0 & 0.3 & 2.9 \\
\hline & L5P3B4 & 2.2 & 0.2 & 1.4 & 0.2 & 3.5 \\
\hline & L5P3C2 & 6.5 & 0.2 & 6.3 & 0.2 & 8.5 \\
\hline & L5P3C 3 & 4.4 & 0.2 & 3.9 & 0.2 & 5.9 \\
\hline & L5P3C6 & 3.3 & 0.2 & 2.5 & 0.2 & 4.4 \\
\hline \multirow{8}{*}{ Y3 } & L5P1A5 & 2.6 & 0.3 & 2.3 & 0.3 & 5.4 \\
\hline & L5P1B8 & 1.9 & 0.2 & 1.5 & 0.2 & 2.8 \\
\hline & L5P2C8 & 2.4 & 0.2 & 2.3 & 0.2 & 4.0 \\
\hline & L5P2C9 & 3.6 & 0.2 & 2.5 & 0.1 & 4.8 \\
\hline & L5P3B1 & 3.4 & 0.1 & 2.7 & 0.2 & 4.9 \\
\hline & L5P3B2 & 3.6 & 0.2 & 1.4 & 0.1 & 3.6 \\
\hline & L5P3B3 & 2.3 & 0.2 & 2.3 & 0.2 & 3.8 \\
\hline & L5P3C1 & 3.3 & 0.1 & 2.2 & 0.2 & 3.3 \\
\hline \multirow{8}{*}{$\mathrm{Z1}$} & L1P7A1 & 3.0 & 0.2 & 2.2 & 0.1 & 8.4 \\
\hline & L1P787 & 2.3 & 0.3 & 3.8 & 0.2 & 6.4 \\
\hline & L1P789 & 2.1 & 0.2 & 2.2 & 0.3 & 3.4 \\
\hline & L1P7A0 & 2.3 & 0.2 & 4.0 & 0.1 & 9.0 \\
\hline & L2P481 & 3.5 & 0.2 & 3.4 & 0.2 & 6.3 \\
\hline & L2P482 & 2.3 & 0.1 & 4.0 & 0.1 & 4.9 \\
\hline & L2P498 & 1.8 & 0.2 & 2.2 & 0.2 & 3.7 \\
\hline & L2P499 & 1.7 & 0.2 & 1.7 & 0.1 & 4.6 \\
\hline
\end{tabular}

The values outlined in these tables are plotted against the calculated surface-heat fluxes for each plate in Figure 19. Because the surface-heat fluxes for the Insertion 1 plates were, on average, higher than the plates in Insertion 2, the temperatures of the capsules varies as a function of location within the experiment, and duration in the reactor varied from capsule to capsule, a direct comparison is not possible; however, a similar trend between the two insertions can be observed. 
Based on the results shown, a similar oxide-growth behavior occurred in both the Insertion 1 and Insertion 2 capsules. The growth appears to be stable throughout the entire power regime tested in these two insertions.

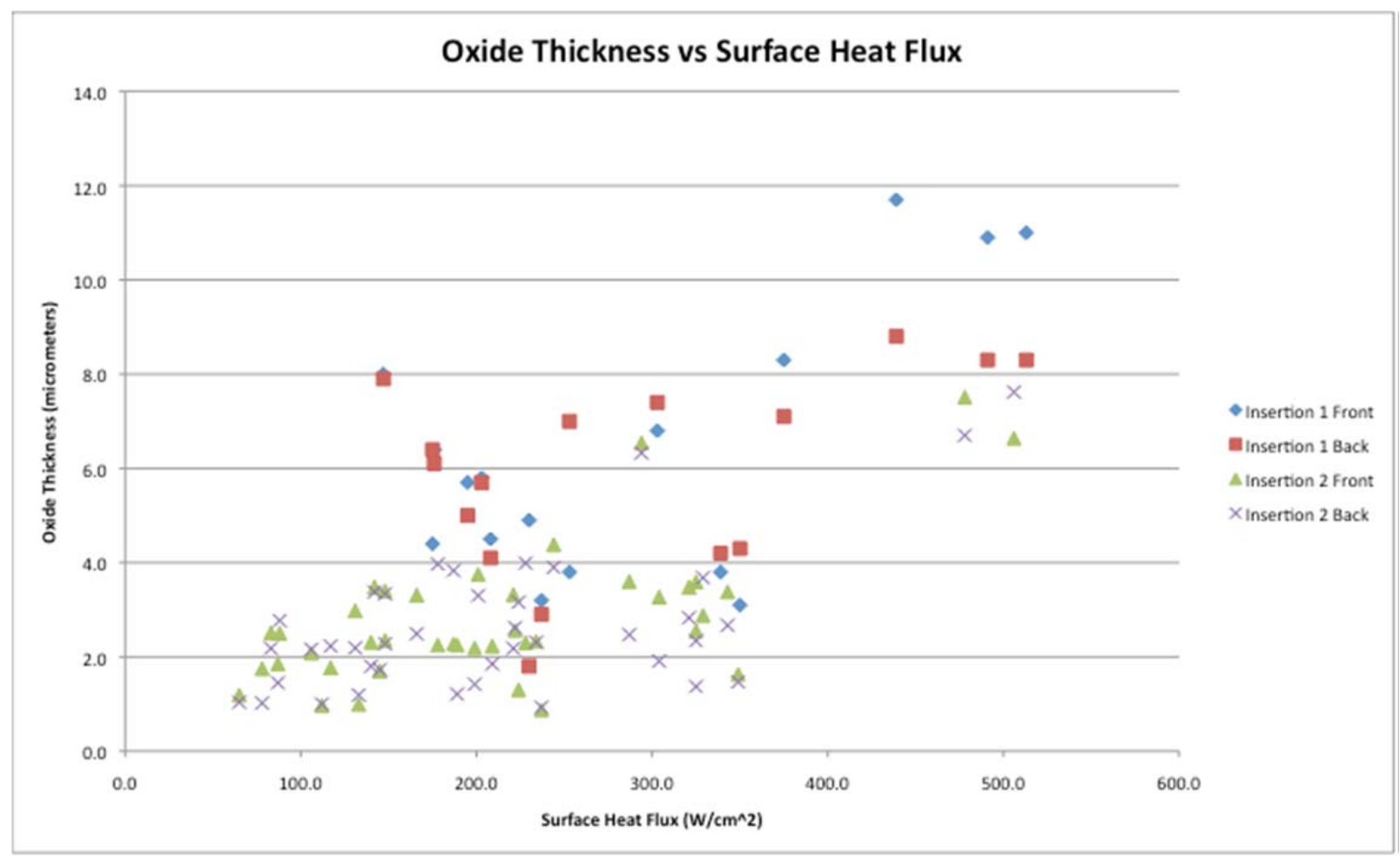

Figure 19. Plate surface oxide-thickness values as a function of average surface heat flux.

Several of the oxide layers on fuel plates irradiated in RERTR-12 were examined by metallographic examination. The oxide that grows on the surface of the plates, however, is very brittle, and significant portions of it can be lost during sectioning and sample preparation (epoxy application, grinding, polishing). Regions that appear to have no oxide cannot be assumed to have had none when removed from the reactor. Nevertheless, significant regions with the oxide intact can be found and measured using a calibrated measurement system. Examples of images with oxide-thickness measurements overlaid can be seen in Figure 20 and Figure 21.

Oxide-thickness measurements were taken in several areas where the oxide layer was intact. The measured thicknesses can be seen in Table 8 as a function of plate and mount number. The plate average oxide measurements via metallography are provided for comparison with the plate average values measured using the eddy-current probe. Values observed using metallography are similar and exhibit relatively large scatter, similar to the values measured by the eddy-current method. 


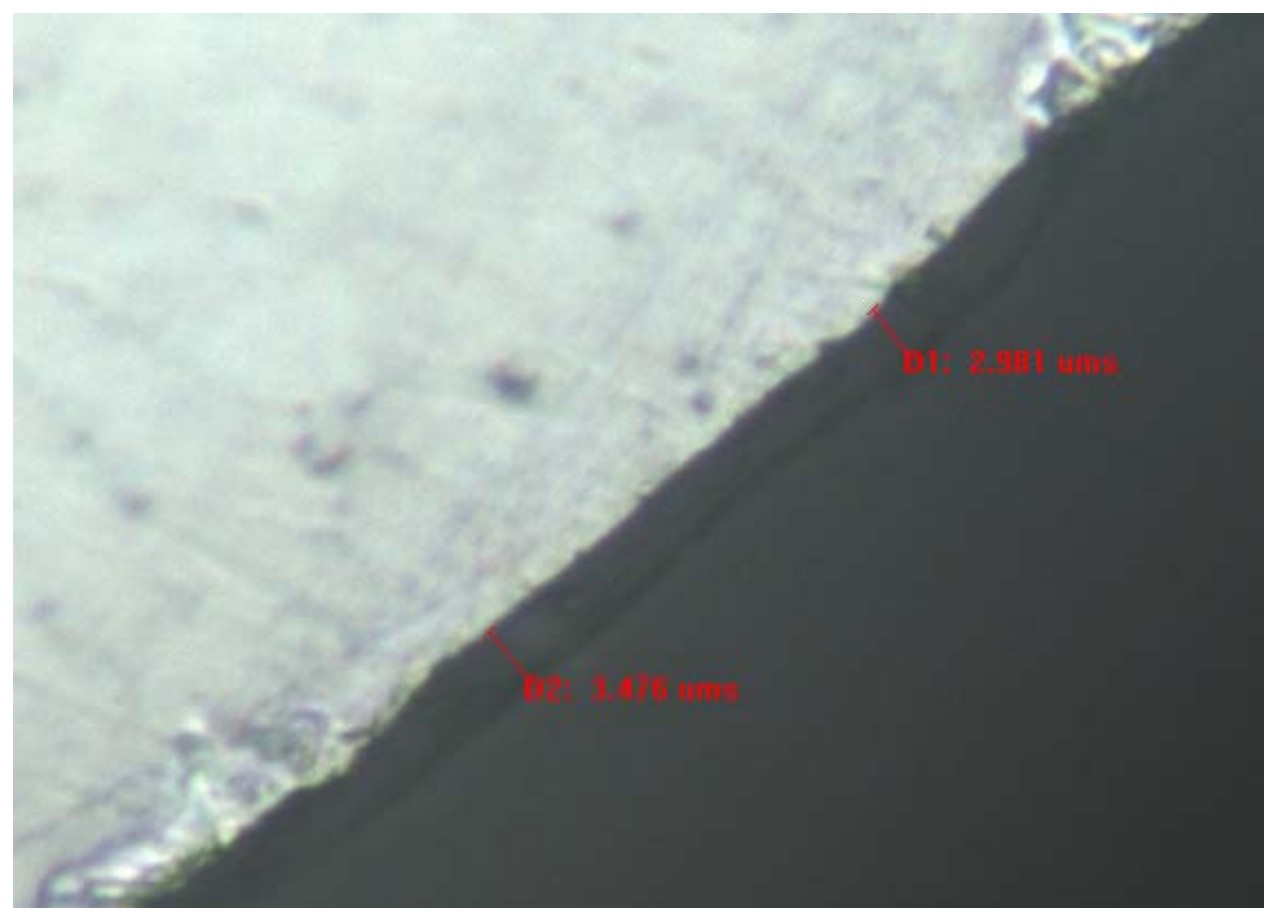

Figure 20. Metallographic image of L1P5C2 showing oxide growth on the plate surface with thickness measurements.

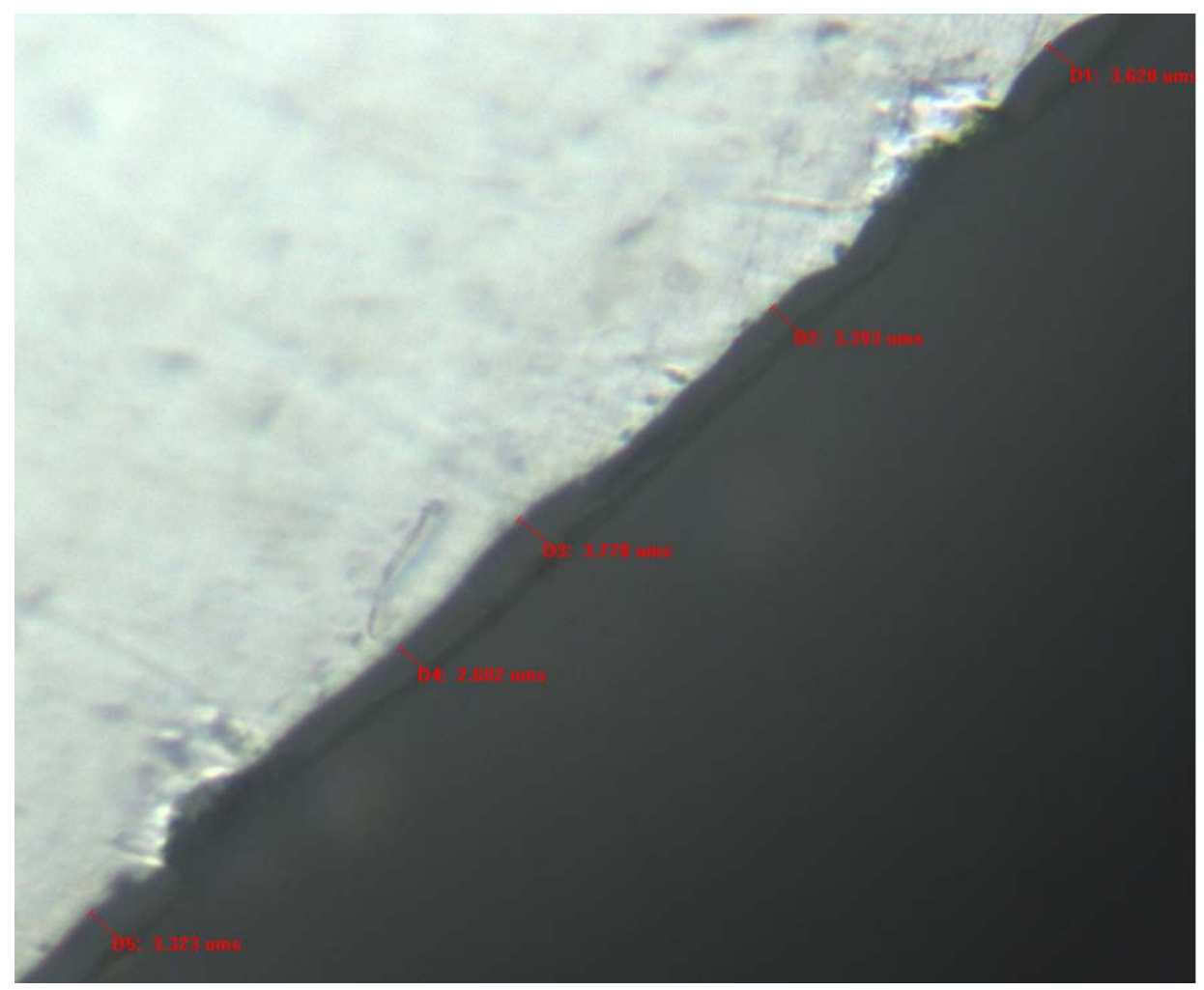

Figure 21. Metallographic image of L1P5C2 showing oxide growth and thickness measurements. 
Table 8. Summary of oxide thickness measured using metallographic cross-sections.

\begin{tabular}{|c|c|c|c|c|c|c|c|c|c|c|}
\hline Plate ID & $\begin{array}{l}\text { Mount } \\
\text { ID }\end{array}$ & \multicolumn{5}{|c|}{ Measured Oxide Thickness $(\mu \mathrm{m})$} & $\begin{array}{c}\text { Image } \\
\text { Ave }(\mu \mathrm{m})\end{array}$ & STDEV & $\begin{array}{c}\text { Plate } \\
\text { Average }\end{array}$ & $\begin{array}{c}\text { Eddy } \\
\text { Current }\end{array}$ \\
\hline \multirow{10}{*}{ L1P7A0 } & \multirow{10}{*}{29} & 0.8 & 3.9 & 3.8 & 5.2 & & 3.5 & 1.9 & \multirow{10}{*}{3.9} & \multirow{10}{*}{3.15} \\
\hline & & 3.8 & 4.3 & 3.6 & & & 3.9 & 0.3 & & \\
\hline & & 3.6 & 3.7 & 4.1 & 4.3 & & 3.9 & 0.3 & & \\
\hline & & 4.5 & 3.8 & 4.5 & 3.2 & & 4.0 & 0.6 & & \\
\hline & & 3.0 & 3.5 & 2.9 & & & 3.2 & 0.3 & & \\
\hline & & 3.6 & 3.3 & 4.4 & & & 3.5 & 0.2 & & \\
\hline & & 4.1 & 4.8 & 5.8 & & & 4.4 & 0.3 & & \\
\hline & & 3.9 & 4.7 & 4.6 & & & 4.8 & 0.9 & & \\
\hline & & 2.4 & 4.2 & 3.3 & 4.6 & & 3.9 & 1.0 & & \\
\hline & & 3.5 & 3.3 & & 4.5 & & 3.7 & 0.6 & & \\
\hline \multirow{10}{*}{ L5P3C2 } & 52 & 2.6 & 3.9 & 4.6 & 4.9 & 4.1 & 4.0 & 0.9 & \multirow{10}{*}{4.1} & \multirow{10}{*}{6.44} \\
\hline & \multirow{9}{*}{53} & 5.9 & 6.3 & & & & 6.1 & 0.3 & & \\
\hline & & 5.0 & & & & & 5.0 & & & \\
\hline & & 3.5 & 2.7 & & & & 3.1 & 0.6 & & \\
\hline & & 3.3 & & & & & 3.3 & & & \\
\hline & & 3.0 & 3.5 & & & & 3.3 & 0.4 & & \\
\hline & & 5.1 & 4.7 & 3.8 & & & 4.5 & 0.7 & & \\
\hline & & 3.3 & 2.6 & 3.8 & 3.4 & 3.6 & 3.3 & 0.5 & & \\
\hline & & 5.0 & 4.4 & & & & 4.7 & 0.4 & & \\
\hline & & 4.3 & & & & & 4.3 & & & \\
\hline \multirow{6}{*}{ L5P3B4 } & \multirow{5}{*}{39} & 2.5 & 2.5 & 1.5 & & & 2.2 & 0.6 & \multirow{6}{*}{3.8} & \multirow{6}{*}{1.81} \\
\hline & & 4.1 & 5.0 & & & & 4.6 & 1.5 & & \\
\hline & & 3.8 & & & & & 3.8 & & & \\
\hline & & 4.5 & 3.6 & & & & 4.1 & 0.5 & & \\
\hline & & 4.0 & 4.4 & 4.0 & & & 4.1 & 0.7 & & \\
\hline & 40 & 6.9 & 4.4 & 4.9 & 1.0 & & 4.3 & 1.3 & & \\
\hline \multirow{4}{*}{ L5P3B1 } & \multirow{4}{*}{50} & 4.1 & 6.0 & 3.8 & 3.3 & 3.7 & 4.2 & 1.1 & \multirow{4}{*}{3.0} & \multirow{4}{*}{3} \\
\hline & & 2.6 & 2.0 & 3.0 & 3.0 & & 2.8 & 0.8 & & \\
\hline & & 3.1 & 2.0 & 4.3 & 2.2 & & & & & \\
\hline & & 1.8 & 1.9 & 3.0 & 1.3 & & 2.0 & 0.7 & & \\
\hline L2P499 & 42 & 4.5 & 3.7 & 4.7 & 3.0 & & 4.0 & 0.8 & 4.0 & 1.72 \\
\hline \multirow{5}{*}{ L2P482 } & \multirow{5}{*}{47} & 2.7 & 3.3 & 1.9 & 1.5 & & 2.3 & 0.8 & \multirow{5}{*}{2.9} & \multirow{5}{*}{3.11} \\
\hline & & 2.7 & 2.9 & 2.5 & & & 2.7 & 0.2 & & \\
\hline & & 3.8 & 2.8 & 2.5 & 2.2 & & 2.8 & 0.7 & & \\
\hline & & 3.4 & 3.3 & 3.1 & 1.7 & 3.7 & 3.0 & 0.8 & & \\
\hline & & 1.9 & 4.8 & 2.8 & 2.5 & 6.0 & 3.6 & 1.7 & & \\
\hline
\end{tabular}


Several of the plates examined destructively showed surface roughness irregularities that appear to have led to local variations in oxide thickness. These areas are typically small $(10-15 \mu \mathrm{m})$, but oxide values can vary locally by up to $100 \%$. These small local variations are not sufficient to affect the plate thermal performance, but could be a cause for increased sensitivity to measurement location for eddy-current testing. The data do not appear to show variation from measurement to measurement at a single location. An example of the observed sample roughness can be seen in Figure 22.

Figure 23 plots the standard deviation of each measurement set against the average value of the oxide thickness. The plot indicates that scatter in the data for Insertion 2 set is encompassed by the scatter seen in Insertion 1, with the exception of one plate, L1P784, which had an average value of $2.9 \mu \mathrm{m}$ with a deviation of 1.2.

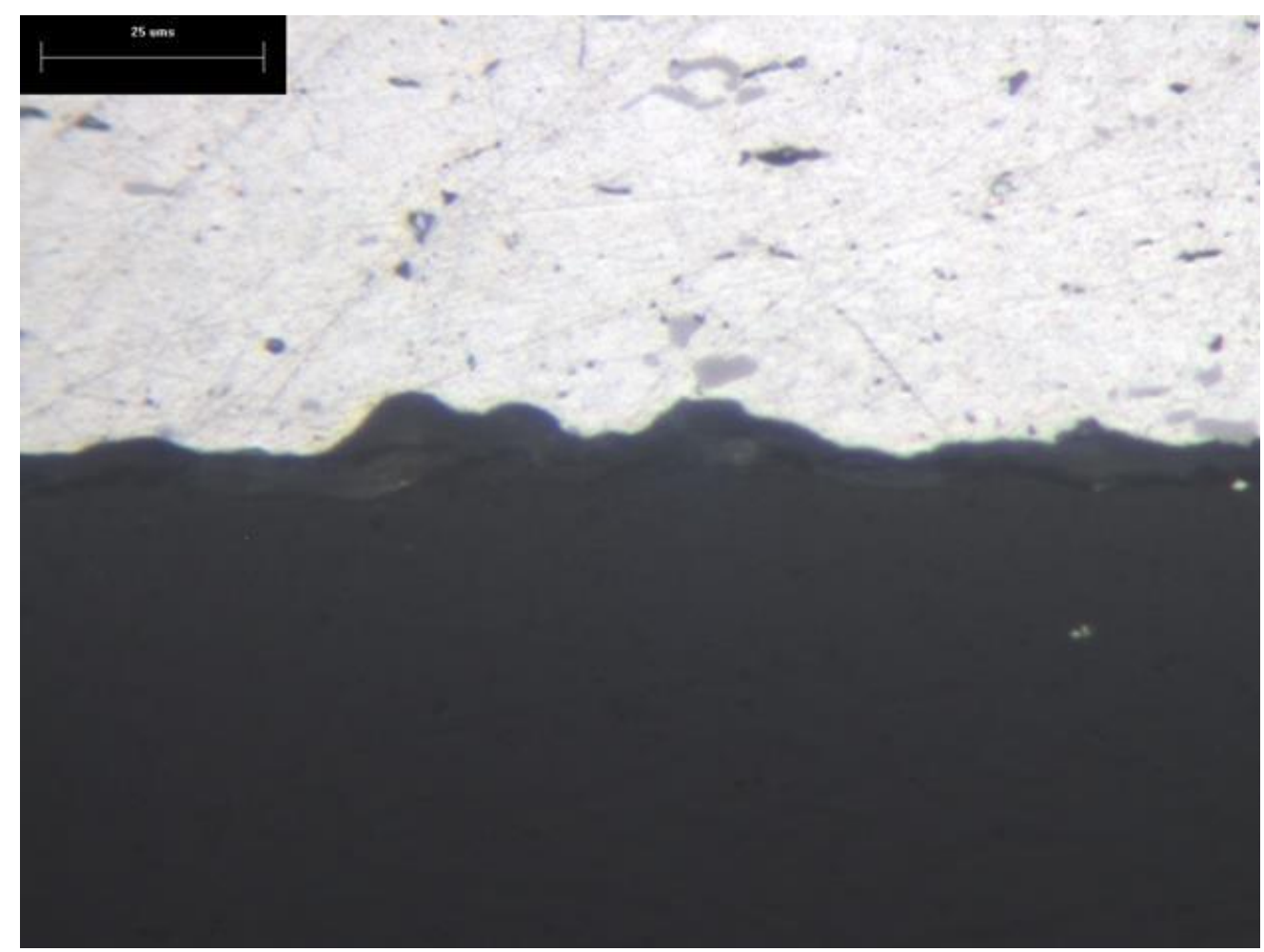

Figure 22. Image of L2P499 showing surface roughness. 


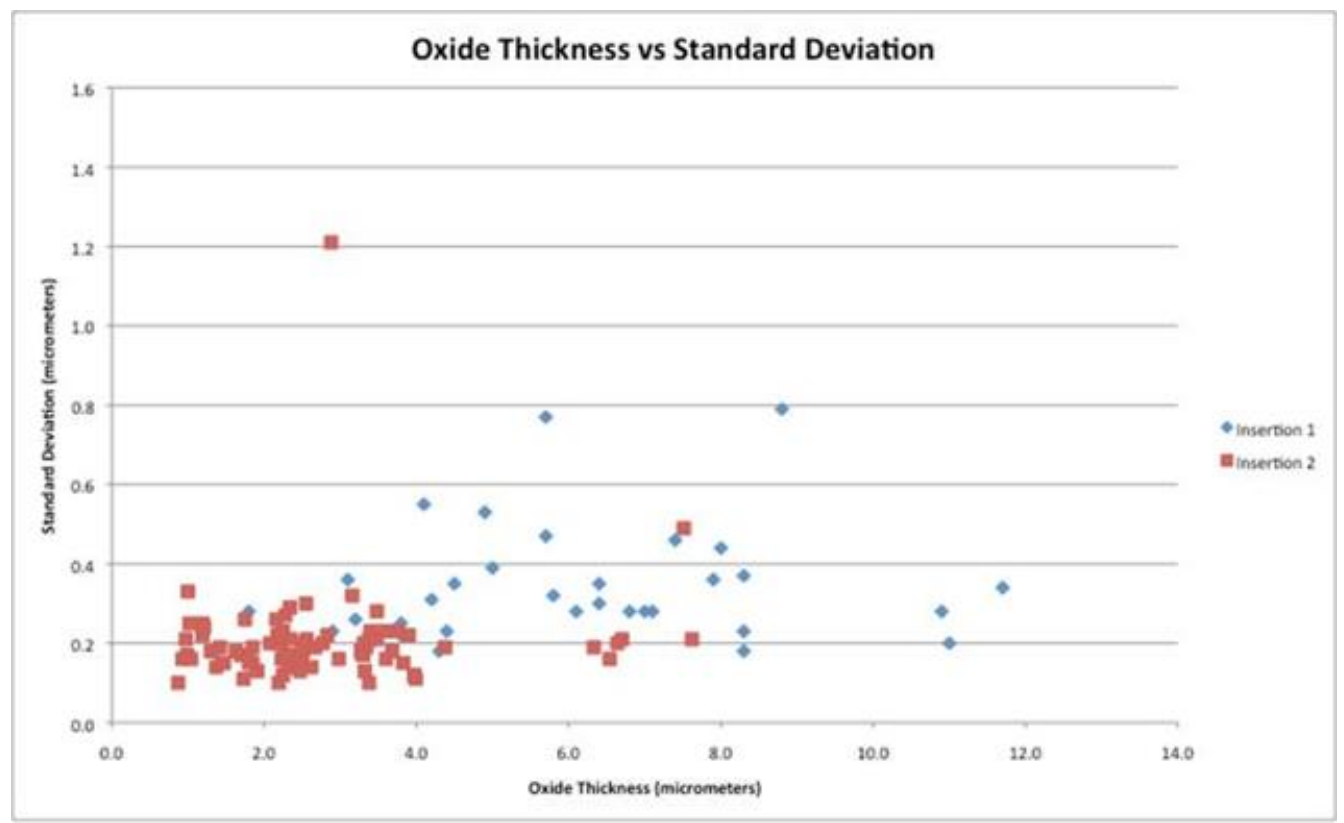

Figure 23. Standard deviation of measurements as a function of oxide thickness.

\subsubsection{Modeling}

Prior to irradiation, estimates of oxide thickness are made to estimate the maximum fuel temperature and to ensure that oxide spallation and breakaway oxide growth do not occur. Plate L5P3B2 was analyzed to be the limiting plate in this experiment, so this capsule was selected for comparison of actual and estimated oxide-thickness values. Table 9 compares the values based on the modified Griess correlation to measured oxide-thickness values at the end of cycle 151B. The methodology used to predict these values can be conservative by more than a factor of two, and often a factor of three or more.

Only two plates (L5P1A5 and L5P2C9) had observed oxide maximums more than half the oxide thickness predicted by the calculation. Plates L5P3B1 and L5P3B2 had significantly overpredicted oxide thicknesses ( 7.7 times and 11.7 times respectively). Figure 24 shows all the RERTR-12 Insertion 2 predicted oxide-thickness maximums as a function of surface heat flux against the actual maximums observed using eddy current testing. At heat fluxes below $\sim 175 \mathrm{~W} / \mathrm{cm}^{2}$, the predicted values are reasonably close to the observed maximums. Above this heat flux, however, large discrepancies are observed.

Table 9. Comparison between measured oxide and predicted oxide using the modified Griess correlation.

\begin{tabular}{|c|c|c|c|c|c|}
\hline \multirow{4}{*}{ Capsule } & Plate ID & $\begin{array}{c}\text { Front Oxide } \\
\text { Ave }\end{array}$ & $\begin{array}{c}\text { Back Oxide } \\
\text { Ave }\end{array}$ & $\begin{array}{c}\text { Maximum } \\
\text { Thickness }\end{array}$ & $\begin{array}{c}\text { Predicted } \\
\text { Maximum } \\
\text { Thickness }\end{array}$ \\
\hline \multirow{5}{*}{} & L5P1A5 & 2.6 & 2.3 & 5.4 & 8.6 \\
\cline { 2 - 6 } & L5P1B8 & 1.9 & 1.5 & 2.8 & 8.7 \\
\cline { 2 - 6 } & L5P2C8 & 2.4 & 2.3 & 4.0 & 9.9 \\
\cline { 2 - 6 } & L5P2C9 & 3.6 & 2.5 & 4.8 & 9.3 \\
\cline { 2 - 6 } & L5P3B1 & 3.4 & 2.7 & 4.9 & 37.7 \\
\cline { 2 - 6 } & L5P3B2 & 3.6 & 1.4 & 3.6 & 42.0 \\
\cline { 2 - 6 } & L5P3B3 & 2.3 & 2.3 & 3.8 & 15.7 \\
\cline { 2 - 6 } & L5P3C1 & 3.3 & 2.2 & 3.3 & 16.0 \\
\hline
\end{tabular}




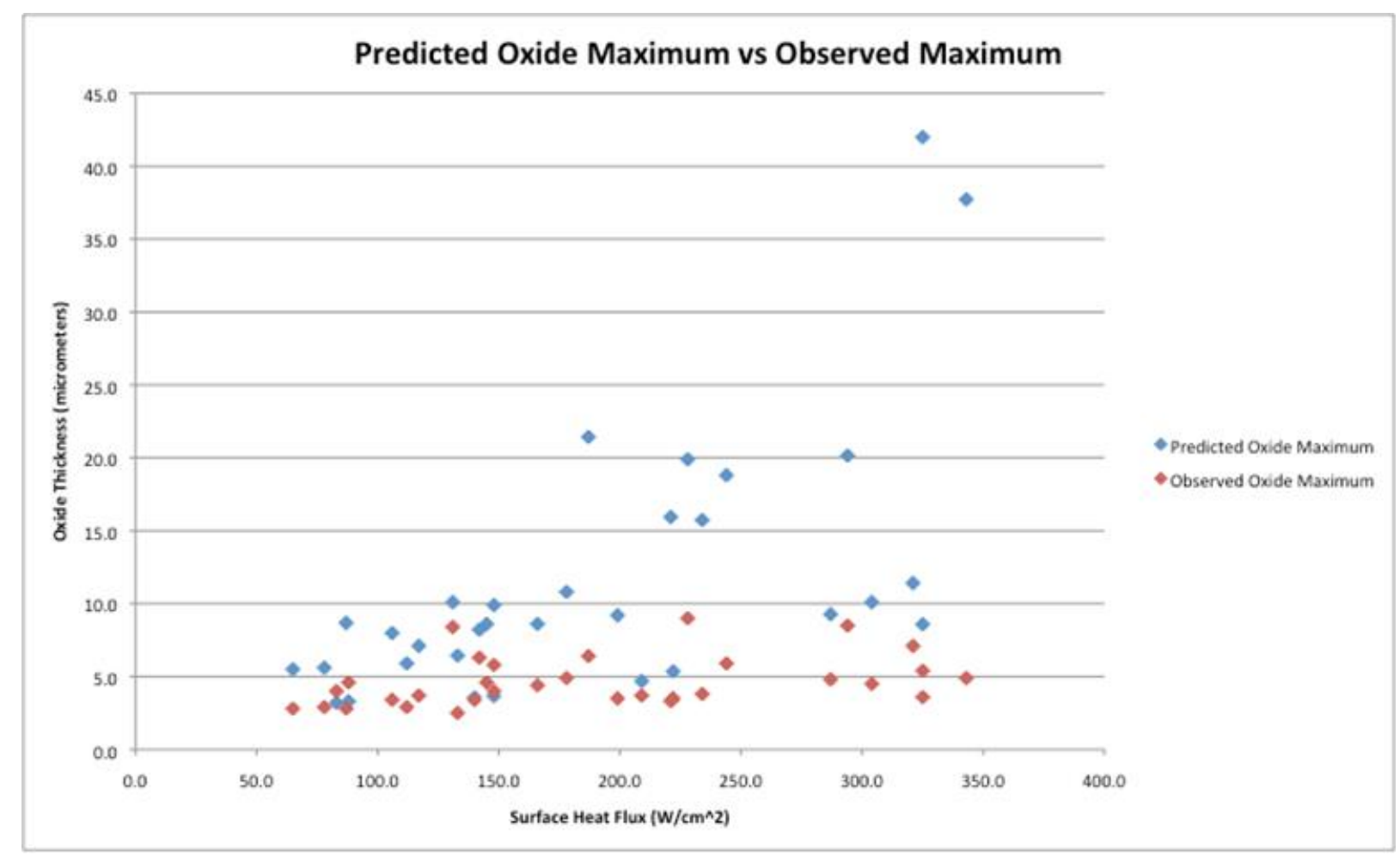

Figure 24. Predicted oxide-thickness maximums versus observed oxide-thickness maximums.

\subsubsection{Failed Plates}

L1P7A0, L1P754, L1P759, and L1P785 all exhibited unusual swelling behavior as measured by immersion density. Analysis of oxide growth rates indicate this is not sufficient to have led to breakaway oxide growth or to cause fuel blistering (or pillowing). Plate L1P7A0 had a maximum measured oxide thickness of 9.0 micrometers. Plate L1P754 had a maximum measured oxide of 15.8 micrometers. This was the highest value observed in the RERTR-12 experiment, but is significantly less than values seen previously in plates that did not fail. L1P759 had a maximum measured oxide thickness of 7.5 micrometers, and L1P785 had a maximum of 7.6 micrometers.

\subsubsection{Recommendations}

There are several recommendations for improving future examinations.

Future experiment campaigns should better coordinate pre-irradiation and post-irradiation oxidethickness measurement locations. While pre-irradiation oxide measurements are typically very thin and uniform, a better comparison can be made if measurements are made in the same location on the plate.

Pre-irradiation modeling of oxide growth should be modified to more accurately predict oxide thicknesses for fuel plates that are prefilmed using the newly implemented processing method. The modified Griess oxide correlation used greatly overpredicted oxide growth in reactor on several of the plates.

\subsection{Profilometry}

\subsubsection{Introduction}

Post-irradiation profilometry results presented herein were calculated using plate averages for preirradiation measurements and burnup. 
Plate thickness profile data for the RERTR-12 experiment was collected using the Remote Fuel Metrology System (RFMS). The plate and rodlet checker used a linear variable differential transducer (LVDT) to make location specific contact measurements. Most plates were examined with a $7 \times 27$ measurement grid over the fuel zone. Immersion-density measurements were compared to profilometry data to validate fuel swelling and density measurements.

\subsubsection{Profilometry Methods and Calculations}

The Remote Fuel Metrology System (RFMS) uses two opposing vertical Sony LVDT probes that range over the area of a plate and obtain thickness measurements at any location. This can be accomplished by either manually positioning the measurement probes to initiate a measurement or by selecting an automated measurement program to position the probes to collect the data in an incremented grid across the plate. The automated program uses a pre-described plate size with an incremented number of samples in both the $x$ and $y$ direction to build the measurement grid.

Two calibrated standards of thicknesses (0.040 in. and 0.060 in.) are mounted in a blank aluminum plate and stored with the plate checker. Before and after checking each plate, it is required to verify the system is still within calibration to within \pm 0.0004 in. on both standards. A zero check must also be performed and shall also be within \pm 0.0004 in.

Most plates were examined with a $7 \times 27$ measurement grid over the fuel zone. Due to the required use of an adaptor to hold mini-plates, some measurements near the edges of the plates are removed in data processing when it was determined that the probes contacted the rail of the holder. This contact generates invalid data as indicated by a $300 \%$ or greater step change in plate thickness. These data were not included in any of the following calculations or analysis.

Graphical displays of the plate thickness measurements included throughout this report are not corrected for pre-irradiation thickness variations or oxide buildup and are intended for qualitative analysis of swelling behavior. These plots portray swelling as only occurring in one direction, resulting in an increase in thickness. Due to the finite number of measurements and the inability to distinguish swelling on the front face from the rear face the graphs often appear with sharp peaks and valleys that are not representative of the physical condition of the plate surface. Likewise, thickness data (i.e., $z$ axis) are presented on a magnified scale on the $x$ and $y$ axes; this is done in order to qualitatively highlight swelling behavior.

Plate thickness measured using contact profilometry is converted into a swelling fraction relative to the as-fabricated fuel meat using Equation 2.

$S_{f}=\frac{\left(t_{p}-\frac{5}{12} t_{o x}\right)-t_{p 0}}{\left(t_{p 0}-2 t_{c}\right) V_{f}}$

In Equation 2, $t_{p}$ is the post irradiation plate thickness, $t_{o x}$ is the oxide thickness, $t_{p 0}$ is the preirradiation plate thickness, tc is the cladding thickness, and Vf is the volume fraction. The value tp is measured using the plate and rodlet checker and includes cladding, fuel meat (including the $\mathrm{Zr}$ barrier later), and oxide-layer thickness.

Swelling fraction is a percent increase in fuel-meat volume from the as-built fuel-meat dimensions. Like immersion density, this value does not take pillowing or delamination into account and, therefore, delaminated fuel plates appear to have undergone drastically higher fuel-meat swelling.

The effect of the oxide layer thickness on fuel swelling calculations is small. An oxide thickness corresponding to the average value of approximately 3.84 microns results in less than $1.5 \%$ difference in calculated fuel-meat swelling. 
The pre-irradiation plate thickness was obtained from the RERTR-12 As-Built Data Package as plate thickness including both cladding and fuel meat. The volume fraction, $\mathrm{V}_{\mathrm{f}}$, is 1 for monolithic fuels, since there is no matrix component. The remaining term, $\left(t_{p 0}-2 t_{c}\right)$, is effectively the as-built fuel-foil thickness. The foil thickness, including the zirconium barrier layer, was directly measured during fuel fabrication. Cladding thickness cannot be measured directly and must be calculated from the difference in the foil and plate thickness. Equation 2 thus simplifies to Equation 3, which assumes all swelling takes place in the fuel meat and not in the cladding.

$S_{f}=\frac{t_{\text {profilometry }}-t_{\text {plate }}}{t_{\text {foil } 0}} * 100$

\subsubsection{Evaluation of Plates}

Average measured fuel-meat thickness and swelling data, listed from lowest to highest average fission density, are presented in Table 10.

Table 10. RERTR-12 Insertion 2 profilometry results.

\begin{tabular}{|c|c|c|c|c|c|c|}
\hline Plate ID & $\begin{array}{c}\text { Fuel } \\
\text { Meat } \\
\text { Swelling } \\
\end{array}$ & Avg Fissions/cc & $\begin{array}{c}\text { Post } \\
\text { Irradiation } \\
\text { Avg Thickness } \\
\text { [in] } \\
\end{array}$ & $\begin{array}{l}\text { Cladding } \\
\text { Thickness }\end{array}$ & $\begin{array}{c}15 \text { pt Avg As- } \\
\text { Built Foil } \\
\text { Thickness [in] }\end{array}$ & $\begin{array}{l}15 \text { pt Avg As- } \\
\text { Built Plate } \\
\text { Thickness [in] }\end{array}$ \\
\hline L5P1B5 & $1.00 \%$ & $3.67 \mathrm{E}+20$ & 0.0575 & 0.015 & 0.028 & 0.05722 \\
\hline L5P1B0 & $0.52 \%$ & $3.86 \mathrm{E}+20$ & 0.0585 & 0.016 & 0.027 & 0.05836 \\
\hline L5P2A4 & $1.83 \%$ & $6.05 \mathrm{E}+20$ & 0.0585 & 0.016 & 0.027 & 0.05801 \\
\hline L5P2C7 & $1.52 \%$ & $6.32 \mathrm{E}+20$ & 0.0578 & 0.015 & 0.028 & 0.05737 \\
\hline L5P1B8 & $1.78 \%$ & $6.88 \mathrm{E}+20$ & 0.0584 & 0.015 & 0.027 & 0.05792 \\
\hline L5P1A5 & $3.52 \%$ & $7.13 \mathrm{E}+20$ & 0.0586 & 0.015 & 0.028 & 0.05761 \\
\hline L5P1B9 & $5.16 \%$ & $8.85 \mathrm{E}+20$ & 0.0590 & 0.015 & 0.027 & 0.05761 \\
\hline L5P3G2 & $2.64 \%$ & $8.99 \mathrm{E}+20$ & 0.0571 & 0.014 & 0.028 & 0.05636 \\
\hline L5P3G3 & $3.90 \%$ & $9.42 \mathrm{E}+20$ & 0.0572 & 0.015 & 0.027 & 0.05615 \\
\hline L5P1B7 & $6.15 \%$ & $1.02 \mathrm{E}+21$ & 0.0596 & 0.015 & 0.027 & 0.05794 \\
\hline L5P2C8 & $3.86 \%$ & $1.14 \mathrm{E}+21$ & 0.0580 & 0.014 & 0.028 & 0.05692 \\
\hline L5P2C9 & $6.36 \%$ & $1.17 \mathrm{E}+21$ & 0.0584 & 0.014 & 0.028 & 0.05662 \\
\hline L5P3F8 & $2.49 \%$ & $1.32 \mathrm{E}+21$ & 0.0574 & 0.015 & 0.027 & 0.05673 \\
\hline L5P3F0 & $5.05 \%$ & $1.37 \mathrm{E}+21$ & 0.0580 & 0.015 & 0.027 & 0.05664 \\
\hline $\mathrm{L} 5 \mathrm{P} 2 \mathrm{C} 0$ & $7.15 \%$ & $1.47 \mathrm{E}+21$ & 0.0596 & 0.014 & 0.029 & 0.05753 \\
\hline L5P3C1 & $8.36 \%$ & $1.66 \mathrm{E}+21$ & 0.0592 & 0.014 & 0.028 & 0.05686 \\
\hline L5P2A3 & $10.94 \%$ & $1.70 \mathrm{E}+21$ & 0.0592 & 0.015 & 0.027 & 0.05625 \\
\hline L5P3B3 & $11.88 \%$ & $1.73 \mathrm{E}+21$ & 0.0602 & 0.014 & 0.028 & 0.05687 \\
\hline L2P498 & $7.64 \%$ & $2.05 \mathrm{E}+21$ & 0.0578 & 0.017 & 0.022 & 0.05612 \\
\hline L5P3C6 & $12.74 \%$ & $2.17 \mathrm{E}+21$ & 0.0610 & 0.016 & 0.026 & 0.05769 \\
\hline L5P3B2 & $11.33 \%$ & $2.39 \mathrm{E}+21$ & 0.0610 & 0.015 & 0.028 & 0.05783 \\
\hline L2P481 & $11.12 \%$ & $2.46 \mathrm{E}+21$ & 0.0598 & 0.018 & 0.022 & 0.05735 \\
\hline L2P499 & $9.52 \%$ & $2.48 \mathrm{E}+21$ & 0.0583 & 0.017 & 0.022 & 0.05621 \\
\hline L5P3B1 & $13.74 \%$ & $2.49 \mathrm{E}+21$ & 0.0611 & 0.015 & 0.028 & 0.05725 \\
\hline L5P3B4 & $20.90 \%$ & $2.51 \mathrm{E}+21$ & 0.0625 & 0.014 & 0.028 & 0.05665 \\
\hline L2P482 & $14.33 \%$ & $2.98 \mathrm{E}+21$ & 0.0600 & 0.017 & 0.022 & 0.05685 \\
\hline L5P3C3 & $19.23 \%$ & $3.08 \mathrm{E}+21$ & 0.0620 & 0.015 & 0.027 & 0.05681 \\
\hline
\end{tabular}




\begin{tabular}{|l|l|l|l|l|l|l|}
\hline & $\begin{array}{c}\text { Fuel } \\
\text { Meat } \\
\text { Swelling }\end{array}$ & Avg Fissions/cc & $\begin{array}{c}\text { Post } \\
\text { Irradiation } \\
\text { Avg Thickness } \\
\text { [in] }\end{array}$ & $\begin{array}{c}\text { Cladding } \\
\text { Thickness }\end{array}$ & $\begin{array}{c}15 \text { pt Avg As- } \\
\text { Built Foil } \\
\text { Thickness [in] }\end{array}$ & $\begin{array}{c}15 \text { pt Avg As- } \\
\text { Built Plate } \\
\text { Thickness [in] }\end{array}$ \\
\hline L5P3C2 & $19.50 \%$ & $3.54 \mathrm{E}+21$ & 0.0633 & 0.015 & 0.028 & 0.05784 \\
\hline L1P789 & $17.50 \%$ & $3.73 \mathrm{E}+21$ & 0.0593 & 0.023 & 0.012 & 0.05720 \\
\hline L1P7A1 & $17.89 \%$ & $4.51 \mathrm{E}+21$ & 0.0597 & 0.023 & 0.012 & 0.05755 \\
\hline L1P787 & $26.79 \%$ & $6.43 \mathrm{E}+21$ & 0.0605 & 0.023 & 0.011 & 0.05755 \\
\hline L1P7A0 & $46.00 \%$ & $7.71 \mathrm{E}+21$ & 0.0607 & 0.022 & 0.012 & 0.05518 \\
\hline
\end{tabular}

Figure 25 plots the percentage of fuel-meat swelling measured by profilometry against the average fission density for RERTR-12 Insertion 2 plates, including failed plates L1P785, L1P759, and L1P754. Figure 26 plots RERTR-12 Insertion 2 plates excluding the three highest swelling plates. These results are plotted with the swelling correlation given in Equation $4 .^{5}$

$\left(\frac{\Delta V}{V_{0}}\right)_{f}=5.0 f_{d}$, for $f_{d} \leq 3 \times 10^{21}$ fissions $/ \mathrm{cm}^{3}$
$\left(\frac{\Delta V}{V_{0}}\right)_{f}=15+6.3\left(f_{d}-3\right)+0.33\left(f_{d}-3\right)^{2}$, for $3 \times 10^{21}<$ fissions $/ \mathrm{cm}^{3}$

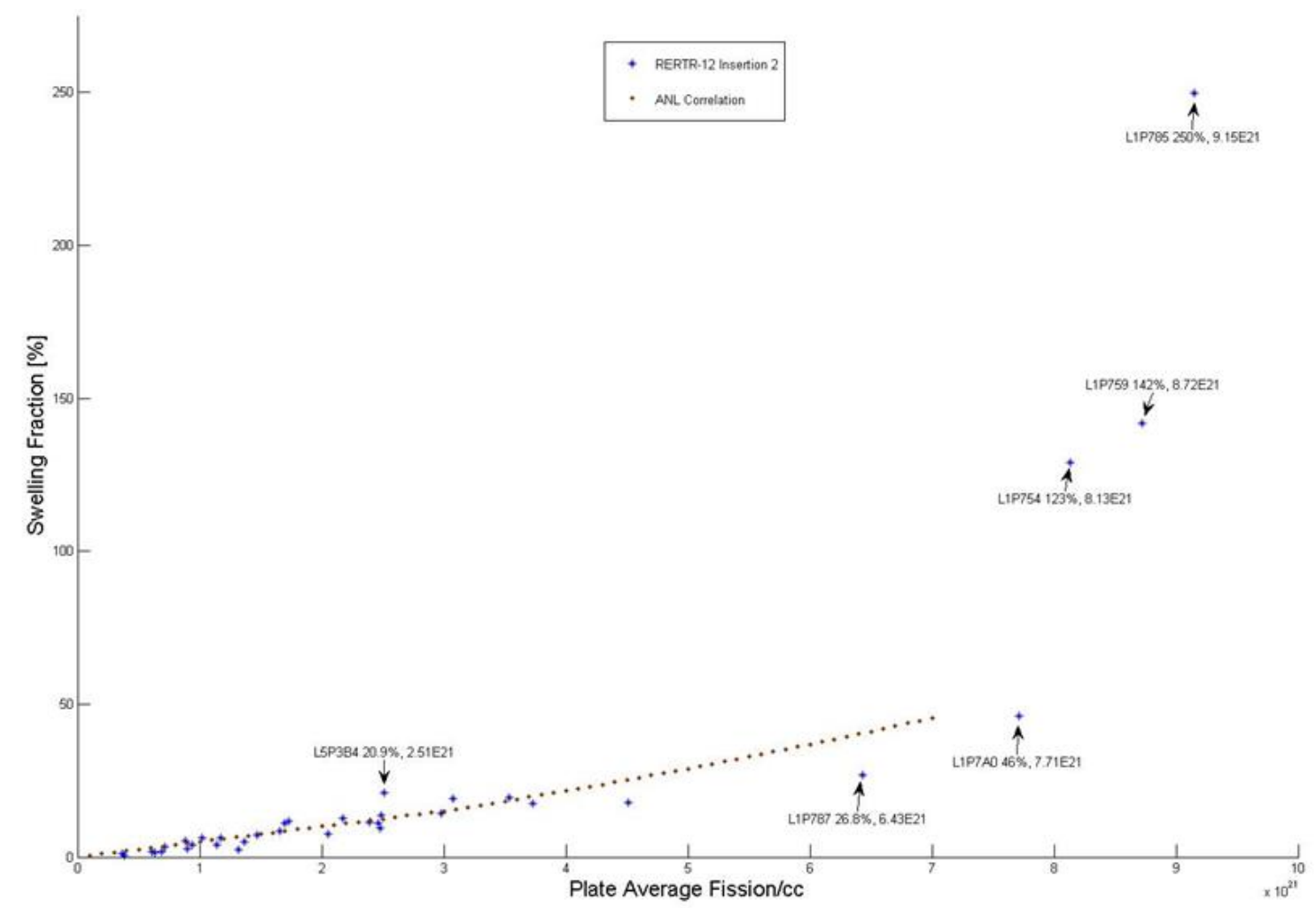

Figure 25. Profilometry-based swelling fraction vs average plate fission density for Insertion 2 and failed plates. 


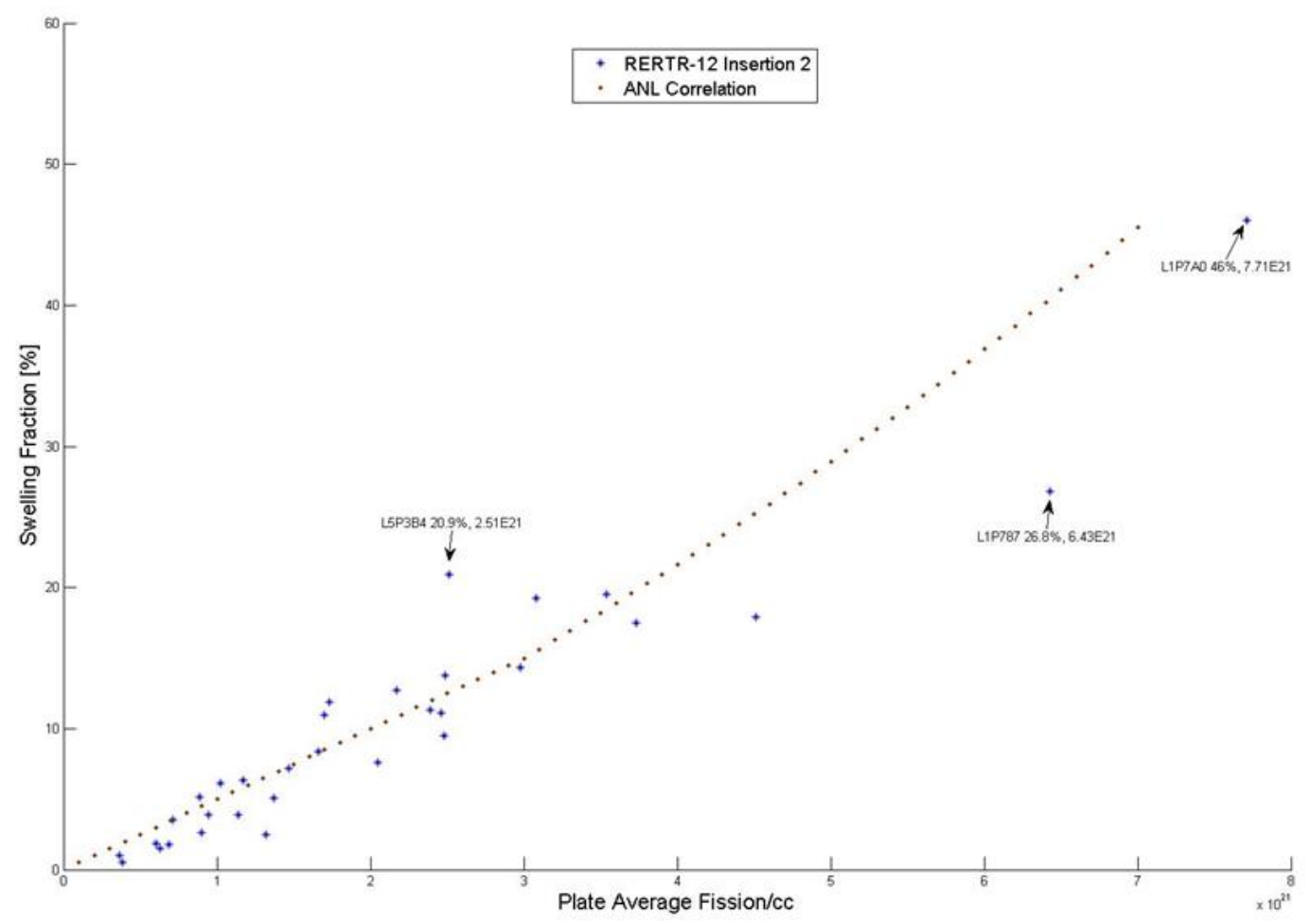

Figure 26. Profilometry-based swelling fraction \% vs average plate fission density for Insertion 2 only.

The swelling trends generally follow the accepted swelling correlation of Equation 4. There is a small amount of scatter at lower fission densities, more apparent in Figure 26. Scatter is likely caused by a combination of measurement uncertainties and the non-uniform nature of swelling in the fuel meat. During irradiation, the fuel creeps laterally, but is restrained by the cladding rail. The net result is a 'bulge' of U-Mo along the edge of the fuel meat. Averaging of the limited number of data points in these thin and thick areas results in some scatter because measurements are taken over the bulge on some plates and on the constrained edge on others. This is evident in the surface profiles of individual plates.

Consistent with immersion-density data, several plates experienced higher-than-expected fuel-meat swelling. From highest to lowest swelling, they are L1P785 $\left(250 \%, 9.15 \times 10^{21}\right)$, L1P759 $(142 \%$, $\left.8.72 \times 10^{21}\right)$, L1P754 $\left(123 \%, 8.13 \times 10^{21}\right)$, L1P7A0 $\left(46 \%, 7.71 \times 10^{21}\right)$, L5P3B4 $\left(20.9 \%, 2.51 \times 10^{21}\right)$. Plate L5P3B4 was slightly bent and would not lay flat in the sample holder during measurement and for this reason the profilometry measurements for this plate were considered invalid.

Fuel-meat swelling measured using profilometry is compared to that measured by immersion density in Figure 27. Both methods are generally consistent with the exception of plate L1P7A0. Fuel-meat swelling in plate L1P7A0, as measured by profilometry, was significantly lower than the corresponding immersion-density measurement, and is consistent with the swelling anticipated by Equation 4 . The cause of this behavior is being investigated.

\subsubsection{Conclusions}

The plates irradiated in the RERTR-12 insertion 2 experiment exhibited stable swelling behavior in accordance with the currently accepted U-Mo swelling correlation up to average fission densities of $7.6 \times 10^{21}$ fission $/ \mathrm{cm}^{3}$. Fuel-meat swelling in the majority of plates irradiated to fission densities less than $7.6 \times 10^{21}$ fission $/ \mathrm{cm}^{3}$ appears to be in line with the currently accepted U-Mo swelling correlation. 


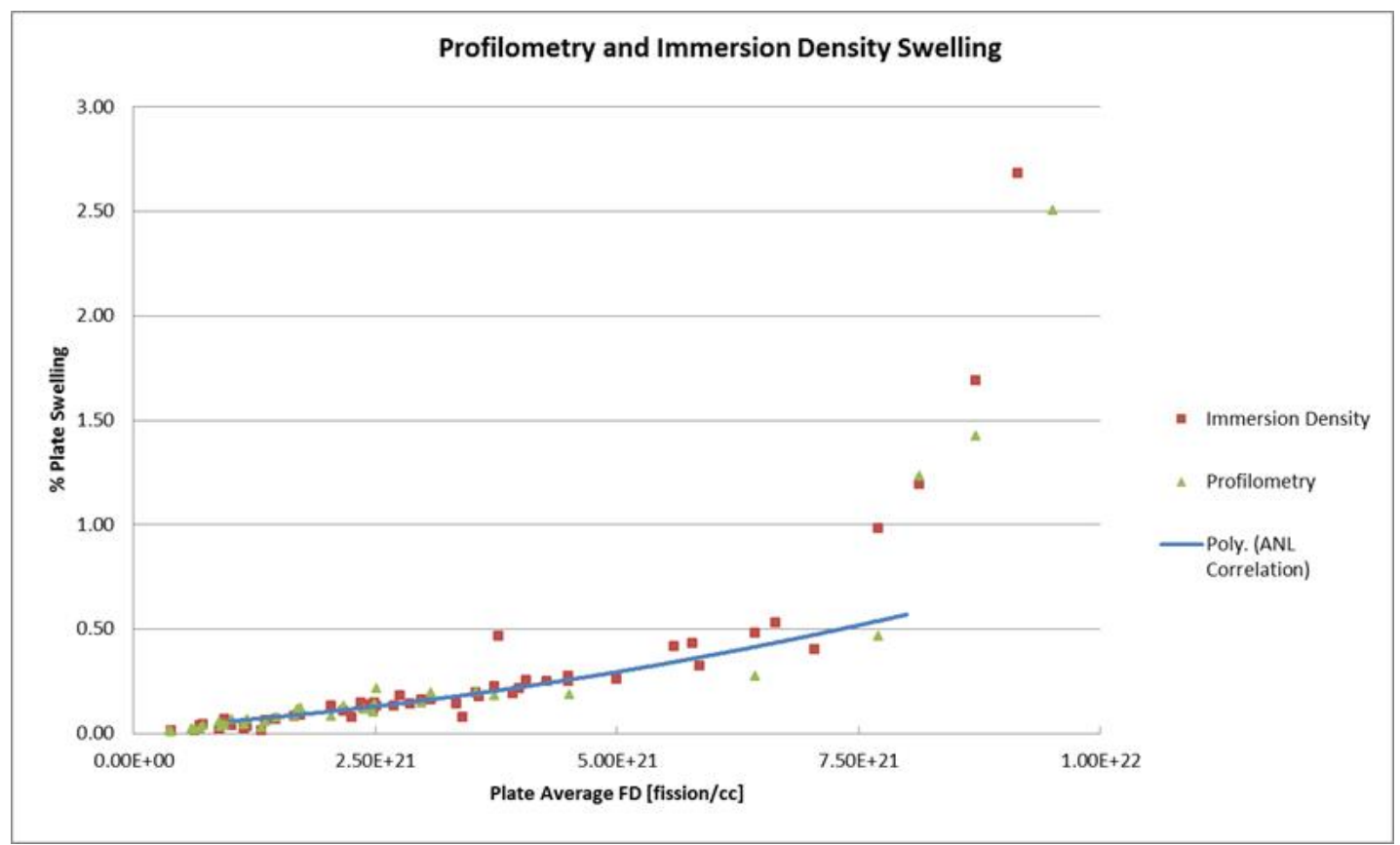

Figure 27. Profilometry and immersion-density results.

Pillowing in high burnup fuel plates L1P754, L1P759, and L1P785 and potential failure in fuel plate L1P7A0 resulted in immersion density and thickness measurements that indicate apparent high fuel-meat-swelling values. Because a considerable amount of the measured plate-volume and plate-thickness increase was the result of internal void volume, the fuel-meat swelling measured in these plates is considered invalid.

Point-by-point analysis of swelling as a function of fission density for specific locations on each plate would reduce the scatter in the fuel-meat-swelling data. This further examination will focus on identifying whether there are identifiable precursors to failure. The use of pre-irradiation x-ray radiographs to more precisely extract as-built foil thicknesses may also decrease data scatter.

\subsection{Gamma Scanning}

\subsubsection{Introduction}

Gamma scanning was performed using the HFEF precision gamma scanner (PGS). The PGS system consists of a collimator that penetrates the HFEF hot cell wall, a high-purity germanium (HPGe) gamma-spectrometry system, and a set of in-cell devices used to position samples for examination. The in-cell side of the collimator consists of tungsten alloy blocks that can be adjusted to create a slit height varying from $0.1-0.001 \mathrm{in}$. The width of the collimator opening is fixed at $0.875 \mathrm{in}$., creating a rectangular viewing area for the PGS system. Gamma rays entering the collimator travel through the hotcell wall, through a second tungsten-alloy beam scraper, and then to the HPGe detector. An assembly drawing of the PGS collimator is shown as Figure 28. 


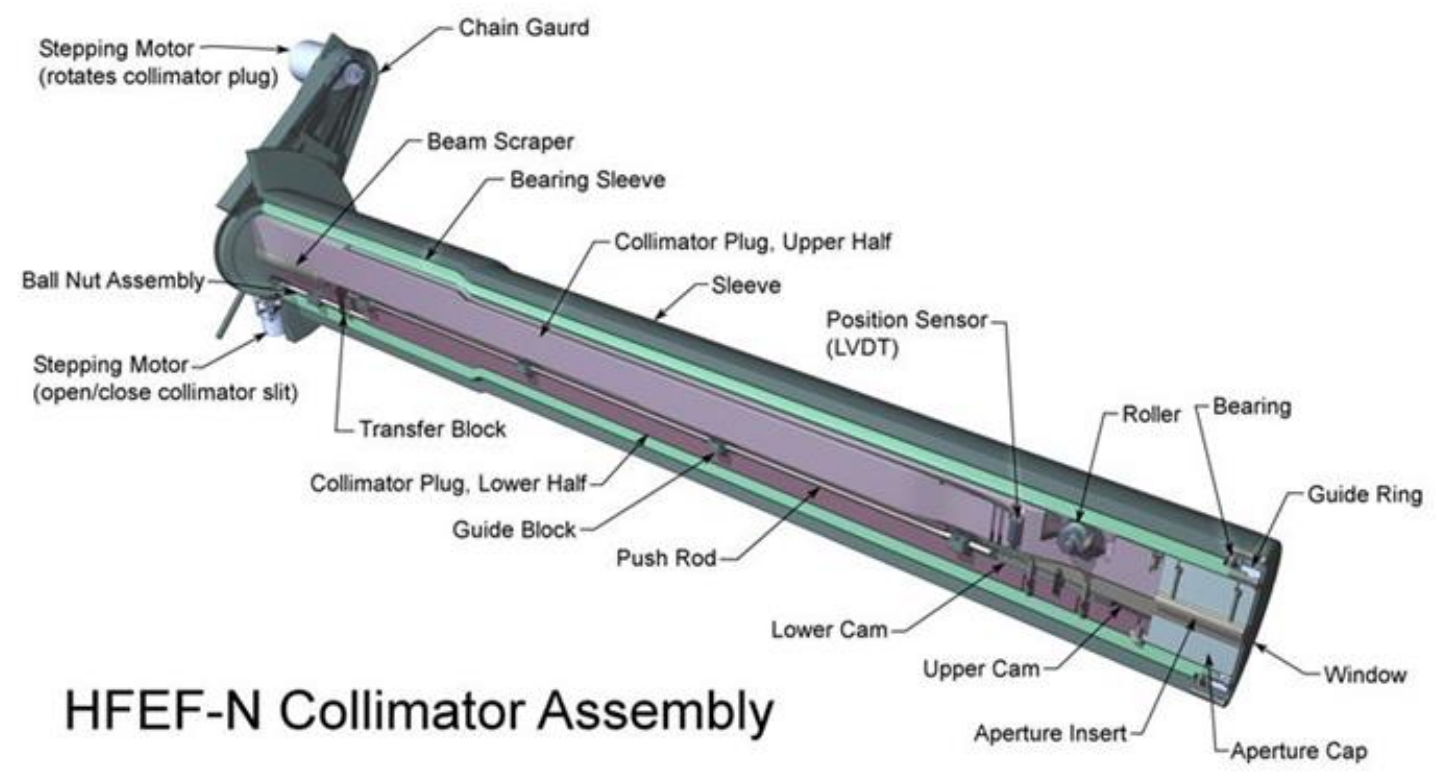

Figure 28. Assembly drawing of PGS collimator.

The PGS uses a custom control-software interface that controls both the collection of gamma-ray spectra and the movement of the sample in the hot cell. Spectroscopic control is achieved by communicating with an ORTEC 921 multi-channel buffer (MCB). Once the sample is positioned, the PGS collects a spectrum until the live time clock on the MCB reaches the desired limit. The contents of the buffer are then stored on the PGS-control computer as a uniquely named ORTEC .chn binaryspectrum file. Additionally, a corresponding .dat file that contains position and system status information related to the PGS during spectrum collection is also saved after each spectrum is collected. All .chn and .dat files collected in scans are archived in controlled records storage. The PGS-control software then moves the sample to the next desired position and begins counting again.

\subsubsection{RERTR-12 Fuel Behavior}

The RERTR-12 test irradiated miniature fuel plates of a single fuel design and three foil-to-cladding thickness ratios over a range of fission densities, including very high fission densities that envelope full ${ }^{235} \mathrm{U}$ burnup in LEU fuel. Figure 2 plots the swelling response of the fuel as a function of fission density. The fuel exhibited a predictable swelling response to average fission densities exceeding $7.6 \times 10^{21} \mathrm{f} / \mathrm{cm}^{3}$. At higher fission densities, the fuel exhibits a higher swelling rate. Four of the 56 plates that were irradiated exhibited higher-than-expected swelling, and of those four, three plates exhibited pillows, all at higher fission density, as shown in Figure 2.

\subsubsection{Description of Gamma Scans}

Plates from RERTR-12 were scanned in two directions across each plate. Vertical scans and transverse scans were performed in two different fixtures that suspended the plate in front of the PGS collimator. During the vertical scan, the plates were centered on the PGS collimator in the vertical fixture. The collimator width is $2.22 \mathrm{~cm}$, so gamma rays from the entire width of the fueled region are effectively integrated into the detector response. The plates were always oriented so that the plate identification number was pointing up in the fixture. In the PGS coordinate system this corresponds to a lower Z coordinate number. For the transverse (lateral) scans, the plates were scanned down the center of the plate. 
Vertical and transverse scans were collected with the collimator height set to both $0.127 \mathrm{~cm}$ and $0.254 \mathrm{~cm}$. The corresponding step size for each scan matched the slit width of the PGS collimator. The orientation data recorded for each scan are summarized in Table 11, below. Figure 29 shows a sketch of the plate orientations and how the plates were scanned for the transverse orientations and vertical orientations.

Table 11. Scanning parameters for the different plate sets.

\begin{tabular}{|c|c|c|c|c|c|}
\hline $\begin{array}{c}\text { RERTR 12 } \\
\text { Capsule }\end{array}$ & $\begin{array}{c}\text { Transverse } \\
\text { Step Size/ } \\
\text { Collimator Size }\end{array}$ & $\begin{array}{c}\text { Transverse } \\
\text { Orientation }\end{array}$ & $\begin{array}{c}\text { Transverse } \\
\text { Scan Live } \\
\text { Time }\end{array}$ & $\begin{array}{c}\text { Vertical Step } \\
\text { Size/ } \\
\text { Collimator Size }\end{array}$ & $\begin{array}{c}\text { Vertical } \\
\text { Scan Live } \\
\text { Time }\end{array}$ \\
\hline $\mathrm{Z}$ & $0.127 \mathrm{~cm}$ & Unknown & $300 \mathrm{~s}$ & $0.254 \mathrm{~cm}$ & $300 \mathrm{~s}$ \\
\hline $\mathrm{X} 3$ & $0.127 \mathrm{~cm}$ & Unknown & $300 \mathrm{~s}$ & $0.127 \mathrm{~cm}$ & $300 \mathrm{~s}$ \\
\hline $\mathrm{X} 1$ & $0.254 \mathrm{~cm}$ & ID Left & $300 \mathrm{~s}$ & $0.254 \mathrm{~cm}$ & $300 \mathrm{~s}$ \\
\hline $\mathrm{X} 2$ & $0.254 \mathrm{~cm}$ & ID Left & $300 \mathrm{~s}$ & $0.254 \mathrm{~cm}$ & $300 \mathrm{~s}$ \\
\hline $\mathrm{Y} 3$ & $0.254 \mathrm{~cm}$ & N/A & $300 \mathrm{~s}$ & $0.127 \mathrm{~cm}$ & $300 \mathrm{~s}$ \\
\hline $\mathrm{Y} 2$ & $0.254 \mathrm{~cm}$ & ID Left & $600 \mathrm{~s}$ & $0.254 \mathrm{~cm}$ & $600 \mathrm{~s}$ \\
\hline Y1 & $0.127 \mathrm{~cm}$ & ID Right & $300 \mathrm{~s}$ & $0.127 \mathrm{~cm}$ & $300 \mathrm{~s}$ \\
\hline
\end{tabular}
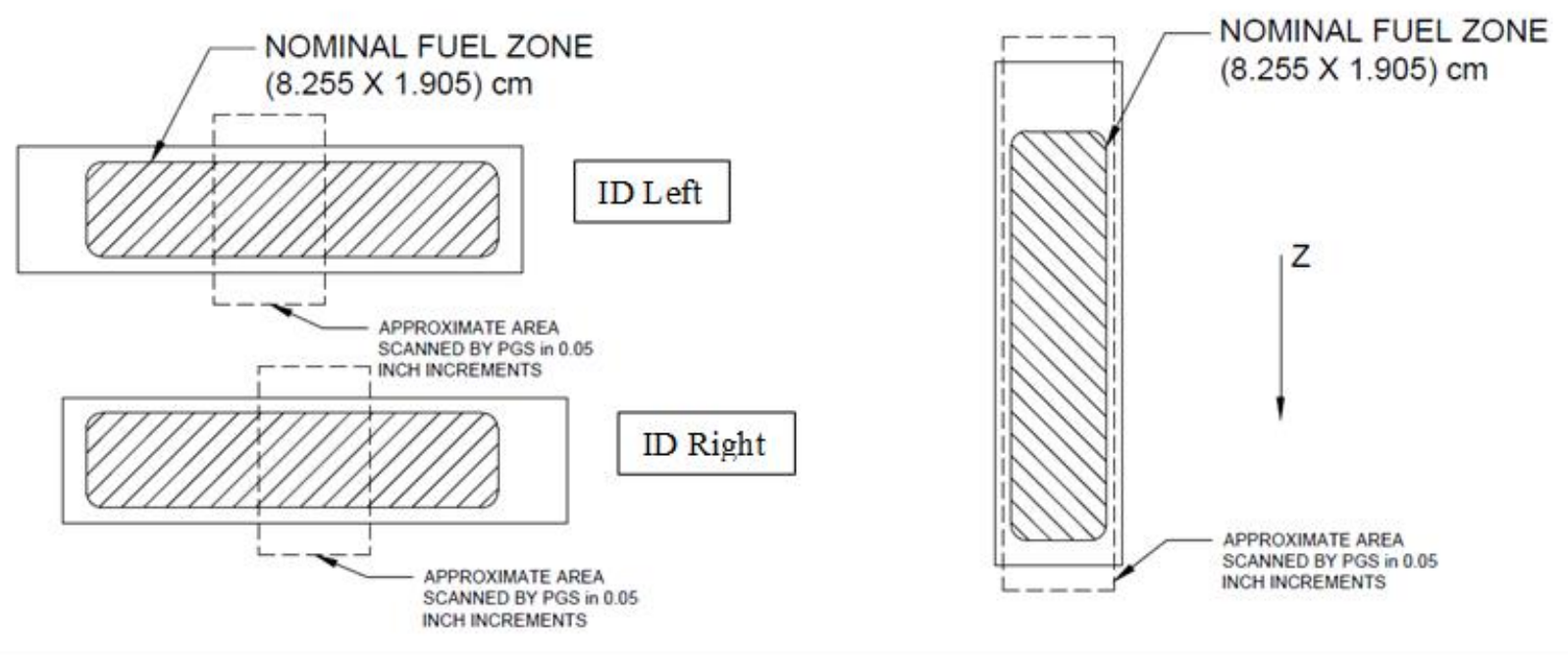

Figure 29. Approximate areas scanned by PGS for RERTR-12 plates at different orientations.

\subsubsection{Energy Calibration}

Before each set of plate scans, spectra from several out-of-cell sources were collected to provide energy calibration information for the plate scans. The sources were ${ }^{133} \mathrm{Ba},{ }^{60} \mathrm{Co}$, and ${ }^{137} \mathrm{Cs}$. No efficiency calibration for RERTR plates was performed to calibrate the efficiency of the collected gamma spectra. Energy-calibration scans were not taken for capsules X1 and X2. The energy spectra for the plates in these capsules were calibrated to the gamma-ray peaks and energies of known common fission-products. 


\subsubsection{Spectral Analysis}

A generic, distributed source efficiency was used to analyze the plates. Therefore, relative intensity, not quantitative activity, is reported here. The use of the generic efficiency curve allowed the use of a gamma-spectrum-analysis program that performed a full spectrum peak search, identified peaks, and found a relative intensity for the various fission products based on all the characteristic gammas that were present, not just the primary gammas for each fission product. The gamma spectrum analysis program used for this work is the INL developed PC-GAP software package. A conversion program in PC-GAP converts and analyzes all the collected spectra. The output of this program is a text file that contains the identified peaks, peak areas, identified isotopes, and calculated relative intensities of those isotopes with their corresponding uncertainties, and minimum detectable quantities for a specified set of key gammaray energies. A typical spectrum from RERTR-12 (L5P3B3) is shown in Figure 30. The spectra were analyzed for the following isotopes: ${ }^{95} \mathrm{Zr},{ }^{103} \mathrm{Ru},{ }^{106} \mathrm{Ru} / \mathrm{Rh},{ }^{110 m} \mathrm{Ag},{ }^{125} \mathrm{Sb},{ }^{134} \mathrm{Cs},{ }^{137} \mathrm{Cs},{ }^{144} \mathrm{Ce},{ }^{154} \mathrm{Eu},{ }^{60} \mathrm{Co}$, ${ }^{95} \mathrm{Nb},{ }^{54} \mathrm{Mn}$, and ${ }^{144} \mathrm{Ce} / \mathrm{Pr}$. After analysis, the output file from PC-GAP was processed by a python script to extract information about specific isotopes and organize the data from all the spectra for interpretation. Decay correction was not performed during spectral analysis.

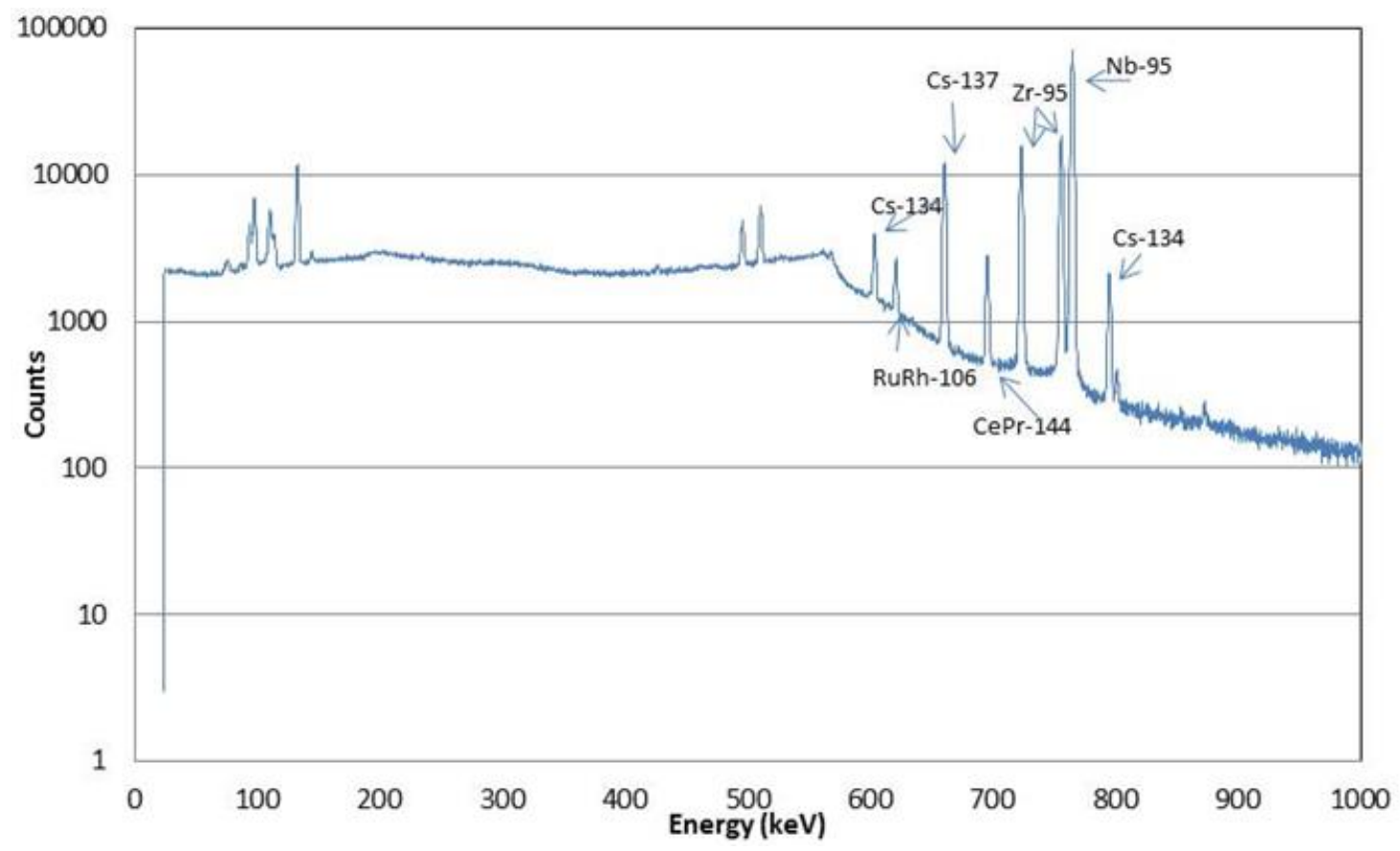

Figure 30. Typical RERTR-12 PGS Spectrum with key peaks labeled by their radionuclide. Plate L5P3B3, capsule 12E, 300 seconds live time.

The majority of plates from RERTR-12 do not show any remarkable behavior in their gamma scans. All fission products tend to follow the same trend across the plates for both transverse and vertical scans. The trend is generally U-shaped across a plate. This is caused by a local increase in the fission density at the edge of the plates that results from increased neutron reflection in the capsule material. Some plates show swings in the $\mathrm{U}$ shape, indicating higher fission density at the top or bottom of the plate. This is due to flux peaking at the ends and edges of the plates caused by a local increase in the moderator-to-fuel ratio and ATR axial flux profile, which has a chopped cosine shape. The peaking effect from local increase in moderator-to-fuel ratio is most obvious in capsule Y1 plates, and the impact from the shape of the ATR 
axial-flux profile is most evident in the capsule $\mathrm{Y} 2$ data. The relative intensity of ${ }^{137} \mathrm{Cs}$ is plotted in

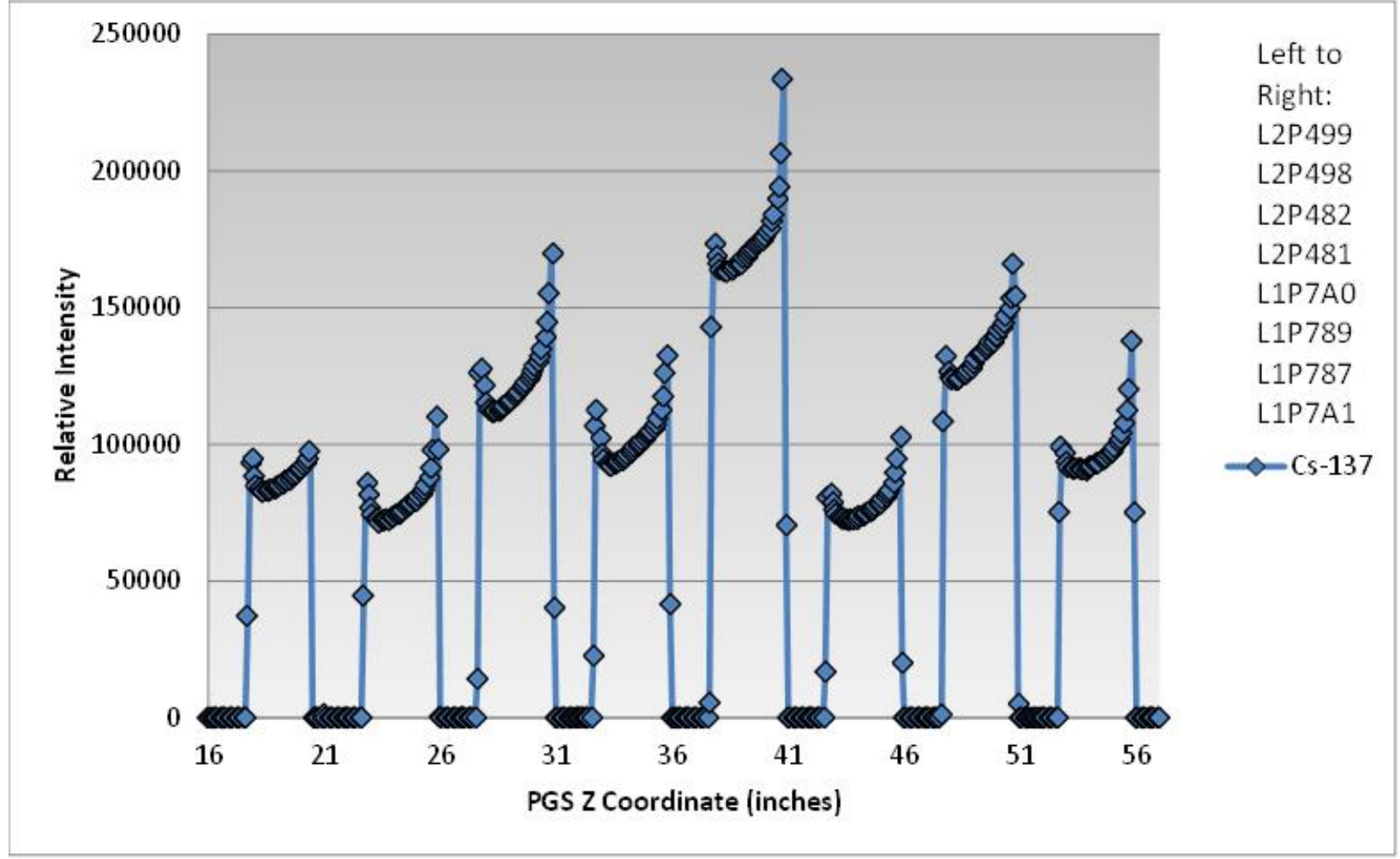

Figure 31 through Figure 37 for plate vertical scans and in Figure 38 through Figure 43 for the transverse scans. The positions plotted on the $\mathrm{x}$-axis are the relative plate positions in the PGS positioning device. 


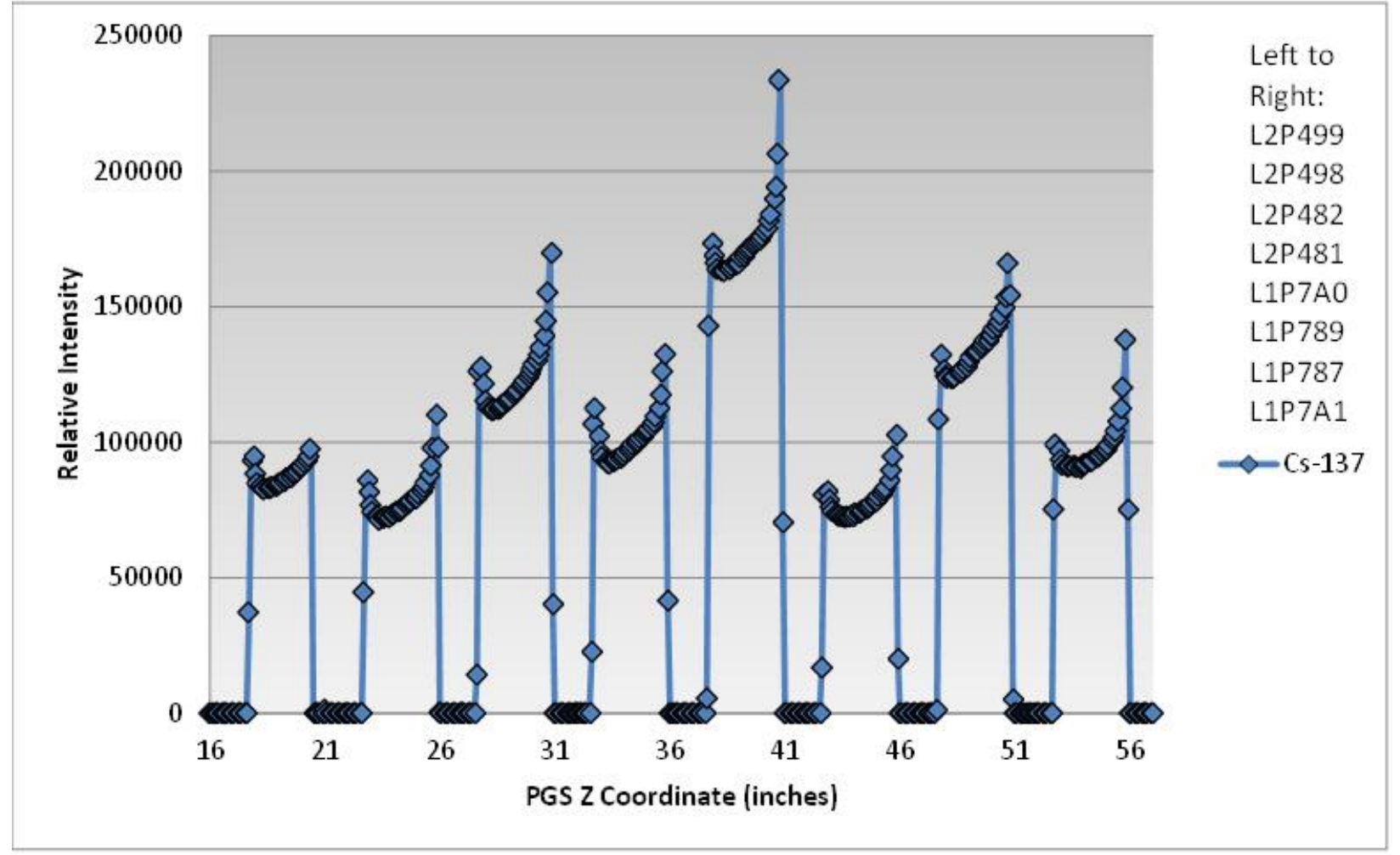

Figure 31. Vertical scan of plates from RERTR-12 Capsule A.

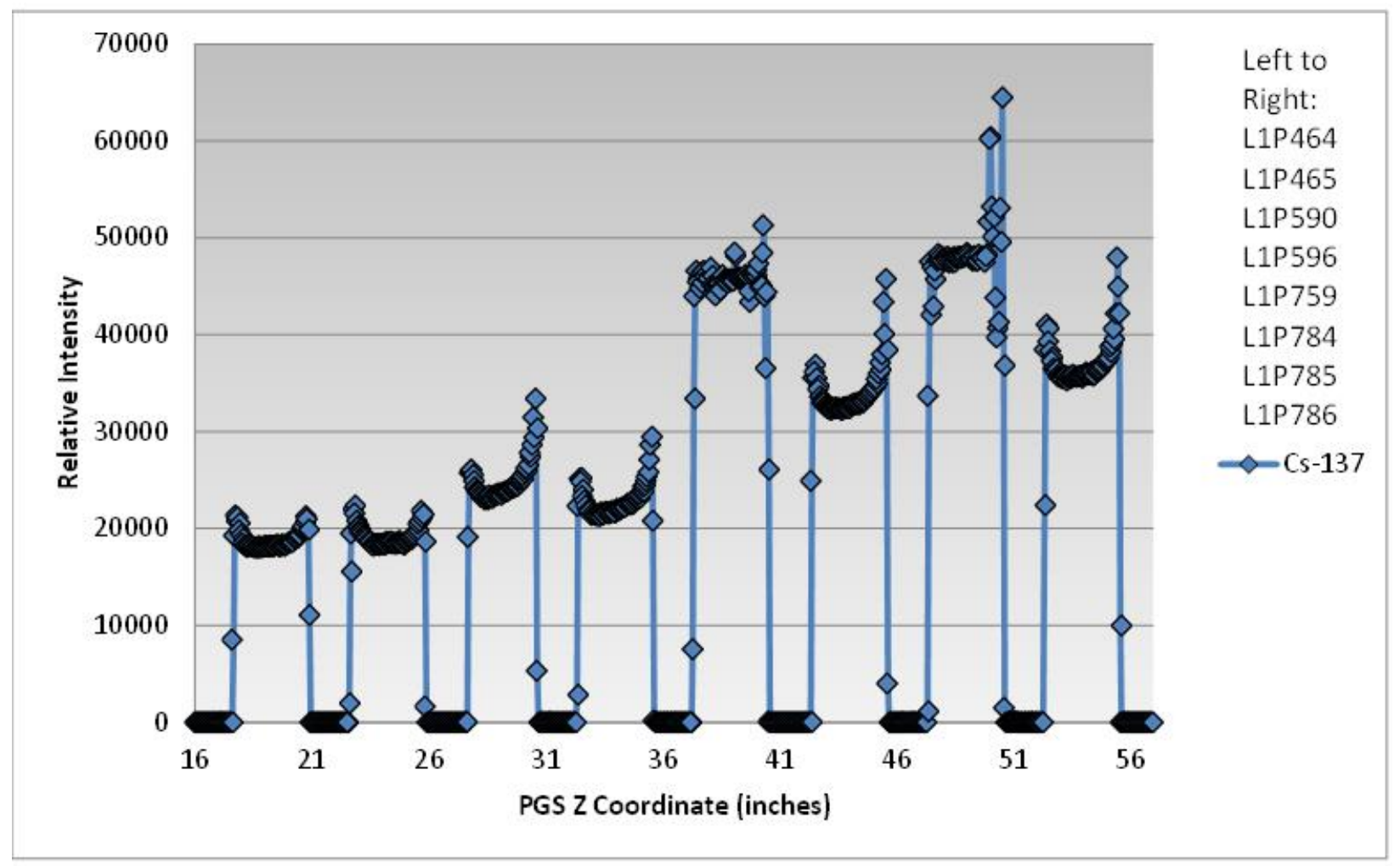

Figure 32. Vertical scan of plates from RERTR-12 Capsule B. 


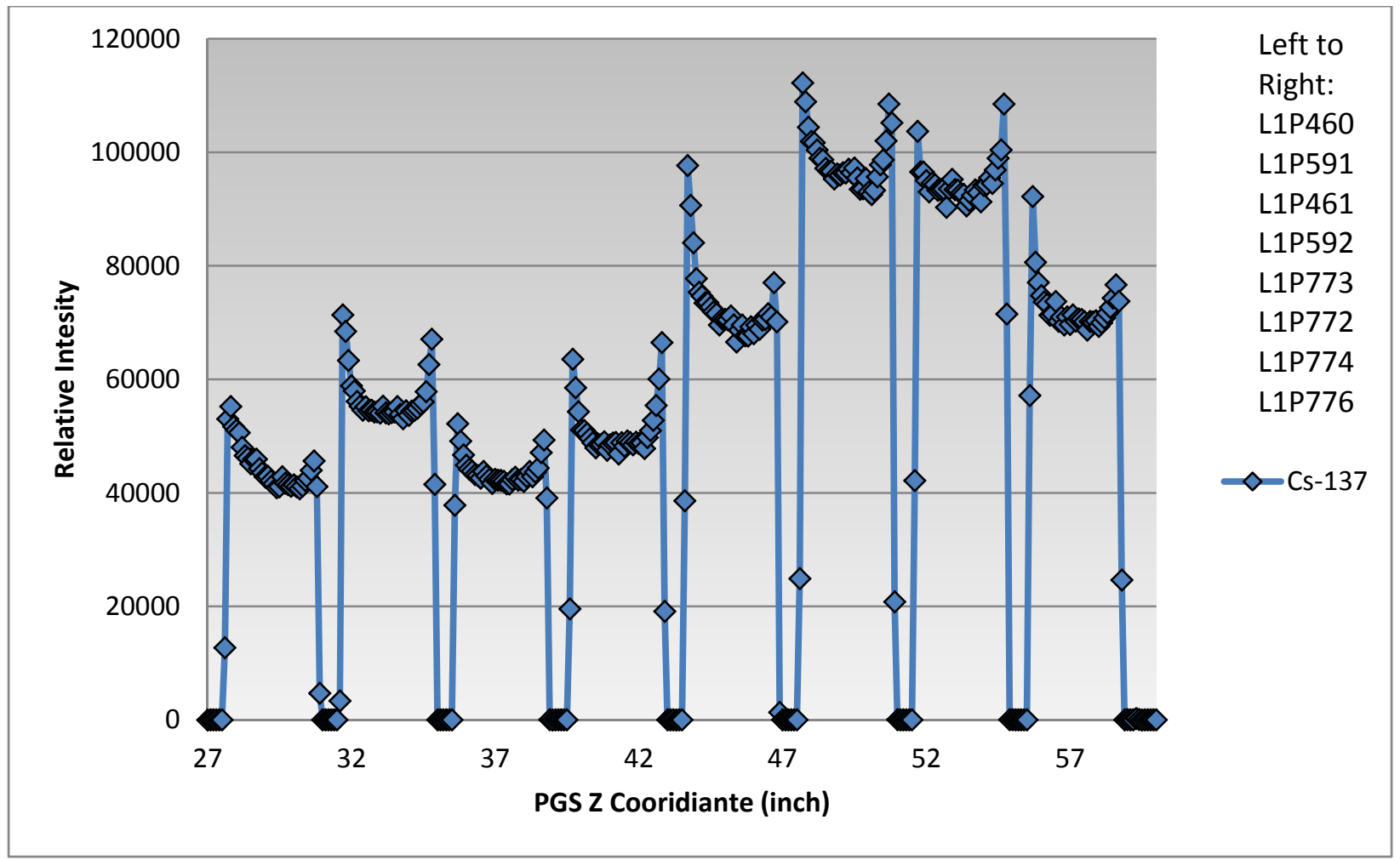

Figure 33. Vertical scan of plates from RERTR-12 Capsule C.

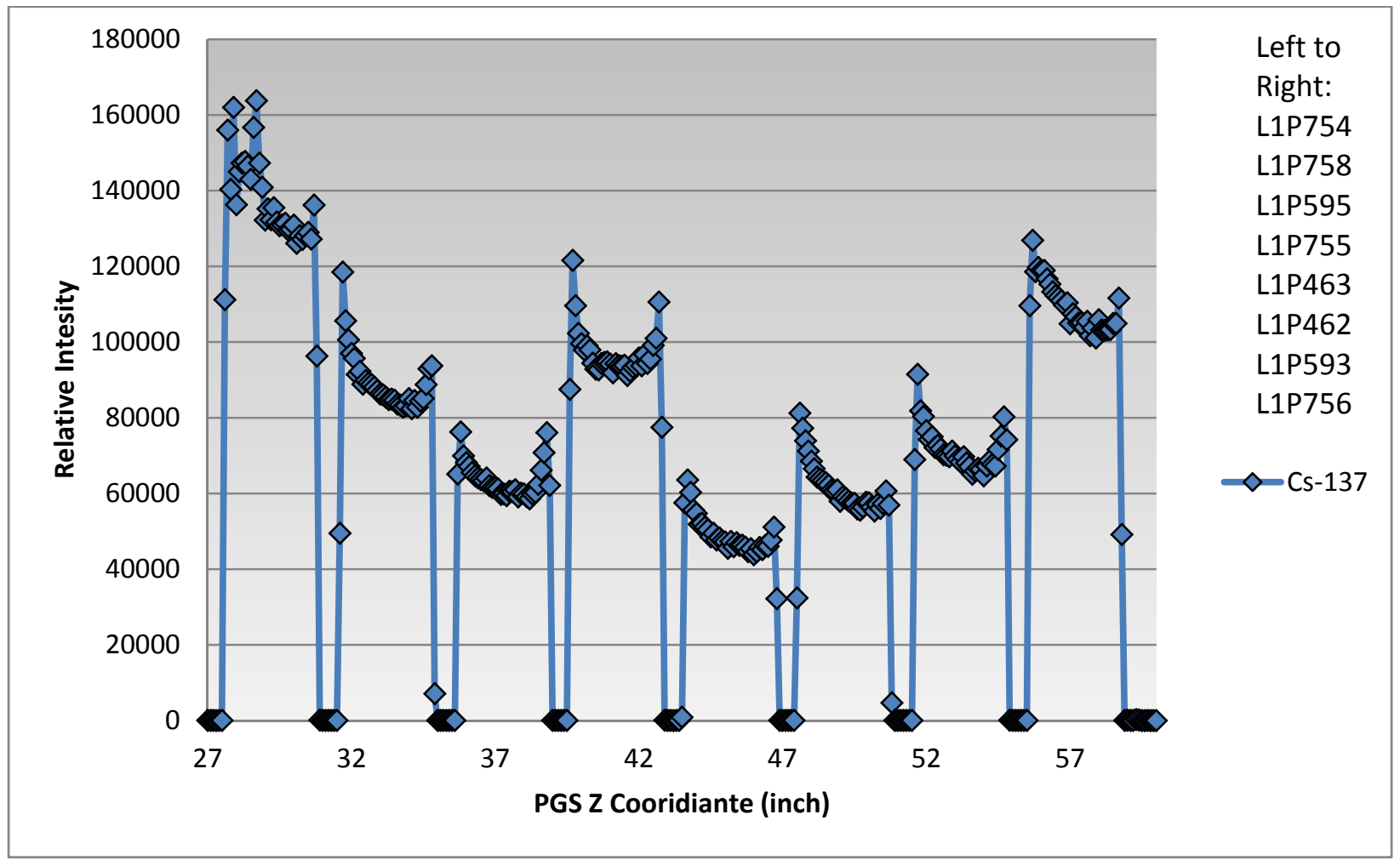

Figure 34. Vertical scan of plates from RERTR-12 Capsule D. 


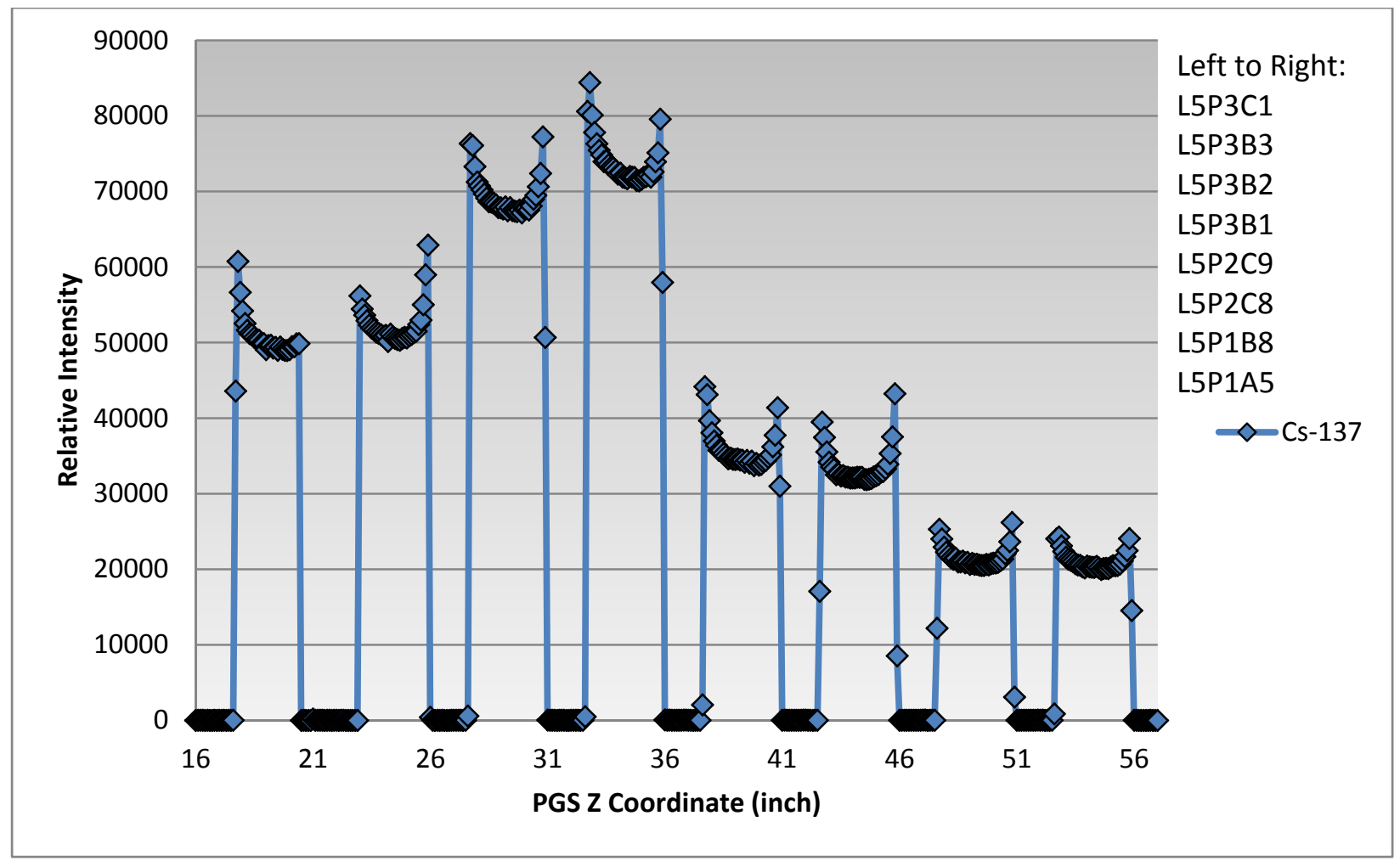

Figure 35. Vertical scan of plates from RERTR-12 Capsule E.

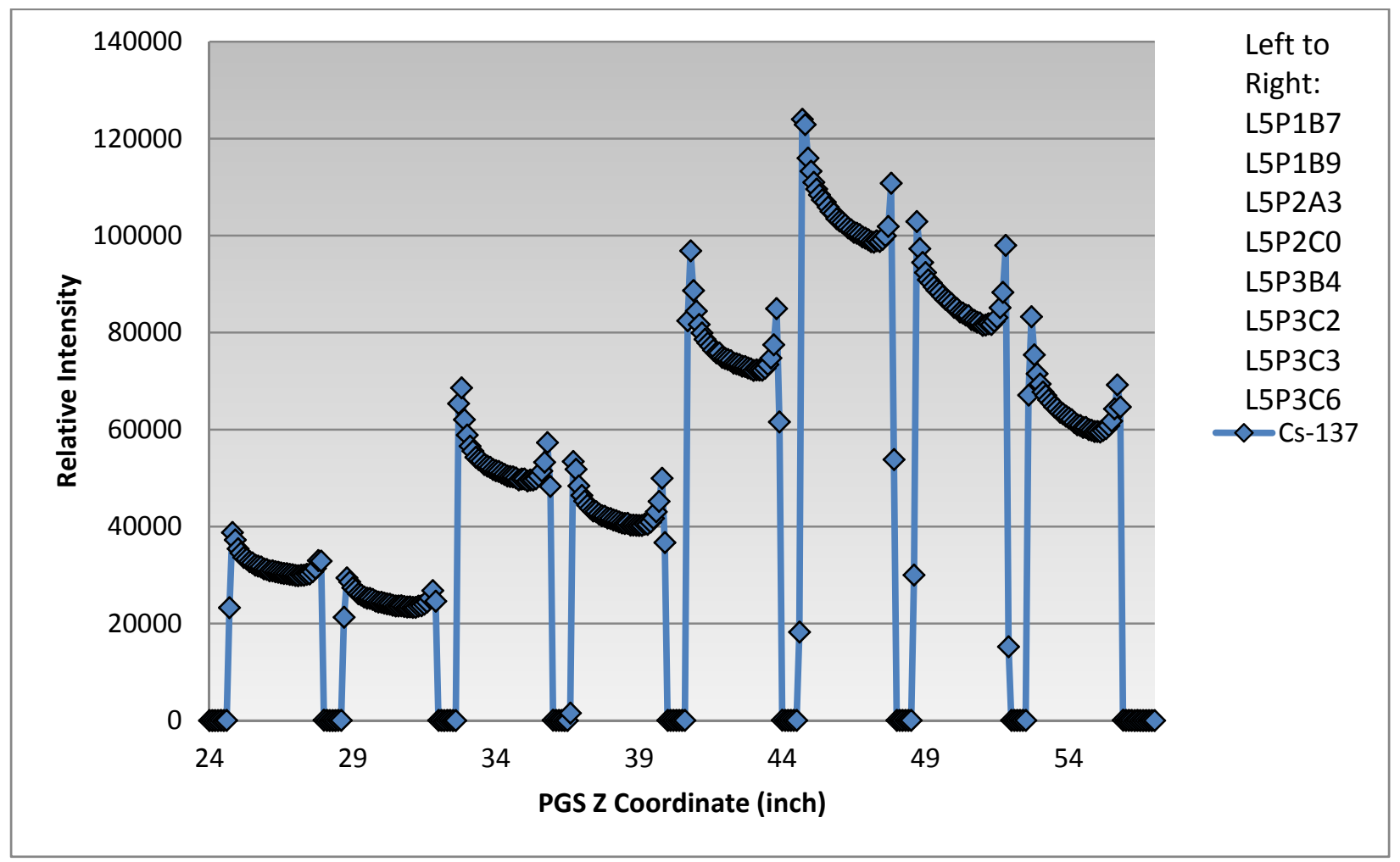

Figure 36. Vertical scan of plates from RERTR-12 Capsule F. 


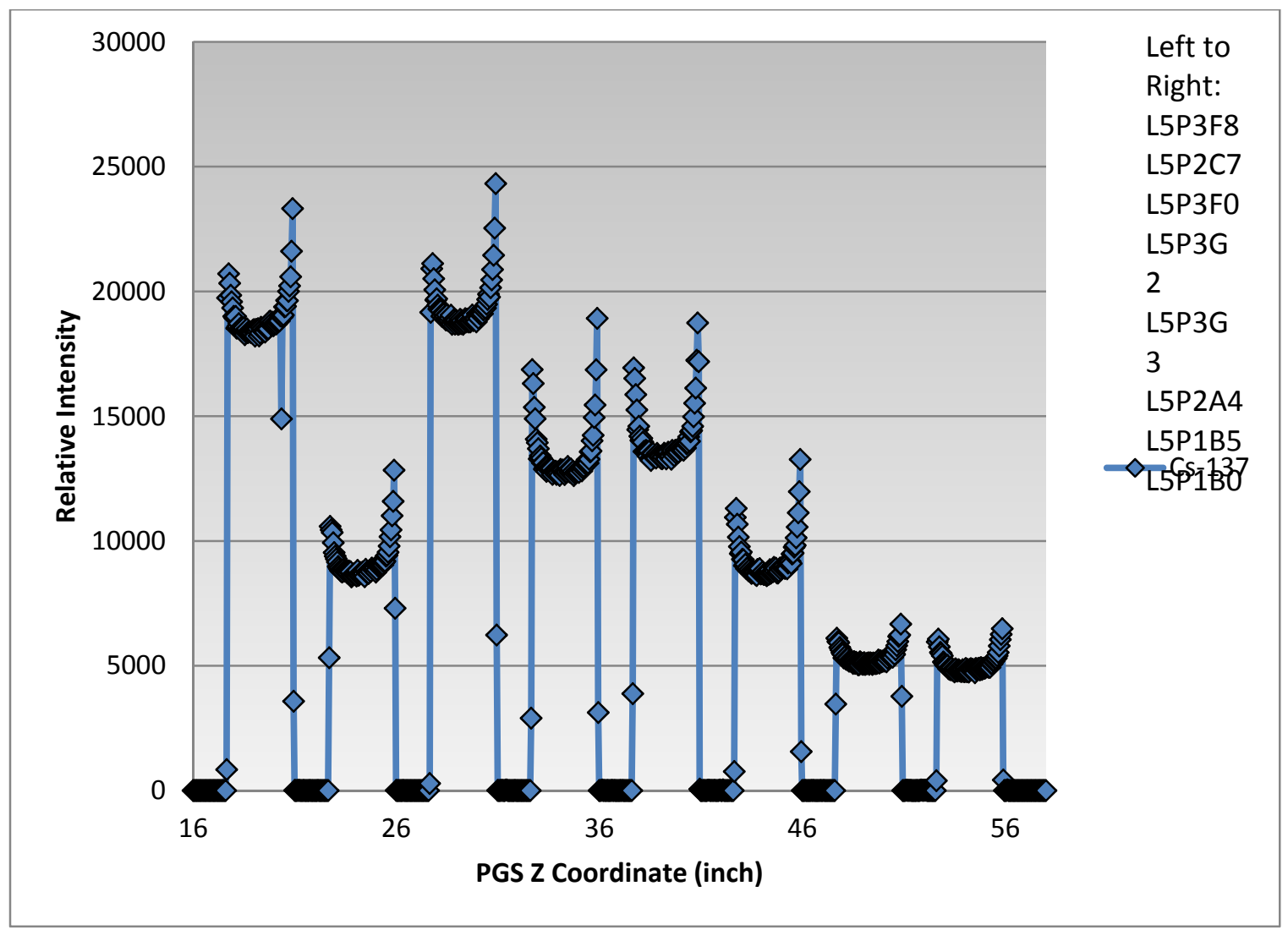

Figure 37. Vertical scan of plates from RERTR-12 Capsule G.

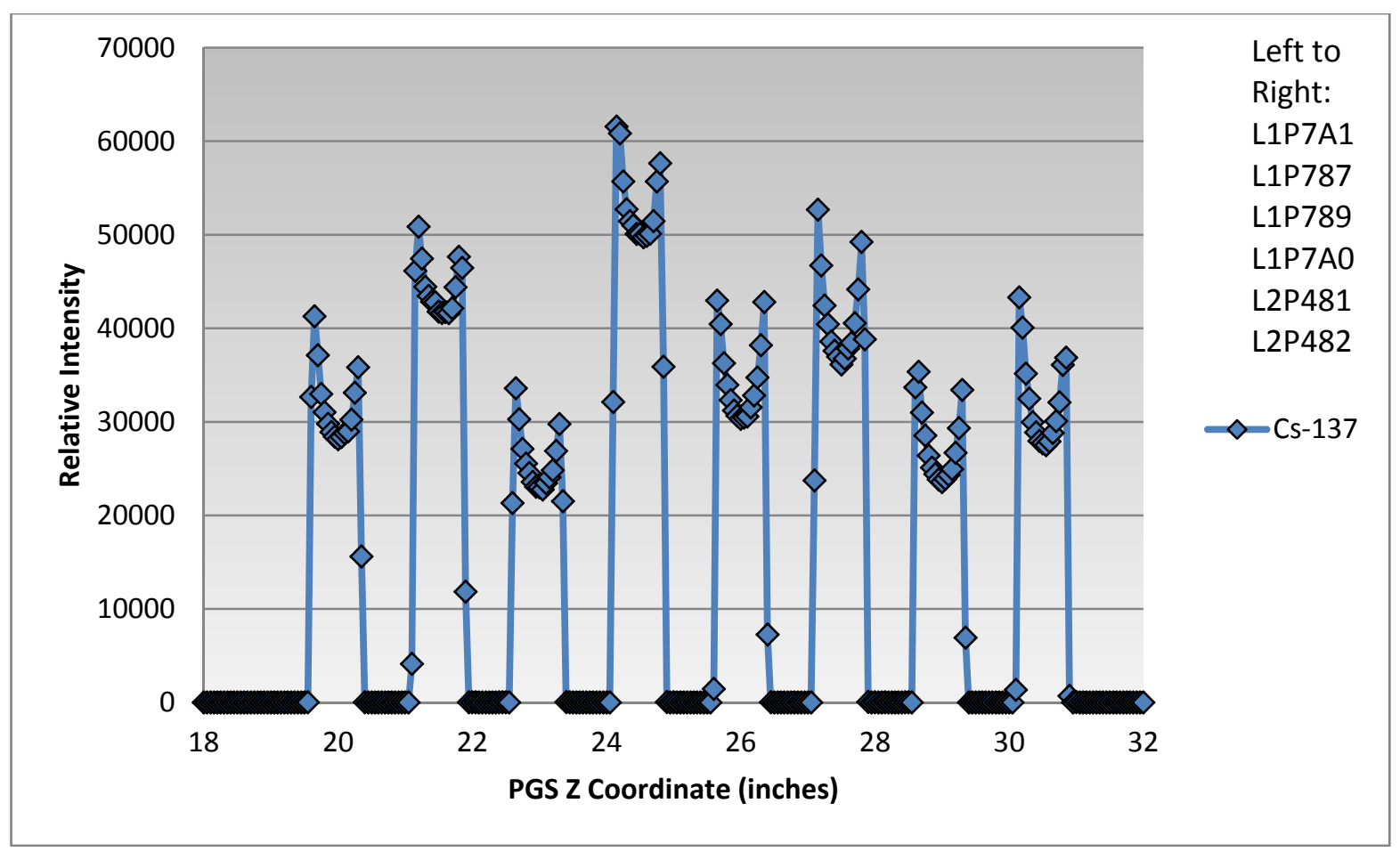

Figure 38. Transverse scan of plates from RERTR-12 Capsule A. 


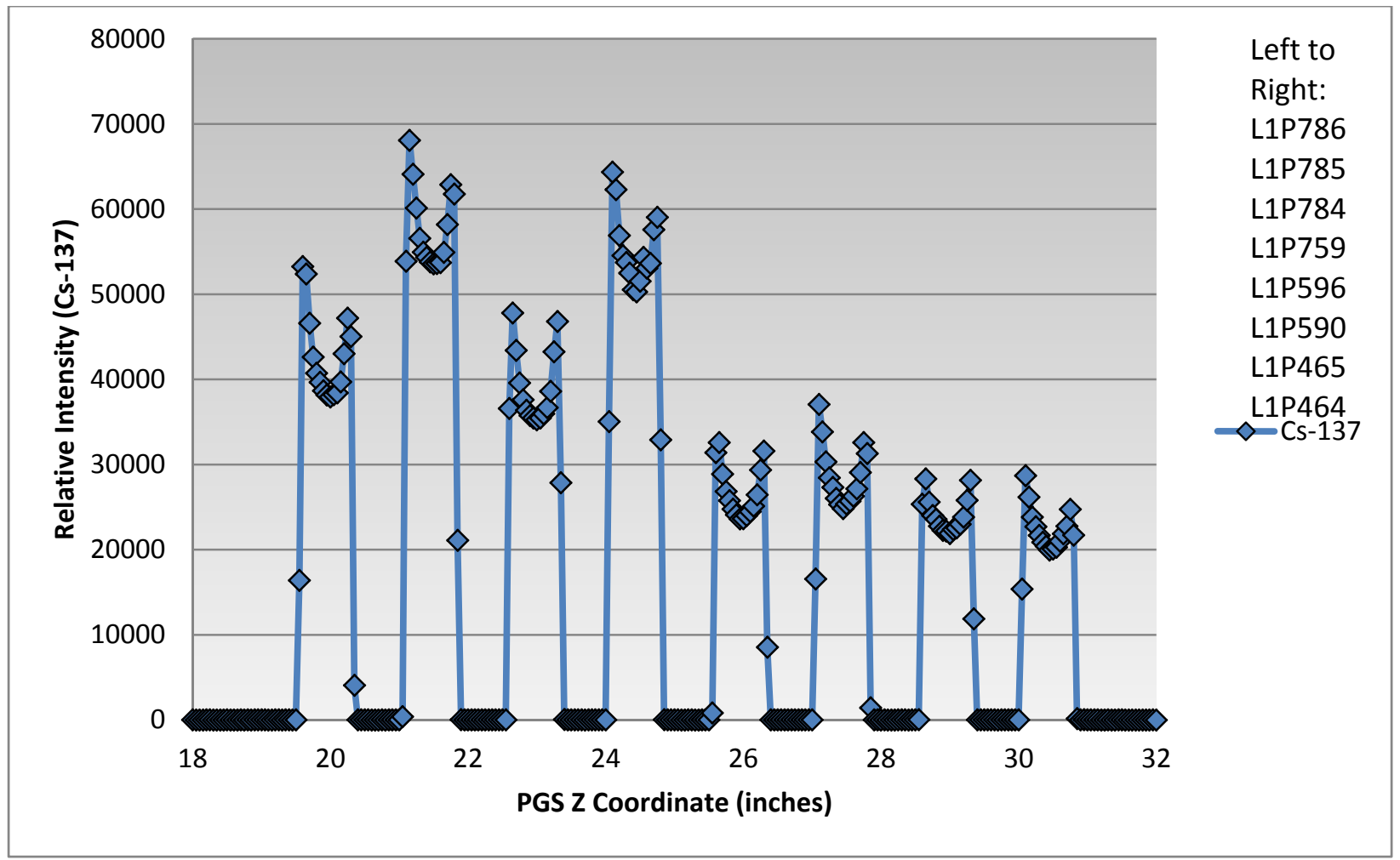

Figure 39. Transverse scan of plates from RERTR-12 Capsule B.

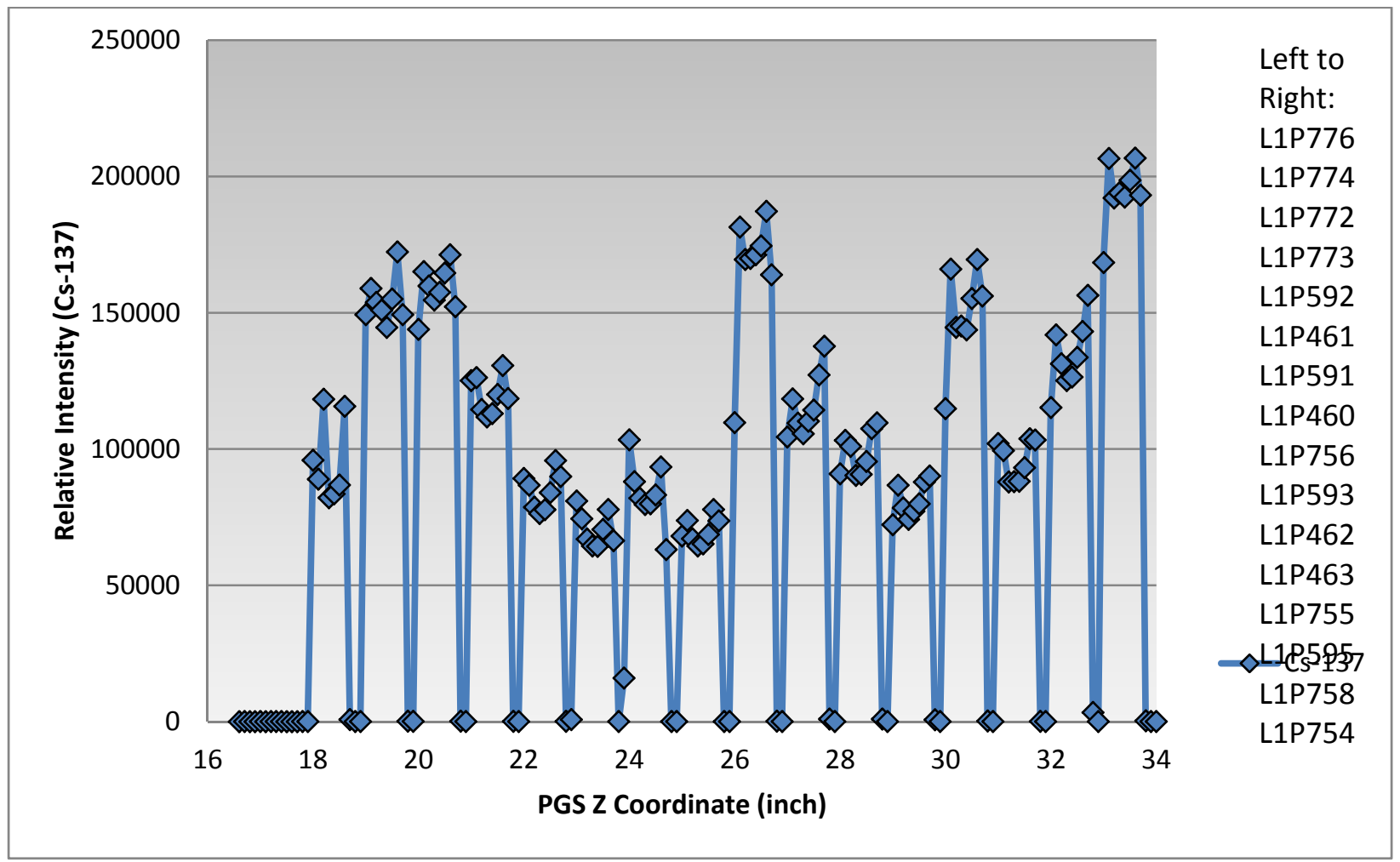

Figure 40. Transverse scan of plates from RERTR-12 Capsule C and Capsule D. 


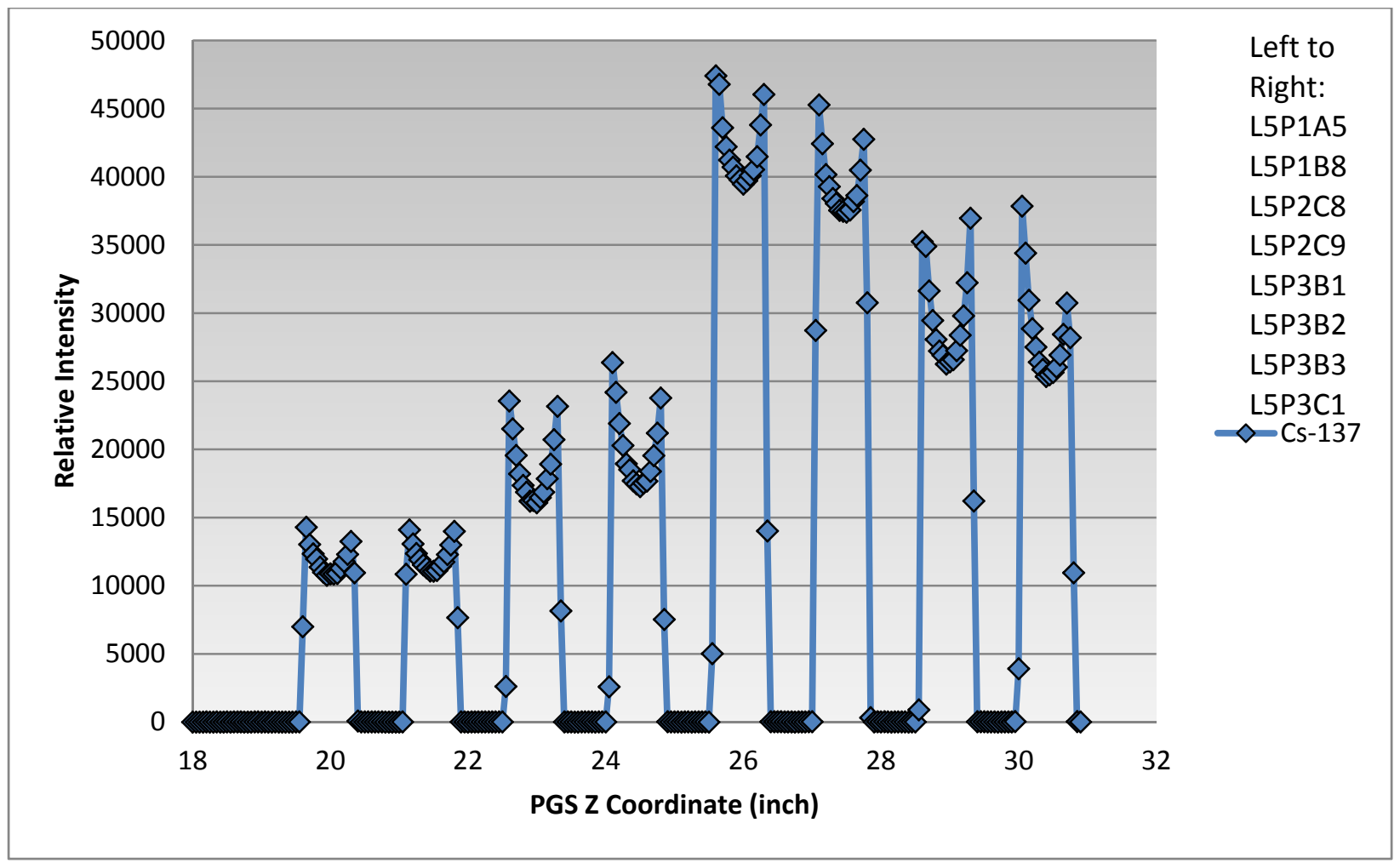

Figure 41. Transverse scan of plates from RERTR-12 Capsule E.

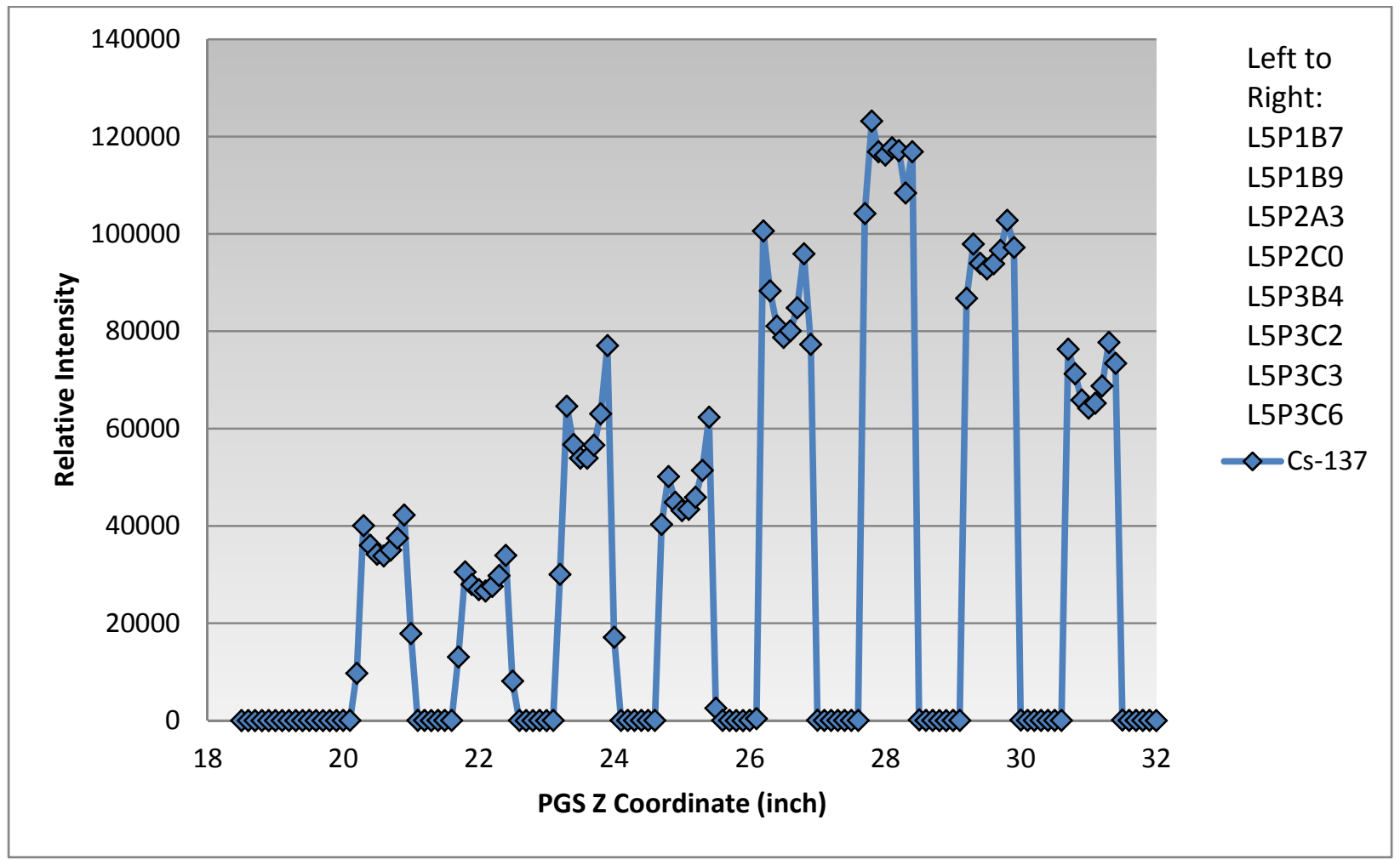

Figure 42. Transverse scan of plates from RERTR 12-Capsule F. 


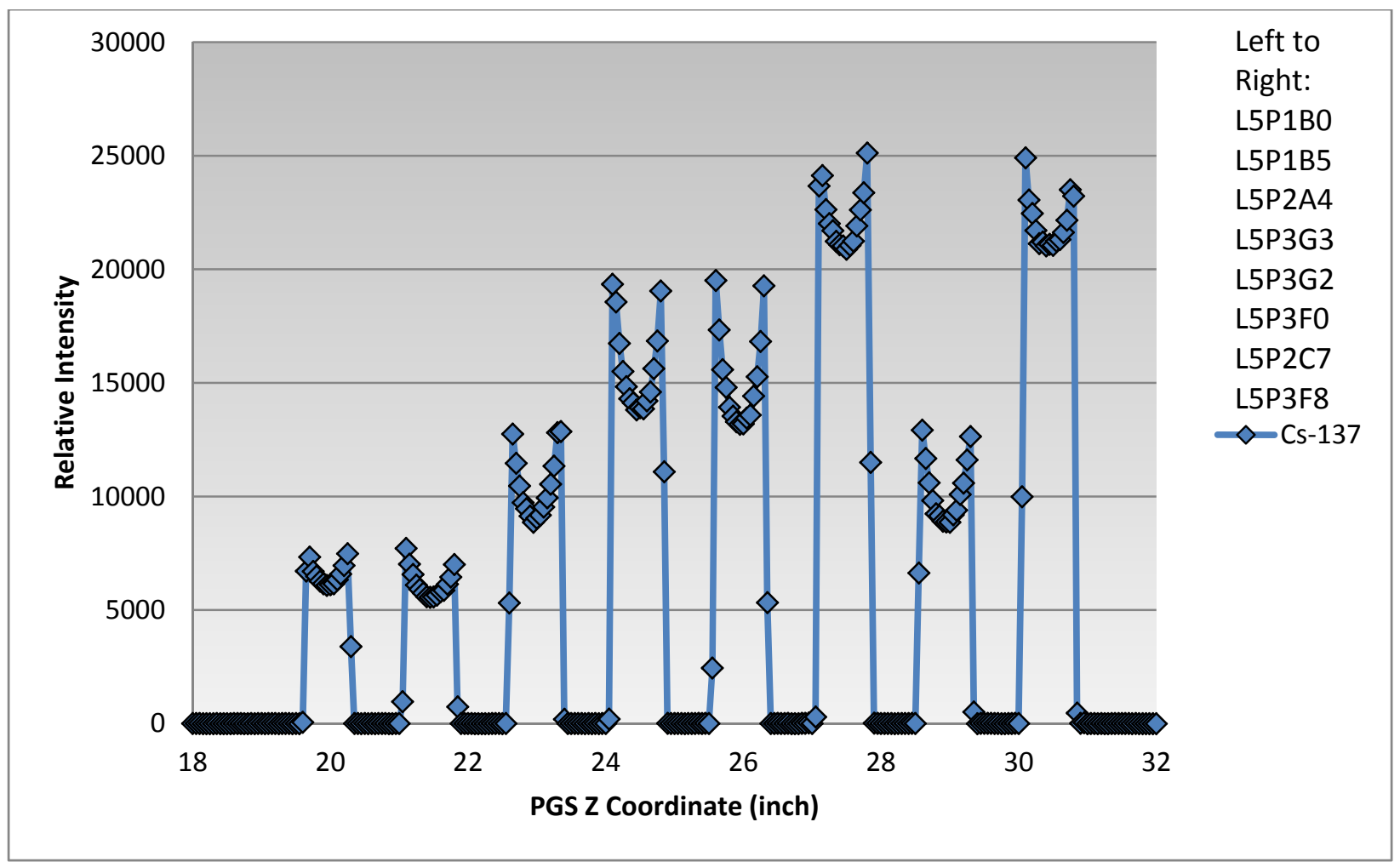

Figure 43. Transverse scan of plates from RERTR-12 Capsule G.

\subsubsection{Discussion}

A few scans involved errors in data collection, which caused a much lower-than-expected number of counts to be collected. Most notably, at $Z=20.35$ in the $12 \mathrm{G}$ vertical scan of plate L5P3F8, a count is out of trend with the surrounding data. This was caused by an error in the PGS-detector electronics. This is a known issue that should be remedied in future gamma scanning after the responsible electronic module is replaced, but does not impact the overall conclusions of this analysis or the quality of the rest of the gamma scan data. Data from the transverse scans are noisier than the vertical scans, especially where the scan step size and collimator width was $0.254 \mathrm{~cm}(0.1 \mathrm{inch})$. There are distortions in the expected U shape of the transverse scans that occur when scans pick up the edges of the fuel meat in multiple scans. When the transverse scans were collected with $0.127 \mathrm{~cm}(0.05$ inch) step size and collimator width $0.127 \mathrm{~cm}$, the ${ }^{137} \mathrm{Cs}$ intensity trends were smooth and U-shaped, as expected.

A smooth U-shaped trend in the ${ }^{137} \mathrm{Cs}$ intensity in vertical scans that reflects the plate burnup profile appears to indicate good plate performance. A deviation from smooth ${ }^{137} \mathrm{Cs}$ distribution is likely due to fuel-plate failure. This is readily apparent in three plates. Two of the plates that exhibit anomalies in the 
${ }^{137}$ Cs profile were from the RERTR-12B capsule: L1P759 and L1P785 (see

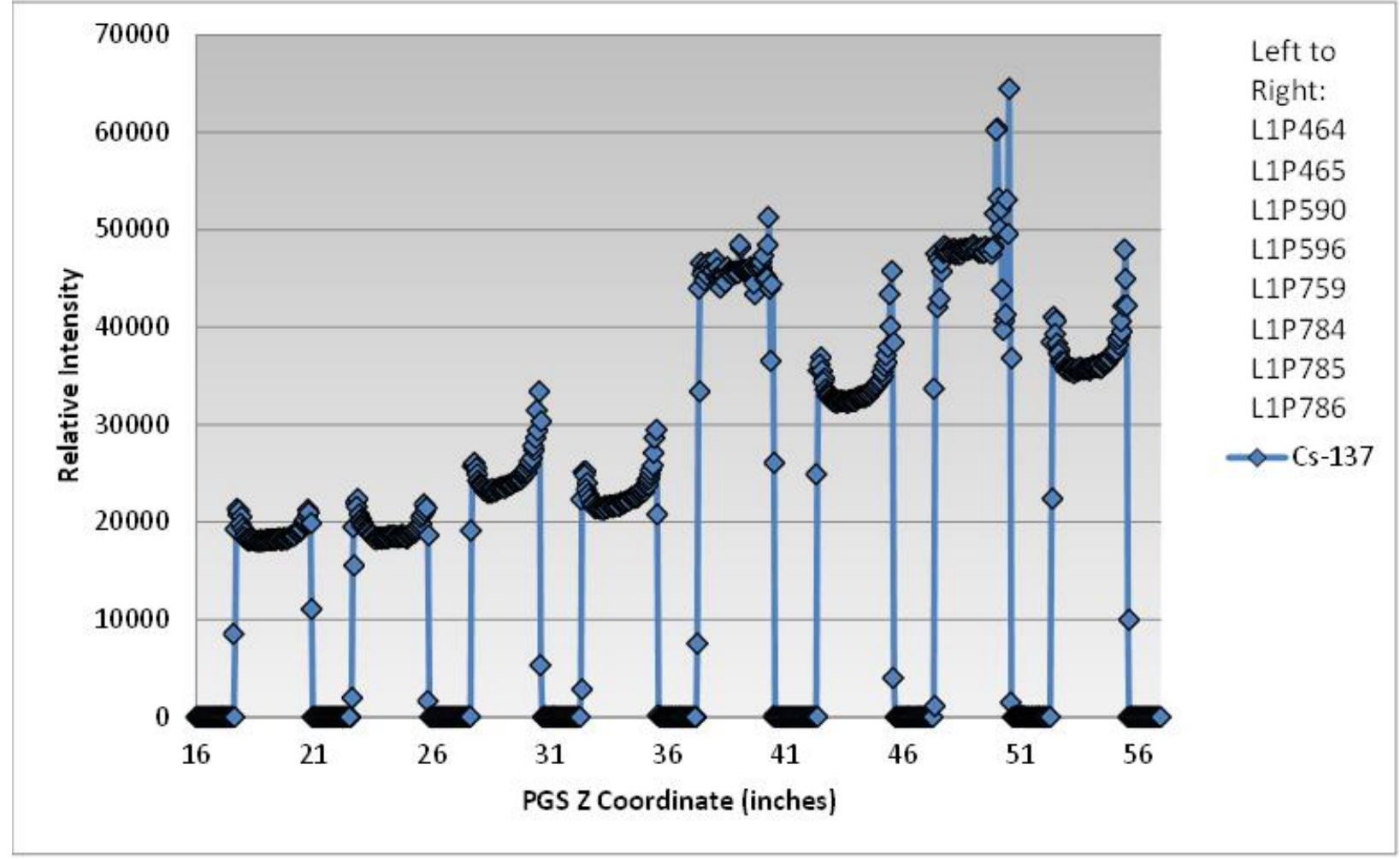

Figure 32). These plates both exhibited pillowing failure. The other atypical ${ }^{137} \mathrm{Cs}$ behavior is in capsule RERTR-12D plate L1P754 which also failed by pillowing (see Figure 34). Another plate, L1P7A0 from RERTR-12A, also indicated high swelling by immersion density, but not by profilometry. 
L1P7A0 does not exhibit any unusual ${ }^{137} \mathrm{Cs}$ trends (see

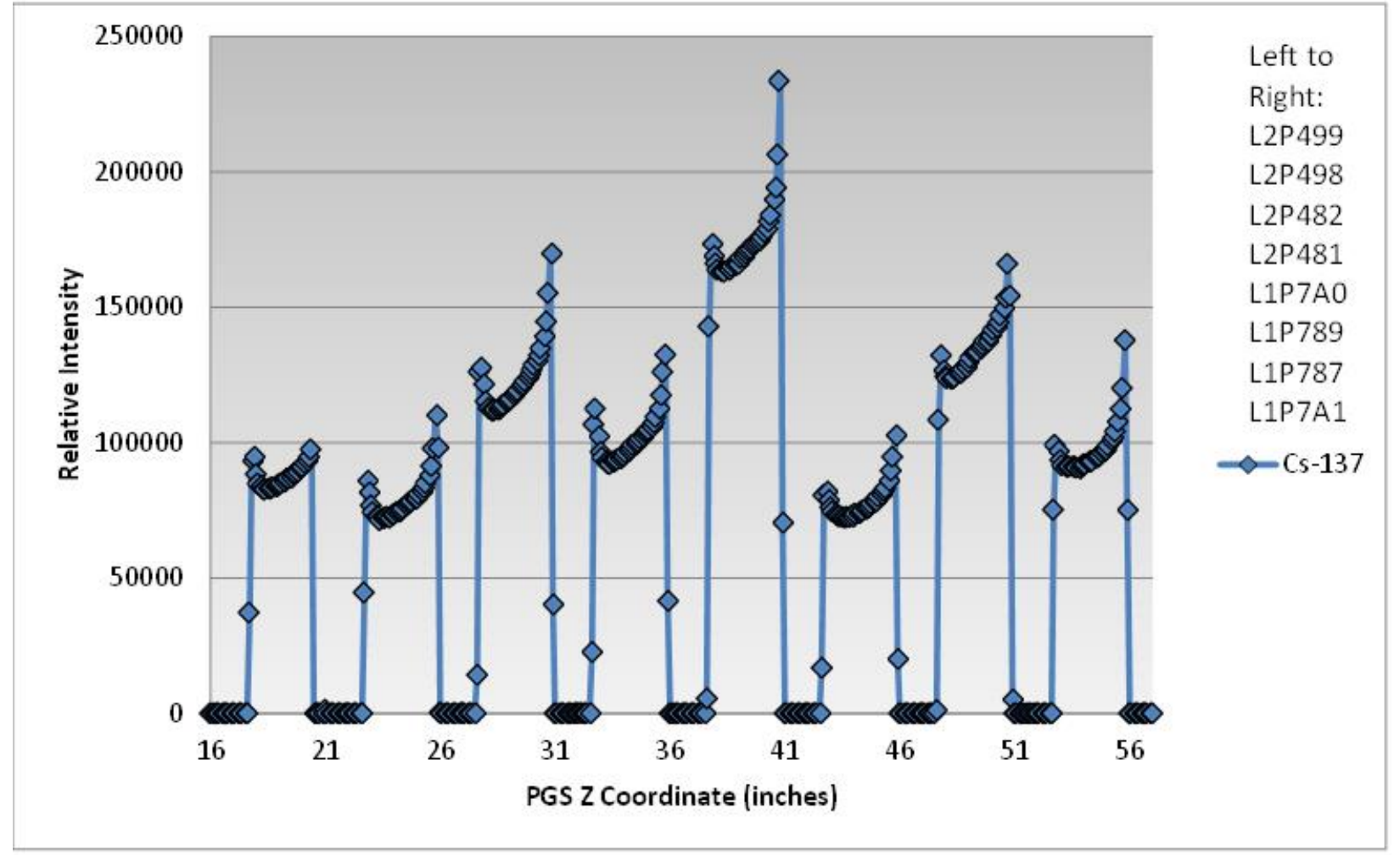

Figure 31). It should be noted that the three plates that exhibited pillowing are also three of the four plates with the highest fission density in the RERTR-12 irradiation.

The plates with large pillow defects (L1P785, L1P759, and L1P754) are shown plotted with neutron radiographs of the plates the ${ }^{144} \mathrm{Ce} / \mathrm{Pr}$ signal, and the ${ }^{137} \mathrm{Cs}$ signal in Figures 46-48. Photographs of these three pillow defect plates and L1P7A0 which also had a pillow defect are also shown in Figure 2. Interconnected porosity or pillowing of the fuel plates may allow volatile Cs to migrate in the vapor phase within the plates while $\mathrm{Ce}$, with lower vapor pressure, would likely not migrate.

In the scan of L1P759 (Figure 44), fuel relocation appears as a decrease in Ce/Pr-144 intensity at locations that correspond to fuel relocation in the neutron radiograph (approximately 38.3, 38.5, and $39.7 \mathrm{in}$. relative plate position). The distribution of the ${ }^{137} \mathrm{Cs}$ in the plate has also flattened compared to the expected fission-density trend shown by the ${ }^{144} \mathrm{Ce} / \mathrm{Pr}$ intensity curve. ${ }^{137} \mathrm{Cs}$ migration is also noted in the region of plate pillowing near 40.4 in.

The neutron radiography and corresponding gamma scan of plate L1P785 (Figure 45) indicate less fuel relocation. Cs has migrated at both ends of the fuel plate. The Cs distribution throughout the central region of the fuel plate has also been flattened. The distribution of ${ }^{144} \mathrm{Ce} / \mathrm{Pr}$ indicates that fuel relocation did not occur. The contrast of the radiograph has been enhanced and presented at the top of Figure 45 to help show the fuel pillowing and relocation that occurred in L1P785.

Plate L1P754 (Figure 46) pillowed near the top of the plate. The overall trend of Cs distribution in comparison to ${ }^{144} \mathrm{Ce} / \mathrm{Pr}$ in this plate suggests that there is less Cs migration than in plates L1P759 and L1P785. The ${ }^{137} \mathrm{Cs}$ gamma signal is increased near $28.7 \mathrm{in}$. where a piece of fuel foil has detached and relocated from the area around 28 in.

In the highest-fission-density plates (L1P759 and L1P785), it is possible that a network of interconnected porosity formed, providing Cs a pathway for migration in the fuel. Because the 
temperature distribution in the fuel plates is relatively flat, the Cs appears to have distributed more or less evenly in these plates. At the ends of the plates, where there is additional constraint imposed by the cladding, porosity may not be interconnected, and an increase in Cs signal may be expected. Plate L1P754, at lower burnup, may not have formed a network of interconnected porosity, since the Cs appears to have remained in place.

Detail plots of the ${ }^{137} \mathrm{Cs}$ signal and ${ }^{144} \mathrm{Ce} / \mathrm{Pr}$ signal from plates L1P7A0 and L1P756 are also shown in Figure 47 and Figure 48. Plate L1P7A0 is the plate lowest in fission density that exhibited anomalous swelling, and plate L1P756 is the plate with the highest fission density of all plates that did not pillow or exhibit signs of high swelling. There are no anomalies in the fission-product distribution that indicate failure in plate L1P7A0. Likewise, nothing appears in the fission-product distribution from L1P756 to indicate fission-product migration that could be used to predict impending failure.

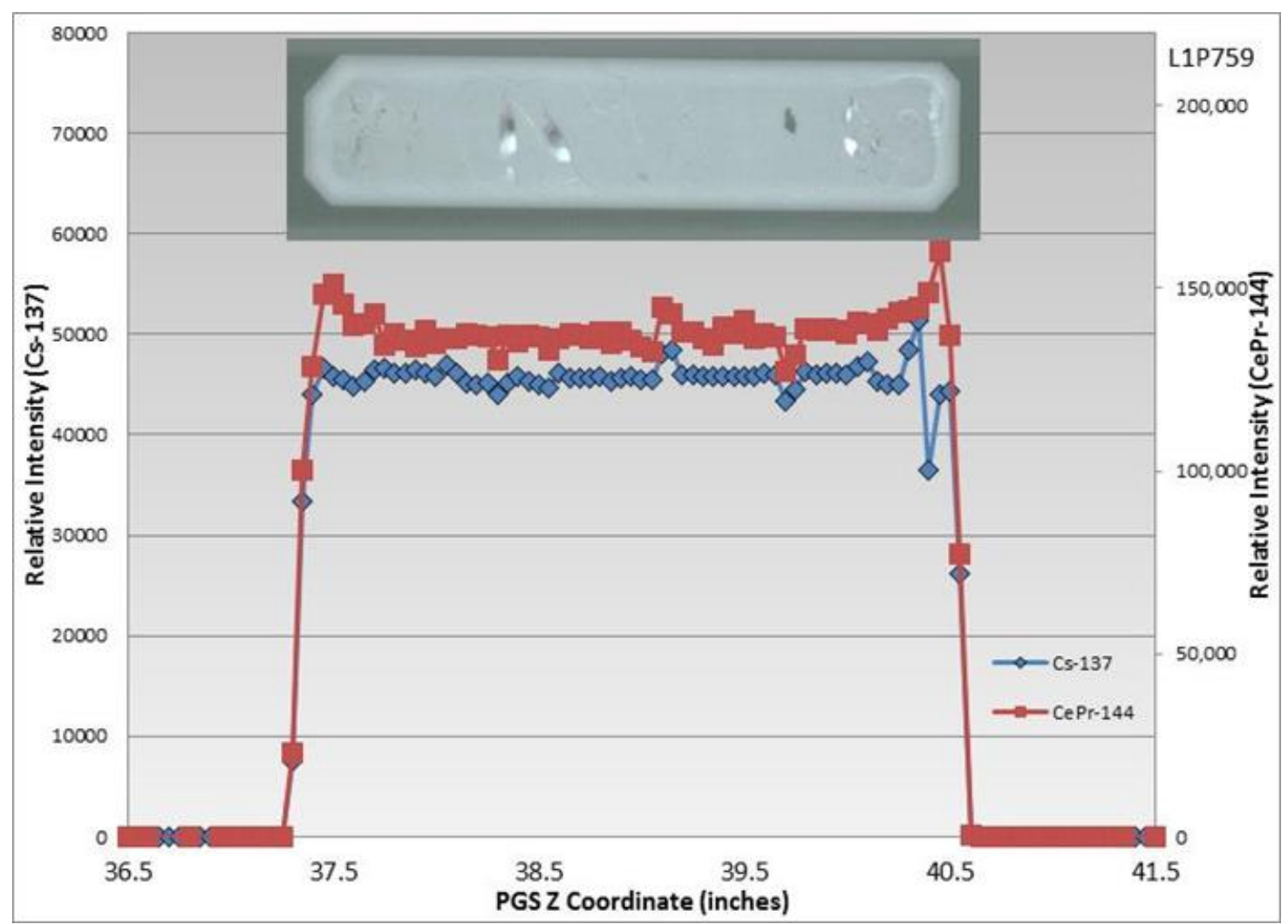

Figure 44. Gamma scan and neutron radiograph from plate L1P759. 


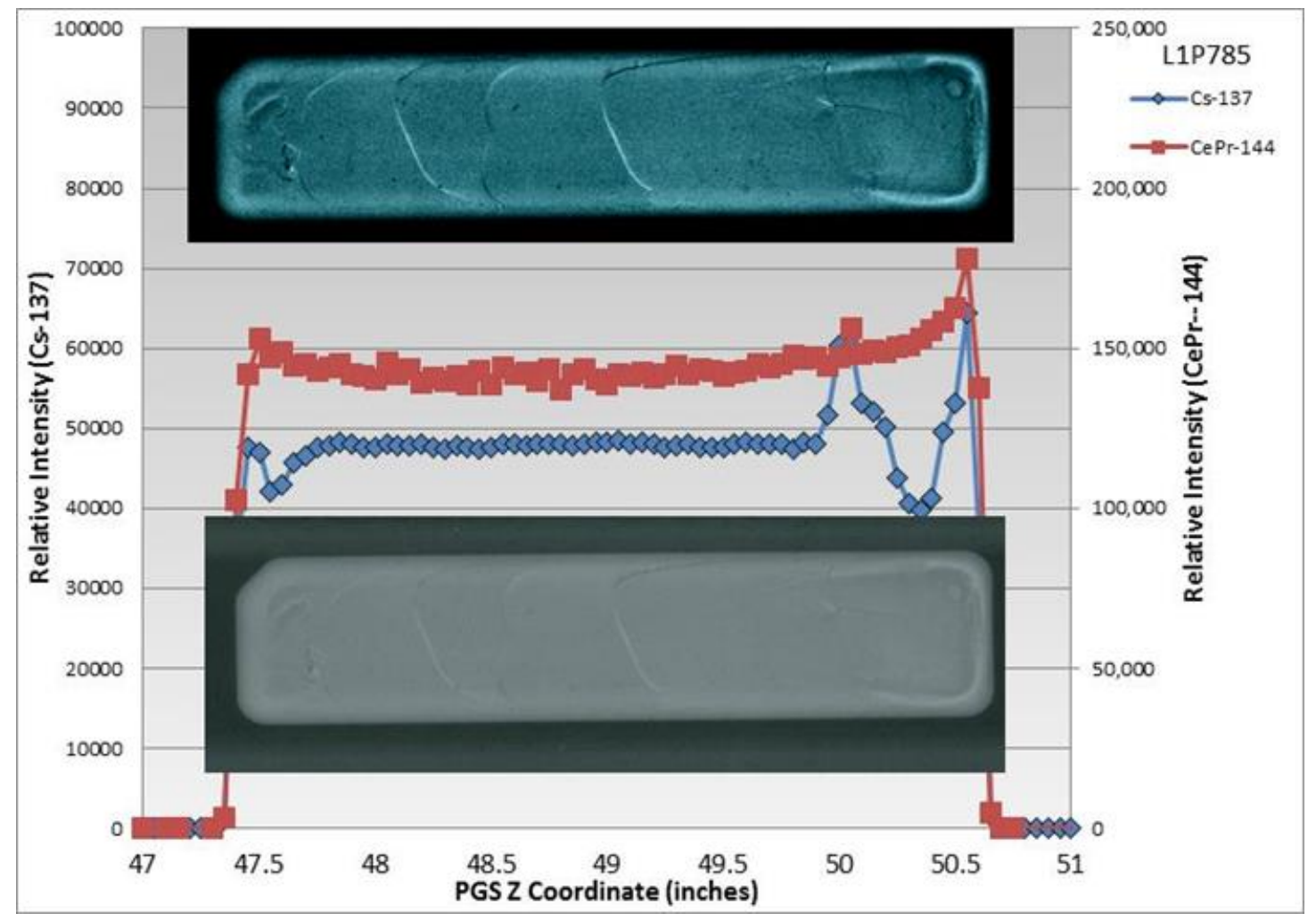

Figure 45. Gamma scan and neutron radiograph from plate L1P785.

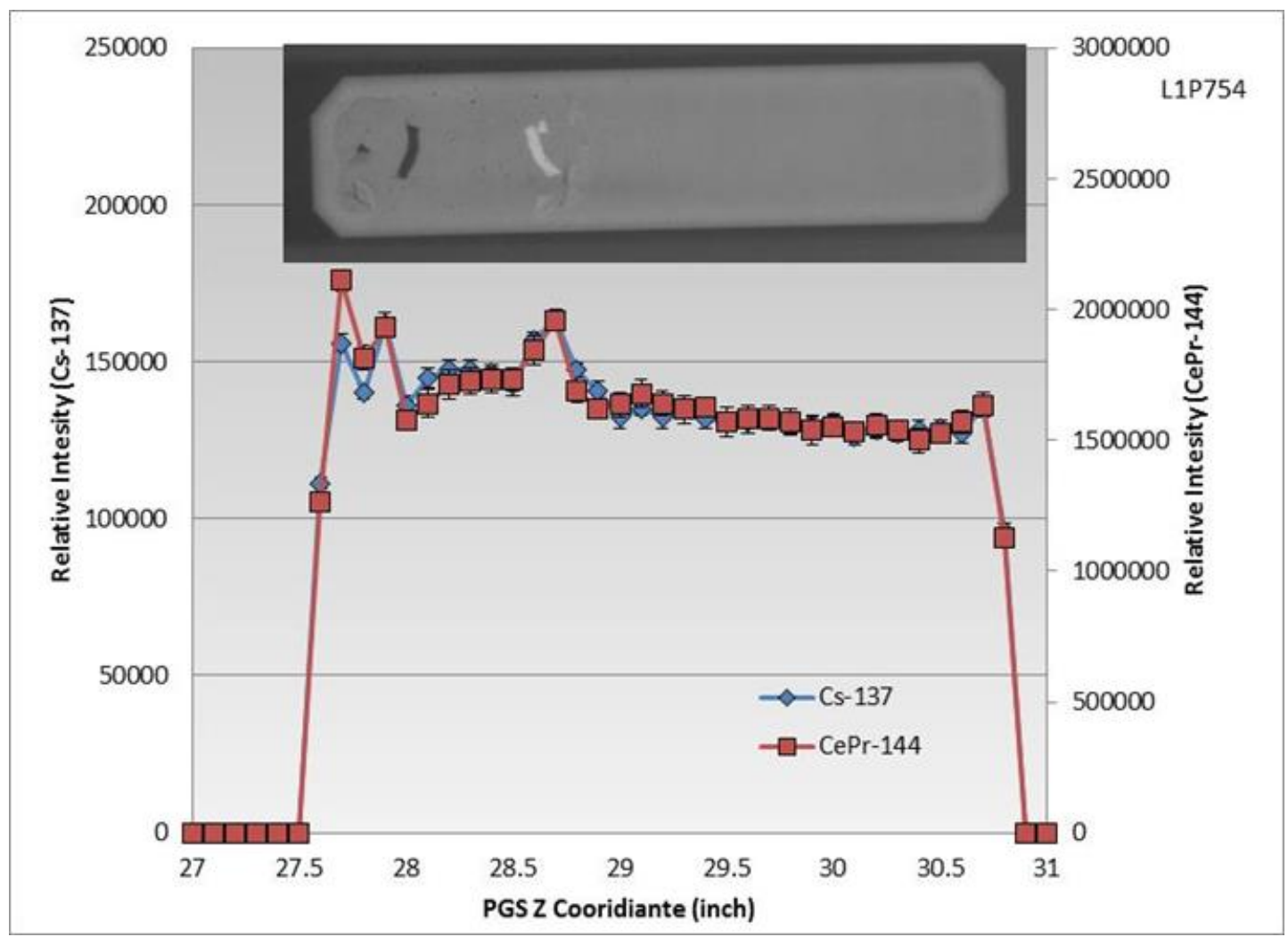

Figure 46. Gamma scan and neutron radiograph from plate L1P754. 


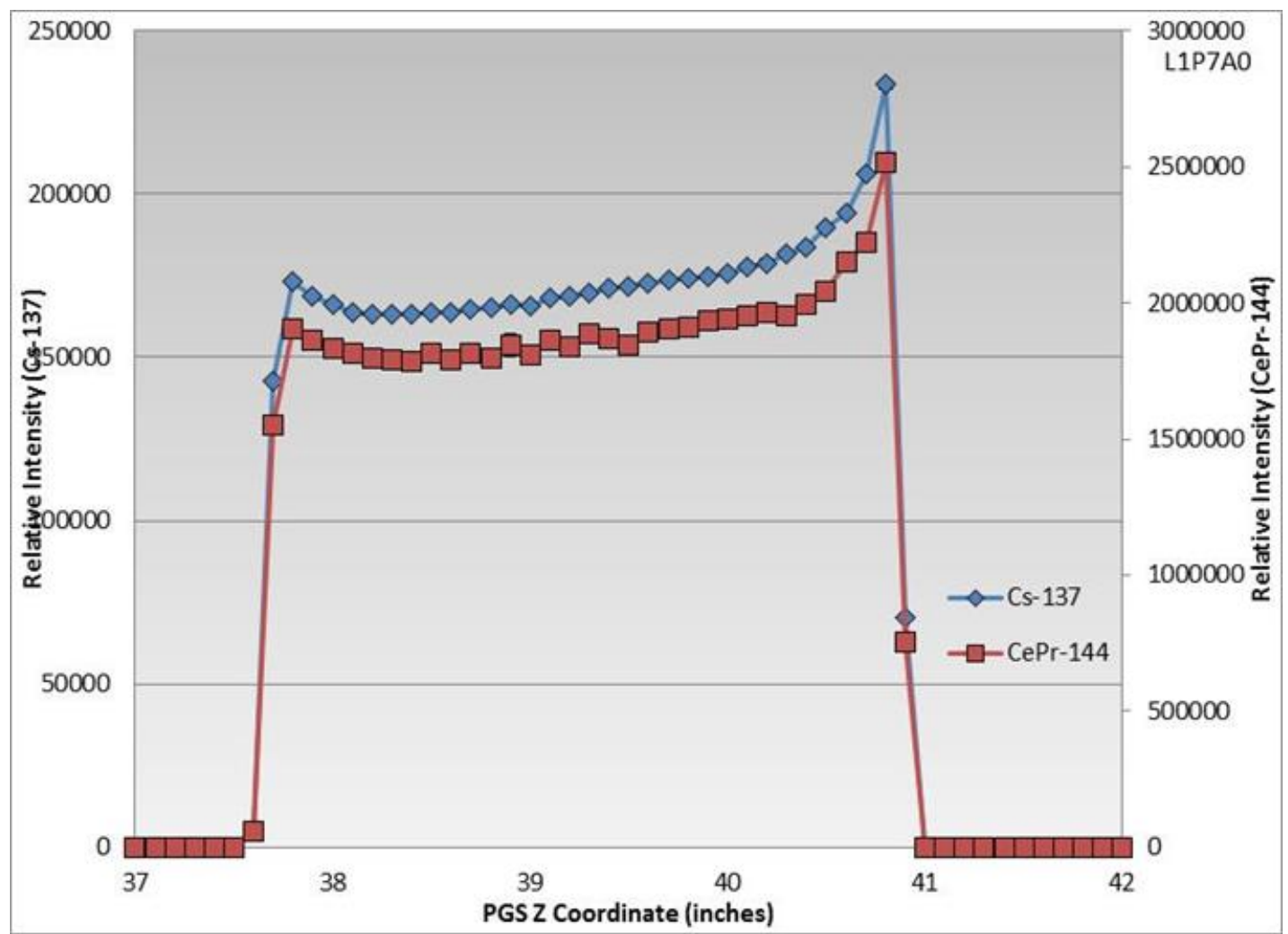

Figure 47. Gamma scan from plate L1P7A0. 


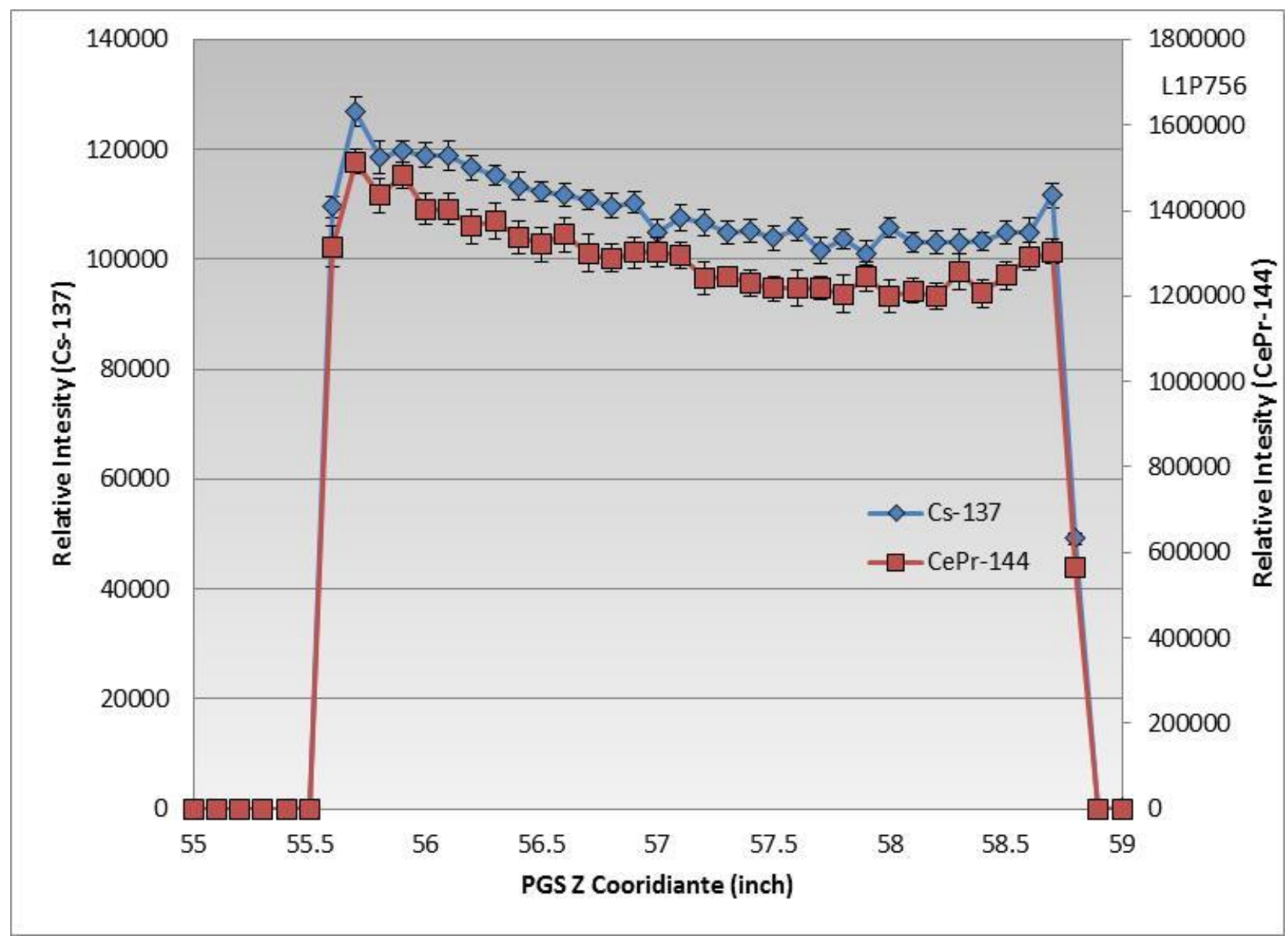

Figure 48. Gamma scan from plate L1P756. 


\section{DESTRUCTIVE ANALYSIS \\ 4.1 Chemical Analysis}

\subsubsection{Measurement of ${ }^{235} \mathrm{U}$ Depletion in Six RERTR-12 Mini-plates}

A set of measurements involving six RERTR-12 plates verified ${ }^{235} \mathrm{U}$ depletion (via fission and neutron capture). For this purpose 0.25 in. $\times 0.25$ in. samples were taken from each plate just below the axial midplane, in the central region of the fuel meat (see Figure 49). These samples contained both fuel and cladding. The samples were weighed and dissolved, and the resultant solutions were analyzed for uranium, plutonium and selected fission-products isotopes using inductively coupled plasma mass spectrometry (ICP-MS). In addition, to confirm ICP-MS results for uranium and plutonium isotopes, the same samples were analyzed using thermal ionization mass spectrometry (TIMS).

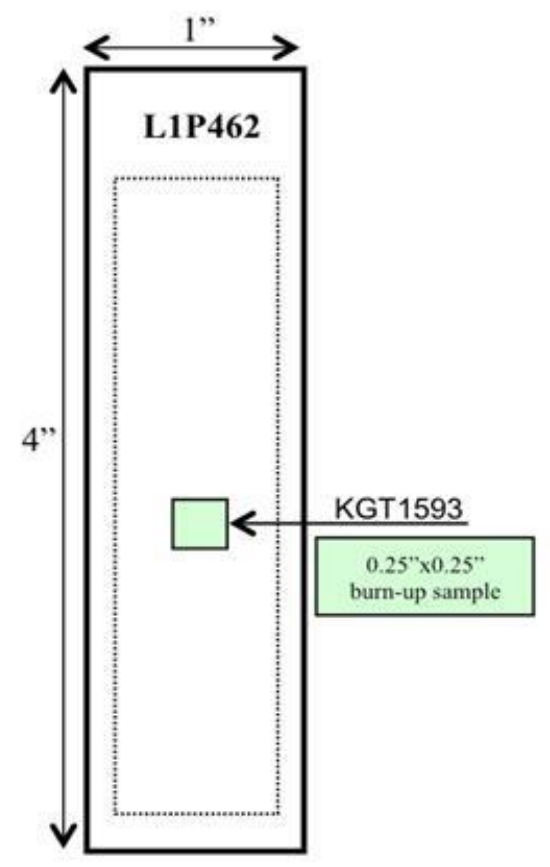

Figure 49. Example of sample location for verification of ${ }^{235} \mathrm{U}$ depletion in RERTR-12 plates.

Two independent methods of analysis were used to establish ${ }^{235} \mathrm{U}$ depletion in RERTR-12 plates from measured data. The first method is based on measurement of fission product isotopes to determine total number of fissions in the sample and on measurement of the ${ }^{236} \mathrm{U}$ isotope to account for ${ }^{235} \mathrm{U}$ neutron capture. Three different fission-product isotopes, i.e., ${ }^{99} \mathrm{Tc},{ }^{139} \mathrm{La}$ and ${ }^{141} \mathrm{Pr}$, were used in this analysis. Given initial fuel enrichments and projected burnup levels, it was assumed that contribution from $\mathrm{Pu}$ isotopes to fission was insignificant. For this reason ${ }^{235} \mathrm{U}$ thermal-fission yields from the ENDF/B-VII library were utilized for ${ }^{99} \mathrm{Tc},{ }^{139} \mathrm{La}$ and ${ }^{141} \mathrm{Pr}$ isotopes in this analysis.

The second method of estimating ${ }^{235} \mathrm{U}$ depletion is based on changes in ${ }^{235} \mathrm{U}$ to ${ }^{238} \mathrm{U}$ ratio before and after irradiation. A small correction had to be made to the final ${ }^{235} \mathrm{U}$ to ${ }^{238} \mathrm{U}$ ratio to account for ${ }^{238} \mathrm{U}$ transmutation to $\mathrm{Pu}$. 
Results for ${ }^{235} \mathrm{U}$ depletion established in samples from six RERTR-12 mini-plates using three different fission-product isotopes and the ${ }^{235} \mathrm{U}$ to ${ }^{238} \mathrm{U}$ ratio are summarized in Table 12 . As seen in the tabulated results, ${ }^{235} \mathrm{U}$ results determined using the three fission products agree within $4.3 \%$. Agreement between results established via the two different methods is within 10.5\%. A comparison of MCNPcalculated ${ }^{235} \mathrm{U}$ depletion with TIMS depletion data shows that there is considerable disagreement between calculation and analysis. It is strongly recommended that physics results be recalculated for this irradiation experiment.

Table 12. ${ }^{235} \mathrm{U}$ depletion in samples from RERTR-12 mini-plates established using three different fission products and ${ }^{235} \mathrm{U}^{238} \mathrm{U}$ ratio.

\begin{tabular}{|c|c|c|c|c|c|c|c|}
\hline \multirow[b]{2}{*}{ Plate ID } & \multirow[b]{2}{*}{ Sample ID } & \multirow[b]{2}{*}{$\begin{array}{l}\text { Analytical } \\
\text { Lab log \# }\end{array}$} & \multicolumn{5}{|c|}{${ }^{235} \mathrm{U}$ depletion (via fission and capture), at. \% } \\
\hline & & & $\begin{array}{c}\text { MCNP } \\
\text { Calculated } \\
\text { Depletion } \\
\end{array}$ & via ${ }^{99} \mathrm{Tc}$ & via ${ }^{139} \mathrm{La}$ & via ${ }^{141} \operatorname{Pr}$ & $\begin{array}{c}\text { via } \\
{ }^{235} \mathrm{U} /{ }^{238} \mathrm{U}^{1} \\
\end{array}$ \\
\hline $\mathrm{L} 2 \mathrm{P} 499^{3}$ & KGT1571 & 97347 & 18.6 & 17 & 17 & 17 & 16 \\
\hline $\mathrm{L} 5 \mathrm{P} 3 \mathrm{~B} 4^{3}$ & KGT1596 & 97342 & 24.7 & 23 & 24 & 24 & 24 \\
\hline L1P776 & KGT1547 & 97343 & 16.5 & 16 & 16 & 16 & 15 \\
\hline $\mathrm{L} 5 \mathrm{P} 2 \mathrm{~A} 4^{3}$ & KGT1691 & 97344 & 9.0 & 8 & 8 & 8 & 8 \\
\hline L1P784 & KGT1572 & 97345 & 26.4 & 23 & 24 & 24 & 22 \\
\hline L1P462 & KGT1593 & 97346 & 24.4 & 21 & 21 & 21 & 19 \\
\hline \multicolumn{8}{|c|}{ 1. The ratio is established based on TIMS data. } \\
\hline \multicolumn{8}{|c|}{ 2. The ratio is established based on ICP-MS data. } \\
\hline
\end{tabular}

\subsubsection{1 ${ }^{235} U$ Depletion along the Width of RERTR-12 Mini-plate L1P773}

Another set of measurements verified ${ }^{235} \mathrm{U}$ depletion (via fission and neutron capture) along the width of RERTR-12 mini-plate L1P773. For this purpose a 0.06 in.-thick stripe was cut along the width of the mini-plate below the axial midplane (see Figure 50). Ten 0.06 in. $\times 0.06$ in. samples were obtained from this stripe. Each contained both fuel and cladding. The samples were weighed, dissolved, and the resultant solutions were analyzed for uranium, plutonium and selected fission-product isotopes using ICP-MS. 


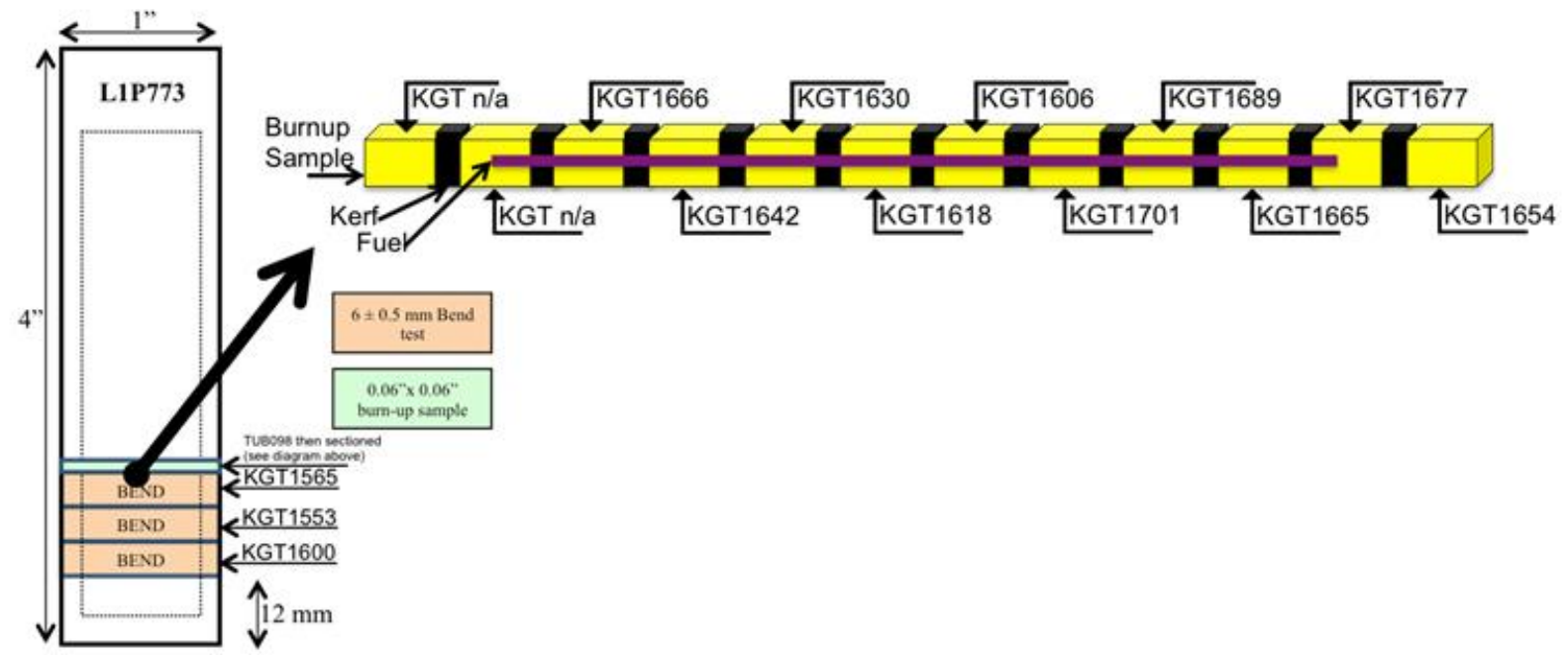

Figure 50. Location of samples for verification of ${ }^{235} \mathrm{U}$ depletion along the width of RERTR-12 miniplate L1P773.

Results for ${ }^{235} \mathrm{U}$ depletion established in ten samples from RERTR-12 mini-plate L1P773 using three different fission-product isotopes and ${ }^{235} \mathrm{U}$ to ${ }^{238} \mathrm{U}$ ratio are summarized in Table 13. Average ${ }^{235} \mathrm{U}$ depletion, calculated by MCNP, was $17.0 \%$. As seen from the table, ${ }^{235} \mathrm{U}$ results determined using three fission products agree within $6.7 \%$. Agreement between results established via two different methods (fission products and ${ }^{235} \mathrm{U}$ to ${ }^{238} \mathrm{U}$ ratio) is also within $6.7 \%$.

Table 13. ${ }^{235} \mathrm{U}$ depletion in ten samples from RERTR-12 mini-plate LP1773 established using three different fission products and ${ }^{235} \mathrm{U}{ }^{238} \mathrm{U}$ ratio.

\begin{tabular}{|c|c|c|c|c|c|c|}
\hline \multirow[b]{2}{*}{ Plate ID } & \multirow[b]{2}{*}{ Sample ID } & \multirow[b]{2}{*}{$\begin{array}{l}\text { Analytical } \\
\text { Lab log \# }\end{array}$} & \multicolumn{4}{|c|}{${ }^{235} \mathrm{U}$ depletion (via fission and capture), at. \% } \\
\hline & & & via ${ }^{99} \mathrm{Tc}$ & via ${ }^{139} \mathrm{La}$ & via ${ }^{141} \mathrm{Pr}$ & $\begin{array}{l}\text { via }{ }^{235} \mathrm{U} \\
{ }^{238} \mathrm{U}^{1}\end{array}$ \\
\hline L1P773 & KGT1654 & 97838 & 21 & 22 & 22 & 21 \\
\hline L1P773 & KGT1677 & 97839 & 18 & 19 & 19 & 18 \\
\hline L1P773 & KGT1665 & 97840 & 16 & 17 & 17 & 17 \\
\hline L1P773 & KGT1689 & 97841 & 16 & 17 & 17 & 16 \\
\hline L1P773 & KGT1701 & 97842 & 15 & 16 & 16 & 16 \\
\hline L1P773 & KGT1606 & 97843 & 16 & 17 & 17 & 16 \\
\hline L1P773 & KGT1618 & 97844 & 16 & 17 & 17 & 16 \\
\hline L1P773 & KGT1630 & 97845 & 17 & 18 & 18 & 17 \\
\hline L1P773 & KGT1642 & 97846 & 19 & 20 & 20 & 19 \\
\hline L1P773 & KGT1666 & 97847 & 23 & 24 & 24 & 24 \\
\hline L1P773 & KGT1654 & 97838 & 21 & 22 & 22 & 21 \\
\hline
\end{tabular}




\subsection{Metallography}

\subsubsection{Introduction}

Representative metallographic specimens were taken from fuel plates with $0.25,0.51$ and $0.64 \mathrm{~mm}$ fuel-meat thicknesses. Plates that exhibited pillowing and/or with high swelling were sectioned such that metallographic specimens were taken from the high-, medium-, and low-fission-density regions of the plate. Post-irradiation radiography images, metrology, and visual examination provided information on regions with fuel damage and other regions of interest prior to sectioning. Additionally, locations of high fission density from several non-blistered plates were selected for optical metallography to characterize fission-gas-bubble morphology.

\subsubsection{General Comments}

Pre-irradiation examinations reveal the RERTR-12 fuel foils to be, in general, of uniform thicknesses, but with variability in characteristics in the form of $\gamma$-phase decomposition, non-uniform grain structure and size, carbide/oxide inclusions, and chemical banding. These traits were found to be present in the post-irradiation microstructure, depending on source material and relative fission density. Because the RERTR-12 experiment enveloped a variety of U-10Mo source materials in addition to a range of average fission densities from very low ( $\min : 2.9 \times 10^{20}$ ) to very high (max: $1.25 \times 10^{22}$ ), a broad picture of the performance characteristics of $\mathrm{U}-$ Mo monolithic alloy is captured from these examinations. Some microstructural data from the earlier portion of the RERTR-12 test (first insertion) is included in this report to provide information on changes in the fuel meat microstructure relative to increasing plate fission density.

Micrographs found in the figures to follow were selected to illustrate changes as a function of fission density. The discussions include general observations specific to each micrograph. It is known, from prior examinations using focused ion beam methods to prepare specimens, that smearing and/or pullout may skew data and observations relative to gas-bubble fraction and morphology; these potential artifacts are not accounted for in the observations presented here.

Detailed observations and conclusions are organized in sections according to the fuel-system components. Where available, micrographs from unirradiated archive fuel specimens are provided for comparison. ${ }^{a}$ Micrographs of etched regions of the fuel illustrate bulk grains and grain-refinement areas and resolve interaction layers. The etching process was tailored to the specific feature requiring resolution. While the effort may be described as trial and error, the selected etchants were applied in a conservative manner, with the least aggressive being applied first and results determined before increasing etching time or using more aggressive etchants. Etchant recipes and approximate etch times are retained and available from the authors.

\subsubsection{Metallography}

\subsubsection{Cladding and Cladding-cladding Bond Line}

Characterization of the RERTR-12 plates reveals that cladding in unirradiated fuel plates had normal levels of impurities, with two main types being silicides rich in magnesium and iron. The characterization also included a scanning-electron-microscopy (SEM) image revealing no anomalies, such as porosity or unexpected phases, and an observable bond line. Figure 51 and Figure 52 illustrate examples of cladding-to-cladding bonds in a fresh fuel plate and an irradiated fuel plate, respectively. A visual comparison between the two bond-line images indicates a similar appearance. Aluminum cladding shear drops from both plates (L1P756 and L1P759) were subject to and passed the bend test that is applied to all shear-drop pieces adjacent to the final plate edges. The bend test is a standard test that all plates that

a. Nota bene: micron bars indicate that images pre- and post-irradiation are not recorded at identical magnifications. 
are candidates for irradiation must pass and is an indication of the cladding-to-cladding (pass/fail) bond quality.

The results from the SEM examinations (optical images are not available) of the unirradiated cladding-to-cladding bonds (example shown in Figure 51; other archive specimens that were interrogated) determined that all the RERTR-12 cladding-to-cladding bonds exhibited similar features. Post-irradiation metallographic characterization (SEM images are not available) did not reveal any non-typical features in the cladding-to-cladding bond line and were consistent in appearance with the micrographs of unirradiated fuel specimens at similar magnification and demonstrated no appreciable changes or evidence of debonds.

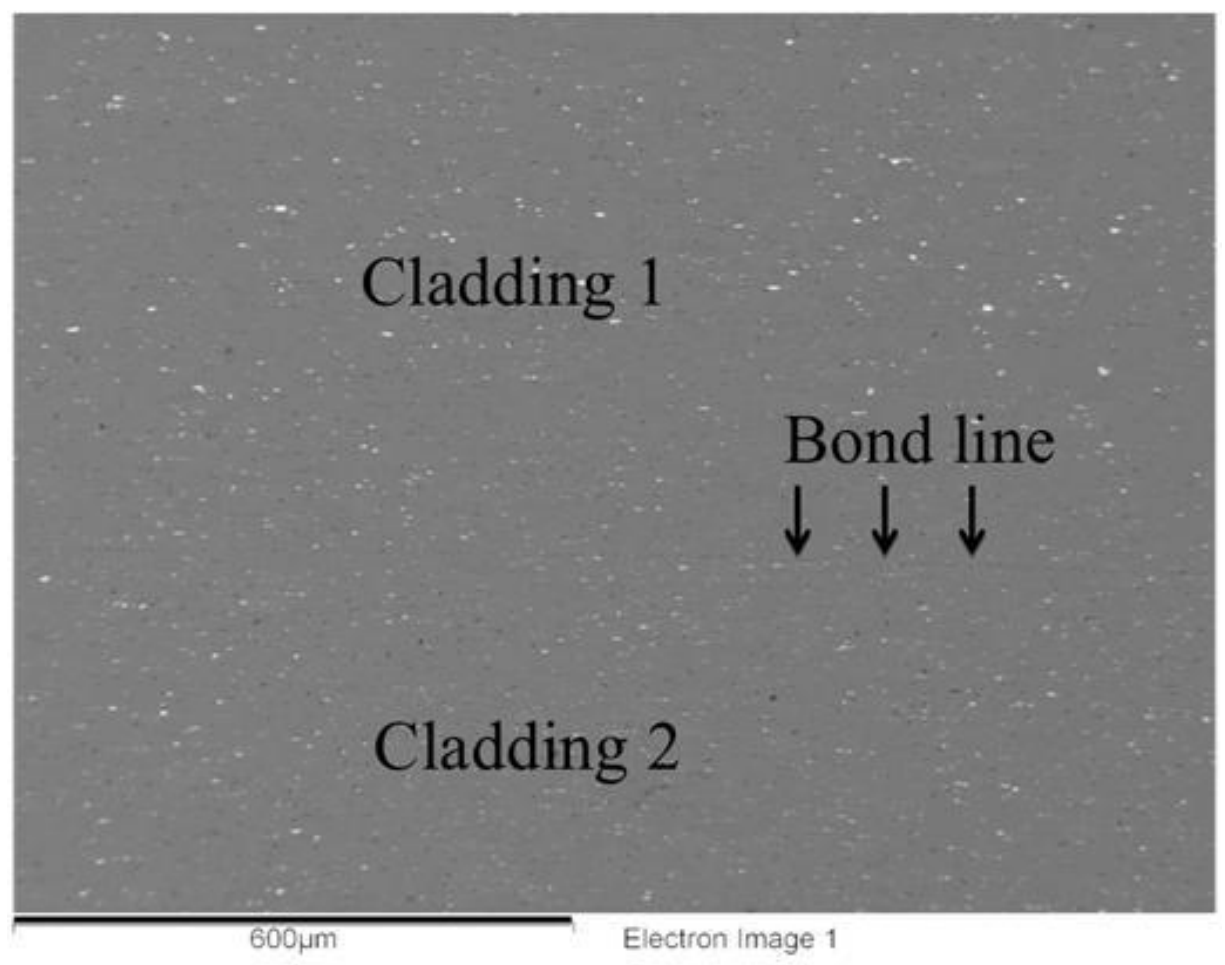

Figure 51. SEM image of the cladding-to-cladding bond line and surrounding area in unirradiated fuel plate L1P756. 


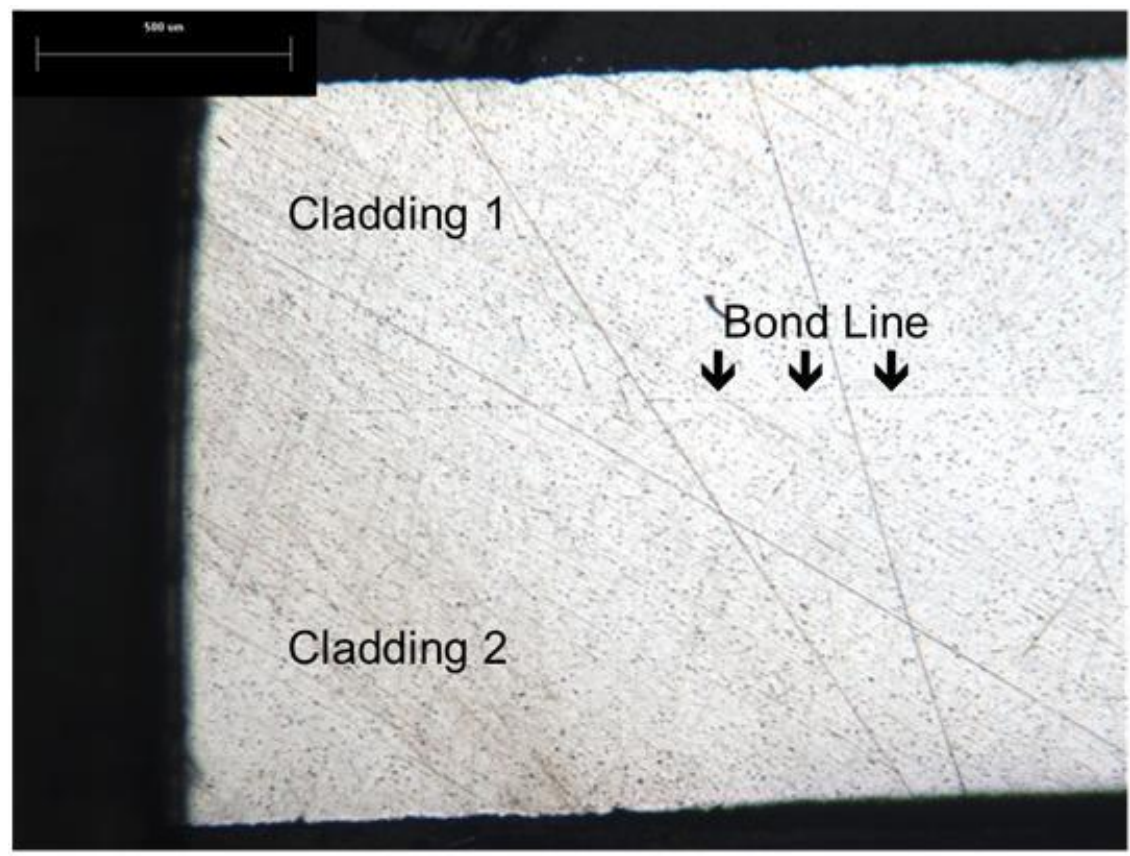

Figure 52. Optical image of the cladding-to-cladding bond line and surrounding area in irradiated fuel plate L1P759.

\subsubsection{U-10Mo Fuel Meat}

Figure 53 through Figure 64 show U-Mo fuel-meat microstructure at progressively higher fission densities. The source and processing history of the U-Mo influences the pre-irradiation microstructural characteristics of the fuel meat. These variances, in turn, may influence the rate and level of irradiationinduced recrystallization and the final grain size distribution relative to fission density. Additional microstructural information is provided in reference [6].

During the initial stages of irradiation, regions of visible fission gas bubbles corresponding with the original grain boundaries and are evident in Figure 54, Figure 55, Figure 56, Figure 58, and Figure 59. Fission-gas bubbles first nucleate, coarsen, and eventually interconnect, at the same time that irradiationinduced recrystallization is occurring in these regions. 


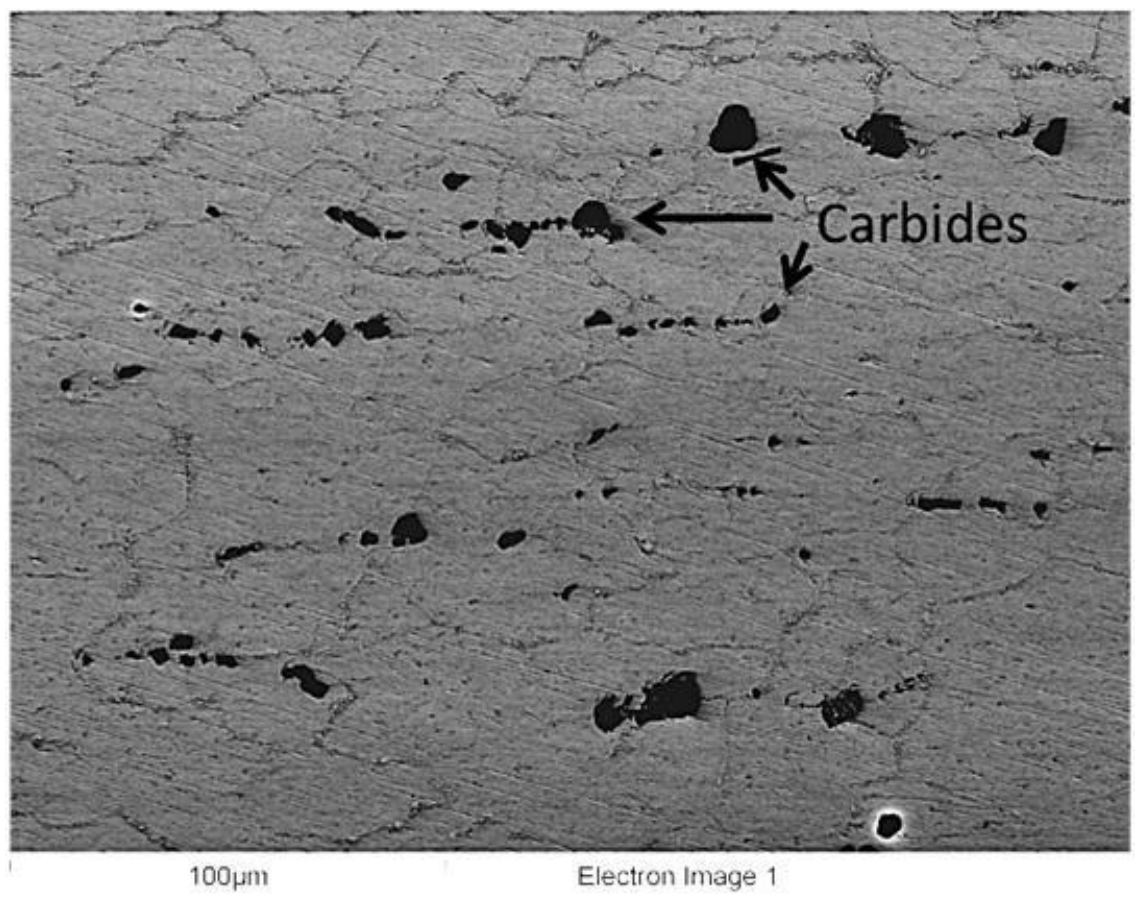

Figure 53. SEM micrograph of unirradiated archive plate L2P497 of the same feedstock material (alloy 344) that comprises L2P499 which was irradiated. It contains carbide/oxide inclusions that are characteristic of this feedstock with carbon content of $>500 \mathrm{ppm}$. It can be seen that the asymmetric grains up to 100 micrometers in length are present in the microstructure.

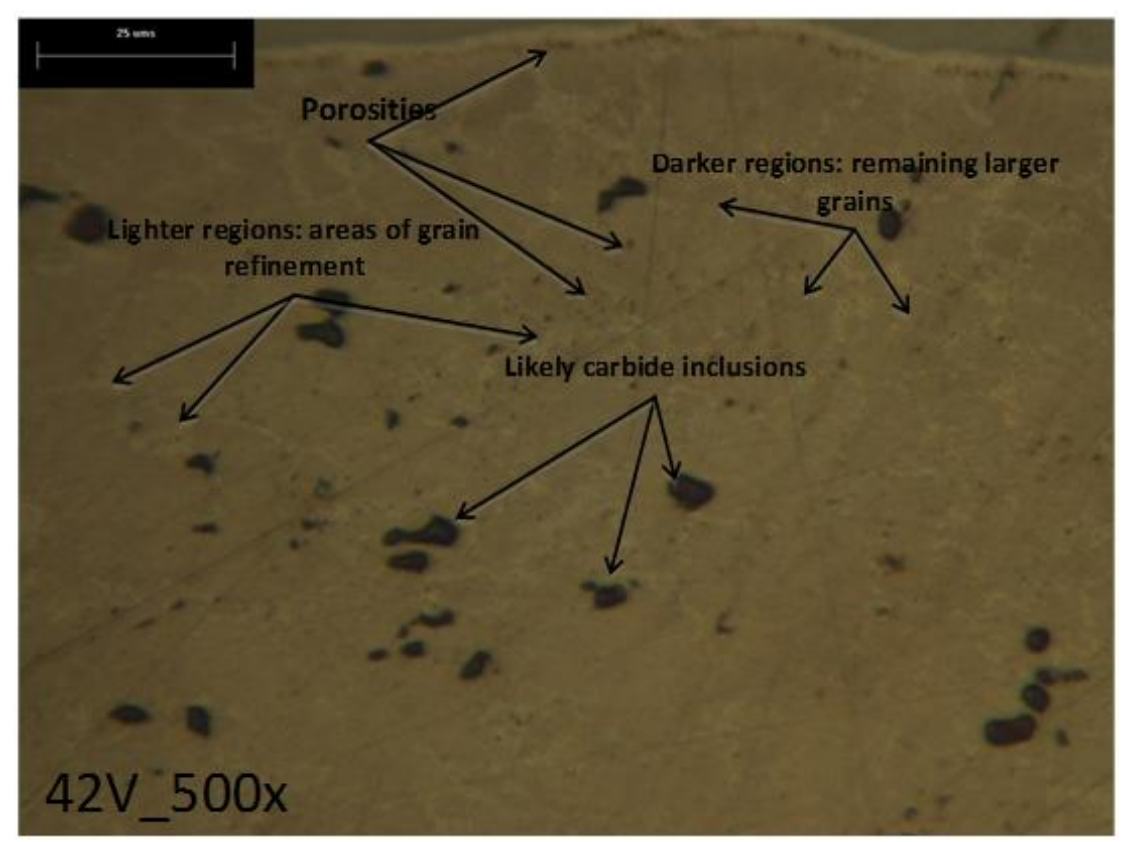

Figure 54. Optical micrograph of fuel plate L2P499 (Mount: 42V) after irradiation to a fission density of $2.5 \times 10^{21} \mathrm{f} / \mathrm{cm}^{3}$. The remaining grains are approximately half of the starting grain size for this material. Fission-gas bubbles decorate the grain boundaries. 


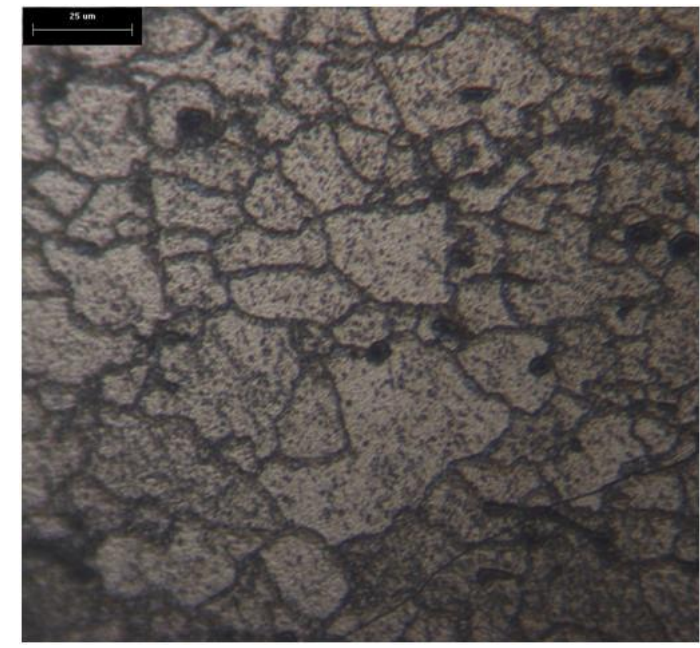

(a)

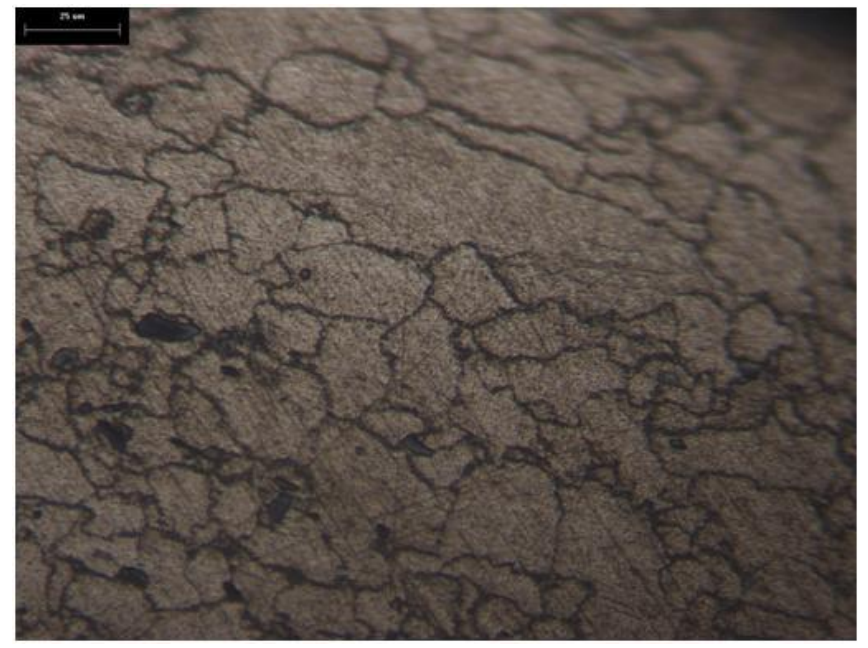

(b)

Figure 55. Shown in the two micrographs, (a) and (b) of L2P499/42V (etched). Average fission density: $2.48 \times 10^{21} \mathrm{f} / \mathrm{cm}^{3}$. Y-12 source material with the characteristic carbide/oxide inclusions. The micrographs illustrate the efficacy of a nitric solution to further resolve grain structure. In image (a), the fission-gas bubbles at the grain boundaries appear to indicate the initial growth of the boundaries between grains as a result of fission-gas-induced recrystallization.

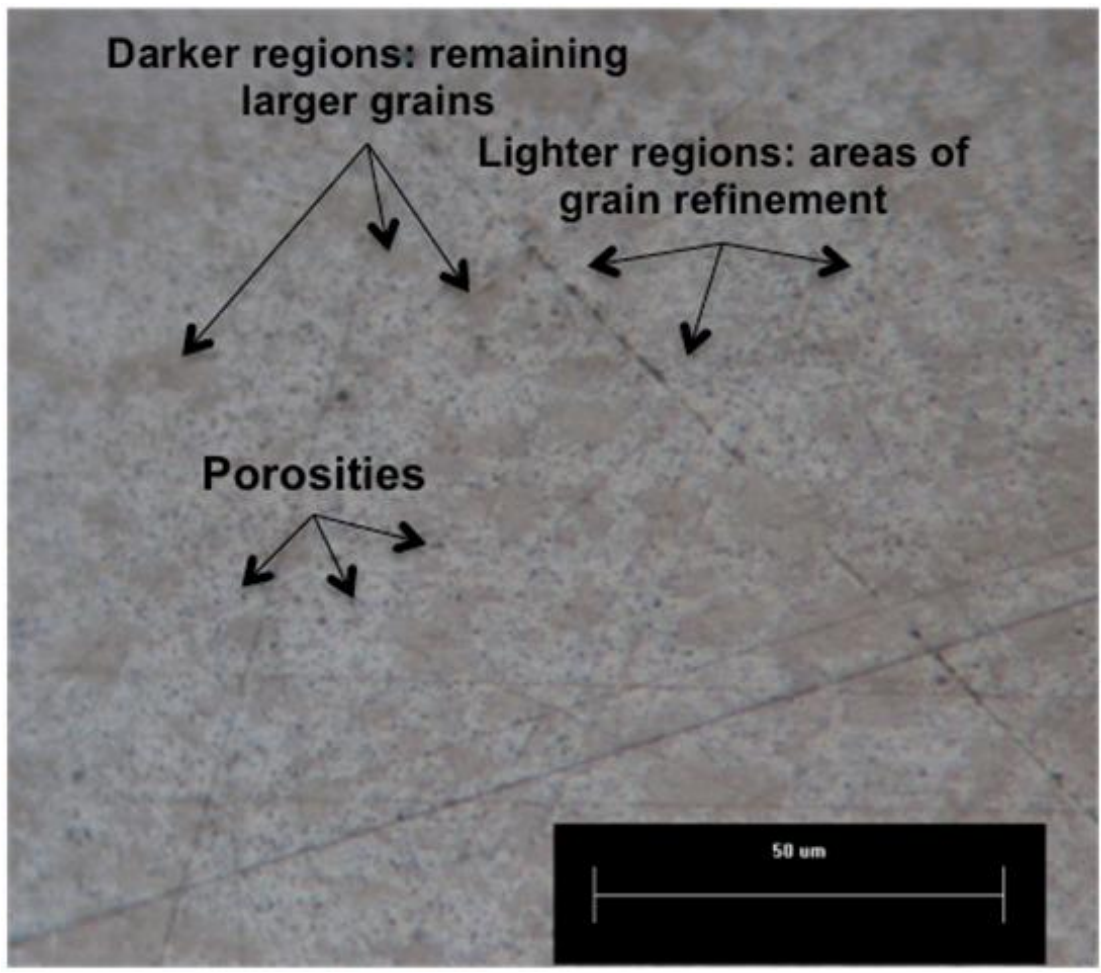

Figure 56. L1P462, mount of the middle cross-section. Average fission density: $3.34 \times 10^{21} \mathrm{f} / \mathrm{cm}^{3}$. The fraction recrystallized for the given fission density is similar to L1P020 shown in Figure 59. 


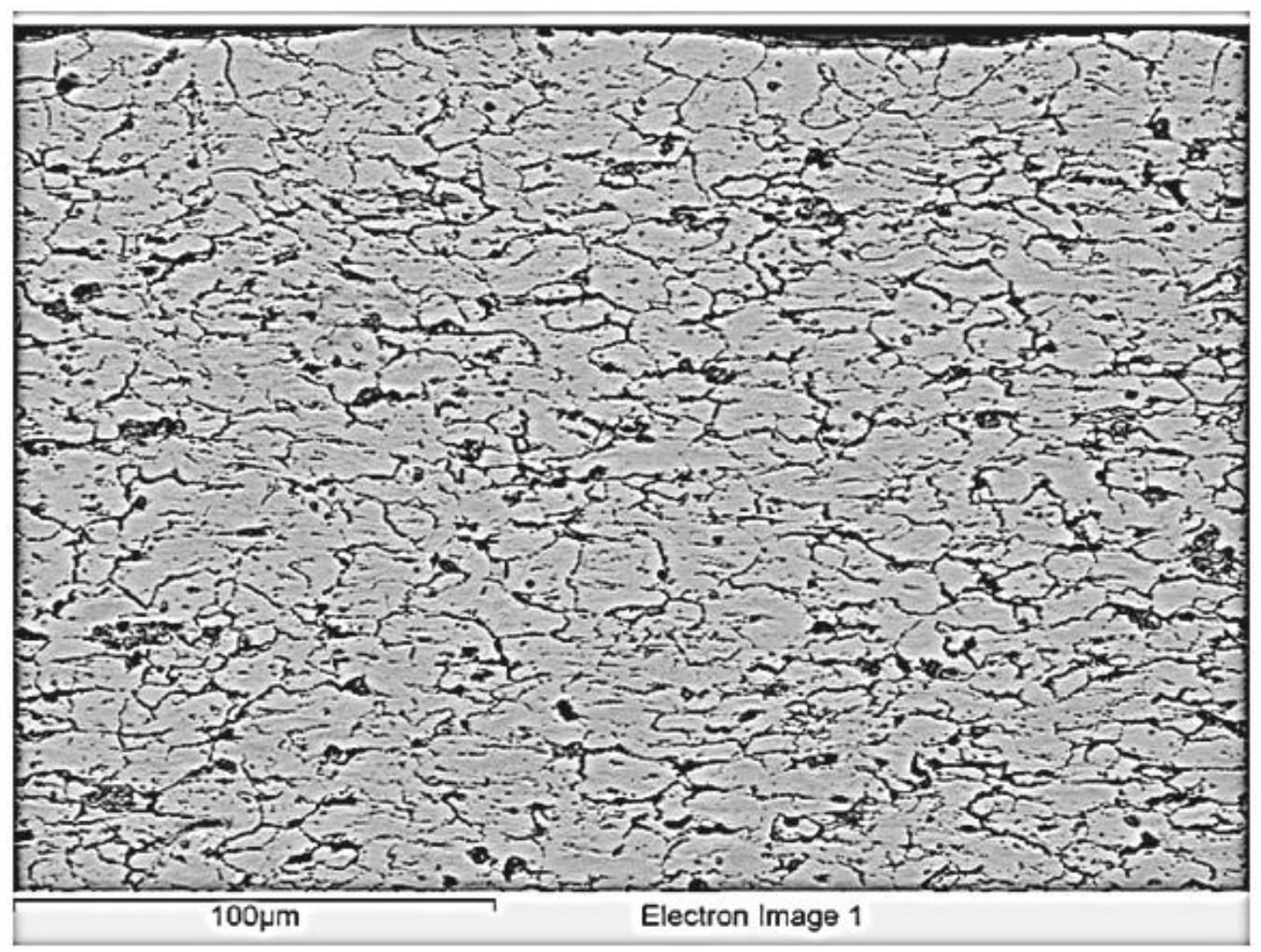

Figure 57. SEM micrograph of unirradiated plate L1P775, which is the same alloy material (alloy 328) and the starting microstructure as the irradiated plate L1P776 shown in Figure 58.

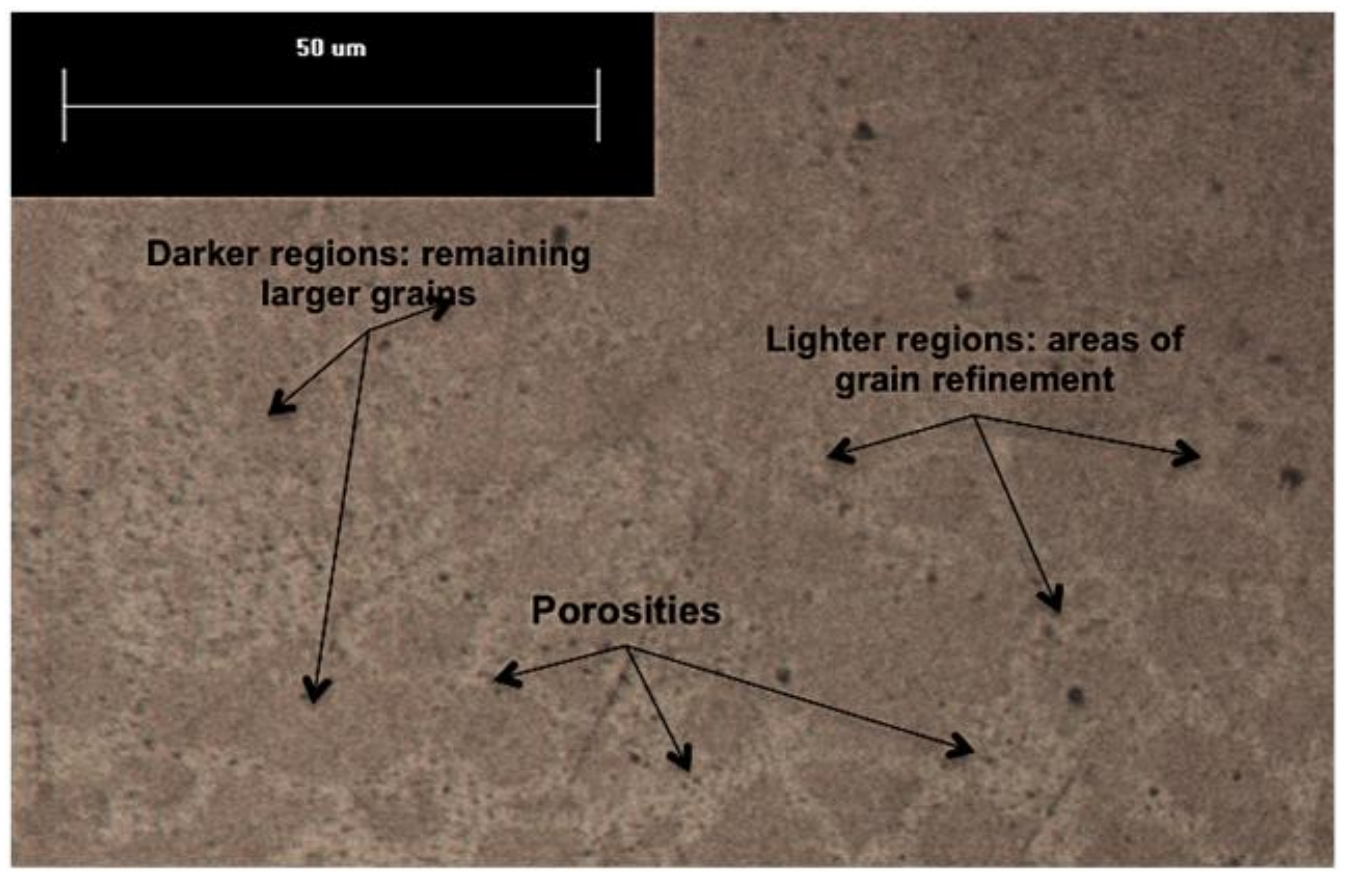

Figure 58. L1P776, mount of the mid-plane section. Fission density: $3.9 \times 10^{21} \mathrm{f} / \mathrm{cm}^{3}$. The fraction recrystallized is obviously increasing and fission-gas bubbles are more apparent. 


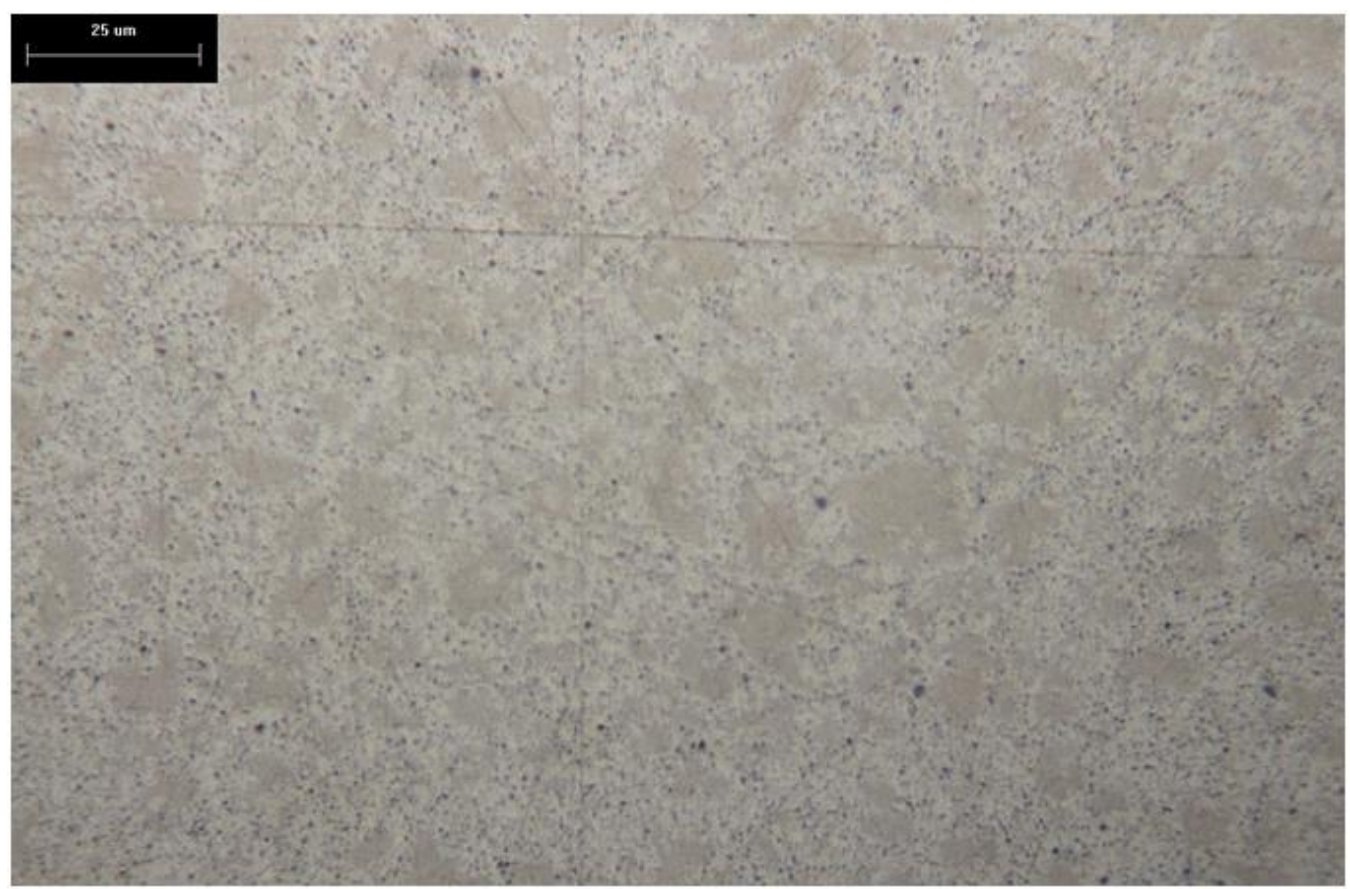

Figure 59. RERTR-8 Plate L1P020, mount 39W. Average fission density: $6.0 \times 10^{21} \mathrm{f} / \mathrm{cm}^{3}$. Remaining grain structure can still be resolved optically.

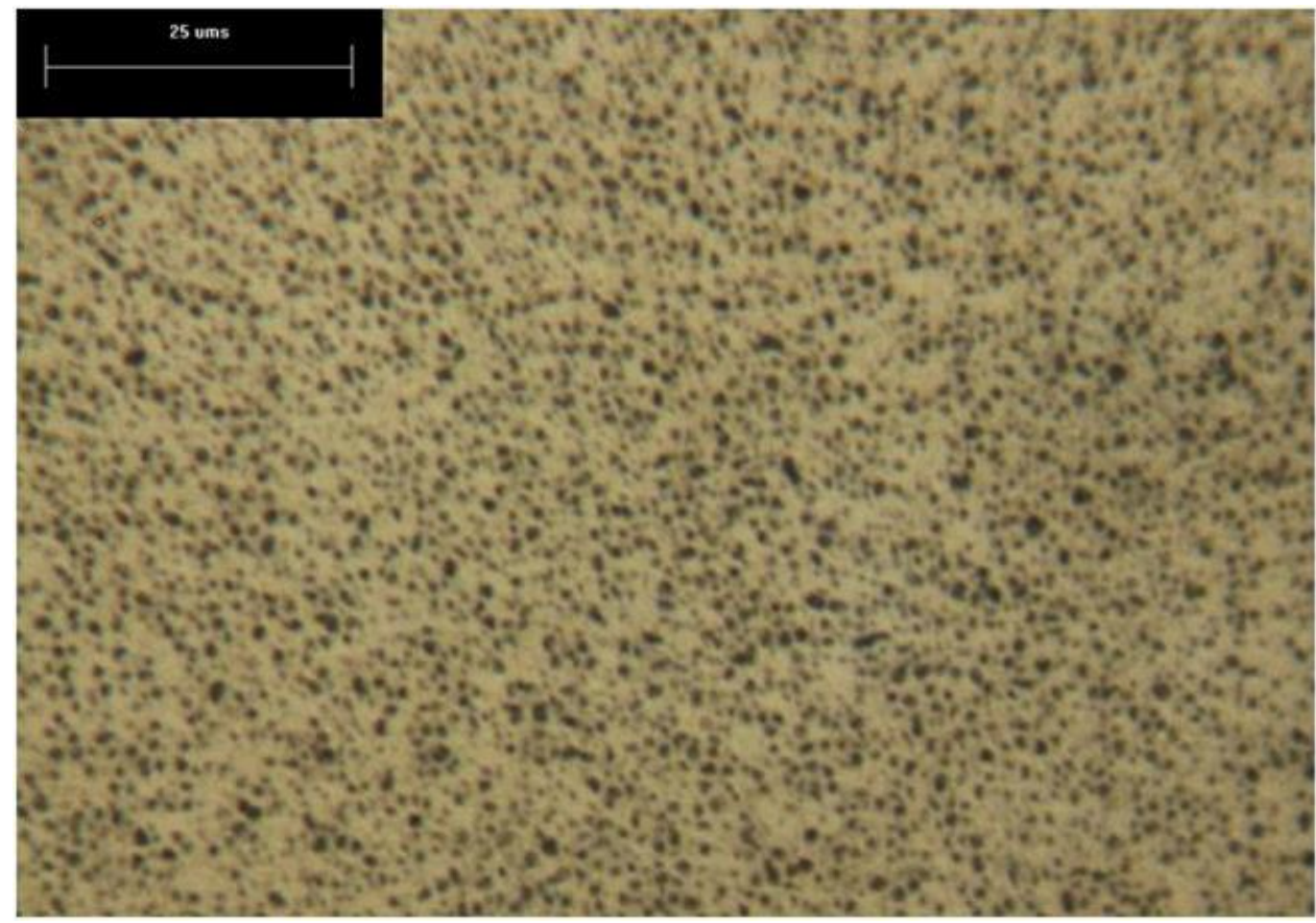

Figure 60. L1P784, mount 44V. Average fission density: $6.3 \times 10^{21} \mathrm{f} / \mathrm{cm}^{3}$. Optically resolvable grains have been almost completely transformed. Fission-gas bubbles are coarsening, and incipient interconnection of bubbles is evident. 


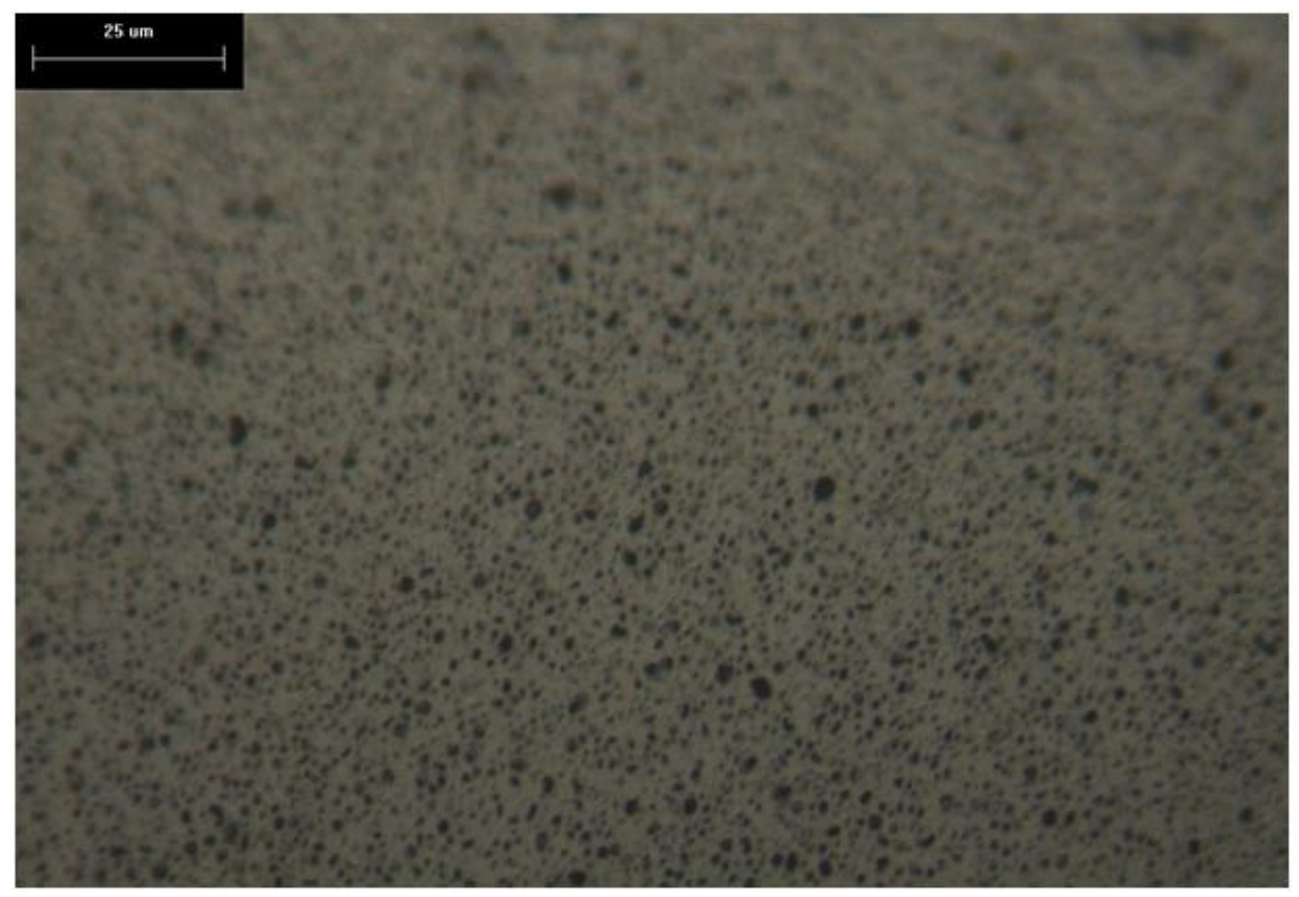

Figure 61. L1P7A0, mount 28W. Average fission density: $7.7 \times 10^{21} \mathrm{f} / \mathrm{cm}^{3}$. Optically resolvable grains have been consumed by recrystallization. Fission-gas bubbles are coarsening, and interconnection of bubbles is evident.

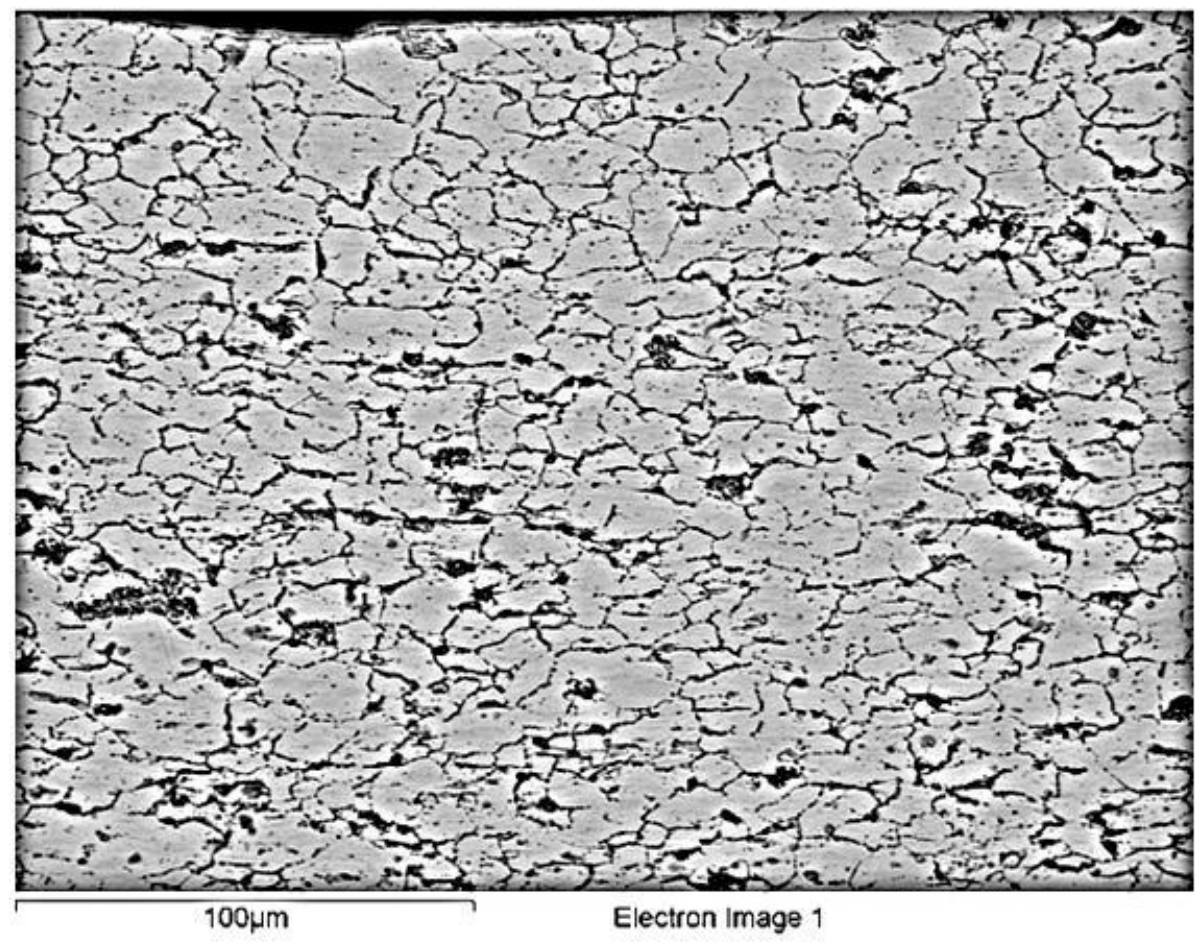

Figure 62. SEM micrograph of plate L1P757, which is the same alloy material (alloy 331) and the starting microstructure for the irradiated plate L1P759, shown in Figure 63. 


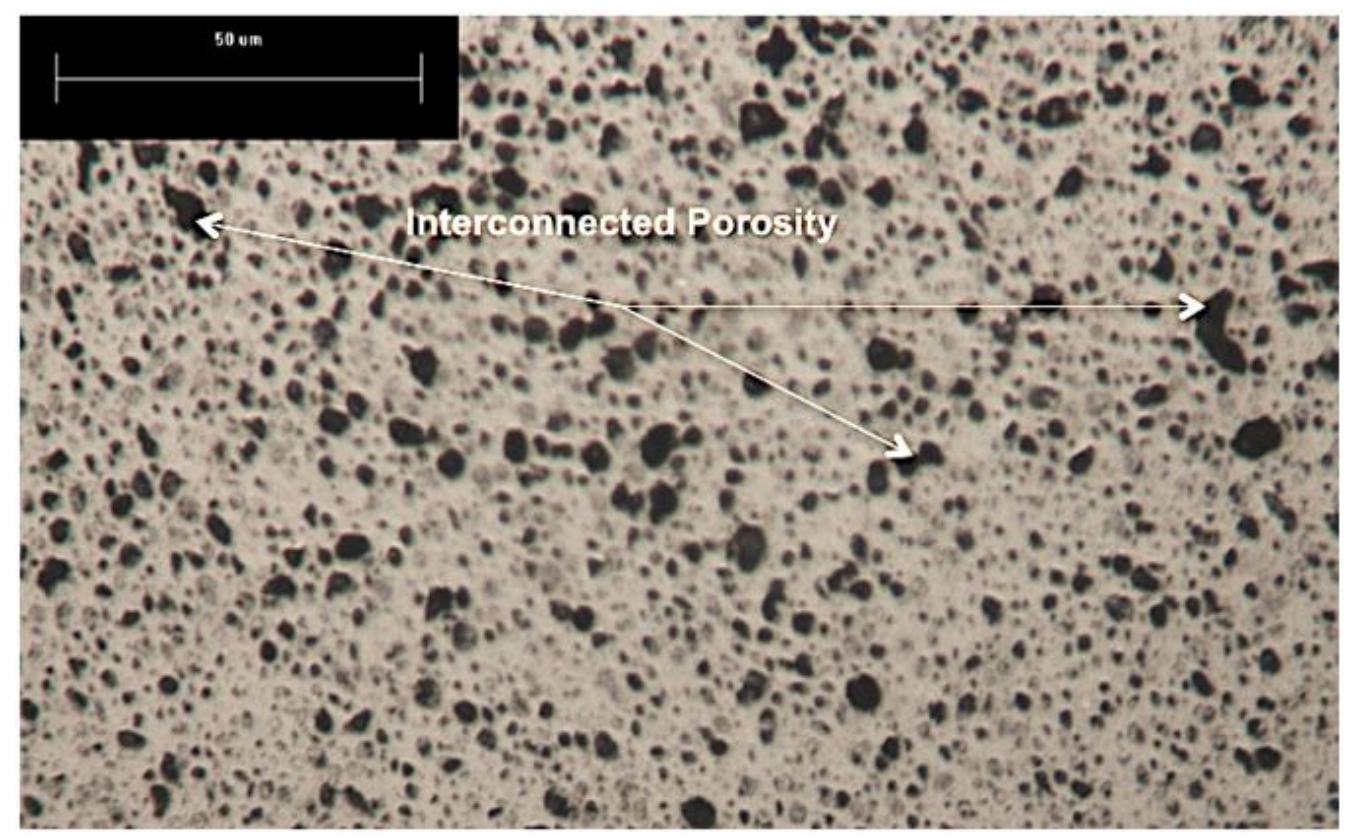

Figure 63. Plate L1P759, mount 26W. Average fission density: $8.7 \times 10^{21} \mathrm{f} / \mathrm{cm}^{3}$. This plate blistered inreactor. Interconnection of bubbles is evident in this micrograph of the middle of the fuel meat.

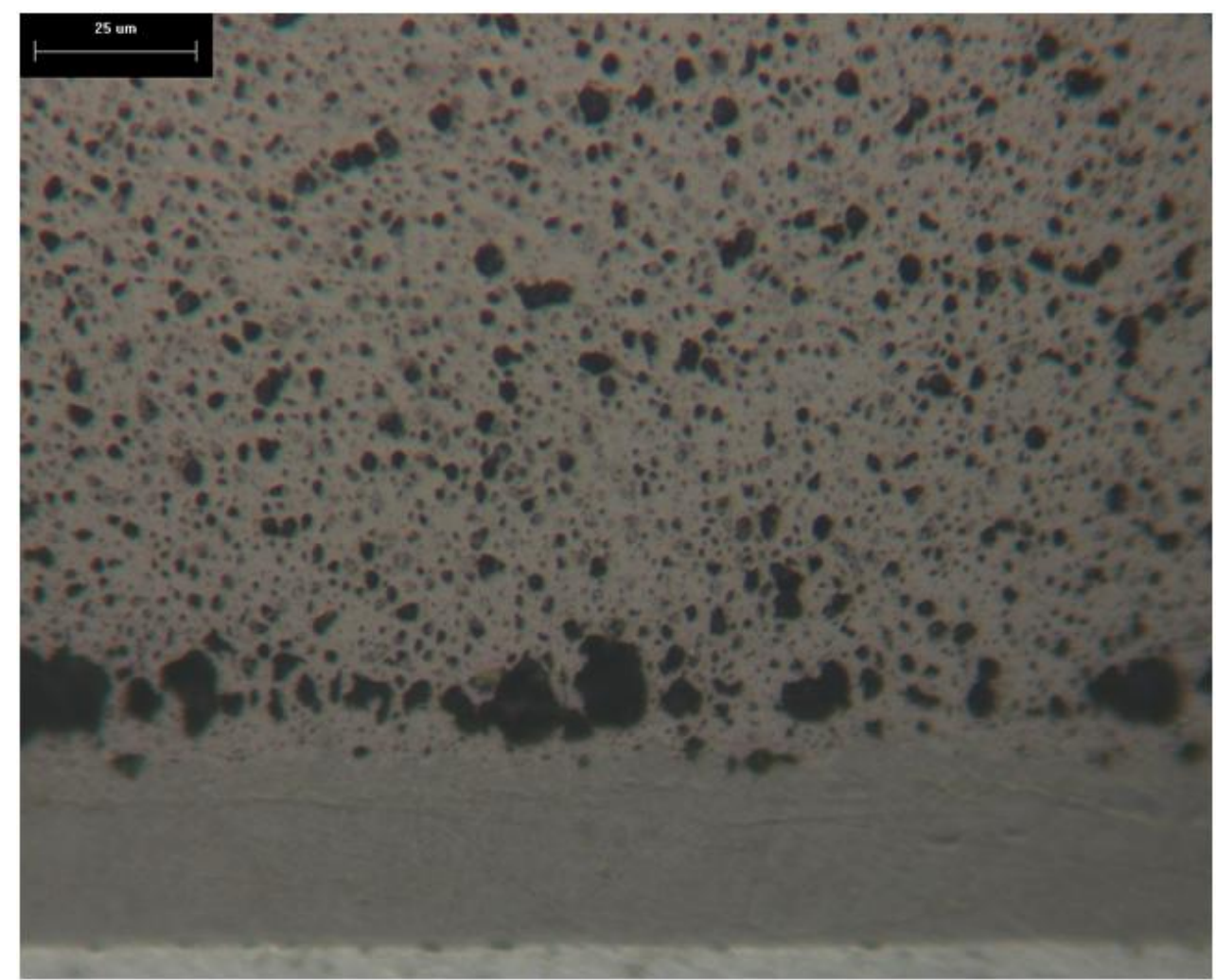

Figure 64. Plate L1P759, mount 25W. Average fission density: $8.7 \times 10^{21} \mathrm{f} / \mathrm{cm}^{3}$. The micrograph shows the $\mathrm{U}-\mathrm{Mo} / \mathrm{Zr}$ interaction zone. This bubble interconnection (perhaps exaggerated by specimen preparation pullout from polishing) effect is far more pronounced in the Mo-depleted region just into the fuel from the Zr interlayer. 


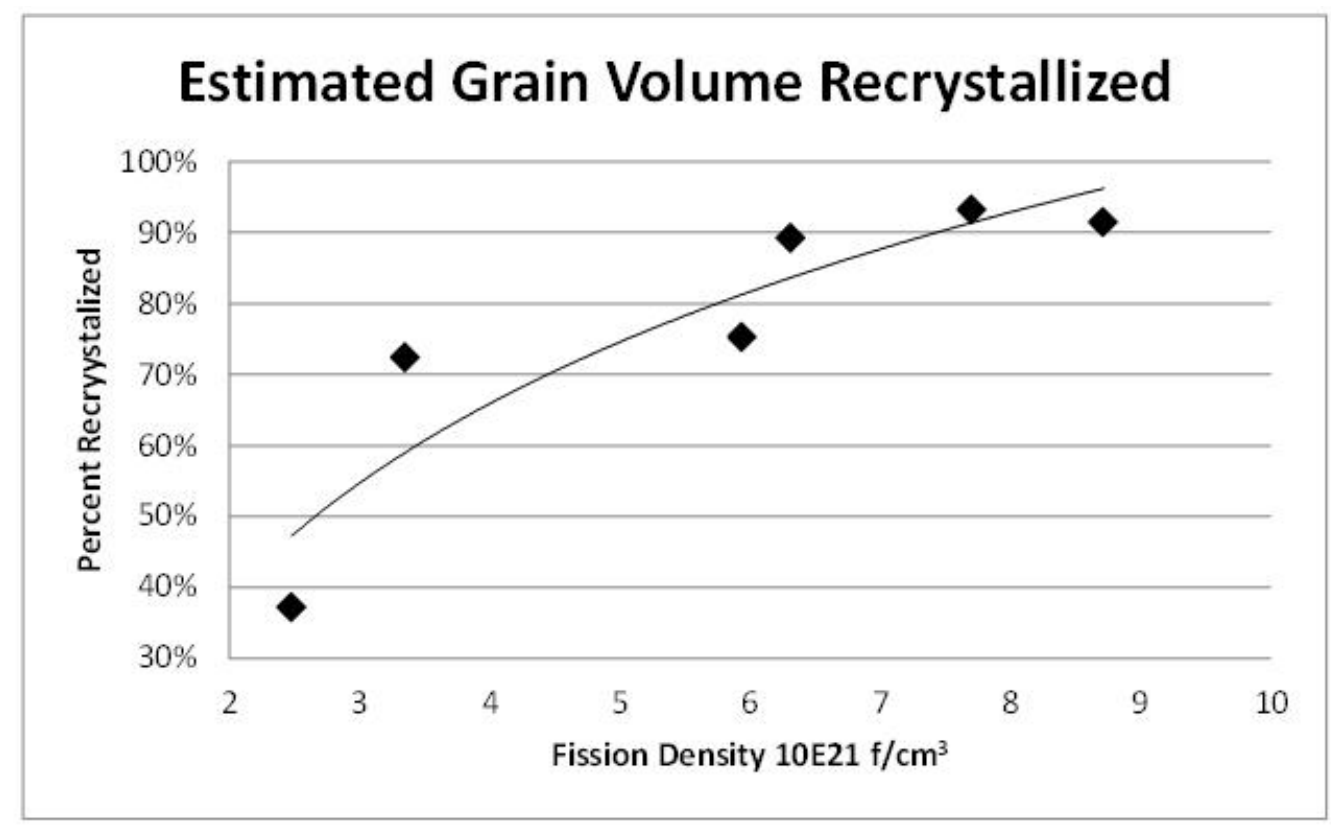

Figure 65. Estimated grain volume fraction recrystallized as a function of fission density. These data were generated using point counting (this method is explained in Section 4.2.2.5) and are considered preliminary pending studies of specimens following etching treatments (recommended to better resolve grains) and a larger sampling of microstructural data.

Table 14. Percentage of sample with recrystallized grains.

\begin{tabular}{|c|c|c|}
\hline Plate ID & $\begin{array}{c}\text { Fission Density } \\
10 \mathrm{E} 21 \mathrm{f} / \mathrm{cm}^{3}\end{array}$ & $\begin{array}{c}\text { Volume Percent } \\
\text { Recrystallized }\end{array}$ \\
\hline L1P020 & 5.95 & $75 \%$ \\
\hline L2P499 & 2.48 & $37 \%$ \\
\hline L1P462 & 3.34 & $72 \%$ \\
\hline L1P784 & 6.31 & $89 \%$ \\
\hline L1P7A0 & 7.71 & $93 \%$ \\
\hline L1P759 & 8.72 & $91 \%$ \\
\hline
\end{tabular}

Comparison of the unirradiated U-Mo fuel plate microstructure in Figure 53 with the irradiated fuel plate microstructure in Figure 54 illustrates the evolution of the microstructure at low burnup for fuel plates with a larger than usual volume fraction of carbide and oxycarbide phases. Plate L2P499fabricated from Y-12 U-Mo feedstock with high carbon content relative to feedstock sourced from INL inventories - shows the carbide/oxide inclusions characteristic of this feedstock. It can also be seen that U-Mo grains are asymmetric, with a maximum grain size on the order of $100 \mu \mathrm{m}$. After irradiation to an average fission density of $2.5 \times 10^{21} \mathrm{f} / \mathrm{cm}^{3}$, (Figure 55 and Figure 56), fission-gas bubbles have nucleated on the grain boundaries and cover approximately $4 \%$ of the surface of the cross-section. Carbide/oxide inclusions persist, as can be seen in Figure 54 and Figure 55. Preliminary conclusions relative to the optical examination of this material indicate that these inclusions do not necessarily serve as preferred nucleation sites for fission-gas bubbles at this fission density. Data from higher fission density specimens could serve to either confirm or refute this observation. The etched microstructures in Figure 55 show that elongated grains of up to $100 \mu \mathrm{m}$ in length still persist, indicating that little grain refinement has occurred at this fission density. It is not yet clearly evident if certain microstructural features or combinations of 
microstructural features impute added or diminished resistance to recrystallization and/or fission-gas-bubble coarsening and coalescence with increasing fission density. Additional data are required before a recrystallization and coarsening-rate characteristic can be attributed to a particular starting microstructure.

Fuel plate L1P462 (Figure 57) was irradiated to an average fission density of $3.3 \times 10^{21} \mathrm{f} / \mathrm{cm}^{3}$. At this fission density, visible fission-gas bubbles cover approximately $10 \%$ of the surface of the cross-section. The largest apparent grain is approximately $20 \mu \mathrm{m}$. It is uncertain whether the few very dark spots are carbide/oxide inclusions, artifacts of specimen preparation or coarse gas bubbles.

Figure 59 is an image of fuel plate L1P020 with an average fission density of $5.9 \times 10^{21} \mathrm{f} / \mathrm{cm}^{3}$, that was irradiated edge-on in the RERTR-8 experiment campaign (as opposed to face-on for RERTR-12). This plate is included for the purpose of illustrating the U-10Mo the microstructure at an intermediate fission density. The micrograph was collected away from the peak fission density and bulge region of the cross-section (caused by fuel creep) to avoid a bias in the image. It is interesting to note that the microstructural transformation occurs rapidly at this fission density, and appears to be basically complete at approximately $6.3 \times 10^{21} \mathrm{f} / \mathrm{cm}^{3}$ as indicated by the micrograph of L1P784 in Figure 60 .

Evident in Figure 60, Figure 61, Figure 63 and Figure 64 is the nearly complete recrystallization of optically visible grains at higher fission density. A preliminary trend of grain recrystallization as a function of fission density is illustrated in

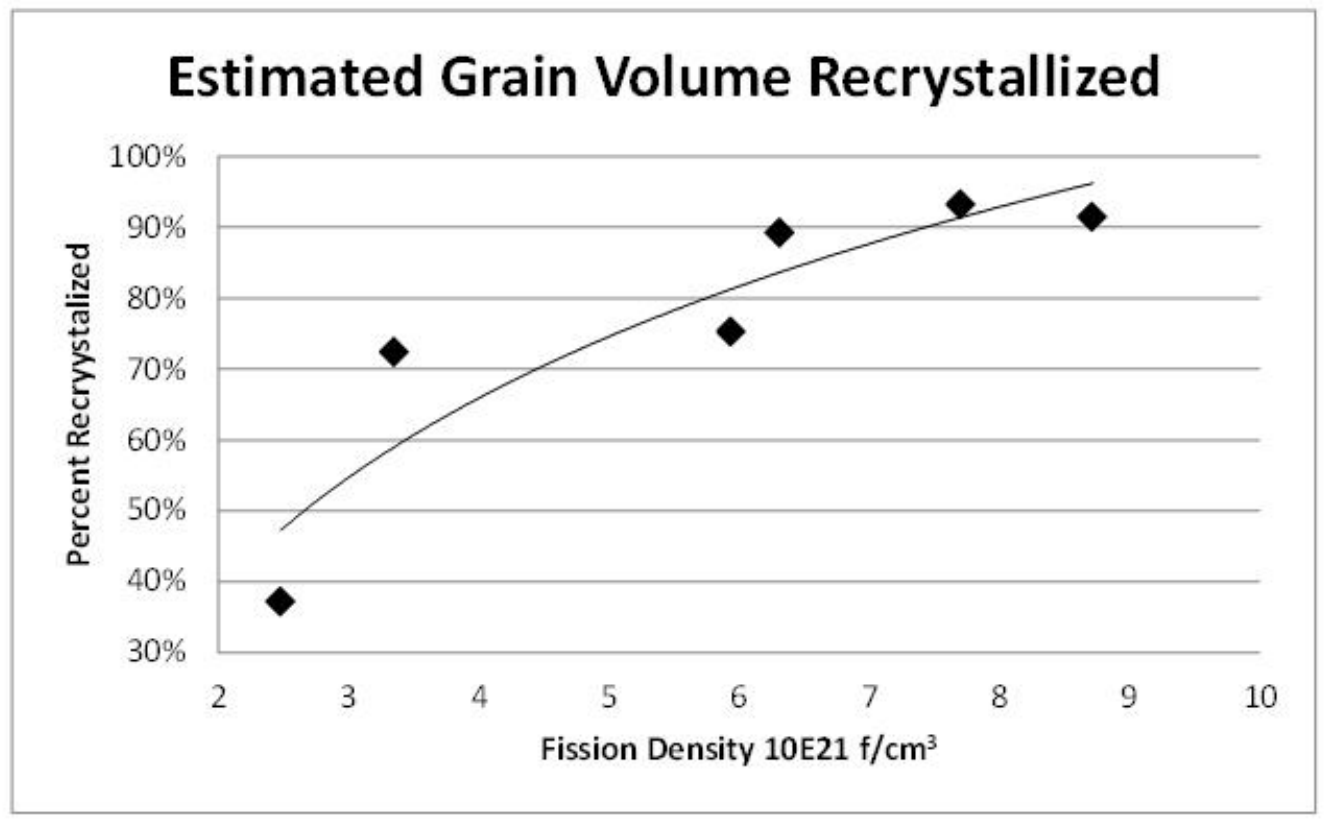

Figure 65 (data are tabulated in Table 14).

\subsubsection{Zr Diffusion Barrier}

\section{Cladding-to-Zirconium Diffusion Barrier Interface}

The zirconium-to-cladding interface exhibited no discernable changes from the unirradiated archive specimen characteristics. No growth in the interaction layer thickness at this interface was observed nor were any areas of debonding noted. Figure 66 and Figure 67 show an unirradiated and an irradiated specimen respectively. The SEM image shows an obvious interaction layer just a few $\mu \mathrm{m}$ thick with slight variability in thickness, while the optical image of the irradiated specimen presents a similar appearance and thickness implying stability during irradiation. 


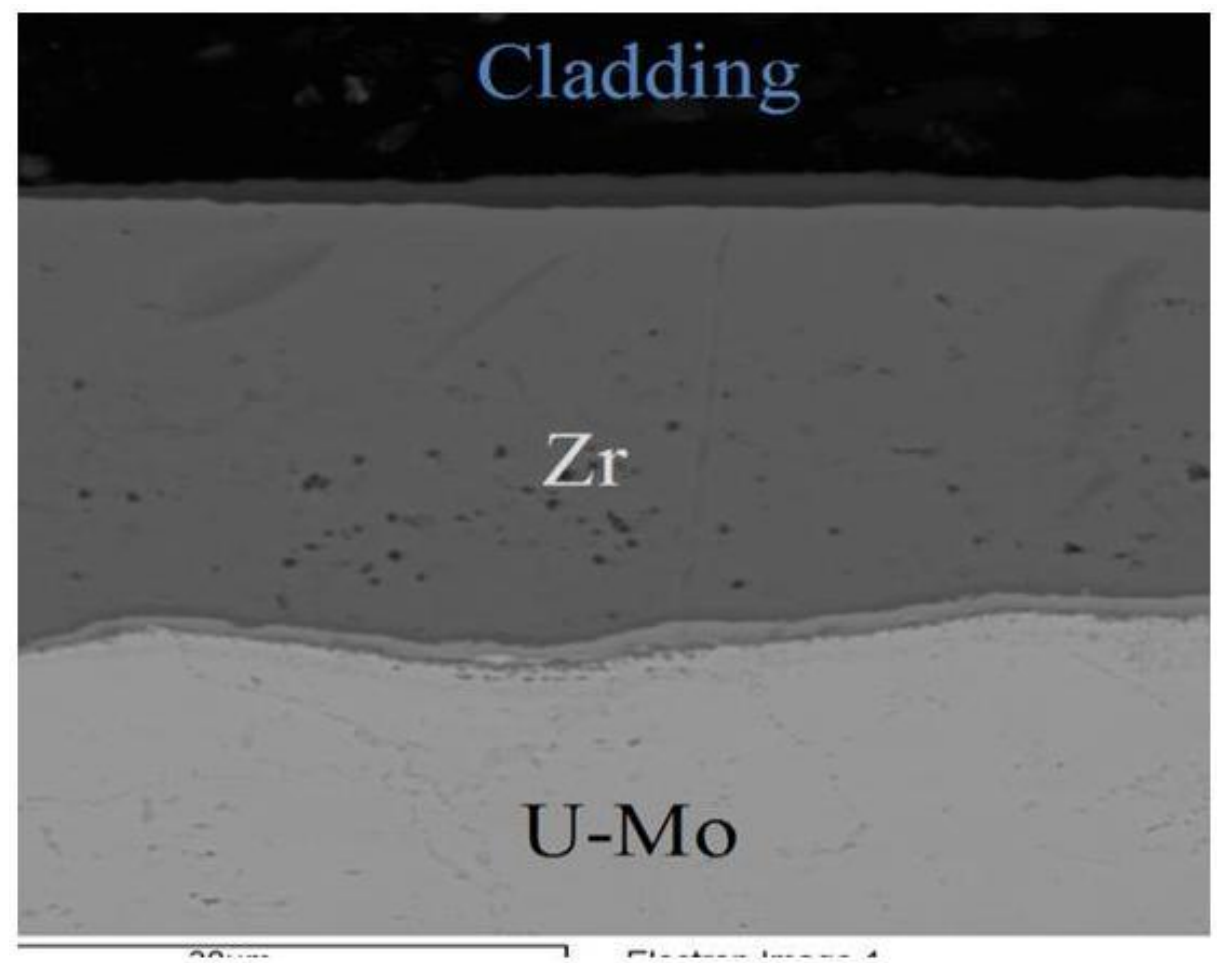

Figure 66. An SEM image of the cladding/zirconium/U-10Mo interfaces. A well-defined interaction layer can be observed at the cladding-to-zirconium interface.

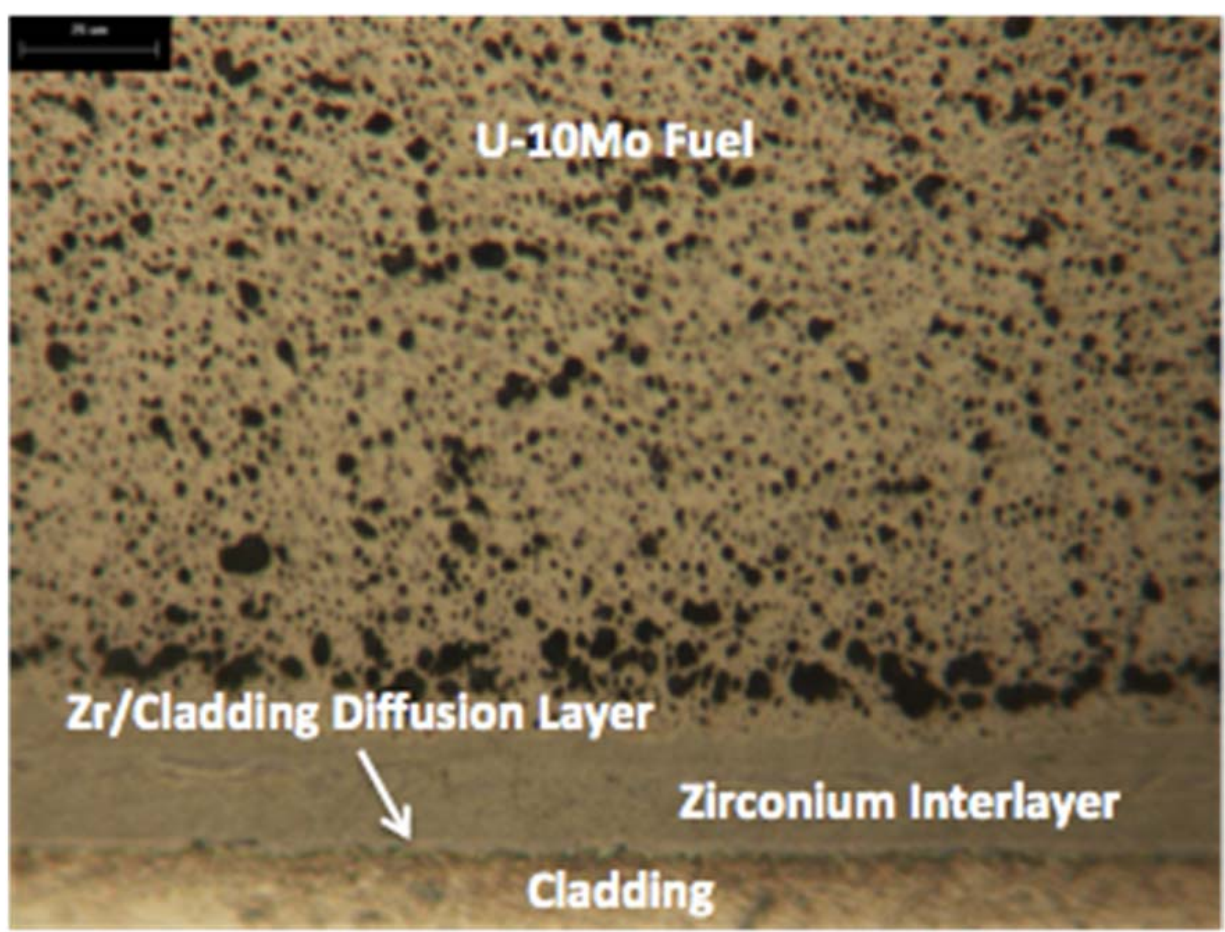

Figure 67. An optical image of plate L1P759, mount: 26W at 500× magnification. Average fission density: $8.7 \times 10^{21} \mathrm{f} / \mathrm{cm}^{3}$. The indicated diffusion layer is typical of the post-irradiation condition. ${ }^{3}$ 


\section{Zirconium Diffusion Barrier-to-Fuel Interface}

A preliminary trend was established by calculating the average of 4 measurements taken of the optically visible layers in the micrographs, and this trend is shown in Figure 68. The Zr diffusion barrier itself is typically $25-30 \mu \mathrm{m}$ thick. The zirconium diffusion barrier $\mathrm{U}-\mathrm{Zr}_{2}$ interaction layer (IL) located at the fuel meat interface has an average starting thickness of $\sim 0.0-1.2 \mu \mathrm{m}$. A schematic of the fuel plate microstructure near the interface region is shown in Figure 69, and a typical interface prior to irradiation is shown in Figure 70. Post-irradiation observations are consistent with the fresh-fuel characterization in that there are regions with negligible IL, and occasional small gaps between the $\mathrm{Zr}$ and fuel meat (these could be specimen-preparation artifacts). An example of this is shown in Figure 71, the archived "sister" specimen of irradiated plate L1P776, which is shown in Figure 72. The regions without a visible interaction layer do not stand out as failure initiation sites or as regions with non-typical material changes. A general trend is observed relative to fission density with the highest fission density specimens having the thickest interaction layer, which in some cases appeared to comprise approximately $50 \% \mathrm{of}$ the $\mathrm{Zr}$ layer. Image processing software (Adobe Photoshop) was utilized to take relative (i.e., qualitative) measurements based on the micron-scale marker in the micrographs, recognizing that results are highly dependent upon pixel resolution and the ability to resolve features assumed to be indicative of the interaction layer. The micrographs sampled are found in Figure 73-Figure 77. Estimated thickness values are provided in Table 15.

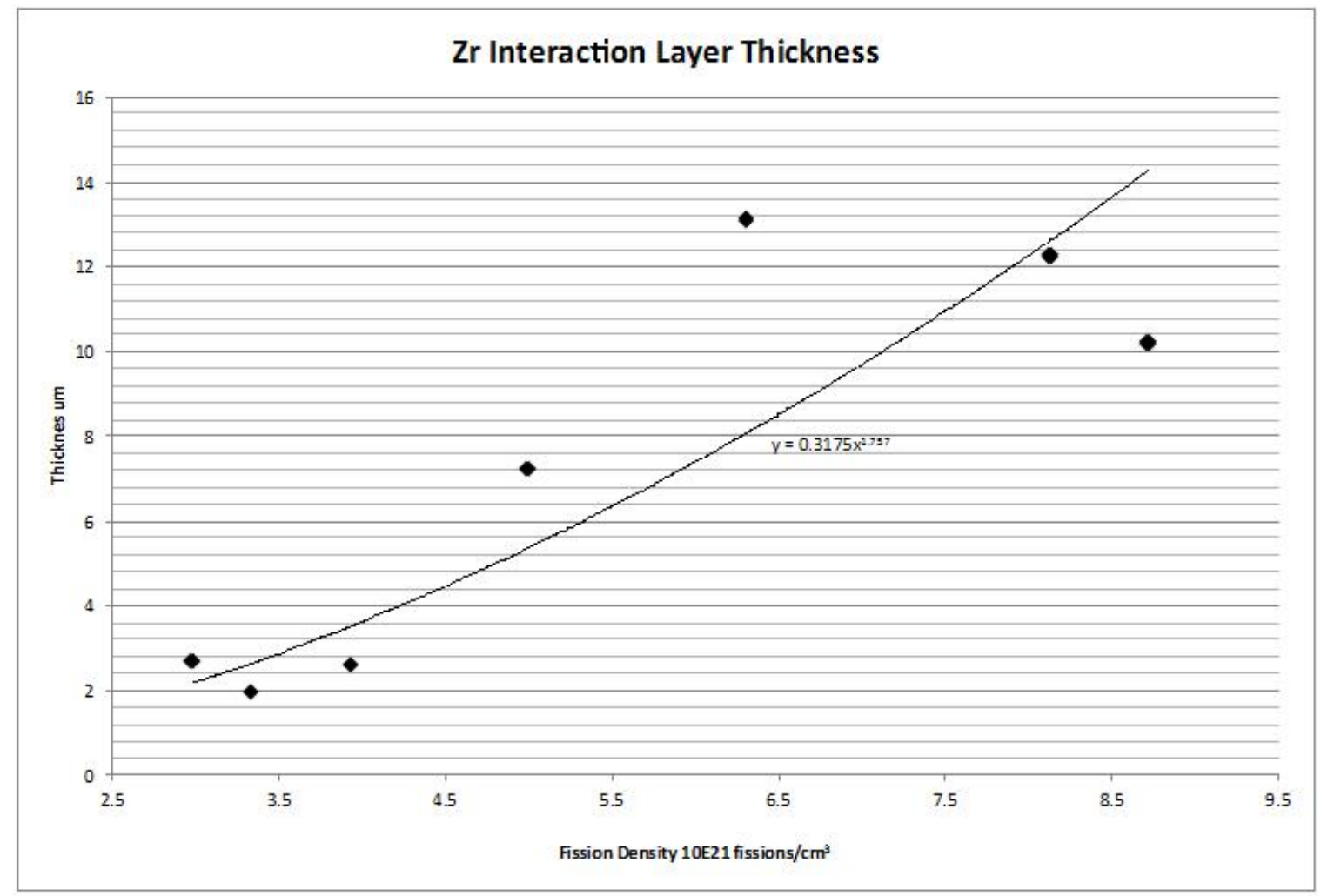

Figure 68. Preliminary trend approximation based of interaction layer growth as a function of fission density for plates shown in Figure 73-Figure 77. 


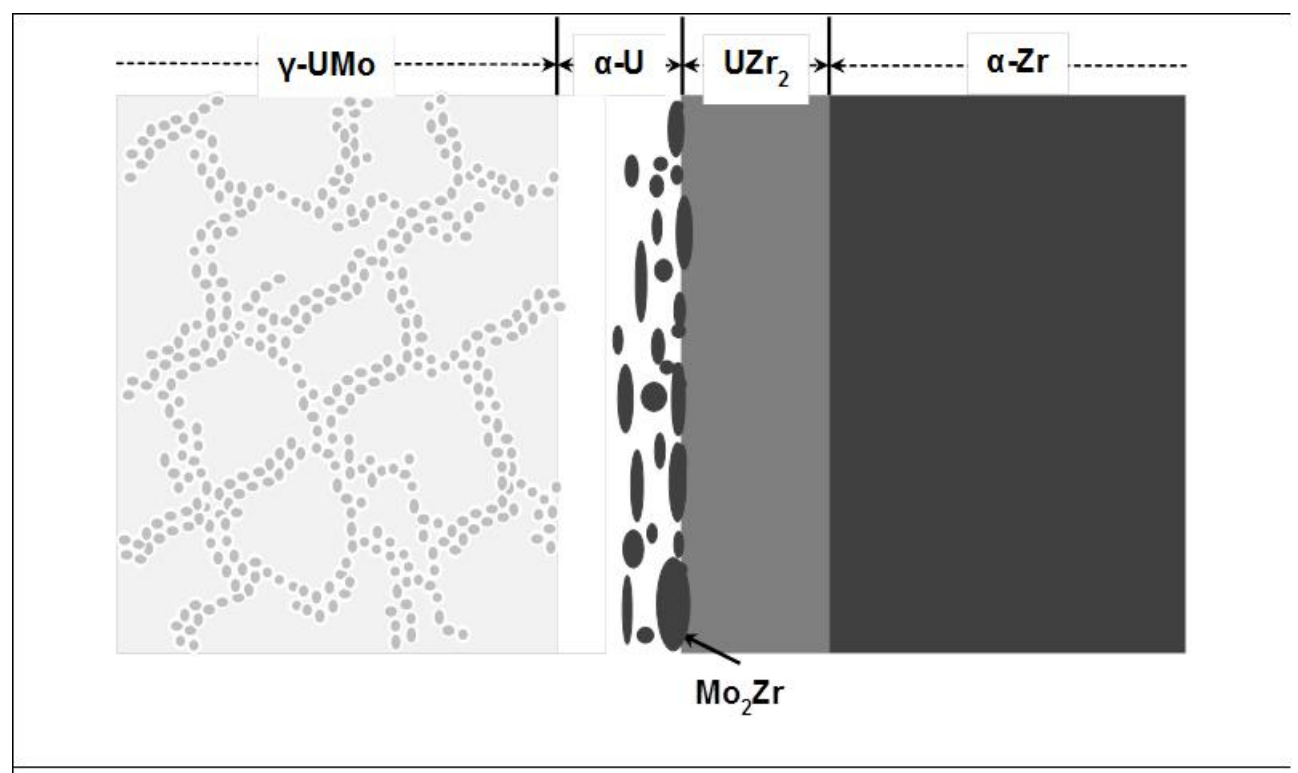

Figure 69. A schematic of the microstructure of a HIPed fuel plate co-rolled at $650^{\circ} \mathrm{C}$ and $\mathrm{HIPed}$ at $560^{\circ} \mathrm{C}$ with $70^{\circ} \mathrm{C} /$ hour cooling rate.

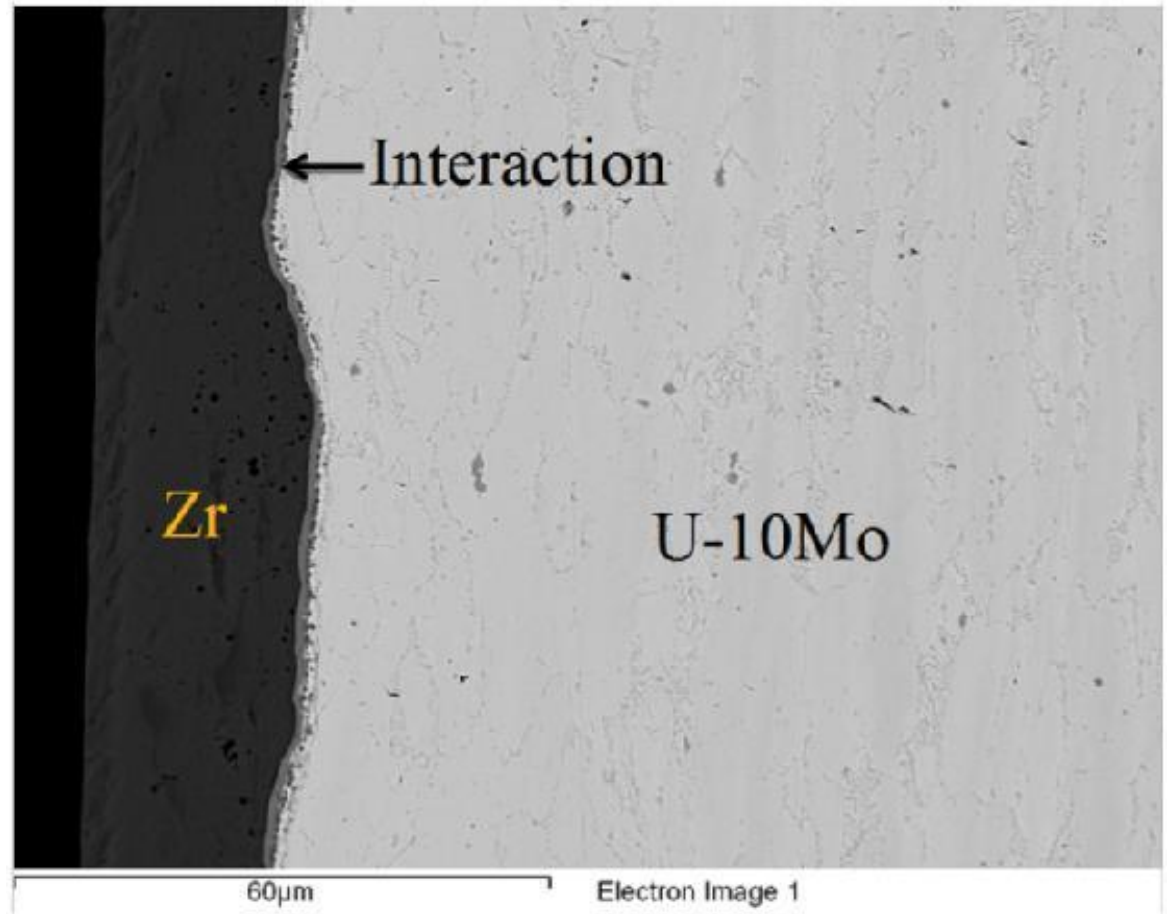

Figure 70. A low-magnification SEM micrograph showing the typical interaction layer between U-Mo and $\mathrm{Zr}$. 


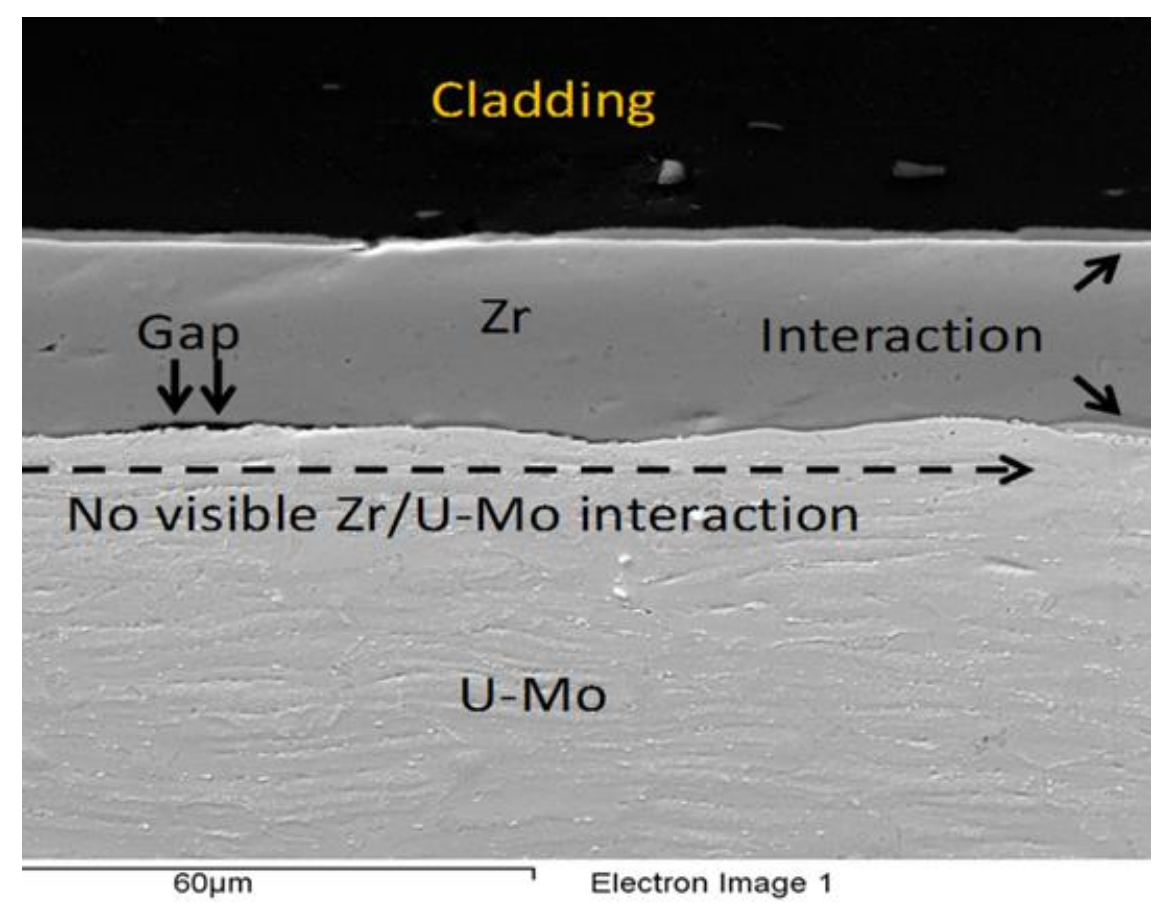

Figure 71. SEM image of met mount JJ1032 (the archived sister for the irradiated plate L1P776) shown in Figure 72, showing a large area without a visible interaction layer on $\mathrm{U}-\mathrm{Mo} / \mathrm{Zr}$ interface. A gap between $\mathrm{Zr}$ and U-Mo, about 20-30 $\mu \mathrm{m}$ long, was observed.

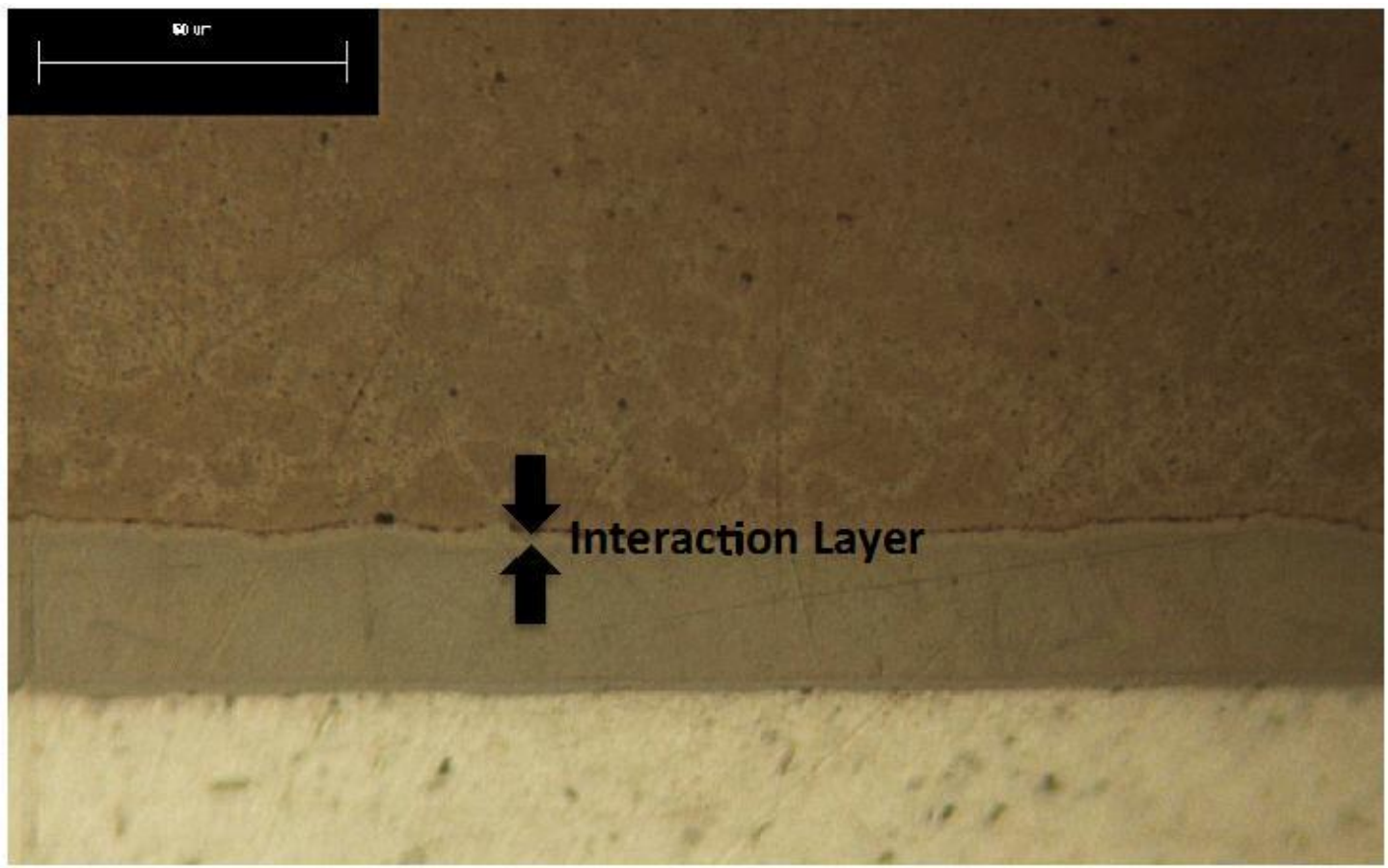

Figure 72. Plate L1P776. Average fission density $3.9 \times 10^{21} \mathrm{f} / \mathrm{cm}^{3}$. APD: $25049 \mathrm{~W} / \mathrm{cm}^{3}$. 


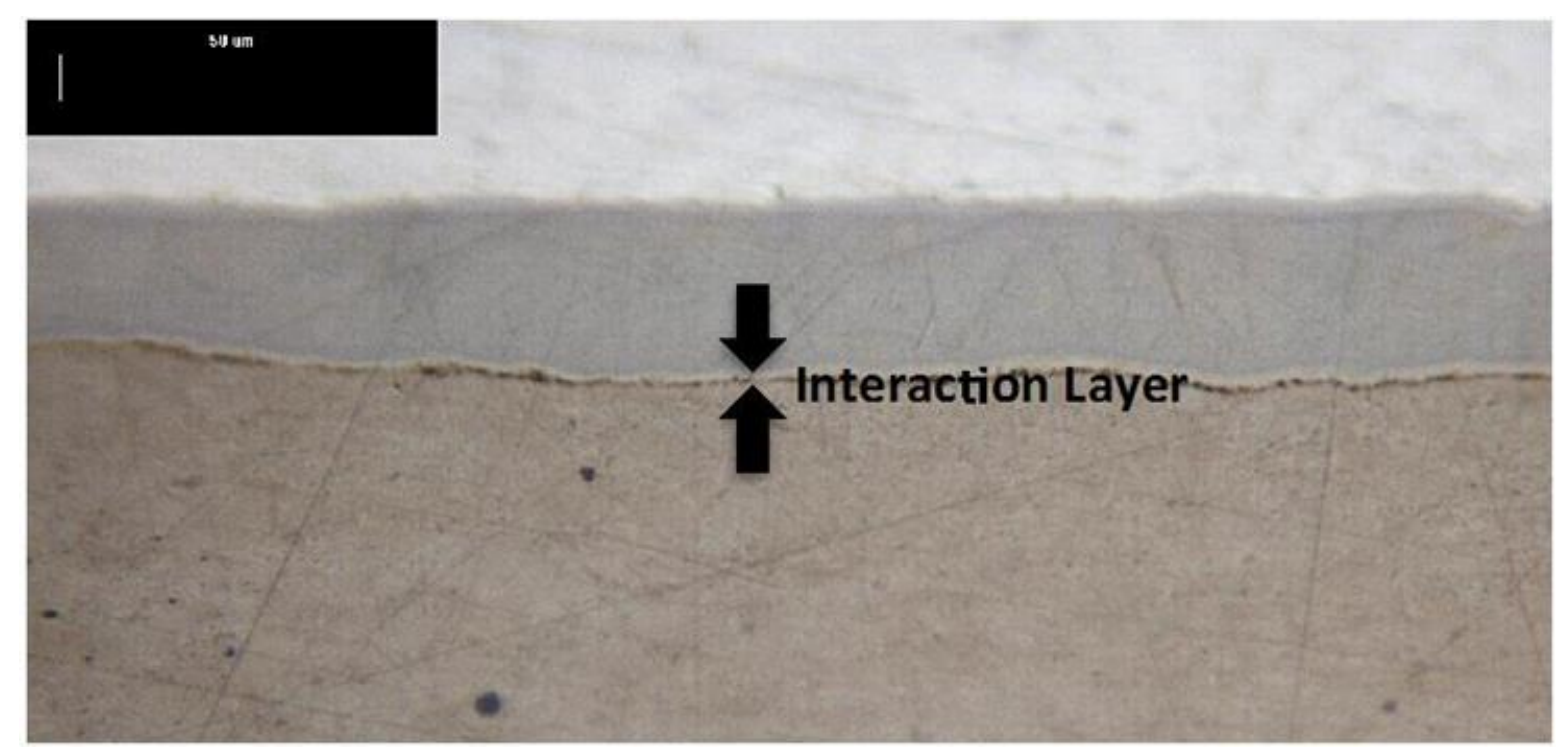

Figure 73. Plate L1P462. Average fission density: $3.3 \times 10^{21} \mathrm{f} / \mathrm{cm}^{3}$. APD: $11037 \mathrm{~W} / \mathrm{cm}^{3}$.

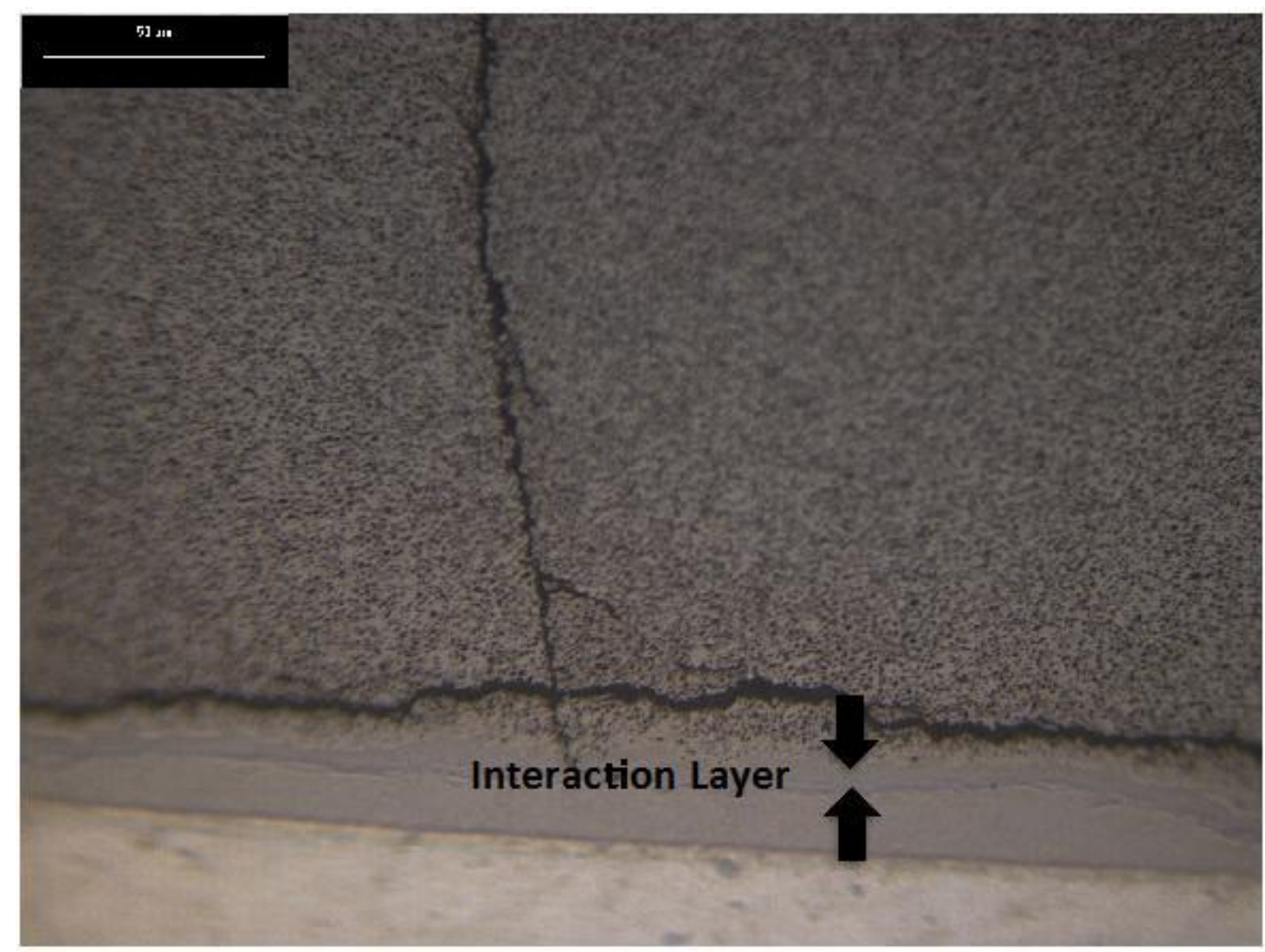

Figure 74. Plate L1P758. Average fission density: $5.0 \times 10^{21} \mathrm{f} / \mathrm{cm}^{3}$. APD: $17251 \mathrm{~W} / \mathrm{cm}^{3}$. 


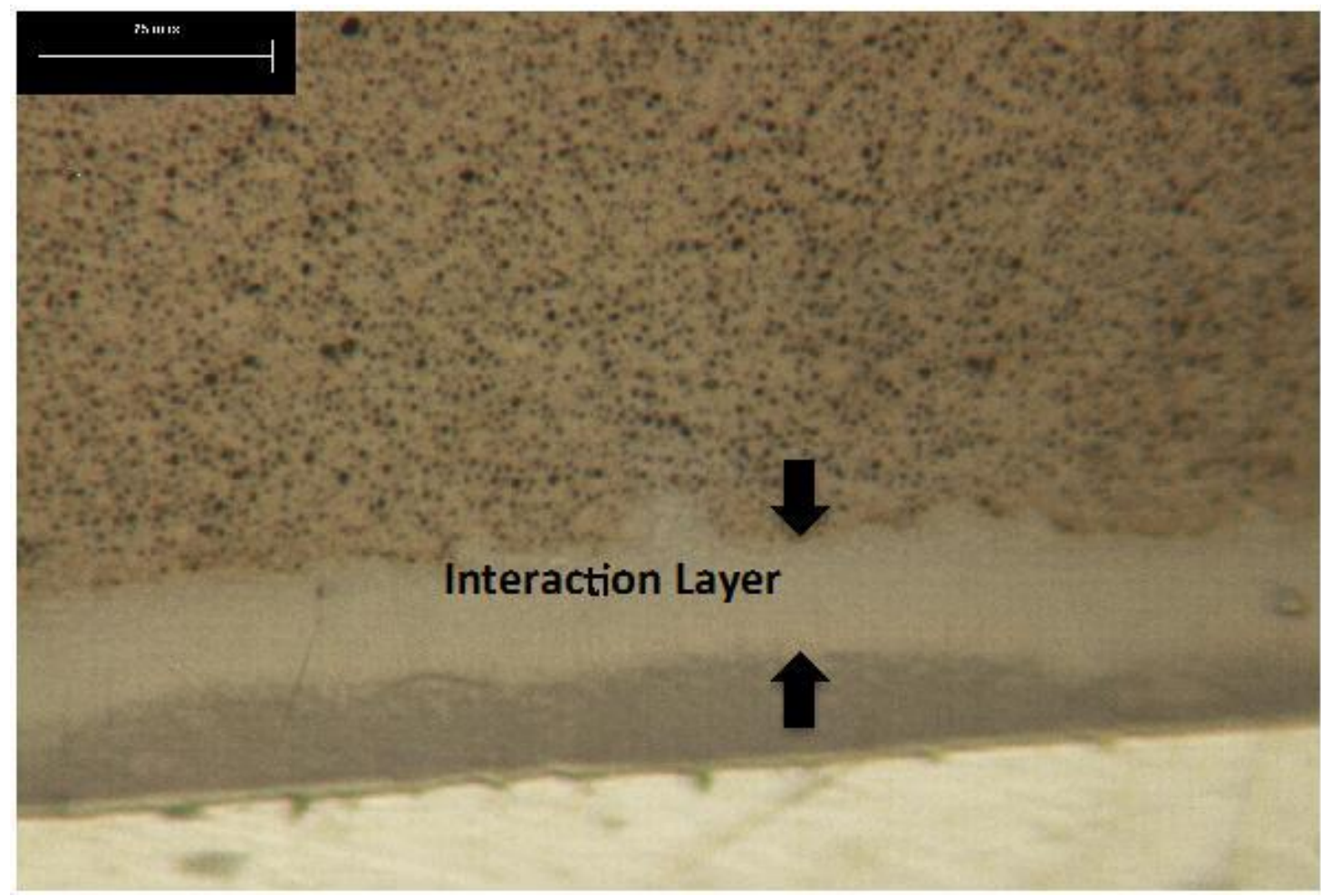

Figure 75. Plate L1P784. Average fission density: $6.3 \times 10^{21} \mathrm{f} / \mathrm{cm}^{3}$. APD: $21383 \mathrm{~W} / \mathrm{cm}^{3}$.

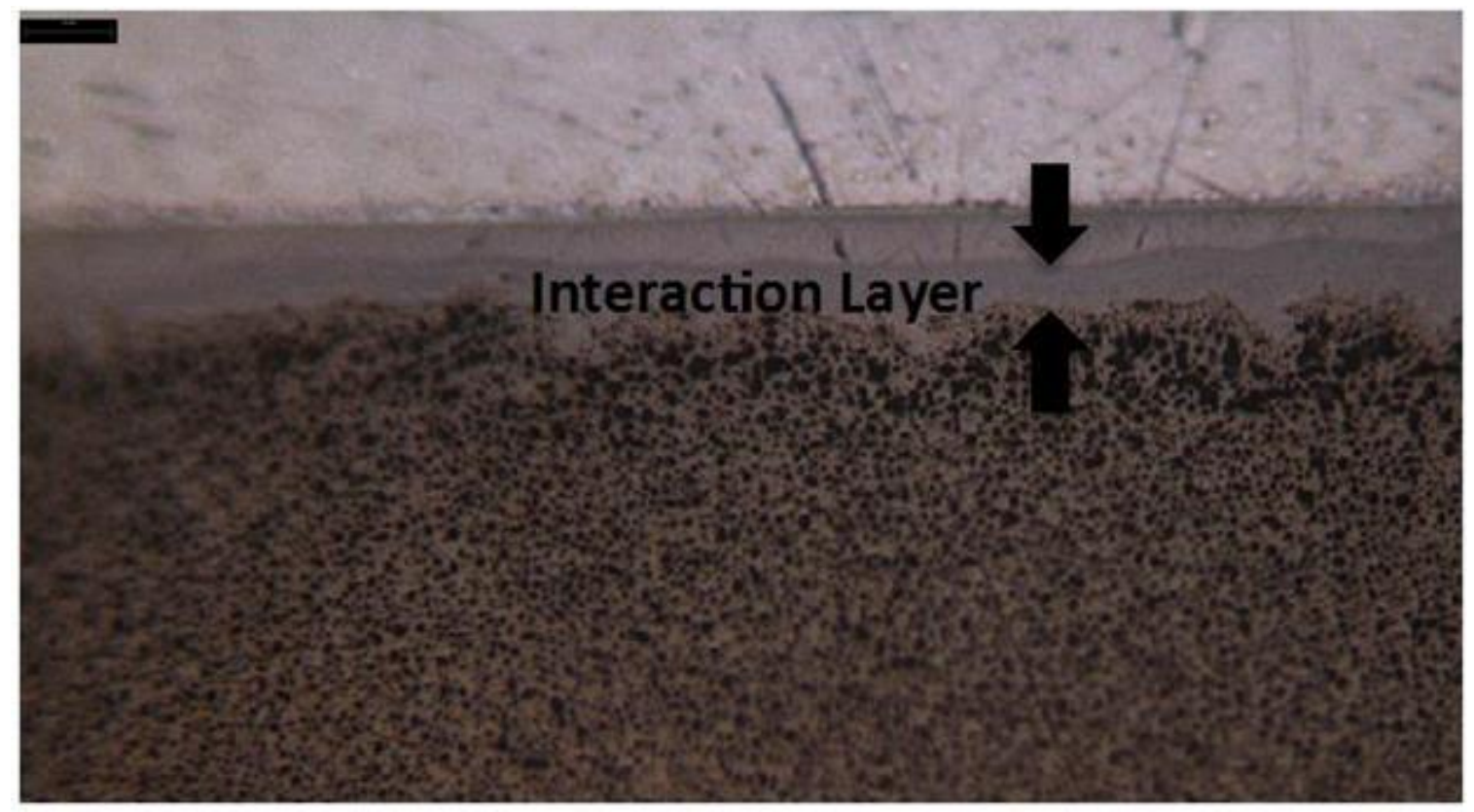

Figure 76. Plate L1P754. Average fission density: $8.1 \times 10^{21} \mathrm{f} / \mathrm{cm}^{3}$. APD: $25372 \mathrm{~W} / \mathrm{cm}^{3}$. 


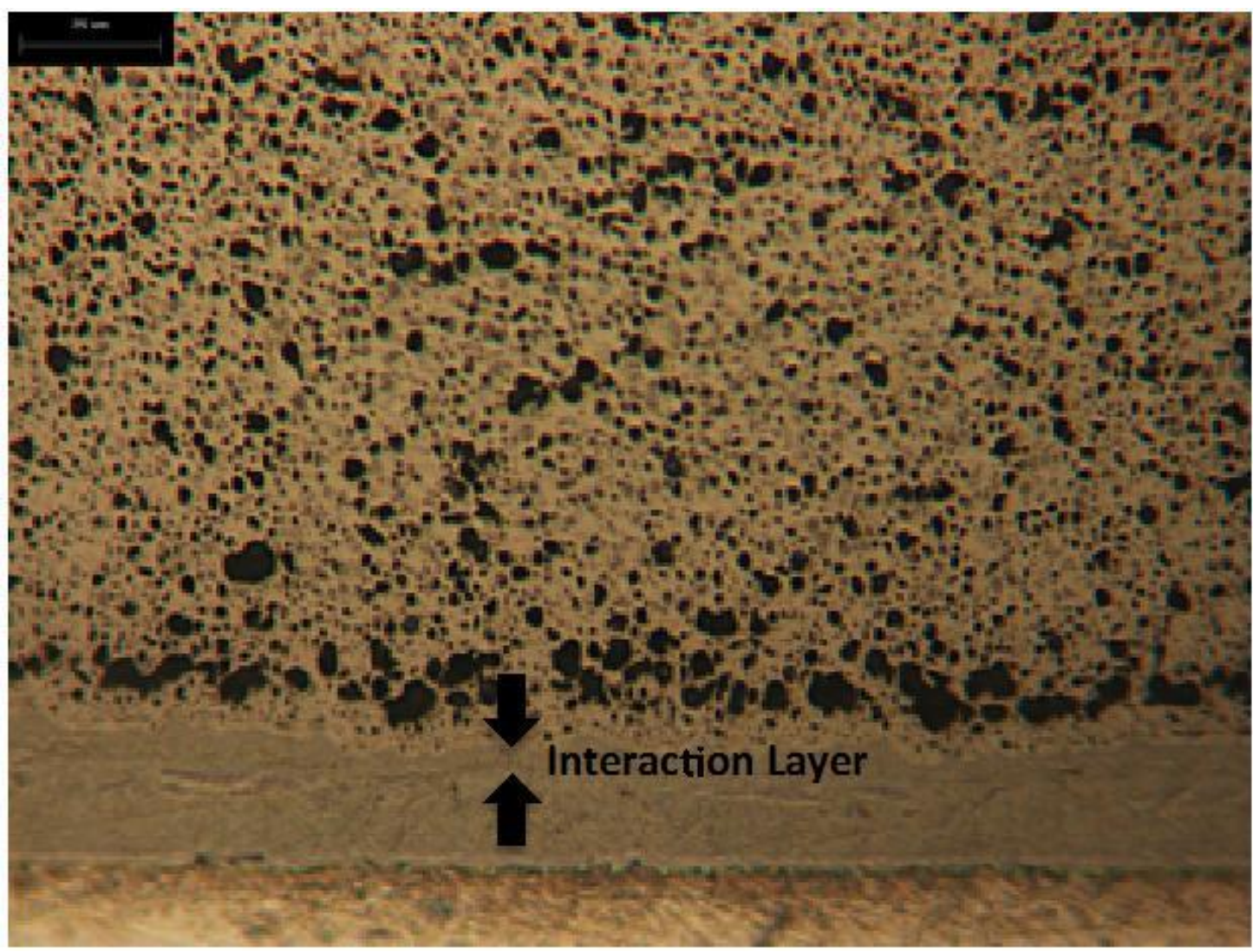

Figure 77. Plate L1P759. Average fission density: $8.7 \times 10^{21} \mathrm{f} / \mathrm{cm}^{3}$. APD: $26745 \mathrm{~W} / \mathrm{cm}^{3}$.

Table 15. Estimated interaction layer thickness values of examined plates.

\begin{tabular}{|c|c|c|}
\hline Plate ID & $\begin{array}{c}\text { Fission } \\
\text { density } \\
(10 \mathrm{E}+21 \\
\left.\mathrm{f} / \mathrm{cm}^{3}\right)\end{array}$ & $\begin{array}{c}\text { Interaction Layer } \\
\text { Thickness } \\
(\mu \mathrm{m})\end{array}$ \\
\hline L1P482 & 2.98 & 2.69 \\
\hline L1P462 & 3.34 & 1.94 \\
\hline L1P776 & 3.93 & 2.57 \\
\hline L1P758 & 5.00 & 7.19 \\
\hline L1P784 & 6.31 & 13.09 \\
\hline L1P754 & 8.13 & 12.22 \\
\hline L1P759 & 8.72 & 10.21 \\
\hline
\end{tabular}

Additional characterization is needed to determine the thickness of the interaction layer that could not be well resolved optically (an example is provided in Figure 78) and to verify the estimated growth of the interaction layer that was observed. This was accomplished successfully on a few specimens by applying an etchant that selectively attacked the $\mathrm{Zr}$ so that it could be differentiated from the interaction layer. An etched example is provided in Figure 78, which illustrates the definition in features at the $\mathrm{Zr} / \mathrm{U}-10 \mathrm{Mo}$ interface. It can be seen that two layers have been resolved. Due to the difficulty associated with resolving the interface in some micrographs, uncertainty in these measurements is high and not yet quantified. 


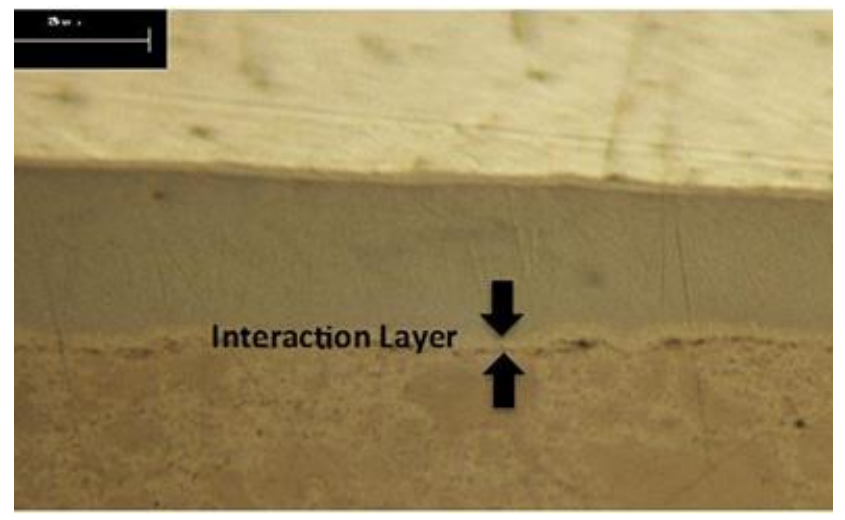

(a)

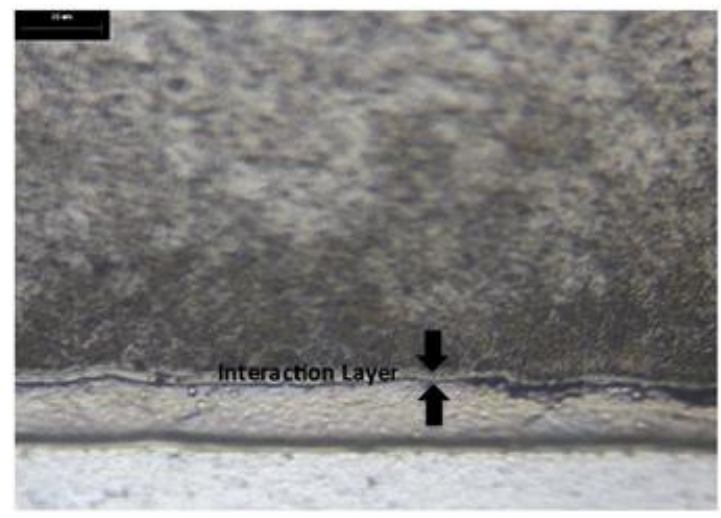

(b)

Figure 78. Optical image of plate L1P482. Average fission density: $3.0 \times 10^{21} \mathrm{f} / \mathrm{cm}^{3}$. Average power density (APD): $5386 \mathrm{~W} / \mathrm{cm}^{3}$. (a) and (b) are not etched and etched, respectively.

As depicted schematically in Figure 69, a zone depleted in Mo content occurs in the region near the $\mathrm{U}-\mathrm{Mo} / \mathrm{Zr}$ interface. The Mo depletion occurs because of the reaction of the $\mathrm{Zr}$ and $\mathrm{U}-\mathrm{Mo}$ to form a $\mathrm{Mo}_{2} \mathrm{Zr}$ intermetallic. The evolution of the fission gas bubbles in this region with increasing fission density can be observed in Figure 76 and Figure 77. A larger population of larger size fission gas bubbles forms in this region at very high fission density. The appearance of a spherical bubble shape is maintained up to the point where bubbles began to interconnect.

\section{Microstructures of Failed Fuel Plates}

During irradiation, three plates (L1P785, L1P754, and L1P759) exhibited pillowing-type failures that were observed on removal from the reactor after irradiation. Plates L1P759 and high swelling but nonpillowed plate L1P7A0 were destructively examined. Montages are found in Figure 79. The microstructure of L1P759 is shown in Figure 67 and Figure 80a. The microstructure of plate L1P754 is shown in Figures Figure 76, Figure 81b, and Figure 83a. The microstructure of L1P7A0 is shown in Figure 61 . All illustrate $100 \%$ recrystallization and visible instances of the interconnection of fission gas bubbles. 


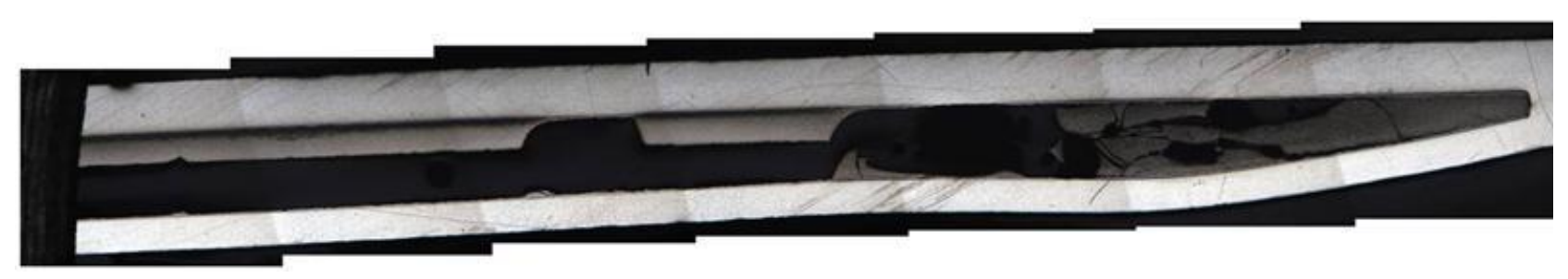

(a)

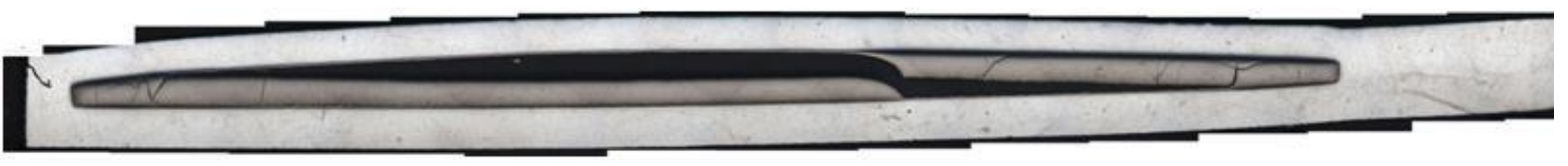

(b)

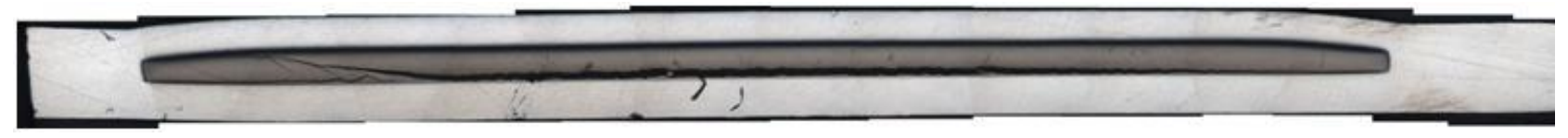

(c)

Figure 79. Cross-section montages of plates L1P754 (a) with a longitudinal segment, L1P759 (b) and L1P7A0 (c) with transverse segments.

The absence of unusual oxide growth on the failed plates lends credence to the hypothesis that the failure occurred late in life or during reactor shutdown. If failure would have occurred earlier in irradiation, asymmetry in oxide growth caused by a higher heat flux from one side of the plate would be expected. Further evidence for a failure late in life or after shutdown is provided by the apparently brittle nature of the failure (Figure 80a), shown by the absence of rounding of corners in the U-10Mo fuel fracture locations. Hoffmann ${ }^{7}$ presented images of pellet-type fuel exhibiting similar types of cracks and crack propagation (an example is shown in Figure 80b) that appear to have characteristics similar to the $\mathrm{U}-10 \mathrm{Mo}$ fuel fractures. Hoffmann points to the following features as being indicative of healing: the changing of crack volume into pore volume, healing by formation of lenticular voids and by grain boundary diffusion. It is not clear whether these observations are consistent with the microstructure shown in Figure 80a, and this remains an area for further investigation. 


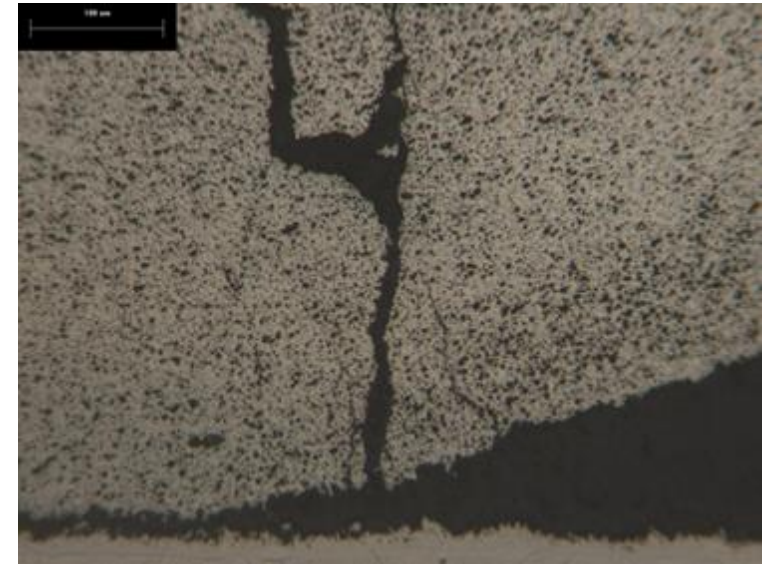

(a)

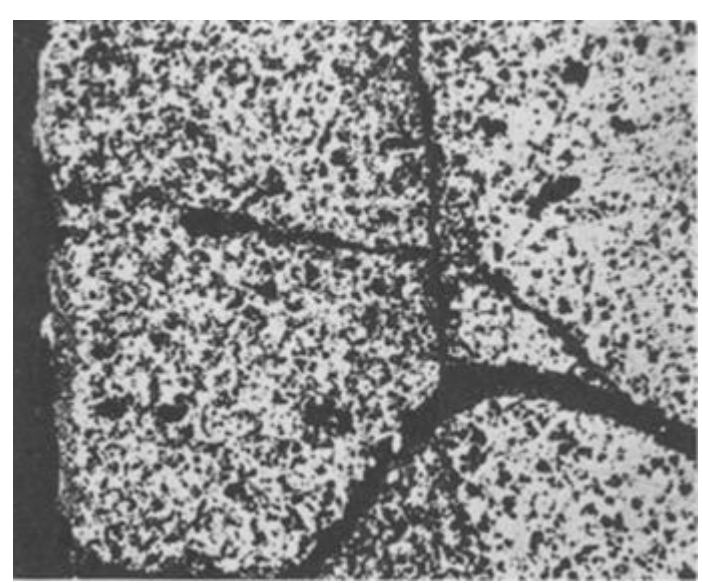

(b)

Figure 80. Micrograph (a) of plate L1P759 Ave FD: $8.7 \times 10^{21} \mathrm{f} / \mathrm{cm}^{3}$ showing brittle cracks with no rounding of corners. Micrograph (b) of a $\mathrm{UO}_{2}$ pellet-type fuel illustrating 'healing' of cracks from Hoffmann. ${ }^{7}$

\subsubsection{Comparison to Fuel without a Zirconium Barrier Layer}

Figure 81 illustrates typical fission-gas-bubble morphology in an RERTR-12 irradiated plate. In contrast, Figure 82 shows a micrograph (from the metallography archives from the RERTR-8, RERTR9A, and RERTR-9B PIE) of an irradiated U-Mo monolithic fuel plate that did not incorporate a diffusion barrier into the fuel design. Plates without a zirconium barrier layer exhibit ellipsoidal fission-gas bubbles in the $(\mathrm{U}-\mathrm{Mo}) \mathrm{Al}_{\mathrm{x}}$ layer at the $\mathrm{U}-\mathrm{Mo} / \mathrm{Al}$ interface. This behavior is consistent with observations of the behavior of U-xMo dispersion fuels ${ }^{8}$ with an aluminum matrix. As shown in Figure 83, this results in separation of the $\mathrm{U}-\mathrm{Mo}$ fuel from the cladding through the (U-Mo) $\mathrm{Al}_{\mathrm{x}}$ layer at the $\mathrm{U}-\mathrm{Mo} / \mathrm{Al}$ interface. 


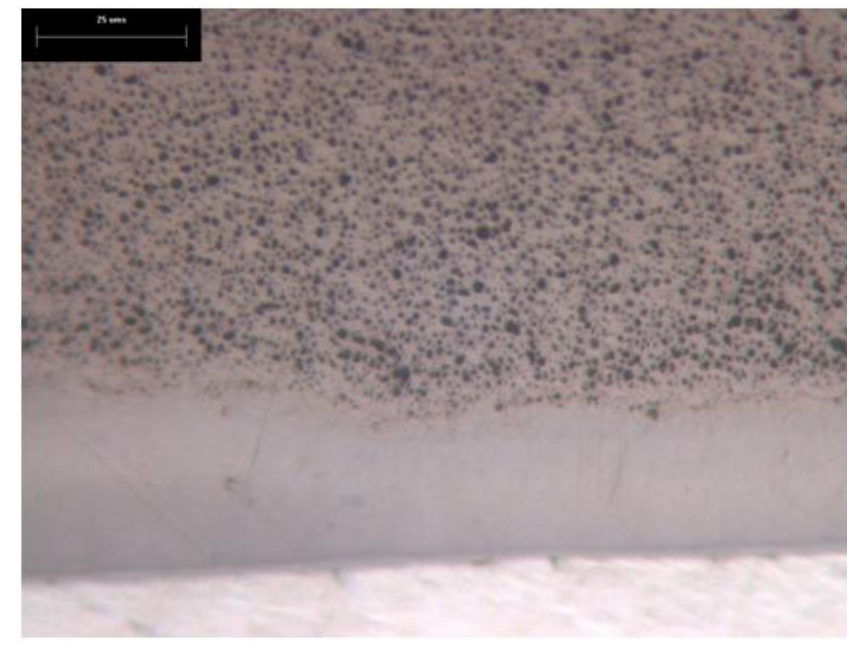

(a)

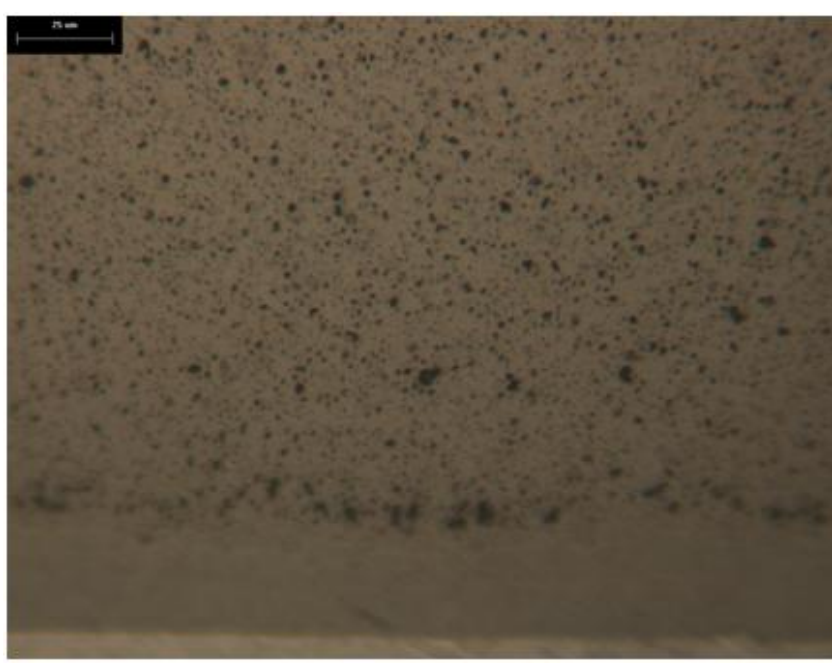

(c)

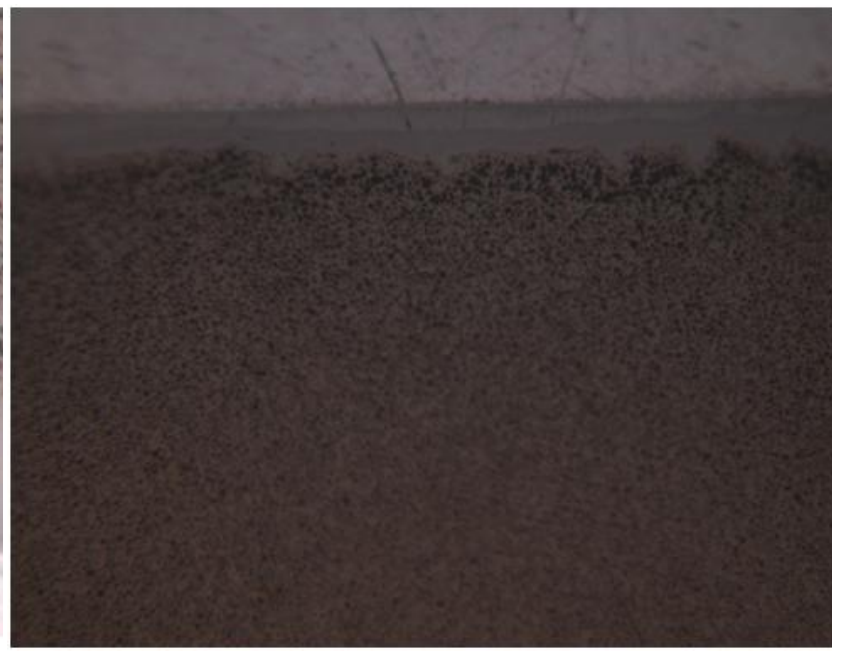

(b)

Figure 81. 500 $\times$ micrographs of cross-sections from RERTR-12 plates L1P784(a), L1P754(b), and L1P759(c), with average fission densities of $6.3 \times 10^{21}, 8.1 \times 10^{21}$ and $8.7 \times 10^{21} \mathrm{f} / \mathrm{cm}^{3}$, respectively, showing the typical bubble morphology at the zirconium $\mathrm{U}-10 \mathrm{Mo}$ fuel interface. 


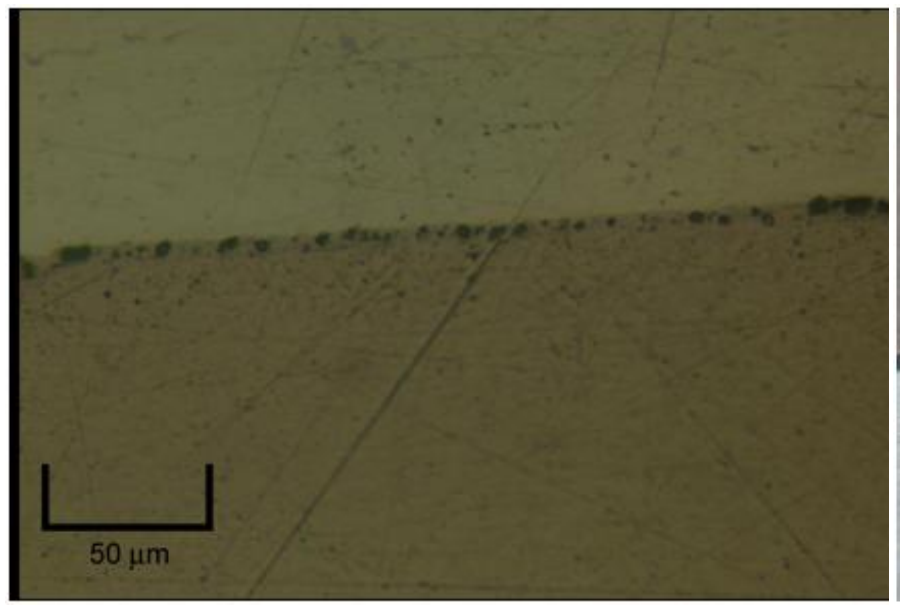

(a)

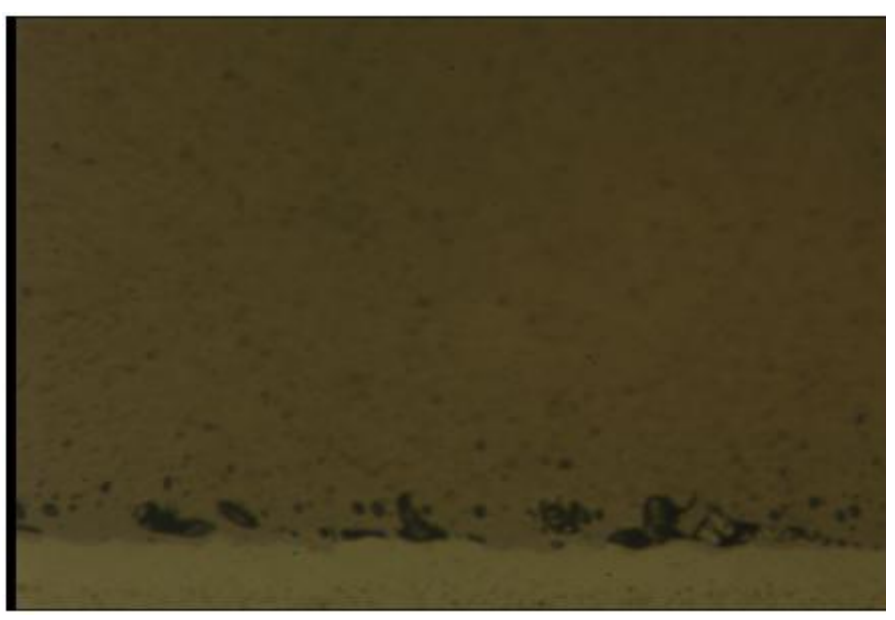

(c)

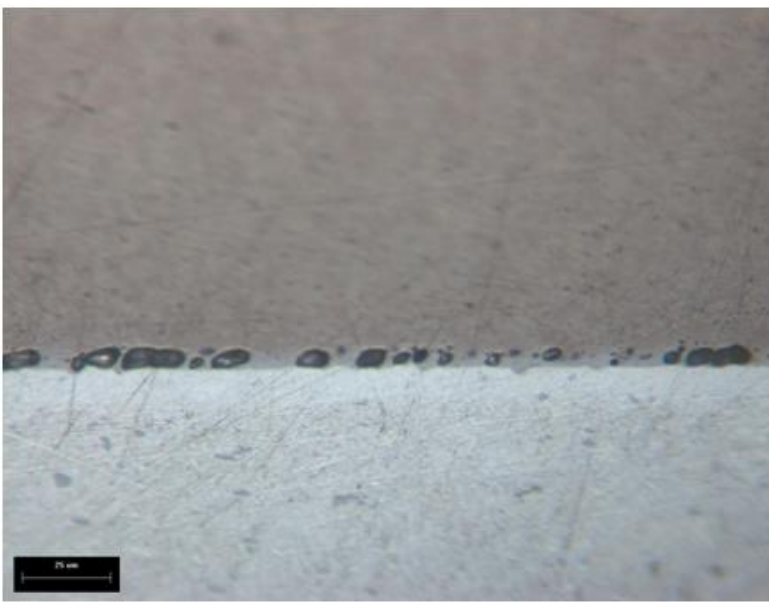

(b)

Figure 82. Micrographs of cross-sections (left to right) from plates L1P04A (RERTR-9A with 4043 A1 interlayer), (a) L1P020 (RERTR-8), (b) and L1P05A (RERTR-9B with 4043-Al interlayer), (c) plates with average fission densities of $5.3 \times 10^{21}, 6.0 \times 10^{21}$, and $6.2 \times 10^{21} \mathrm{f} / \mathrm{cm}^{3}$ respectively. Fuel is the dark region; cladding is lighter, and fission-gas bubbles are black. 


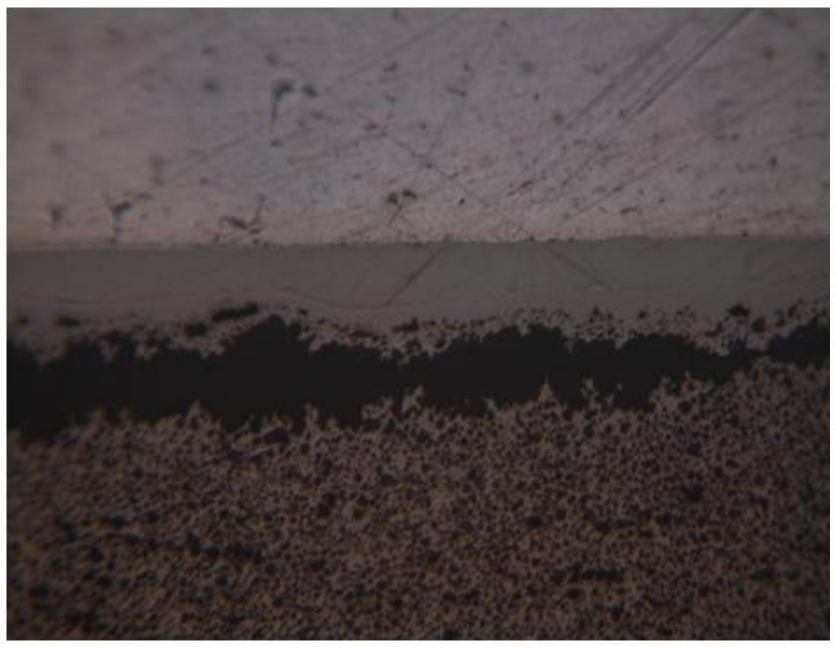

(a)

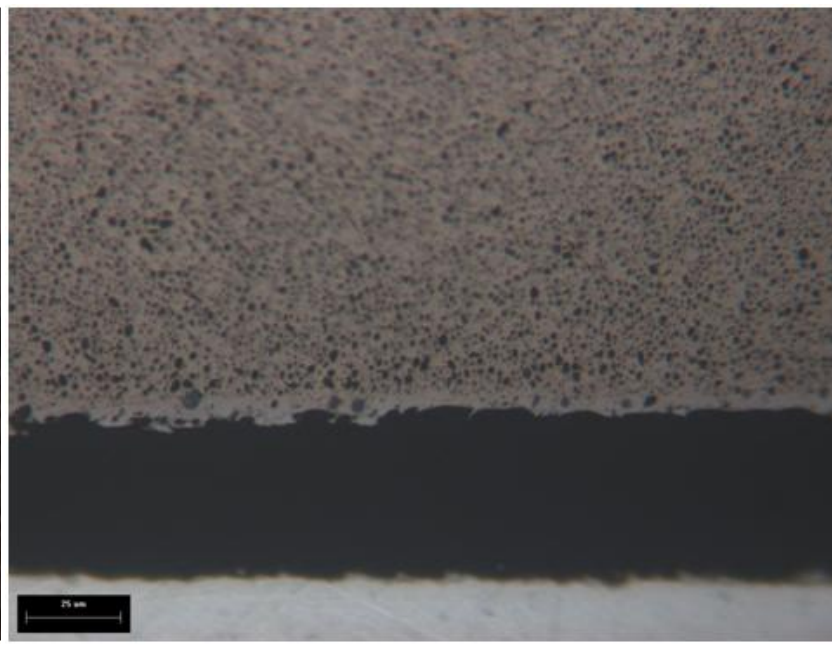

(b)

Figure 83. Examples of fuel separation with (a) and without (b) zirconium interlayer for plates L1P754 (RERTR-12, average fission density: $8.1 \times 10^{21} \mathrm{f} / \mathrm{cm}^{3}$ ) and L1P020 (RERTR-8, average fission density: $6.0 \times 10^{21} \mathrm{f} / \mathrm{cm}^{3}$ ), respectively. L1P754 was observed to be pillowed after irradiation and L1P020 separated during specimen preparation.

\section{Aluminum to Fuel Interface: Fuel Edge Observations}

The edges of the U-Mo fuel meat were not covered with $\mathrm{Zr}$ in the RERTR-12 fuel plates. As a result, the edge of the fuel meat is in direct contact with the 6061 aluminum cladding. Prior to irradiation, microstructural characterization of RERTR-12 archive specimens determined that no abnormal interaction occurred between the Al-6061 cladding and the uncoated edge of the U-Mo fuel meat. This is illustrated in Figure 84. During irradiation, the U-Mo edge/cladding interface showed no appreciable growth of $(\mathrm{U}-\mathrm{Mo}) \mathrm{Al}_{\mathrm{x}}$ reaction products. The lack of a fuel/aluminum reaction in this region is likely the result of the adequate heat-transfer at the edge regions of the fuel meat. Additionally, compressive stress along the fuel edges serves to reduce coarsening of fission-gas bubbles in this region. Figure 84, Figure 85, and Figure 86 show examples of the interlayer for pre-irradiation, low-fission-density, and high-fission-density specimens respectively. 


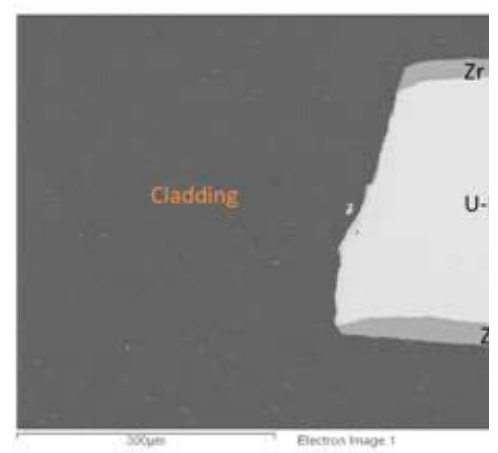

Figure 84. SEM image of a fresh fuel specimen showing features typical of the clad/U-Mo interaction layer.
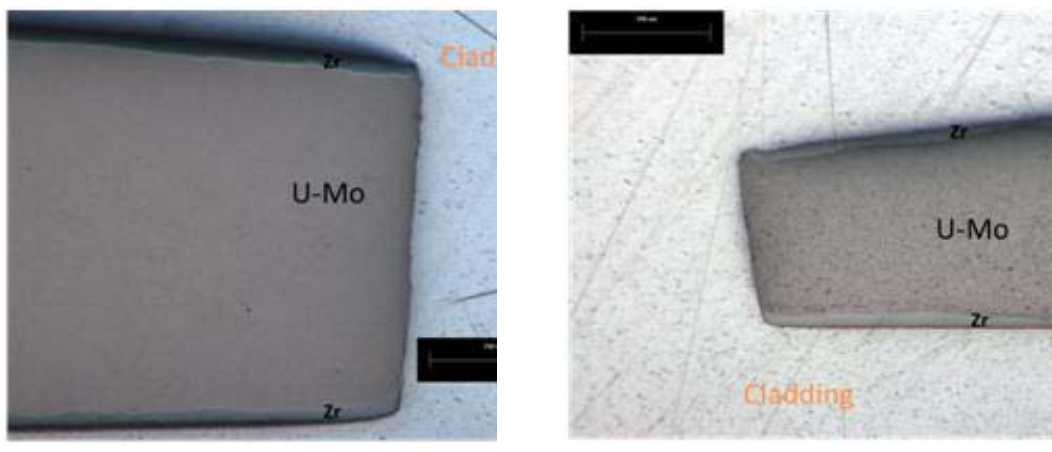

Figure 85. Plate L5P3B1, mount

Figure 86. L1P759, mount 26W. $51 \mathrm{~V}$. Average fission density: $2.49 \mathrm{E}+21 \mathrm{f} / \mathrm{cm}^{3}$.

Average fission density: $8.31 \mathrm{E}+21 \mathrm{f} / \mathrm{cm}^{3}$.

Low-fission-density micrograph of cladding/U-Mo interaction High-fission-density micrograph of cladding/U-Mo interaction layer (thick fuel meat plate). layer.

\subsubsection{Fission-Gas-Bubble Observations}

Predictably, the volume of visible fission-gas bubbles increases with fission density. Bubble size becomes increasingly coarse, and bubbles eventually interconnect as fission density increases. The largest concentration of interconnected porosity at high burnup is in the Mo-depleted area at the U-Mo/Zr interface (see Figure 64) and is a potential initiation site for plate failure.

Point counting was performed on selected micrographs to estimate the fission-gas bubble-to-fuel volume ratio. This is accomplished ${ }^{9}$ by overlaying a grid on the irradiated fuel microstructure and counting a bubble intersections with grid points, as illustrated in Figure 87. A grid with 2601 points was overlaid upon a micrograph. Plate L1P7A0, for example, exhibited 940 bubble intersections out of 2601 grid points, resulting in a bubble-volume fraction of 0.36 . Bubble fraction results listed in Table 16 may be considered non-conservative (i.e., measured values are lower than actual) due to the resolution of the microscope with the smallest optically resolvable bubble being $\sim 1 \mu \mathrm{m}$.

A limited sample set (Table 16 and Table 17) was used to determine the preliminary trend shown in Figure 88 to illustrate the relative increase in fission-gas-bubble fraction in the Mo-depleted region compared to the bulk of the fuel meat. It is recommended that a more statistically significant sample size be analyzed to reduce the uncertainty in the preliminary trend. The increase of fission-gas-bubble areal fraction locally in the Mo-depleted region was accomplished by comparing a sample far from the Modepleted zone to a sample within the Mo-depleted zone. The difference in volume fraction was estimated to be the increase in bubble fraction in the Mo-depleted zone. 

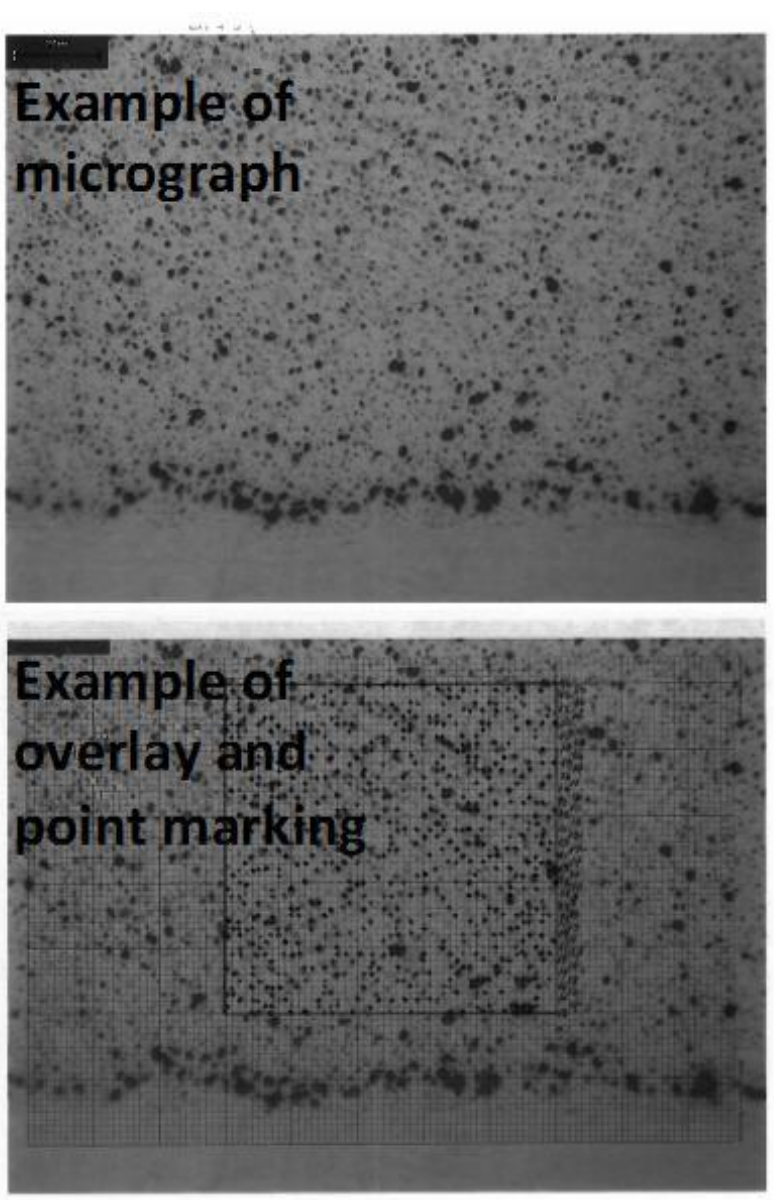
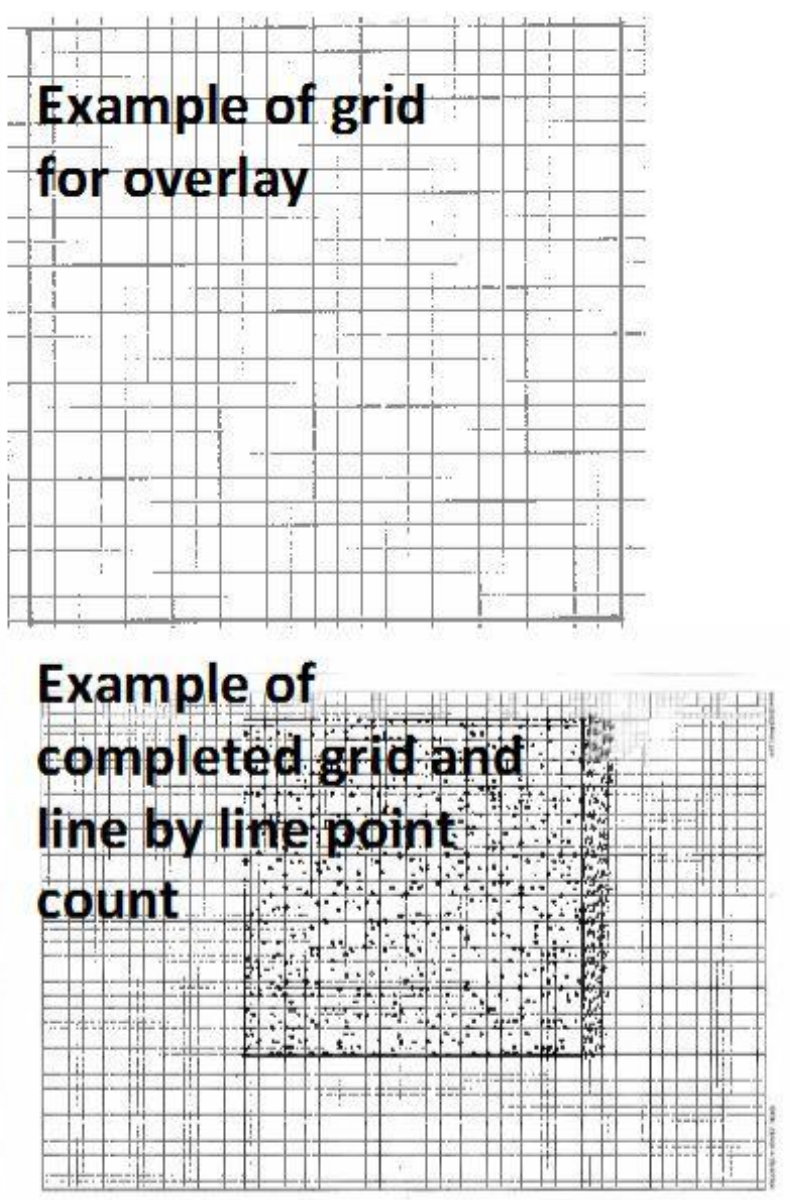

Figure 87. Illustration of point-counting method.

It has been postulated ${ }^{10}$ that the threshold for fission-gas-bubble interconnection that leads to breakaway swelling occurs at approximately 30 volume percent; however, it should be noted that the actual threshold for interconnection of a second phase in three-dimensional structures depends on many factors, such as second-phase size distribution, shape, the propensity for preferential nucleation along grain boundaries, etc. Preliminary measurements of fission gas bubble volume fraction in plates L1P759, L1P784, and L1P7A0 are consistent with interconnected porosity. Gamma spectroscopy indicates ${ }^{137} \mathrm{Cs}$ transport in plate L1P759 that is indicative of internal void volume or interconnected porosity. Differences in the increase in the bubble volume near the interface are also greater for pillowed plate L1P759. Gamma scanning of plates L1P7A0 and L1P784 indicates that ${ }^{137} \mathrm{Cs}$ transport did not occur in these plates (and these plates did not fail). The results of the analysis to date are inconclusive, and additional data is needed to better define fission gas bubble volume fraction as a function of location and the fission gas bubble interconnection threshold in the U-Mo system.

Table 16. Fission-gas-bubble volume-fraction results.

\begin{tabular}{|l|c|c|c|c|c|c|}
\hline \multicolumn{1}{|c|}{ Plate ID } & L2P499 & L1P462 & L1P020 & L1P759 & L1P784 & L1P7A0 \\
\hline $\begin{array}{l}\text { Average Specimen } \\
\begin{array}{l}\text { Fission Density } \\
\text { (fissions/cm3) }\end{array}\end{array}$ & $2.4 \mathrm{E}+21$ & $3.3 \mathrm{E}+21$ & $6.0 \mathrm{E}+21$ & $1.0 \mathrm{E}+22$ & $6.3 \mathrm{E}+21$ & $8.1 \mathrm{E}+21$ \\
\hline $\begin{array}{l}\text { Volume Percentage of } \\
\text { Porosity }\end{array}$ & $4 \%$ & $10 \%$ & $25 \%$ & $27 \%$ & $35 \%$ & $36 \%$ \\
\hline
\end{tabular}


Table 17. Data for estimated areal fraction porosity increase in the Mo-depleted region.

\begin{tabular}{|c|c|c|}
\hline Plate ID & $\begin{array}{c}\text { Fission } \\
\text { density } 10^{21} \\
\mathrm{f} / \mathrm{cm}^{3}\end{array}$ & $\begin{array}{c}\text { Fission gas bubble volume } \\
\text { percent increase in } \\
\text { Mo-depleted zone }\end{array}$ \\
\hline L1P784 & 6.3 & $3 \%$ \\
\hline L1P7A0 & 7.7 & $5 \%$ \\
\hline L1P759 & 8.7 & $13 \%$ \\
\hline
\end{tabular}

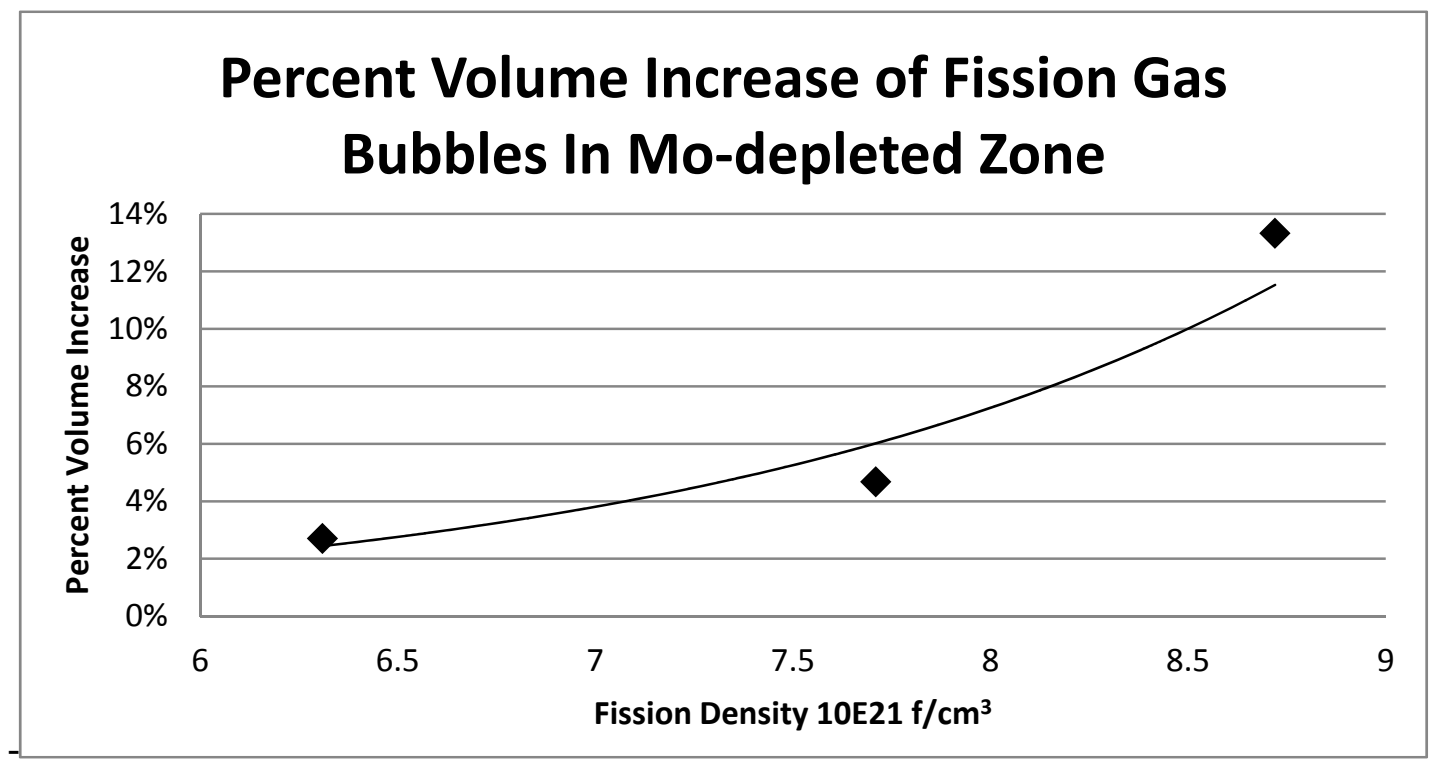

Figure 88. Data for estimated porosity increase in the Mo-depleted region.

\subsubsection{Conclusions}

Post-irradiation metallographic characterization of selected plates from the RERTR-12 irradiation test did not reveal any non-typical features in the cladding-to-cladding bond line and were consistent in appearance with the micrographs at similar magnification collected from the unirradiated archive specimens.

Specific to the U-10Mo fuel meat, variation in source material as well as alloying and casting variables affect the starting grain-size distribution and, subsequently, the rate of grain refinement and grain-distribution size during irradiation observed with increasing irradiation. Regions where fission-gas bubbles initially appear correspond primarily with existing grain boundaries. Grain refinement was observed to initiate along grain boundaries and work into the grain interior as fission density increased. A limited number of micrographs were selected and analyzed using point-counting methods to develop a preliminary recrystallization trend as a function of fission density with results confirming an increasing fraction of grain recrystallization with increasing fission density.

Irradiated microstructures were compared to pre-irradiation microstructures from archived fuel plates. As was the case in unirradiated fuel plates, it was noted during optical examinations that there are regions with negligible $\mathrm{U}-\mathrm{Mo} / \mathrm{Zr}$ interaction layer. Some gaps between the $\mathrm{Zr}$ and fuel meat were also noted, possibly as a result of specimen preparation. These regions do not stand out as failure-initiation sites or as regions with non-typical irradiated microstructures near the interface. The $\mathrm{U}-\mathrm{Mo} / \mathrm{Zr}$ interaction layer varied in thickness in the set of fuel plates examined. A general trend is observed relative to fission density with the highest-fission-density specimens having the thickest $\mathrm{U}-\mathrm{Mo} / \mathrm{Zr}$ interaction layer, which 
in some cases appeared to comprise approximately $50 \%$ of the thickness of the original $\mathrm{Zr}$ diffusion barrier layer. No obvious delamination occurred at either the $\mathrm{Al} / \mathrm{Zr}$ or the $\mathrm{U}-\mathrm{Mo} / \mathrm{Zr}$ interface, although crack propagation was noted to occur in pillowed plates near the $\mathrm{U}-\mathrm{Mo} / \mathrm{Zr}$ interface and even into the $\mathrm{Zr}$ interlayer.

Predictably, fission-gas-bubble volume increased with fission density. Bubble size became increasingly coarse as fission density increased. Fission-gas bubbles retained the appearance of a spherical shape until they eventually interconnected to form larger, lenticular bubbles. The largest concentration of interconnected porosity was in the regions located in the Mo-depleted area near the U$\mathrm{Mo} / \mathrm{Zr}$ interface and is a potential failure initiation site at very high fission densities. Point counting was performed on selected microstructural images to estimate the ratio of fission-gas bubble to fuel, and the percent increase of fission-gas bubbles in the Mo-depleted zone versus the more stable U-10Mo region and compared with the postulated ${ }^{10}$ threshold for interconnected porosity leading to breakaway swelling of $\sim 30$ vol. $\%$.

The interface of the U-Mo fuel edge with the aluminum cladding showed no appreciable growth of undesirable phases resulting from interdiffusion between the $\mathrm{Al}$ and the $\mathrm{U}-10 \mathrm{Mo}$ during irradiation, and appears to be consistent with pre-irradiation characterization results of RERTR-12 archive specimens.

\subsection{Microhardness Testing}

\subsubsection{Introduction}

Microhardness measurements were performed on RERTR-12 mini-plates to measure the mechanical property changes of the $\mathrm{U}-10 \mathrm{Mo}$ relative to the fission density of a given sample. These data were compared to the hardness values of unirradiated samples to document the changes induced during irradiation. An additional sample from RERTR-8 was included in the test matrix for purposes of comparison.

Micro-indentation hardness tests were performed using either a LECO AMH43 micro-indentation hardness testing system using a Vickers ${ }^{11}$ or Knoop indenter, so that the points could be tightly grouped ${ }^{12}$ specific to discreet locations of interest, penetrate possible artifacts on the surface layer from oxidization, and minimize effects of pull-out regions resulting from sample polishing.

The focus of this test was to determine the hardness values from six RERTR-12 plates over a range of fission densities and analyze the data for trends in addition to examining samples for micro-cracks initiated from the indenter, which might allow for possible fracture-toughness calculations. RERTR-12 plates were oriented face to the core in the reactor and have a relatively flat burnup gradient, allowing for a more statistically significant sampling at a given fission density. ${ }^{1}$ One edge-to-the-core plate from RERTR-8 was selected and added to the test matrix for comparison, to better envelop the target range of fission densities. These plates are listed in Table 18.

Table 18. Microhardness sample information. ${ }^{1}$

\begin{tabular}{|l|l|l|l|}
\hline \multicolumn{1}{|c|}{ Experiment } & \multicolumn{1}{|c|}{ Plate ID } & \multicolumn{1}{|c|}{ Avg Fissions/cc } & \multicolumn{1}{c|}{ Mount } \\
\hline RERTR-12 & L5P3B3 & $1.7 \times 10^{21}$ & MNT 49V \\
\hline RERTR-12 & L2P481 & $2.5 \times 10^{21}$ & MNT 48V \\
\hline RERTR-12 & L2P499 & $2.5 \times 10^{21}$ & MNT 42V \\
\hline RERTR-12 & L5P3B1 & $2.5 \times 10^{21}$ & MNT 50V \\
\hline RERTR-12 & L2P482 & $3.0 \times 10^{21}$ & MNT46V \\
\hline RERTR-12 & L5P3C2 & $3.5 \times 10^{21}$ & MNT 52V \\
\hline RERTR-8 & L1P020 & $6.0 \times 10^{21}$ & MNT 39W \\
\hline
\end{tabular}




\subsubsection{Additional Information}

ASTM E384-05 defines a micro-indentation hardness test as "a hardness test using a calibrated machine to force a diamond indenter of specific geometry into the surface of the material being evaluated, in which the test forces range from 1 to $1000 \mathrm{~g}_{\mathrm{f}}$, and the indentation diagonal, or diagonals are measured with a light microscope after load removal. For any indentation, it is assumed that the indentation does not undergo elastic recovery after force removal." 12 The LECO micro-indenter was calibrated following the manufacturers procedure and a standard check was performed on four ASTM qualified Westport Standards, 12642, 12643, 12644, and 12645. These results are illustrated in Figure 89.

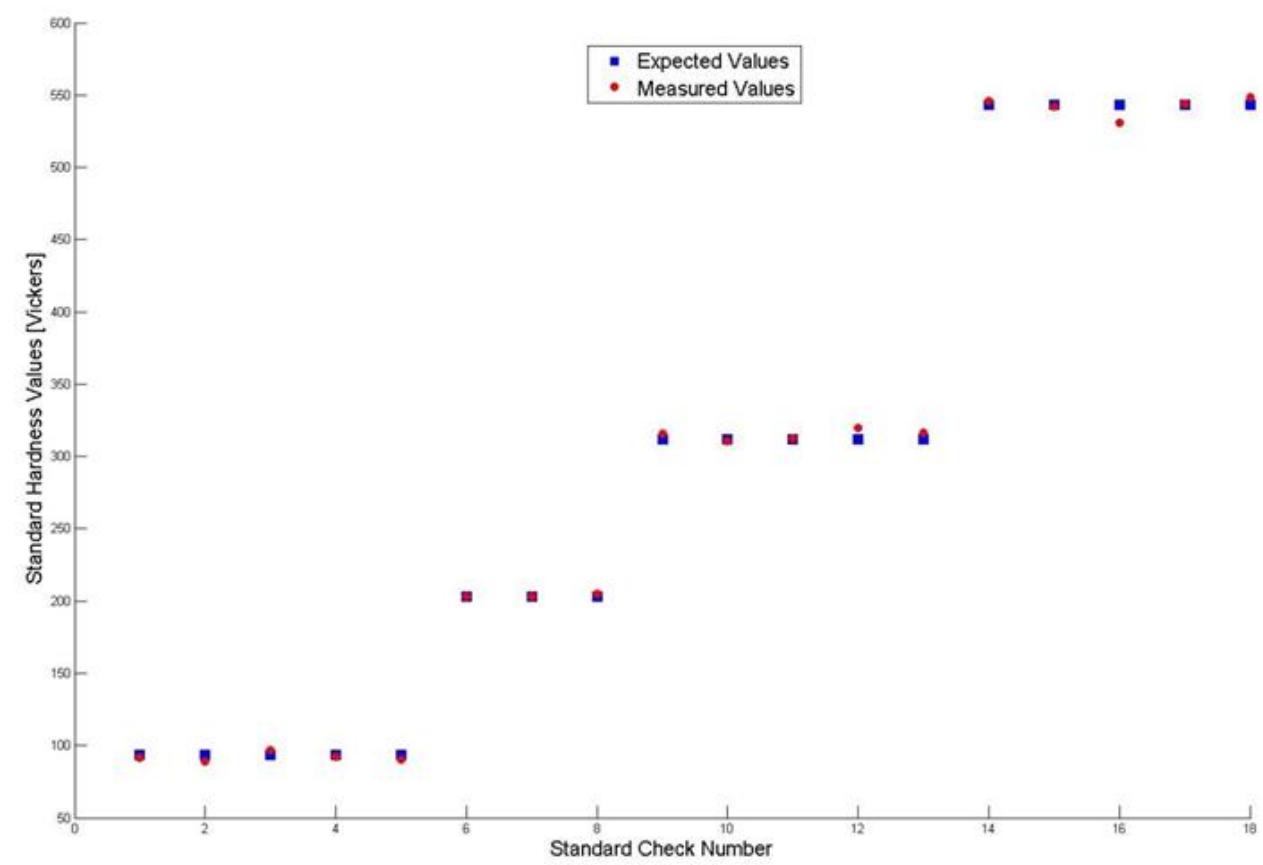

Figure 89. Microhardness standard verification.

The variance was calculated for each of the standard checks. The resulting standard deviations varied between $\sim 2$ and 6.9 Vickers, giving us a conservative uncertainty of 6.9 Vickers for the indents performed in this study.

For Vickers diamond indentation, test loads are measured in grams force $\left(\mathrm{g}_{\mathrm{f}}\right)$ and indentation diagonals are measured in micrometers. Hardness values were calculated using Equation 5 (see Reference 1):

$H V=2.000 * 10^{3} * P * \sin (136 / 2) / d^{2}=>1854.4 * P / d^{2}$

Where 136 degrees is the face angle of the indenter, $d[u m]$ is the mean diagonal length of the indentation, and $P\left(\mathrm{~g}_{\mathrm{f}}\right)$ is the force measurement. The mean angle is used to correct for minute offsets of the indent; however, all indents are visually examined for indent quality. While smaller deformities can be corrected through the mean of the diagonals, more drastic deformities, as shown in Figure 90, are considered a lost data point. Skewed or elongated indents are typically caused sample movement during indentation or indenting on an angled or curved area and are failed indents. Elastic indents are of interest as they arise from elastic recovery along the edges of an indent. The resulting hardness value can still be determined from the diagonals, but the recovery can be used to calculate the elastic modulus. 

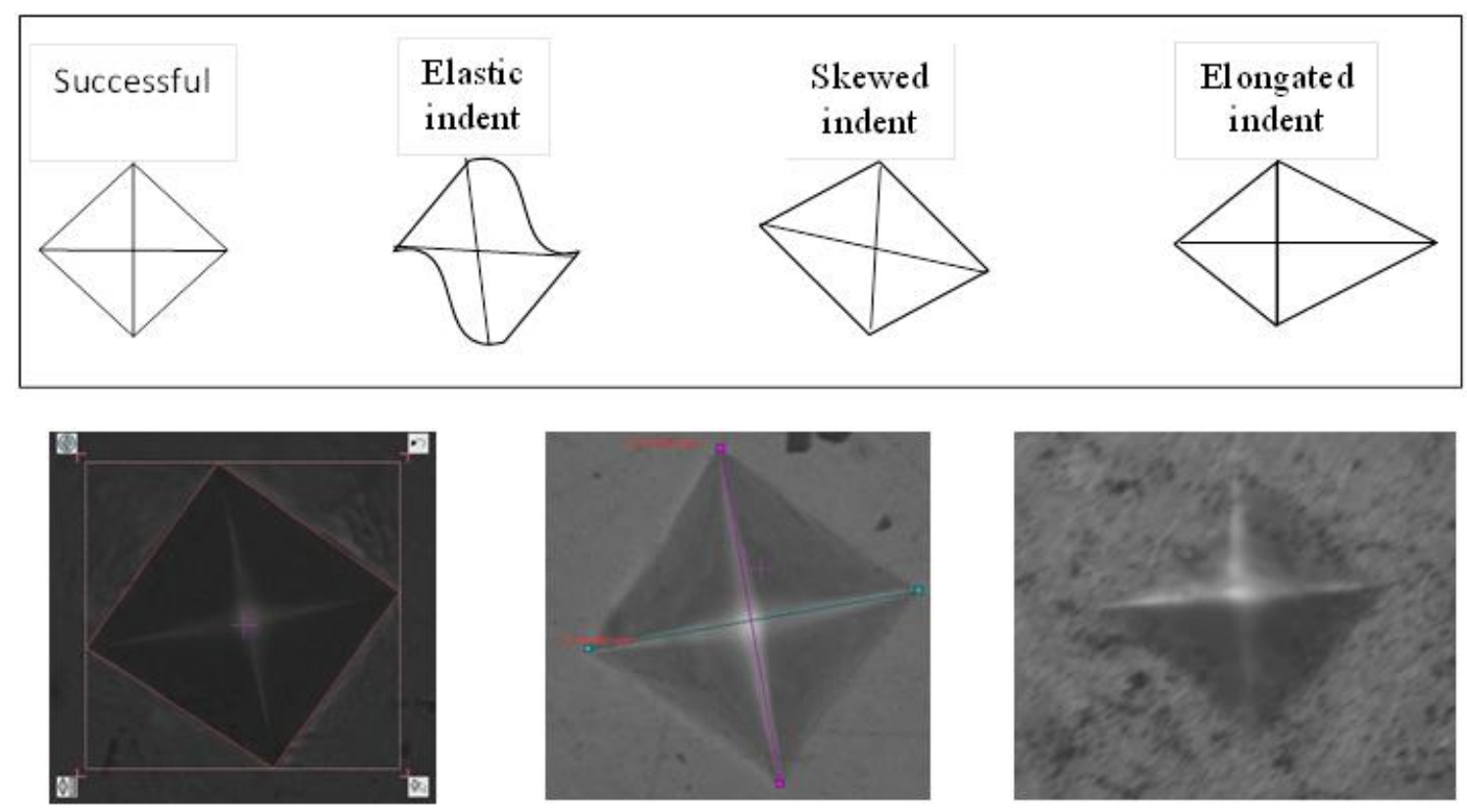

Figure 90. Indentation types.

Additional criteria needed to achieve a proper indentation include dwell time, view field, distance and spacing, and load. Dwell time is the time span that the indenter is held against the sample to ensure the correct load application and material response. The ASTM specification for dwell time is 10-15 seconds. Thirteen seconds provides acceptable indent quality and was used for all the samples tested. View field is the size of the indent under the microscope relative to the total viewable space. Approximately $70 \%$ is recommended during a measurement. Distance and spacing of indents is vital to avoid false readings due to stress interference, either from prior indents or from defects in the material, such as an edge or crack. Thus, individual indents were spaced at least 2.5 times the average diagonal from any defect or edge. In addition, multiple indents were always at least 4 times the average diagonal from another to avoid introducing error.

\subsubsection{Analysis}

An assessment was performed to identify the optimal load for the RERTR-12 specimens using the available loads of 50, 100, 200, 300, 500, and $1000 \mathrm{~g}_{\mathrm{f}}$. Loads of 300,500 , and $1000 \mathrm{~g}_{\mathrm{f}}$ were applied first, with the nominal diagonals resulting in the expected hardness-required loads of 300 and above, as well as resulting in possible fractures. These indents are shown in Figure 91. The load of $300 \mathrm{~g}_{\mathrm{f}}$ resulted in diagonals near 40 micrometers. Loads of 500 and $1000 \mathrm{~g}_{\mathrm{f}}$ were also applied in an attempt to fracture the fuel. Both 500 and $1000 \mathrm{~g}_{\mathrm{f}}$ had diagonals above 50 micrometers; however, fractures were not consistently observed. This assessment resulted in the selection of $300 \mathrm{~g}_{\mathrm{f}}$ load for the remainder of the tests. 


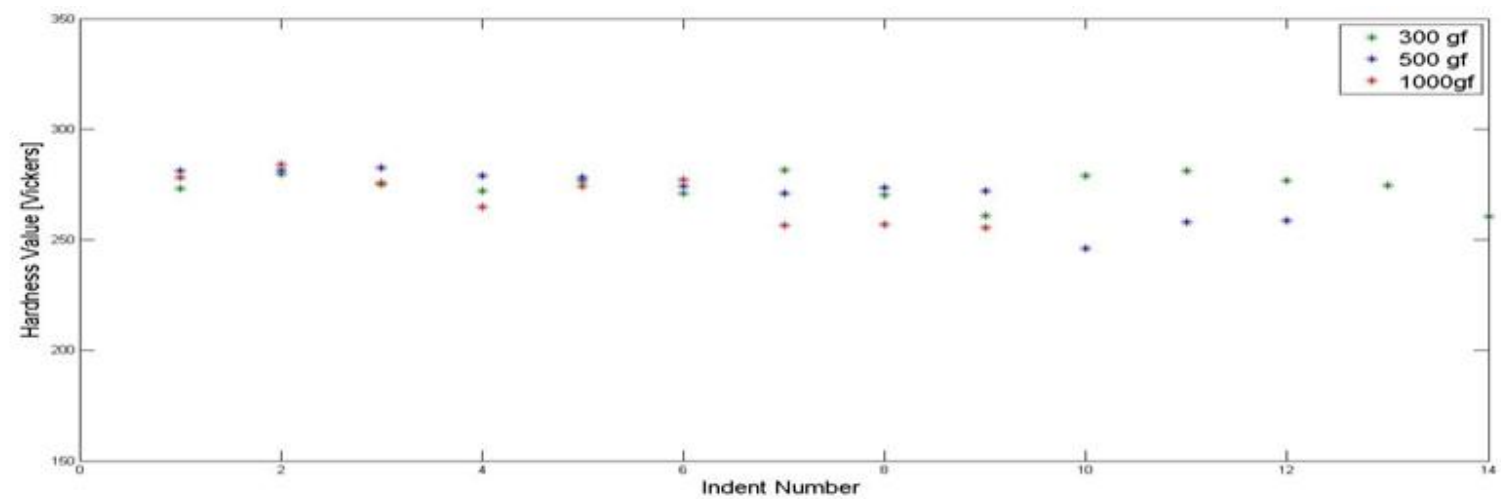

Figure 91. Load investigation.

The microhardness of the cladding was also measured on five plates. The much lower hardness value of the cladding required a load of only $50 \mathrm{~g}_{\mathrm{f}}$ to achieve diagonal dimensions within recommended ranges. The low standard deviation in the clad hardness values precluded the necessity of numerous samples to arrive at the desired confidence interval of 95 percent. These results are illustrated in Figure 92.

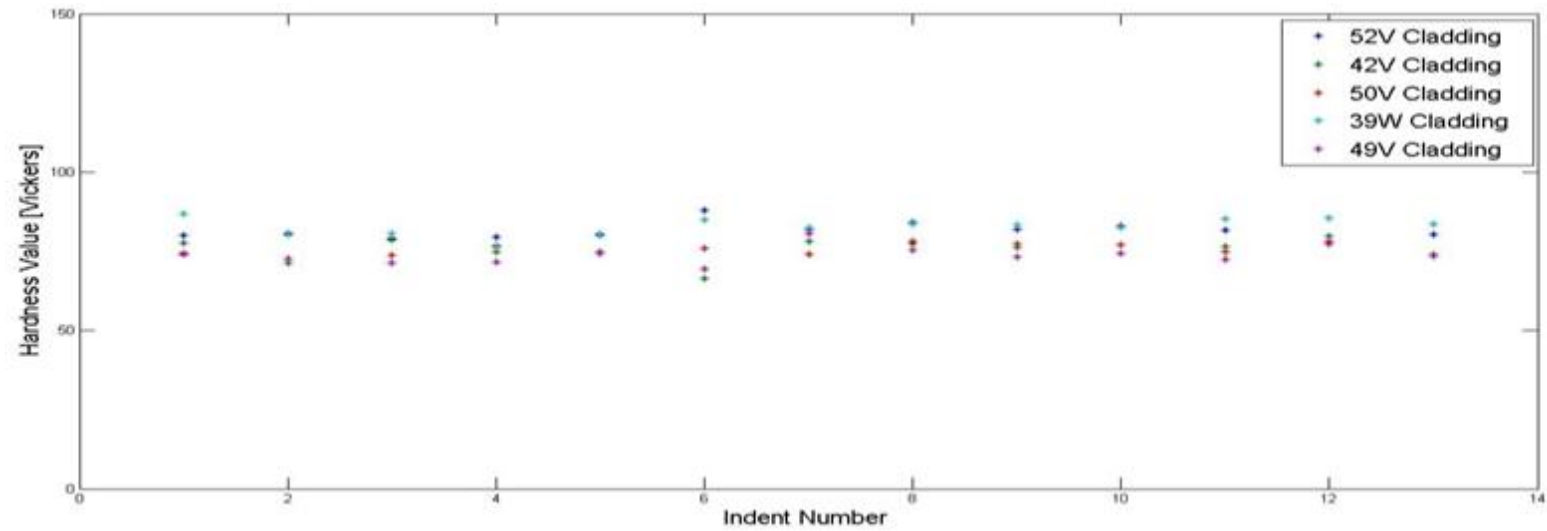

Figure 92. Cladding hardness values.

Fuel-meat measurements, the primary interest of this study, required a minimum of 20 indents down the center of the fuel, with additional points added as warranted. Figure 93 shows a sample micrograph and the associated color map of the measured hardness values for plate L5P3B1. Hardness indents were made in three rows of 39 indents across the mount (with the ID side up). Figure 94 shows the indents and hardness map on the right side of plate L5P3C2 (with the ID side oriented to the right). Both figures illustrate that the hardness of the fuel is highest along the center of the fuel meat, away from both the right and left edges and the front and back faces. Hardness values close to the edges of the sample (left and right of Figure 93) are the lowest. Figure 94 also illustrates that a 15\% change in hardness can occur in a very small range. 

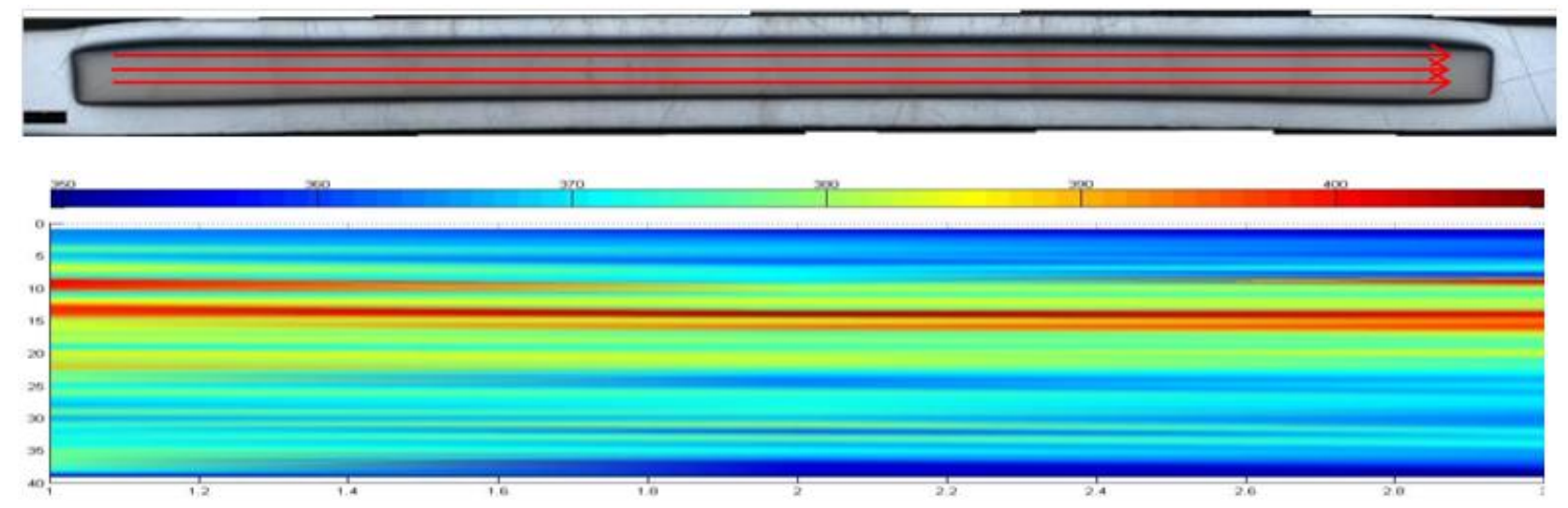

Figure 93. Metallograph and L5P3B1 (MNT 50V) hardness color map.
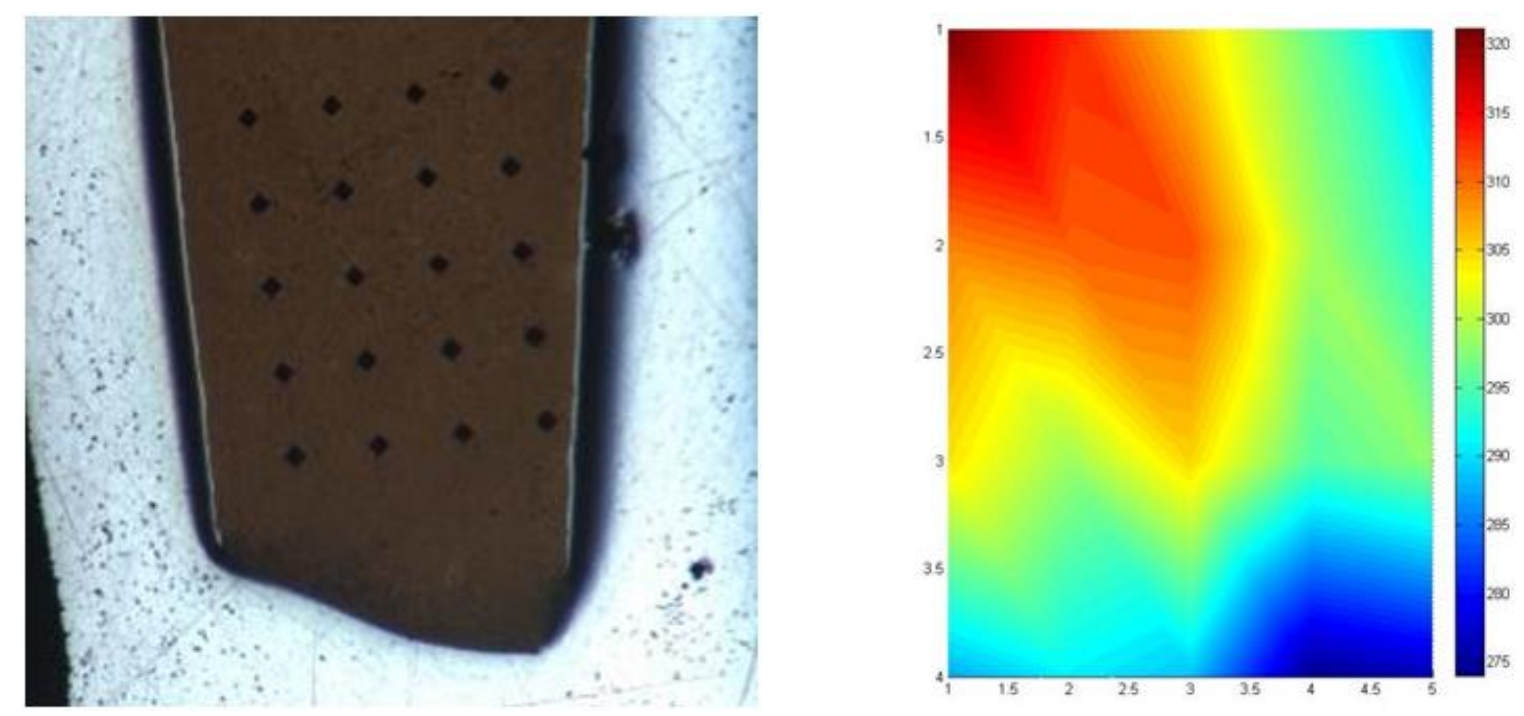

Figure 94. Metallograph and L5P3C2 (MNT 52V), 170 micron grid.

The global view of the hardness values of mount $52 \mathrm{~V}$ in Figure 95 shows a small variance over the fuel from left to right, with higher values being predictably closer to the center than to an edge. 


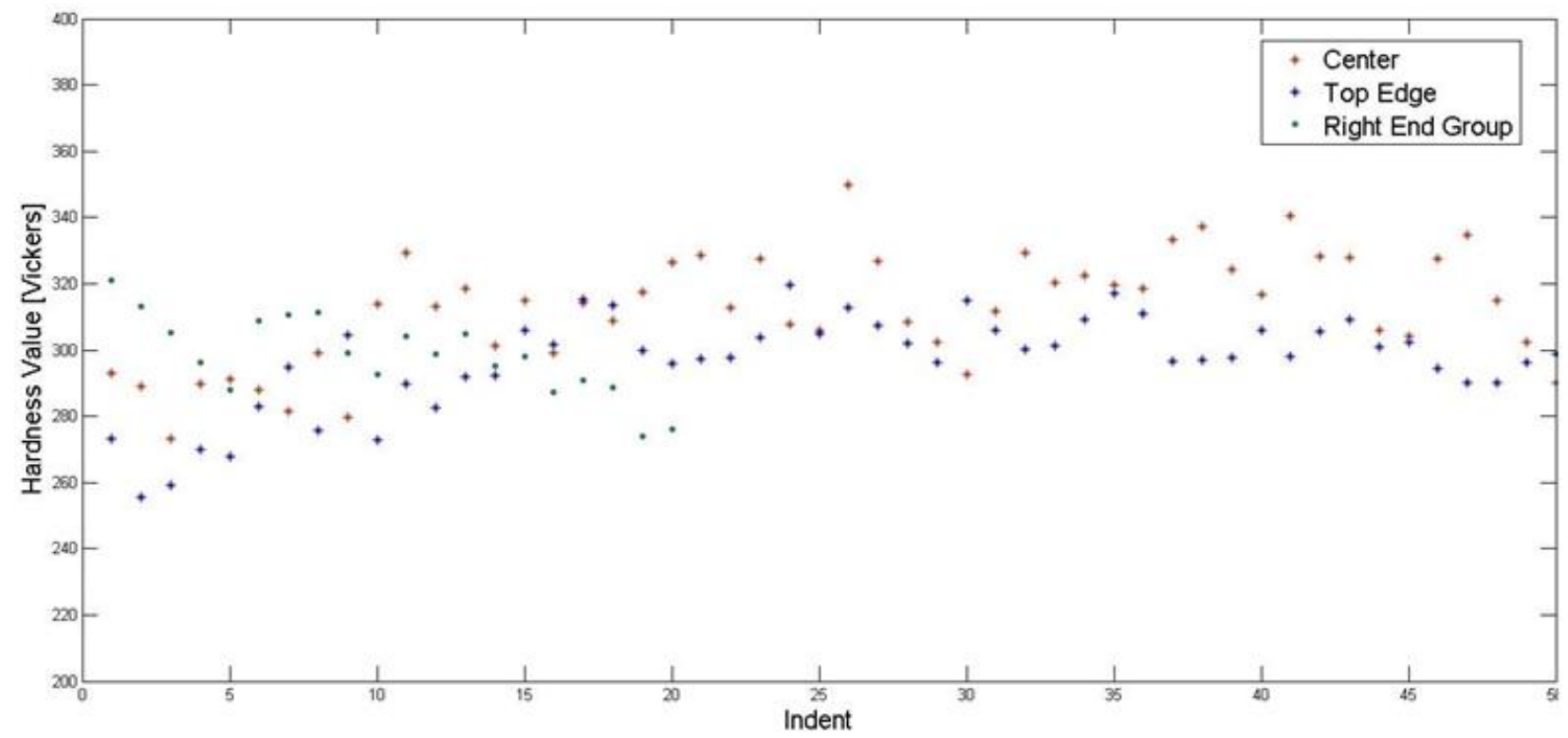

Figure 95. Hardness data from L5P3C2 (MNT 52V).

A closer look at the data obtained from L5P3C2, shown in Figure 96, matches the trend seen in all mounts: the highest hardness values for each plate tend to be away from the corners and edges of the plate. Conversely, the lowest values occur in more highly stressed areas and higher-burnup regions.

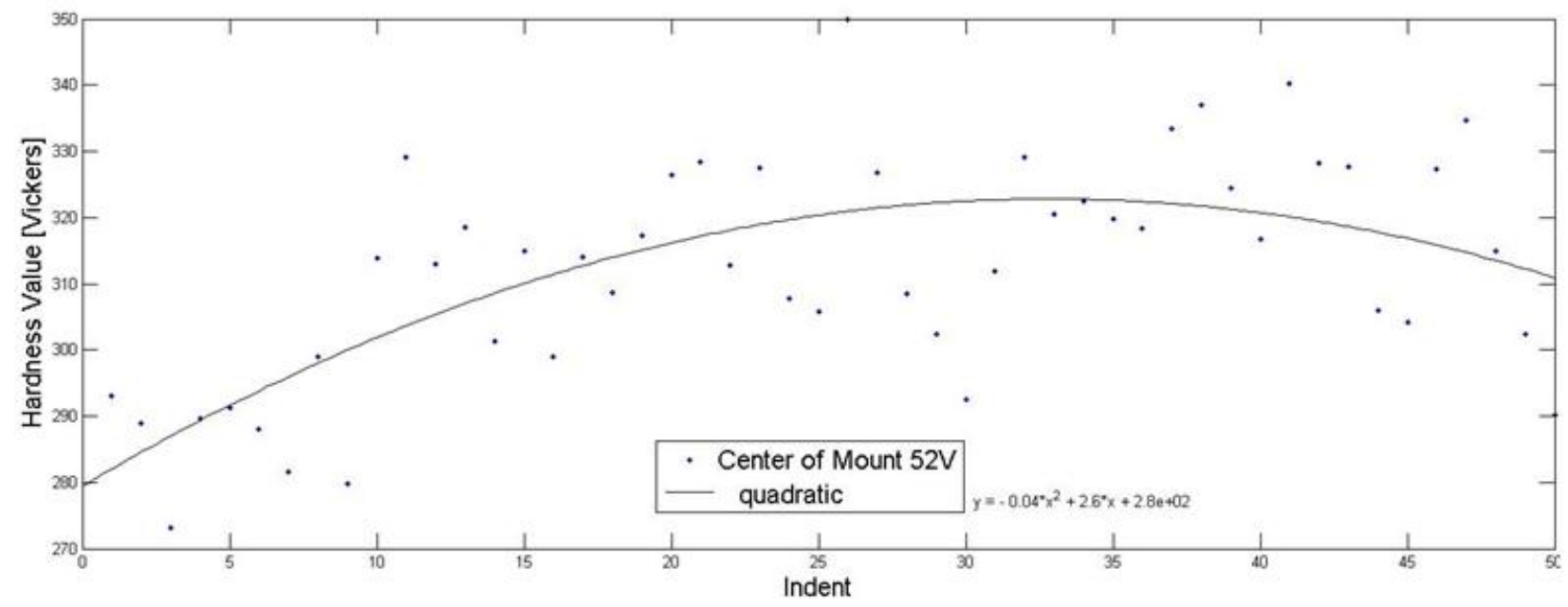

Figure 96. Hardness data from center of plate L5P3C2 center line.

Figure 97 shows all of the center-line hardness values (from left to right) of the plates in this study. L1P020 was the only edge-to-core plate in this test matrix and, thus, has the most extreme burnup gradient, with the right side being at higher fission density. The decrease in hardness with fission density shown in (lowest set of points) suggests that fission density is a significant factor influencing the hardness value of the fuel. 


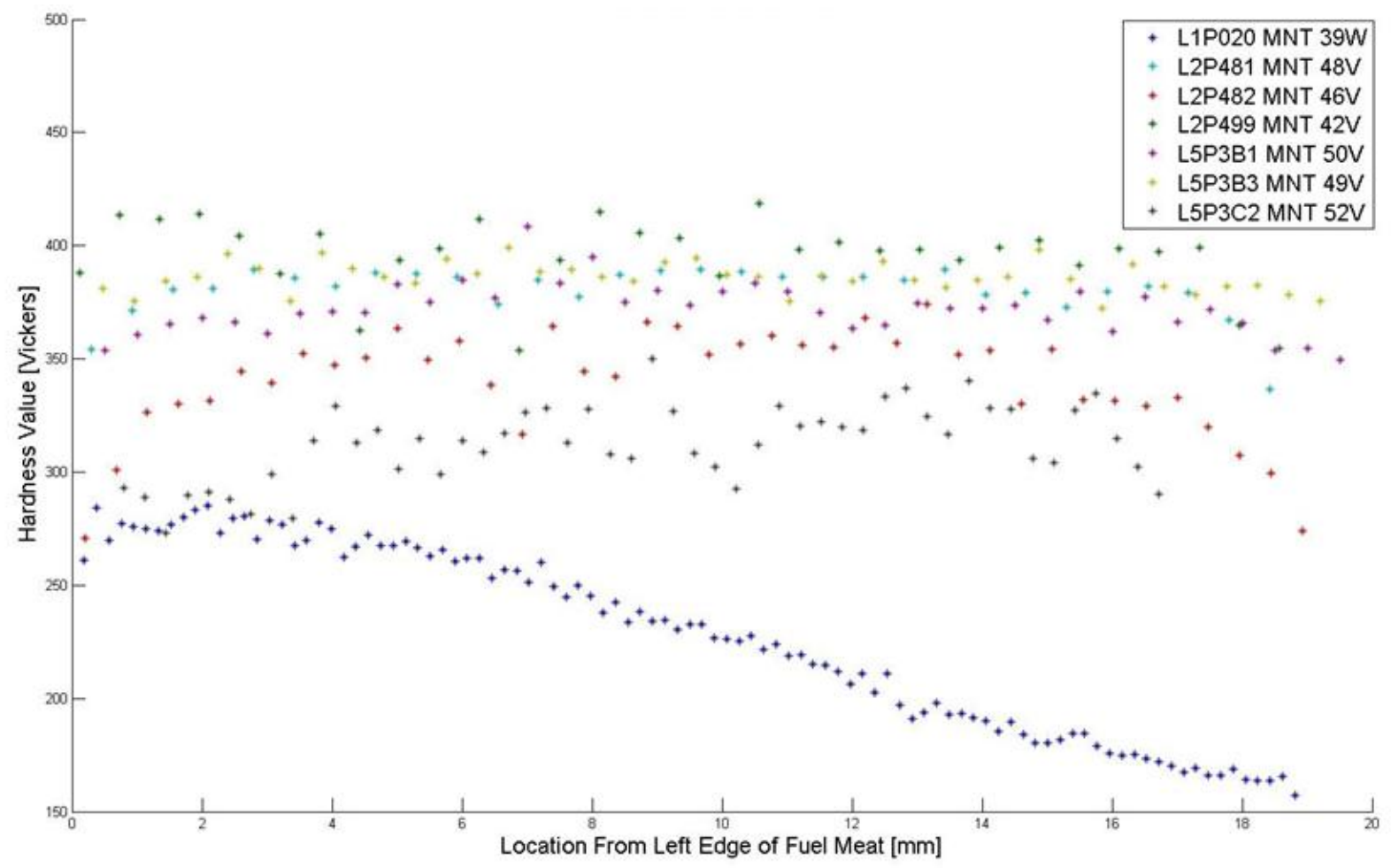

Figure 97. Hardness values through the center values of all mounts.

Figure 98 shows the correlation between hardness values and fission density by plotting measured hardness values against the local MCNP-calculated fission densities. Not shown in this figure are the starting hardness values measured on fresh-fuel archive plates averaging near 316 Vickers. This trend shows that there is significant hardening of the fuel meat in the early stages of irradiation. The hardening eventually plateaus, then begins to drop near $3 \times 10^{21}$ fissions $/ \mathrm{cm}^{3}$, when the ability to measure the fuel hardness is compromised by a postulated influence of increasing porosity beneath the indenter. 


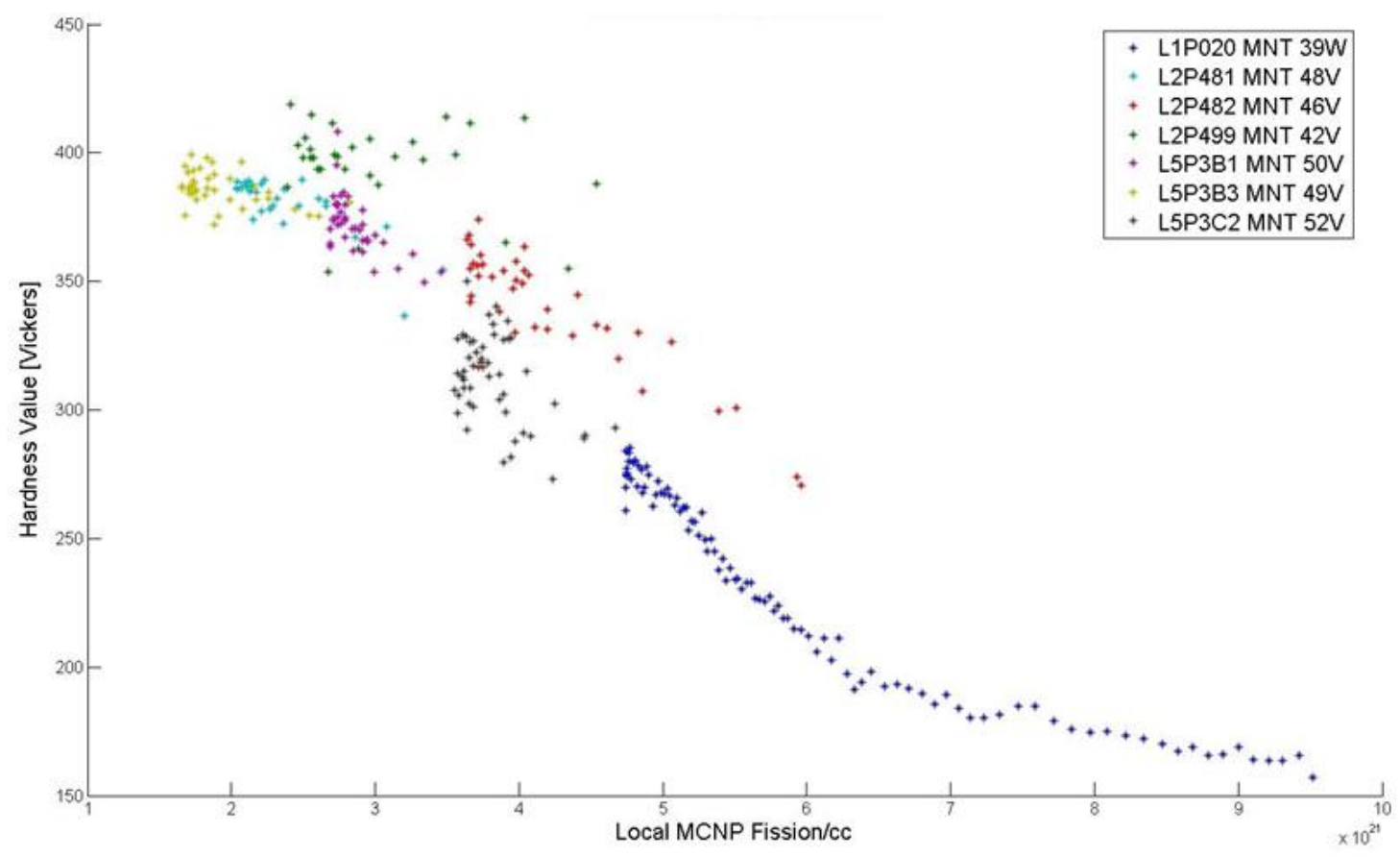

Figure 98. Hardness vs burnup by sample mount number (see Table 18).

\subsubsection{Additional Discussion}

Some indents led to fracturing of the fuel meat, as seen in Figure 99. Ideally, for fracture toughness calculations, cracks should extend from all four points of the hardness indent. The majority of indents resulted in no cracking. As the fuel is irradiated and becomes hardened, porosity also increases. As a result, the fuel may be less susceptible to visible cracking as pores blunt further propagation of the crack and absorb the stress that would have resulted in a fracture. Porous material may collapse under the indenter, increasing the apparent plasticity of the plate surface.
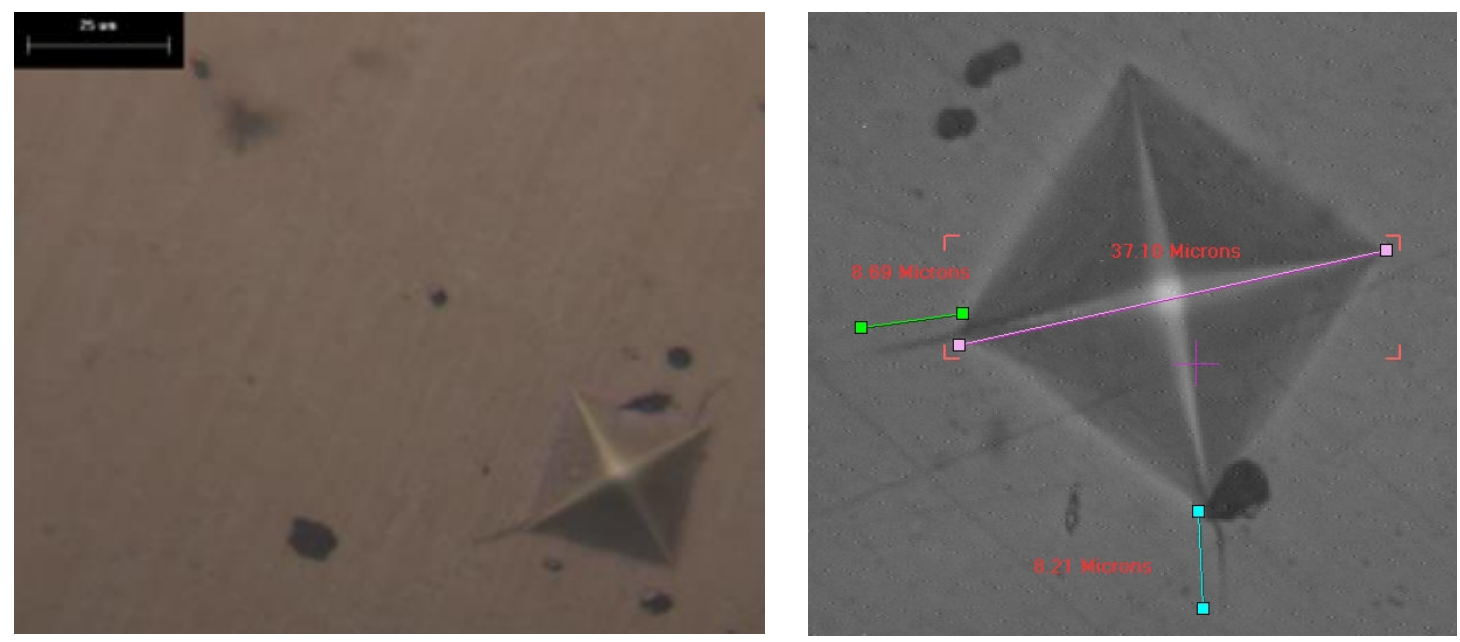

Figure 99. Indent on L2P499 (MNT 42V) micrograph (left) and microhardness tester (right). 

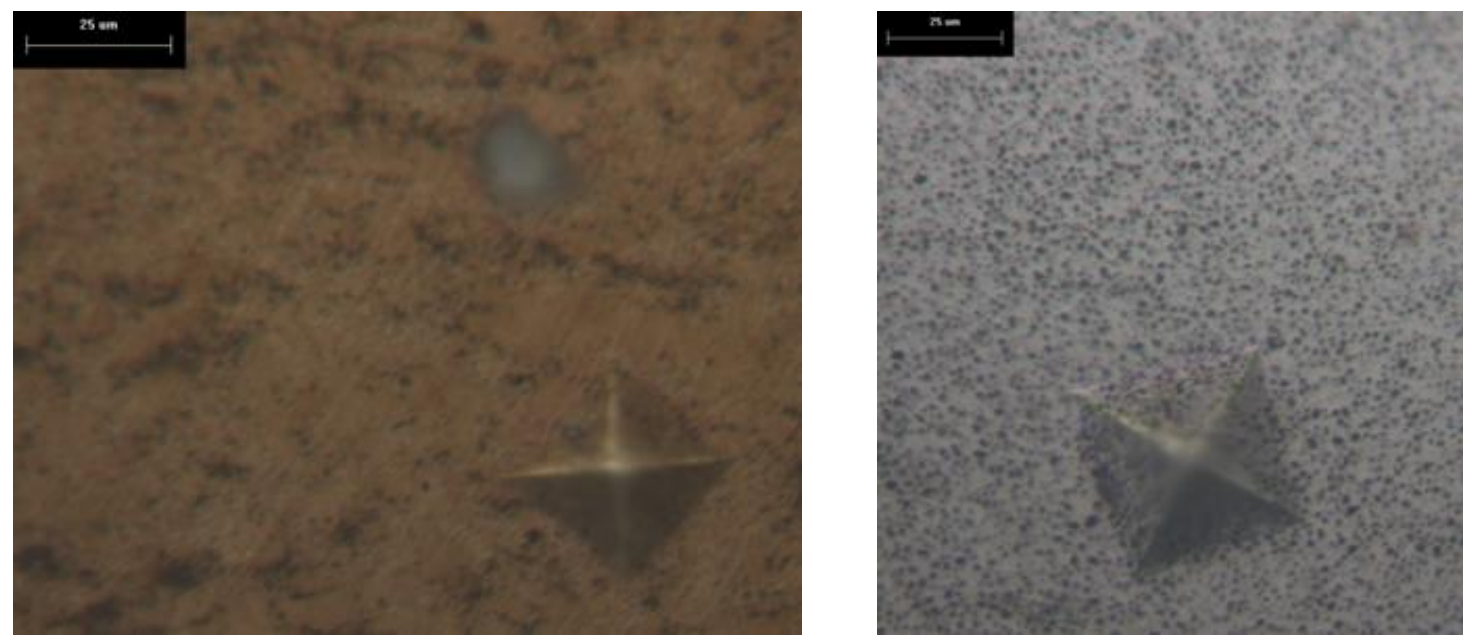

Figure 100. Indents from plate L5P3C2 (MNT 52V, left ) and L1P020 (MNT 39W, right).

\subsubsection{Conclusions}

Irradiation hardening of U-10Mo was quantified and compared to the fresh-fuel starting hardness of 316 Vickers, with the peak hardness value of the irradiated fuel nearing 425 Vickers. This peak value was measured on plate L2P499 and L5P3B1, which both had an average fission density of $2.5 \times 10^{21}$, indicating that change in the U-Mo microstructure is occurring in the fuel near this burnup range. The decrease in fuel-meat hardness values observed at densities higher than $3 \times 10^{21}$ fissions $/ \mathrm{cm}^{3}$ is likely caused by the formation of fission-gas bubbles, rather than a decrease in the hardness of the U-Mo itself. This observation is also supported by correlation of the values across a fuel plate with the local burnup values. The higher hardness values were consistently located near the center of the samples, away from the higher porosity regions along edges and ends of the fuel meats.

An additional observation from the few observed microfractures that radiate from indentations is that their occurrence was specific to fuel near the hardness peak. The absence of fractures on lower-burnup samples, such as L5P3B3 $\left(49 \mathrm{~V}, 1.7 \times 10^{21}\right.$ fission $\left./ \mathrm{cm}^{3}\right)$ verifies the initial hardening of fuel under irradiation, making fractures possible. The lack of fractures on $52 \mathrm{~V}\left(3.5 \times 10^{21}\right.$ fissions $\left./ \mathrm{cm}^{3}\right)$ further reinforces the supposition of a transition phase in the fuel microstructure near $2.5 \times 10^{21} \mathrm{fission} / \mathrm{cm}^{3}$, consistent with crack-blunting by porosity. Reduced hardness might also be explained as the result of incipient recrystallization. Although the fission densities observed are too low to suggest completion of the process, recrystallization is a continuous phenomenon, and is a possible explanation of the data.

Future post-irradiation characterization activities could include nano-indentation of the U-Mo located between fission-gas bubbles to verify this postulated behavior. Lower burnup plates should also be considered for testing to characterize the initial fuel-meat hardening as a function of density. 


\section{SUMMARY}

Radiographic examination of RERTR-12 mini-plates shows fuel creep near the boundaries of the fuel meat, which is consistent with the irradiation behavior of previous mini-plates. This is observed in the intensity of the radiograph and in axial and transverse plots of image density. It is consistent with metallographic observations and increases in severity with burnup. Plate L1P7A0 showed high swelling when measured by immersion density (but not by profilometry); no unusual features were observed in radiography. Plates L1P785 and L1P759 both had large amounts of cracking with fuel relocation, void formation, and pillowing.

Swelling data from profilometry and immersion density indicate that for the RERTR-12 insertion 2 experiment exhibited stable swelling behavior in accordance with the currently accepted U-Mo swelling correlation up to the average fission density of approximately $7 \mathrm{E}+21 \mathrm{f} / \mathrm{cm}^{3}$. Fuel-meat swelling of the majority of plates irradiated to fission densities less than $7 \mathrm{E}+21$ fission $/ \mathrm{cm}^{3}$ appears to be in agreement with values predicted by the U-Mo ANL swelling correlation for the associated fission density. ${ }^{13}$

Pillowing in high-burnup fuel plates L1P754, L1P759, and L1P785 and the potential failure in fuel plate L1P7A0 resulted in immersion density and thickness measurements that indicate high fuel-meat-swelling values. The fuel-meat swelling from these plates is considered invalid because the high values of measured plate-volume and plate-thickness are largely the result of void volume in the pillowed regions. This also resulted in a deviation from the ANL swelling correlation. The hypothesis that the combination of shutdown stress and weakening of the fuel meat due to irradiation as failure mechanisms are the subject of ongoing investigation and fuel-performance modeling.

The smooth U-shaped trend in the ${ }^{137} \mathrm{Cs}$ intensity in vertical gamma scans that reflects the plate burnup profile appears to indicate acceptable plate performance. Deviations from a smooth ${ }^{137} \mathrm{Cs}$ distribution are attributed to fuel-plate failure. This is apparent in three plates. Two of the plates that exhibit anomalies in the ${ }^{137}$ Cs profile were from the X3 capsule: L1P759 and L1P785. These plates both exhibited pillowing failure. The other atypical ${ }^{137} \mathrm{Cs}$ behavior indication is in capsule X2, plate L1P754, which also failed by pillowing. Plate L1P7A0 from capsule Z, which exhibited high swelling on immersion density, but not profilometry, did not exhibit any unusual ${ }^{137} \mathrm{Cs}$ trends. Interconnected porosity or pillowing of the fuel plates may allow volatile Cs to migrate in the vapor phase within the plates while $\mathrm{Ce}$, with lower vapor pressure, would likely not migrate.

Results for ${ }^{235} \mathrm{U}$ depletion established in samples from six RERTR-12 mini-plates using three different fission-product isotopes and the ${ }^{235} \mathrm{U}-\mathrm{to}^{-238} \mathrm{U}$ ratio are summarized in Table 12. Relative to each other, the data presented in the table show that ${ }^{235} \mathrm{U}$ results determined using the three fission products agree within $4.3 \%$. Agreement between results from the two independent analysis methods is within $10.5 \%$.

Metallographic characterization of selected plates from the RERTR-12 irradiation test did not reveal any non-typical features in the cladding-to-cladding bond line and were consistent in appearance with the micrographs at similar magnifications collected from the unirradiated archive specimens. Point-counting methods were used to develop a preliminary trend of increasing fraction of recrystallized grains, fission gas bubble to fuel ratios and the local increase in fission gas bubbles within the Mo-depleted zone as a function of fission density. The preliminary bubble-density data were consistent with the postulated ${ }^{10}$ threshold of $\sim 30 \%$ fission-gas bubbles leading to interconnected gas bubbles, but more detailed analysis is needed to better quantify this threshold.

As was the case in unirradiated fuel plates, it was noted during optical examinations that there are some localized regions with negligible $\mathrm{U}-\mathrm{Mo} / \mathrm{Zr}$ interaction layer and some gaps between the $\mathrm{Zr}$ and fuel meat were also noted, but may have been caused by specimen preparation. These regions do not stand out as failure-initiation sites or as regions with non-typical irradiated microstructures near the interface. The $\mathrm{U}-\mathrm{Mo} / \mathrm{Zr}$ interaction layer exhibited a trend of increasing thickness with increasing fission density. In 
high-fission density plates, the interaction layer comprises approximately $50 \%$ of the thickness of the original $\mathrm{Zr}$ diffusion barrier. No obvious interfacial delaminations were observed at either the Al/Zr or the $\mathrm{U}-\mathrm{Mo} / \mathrm{Zr}$ interface, and crack propagation in pillowed fuel plates was typically noted to occur within the fuel meat near the $\mathrm{U}-\mathrm{Mo} / \mathrm{Zr}$ interface.

U-Mo fuel meat, with fresh-fuel hardness of $316 \mathrm{VHN}$, peaked at a hardness value nearing $425 \mathrm{VHN}$ for two specimens at an approximate fission density of $2.5 \times 10^{21} \mathrm{f} / \mathrm{cm}^{3}$. A decrease in fuel-meat hardness values observed at fission densities higher than $3 \times 10^{21} \mathrm{f} / \mathrm{cm}^{3}$ is likely caused by the formation of fission-gas bubbles, rather than a decrease in the hardness of the U-10Mo fuel itself. Additional observations from the few observed microcracks that radiated from indentations, which were not sufficient to allow a fracture toughness determination, are that their occurrence was specific to fuel near the hardness peak. 


\section{RECOMMENDATIONS}

It is recommended that edge-on radiographs be performed on plates in future PIE campaigns to resolve lateral fractures that may be present, but cannot be resolved using the face-on imaging.

Additional fission product isotopes $\left({ }^{145} \mathrm{Nd} /{ }^{146} \mathrm{Nd}\right.$ pair, ${ }^{148} \mathrm{Nd},{ }^{137} \mathrm{Cs}$, etc. $)$ should be evaluated for use in determination of ${ }^{235} \mathrm{U}$ depletion.

Future experiment campaigns should better coordinate pre-irradiation and post-irradiation oxidethickness measurement locations. While pre-irradiation oxide measurements are typically thin and uniform, a better comparison can be made if measurements are made in the same location.

Pre-irradiation modeling of oxide thicknesses should be modified to more accurately predict oxide thicknesses. The modified Griess oxide correlation used appears to greatly over predict the oxide growth in-reactor on several of the plates.

It is recommended that etching be further utilized in future metallographic examinations to better understand the evolution of grain-size and resolve other microstructural features, such as the $\mathrm{U}-\mathrm{Mo} / \mathrm{Zr}$ interaction layer.

It is recommended that a larger number of specimens be characterized for porosity to reduce uncertainty in the porosity vs. fission density correlation, local increases in fission gas bubble fraction within the Mo-depleted zones adjacent the $\mathrm{U}-\mathrm{Mo} / \mathrm{Zr}$ interface, and to support modeling of fission-gas-bubble distributions as a function of fission density and starting microstructure.

Future post-irradiation characterization activities should include nano-indentation of the U-Mo located between larger fission-gas bubbles to measure intrinsic hardness values. Lower burnup plates should also be tested to characterize the initial fuel-meat hardening as a function of density. 


\section{REFERENCES}

1. D. M. Perez, RERTR-12 Insertion 1 Irradiation Summary Report, INL/EXT-11-24101, Idaho National Laboratory, January 2012.

2. INL/EXT-12-27085, RERTR-12 Insertion 2 Irradiation Summary Report, Idaho National Laboratory, 1 September 2012.

3. P. G. Medvedev, et al., "Shutdown-induced Tensile Stress in Monolithic Miniplates as a Possible Cause of Plate Pillowing at Very High Burnup," Transactions of the European Research Reactor Conference, held 30 March-3 April 2014 in Ljubljana, Slovenia, pp 134-141.

4. ASTM E376-11, "Standard Practice for Measuring Coating Thickness by Magnetic-Field or EddyCurrent (Electromagnetic) Testing Methods, Book of Standards, vol 03.03.

5. Y. S. Kim, G. L. Hofman, "Fission Product Induced Swelling of U-Mo Alloy Fuel,” J. Nucl. Mater. 419 (2011) p. 291.

6. J.-F. Jue, D. D. Keiser, C. R. Breckenridge, G. A. Moore, M. K. Meyer, "Microstructural Characteristics of HIP-bonded Monolithic Nuclear Fuels with a Diffusion Barrier," J. Nucl. Mater. 448 (2014) p. 50.

7. H. Hoffmann, "Crack Formation, Crack Healing and Porosity Redistribution of $\mathrm{UO}_{2}$ and $(\mathrm{U}, \mathrm{Pu}) \mathrm{O}_{2}$ ", Journal of Nuclear Materials 54 (1974) pp. 9-23.

8. D. D. Keiser et al. "Scanning Electron Microscopy Analysis of Fuel/Matrix Interaction Layers in Highly-Irradiated U-Mo Dispersion With Al And Al-Si Alloy Matrices," Nuclear Engineering and Technology 46.2 April 2014.

9. Robert T. DeHoff and Frederick N. Rhines eds., Quantitative Microscopy, New York: McGraw-Hill, 1968.

10. R. S. Barnes, "A Theory Of Swelling And Gas Release For Reactor Material," Journal Of Nuclear Materials 11.2 (1964), 135-148

11. ASTM Standard E384, "Standard Test Method for Knoop and Vickers Hardness of Materials," ASTM International, West Conshohocken, PA, DOI: 10.1520/E0384-11E0, www.astm.org.

12. ASTM Standard E384, "Standard Test Method for Knoop and Vickers Hardness of Materials," ASTM International, West Conshohocken, PA, DOI: 10.1520/E0384-11E0, www.astm.org.

13. Y. S. Kim and G. L. Hofman, "Fission product induced swelling of U-Mo alloy fuel," J. Nucl. Mater. 419 (2011) p. 291. 